\section{Metal Organic Frameworks} At Interfaces

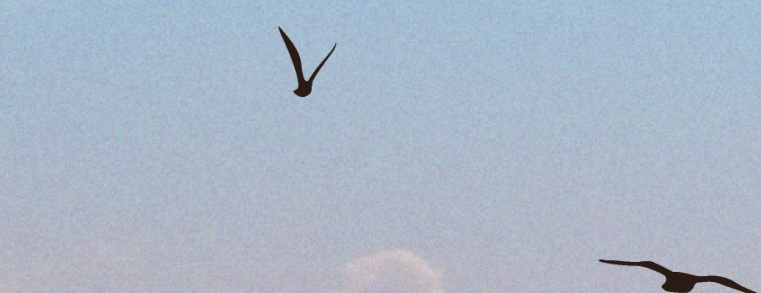

$\infty$

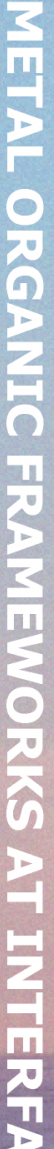

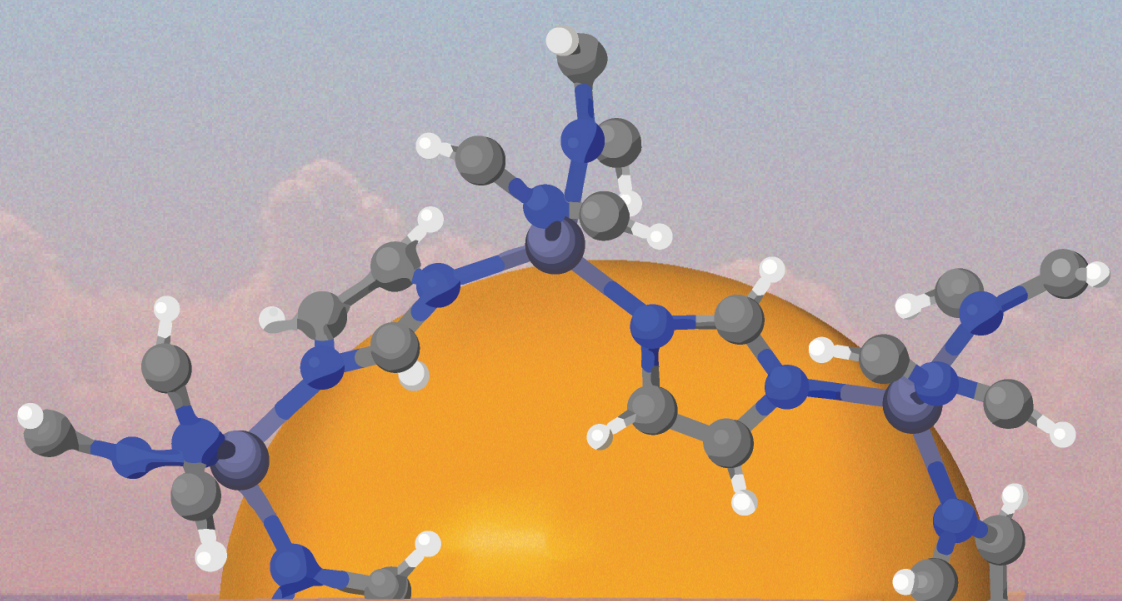

\section{Özlem Haval Demirel}




\section{METAL ORGANIC FRAMEWORKS AT INTERFACES}

Özlem Haval Demirel 



\section{METAL ORGANIC FRAMEWORKS AT INTERFACES}

\section{DISSERTATION}

to obtain

the degree of doctor at the Universiteit Twente, on the authority of the rector magnificus, prof.dr. T.T.M. Palstra, on account of the decision of the Doctorate Board to be publicly defended on Friday the $12^{\text {th }}$ June 2020 at 12.45

$$
\text { by }
$$

\section{Özlem Haval Demirel}

Born on the $12^{\text {th }}$ June 1989 in Üsküdar, Turkey 
This dissertation has been approved by:

Supervisor:

Prof. Dr. Ir. N.E. Benes

Co-supervisor:

Dr. J.A. Wood

Cover design: Jiaying Li

Printed by: Gildeprint

Lay-out: Gildeprint

ISBN: 978-90-365-5010-9

DOI: $10.3990 / 1.9789036550109$

(C) 2020 Özlem Haval Demirel, The Netherlands. All rights reserved. No parts of this thesis may be reproduced, stored in a retrieval system or transmitted in any form or by any means without permission of the author. Alle rechten voorbehouden. Niets uit deze uitgave mag worden vermenigvuldigd, in enige vorm of op enige wijze, zonder voorafgaande schriftelijke toestemming van de auteur. 


\section{Graduation Committee:}

Chairman / secretary

Prof. Dr. J.L. Herek University of Twente

Supervisor:

Prof. Dr. Ir. N.E. Benes University of Twente

Co-supervisor:

Dr. J.A. Wood University of Twente

Committee Members:

Prof. Dr. Ir. R.G.H. Lammertink University of Twente

Dr. Ir. D.W.F. Brilman University of Twente

Prof. Dr. J. Caro $\quad$ Leibniz University Hannover

Prof. Dr. Ș.B. Tantekin Ersolmaz Istanbul Technical University

Dr. M.A. van der Veen Delft University of Technology 



\section{Contents}

Summary ix

Samenvetting xiii

$\begin{array}{lll}\text { Chapter } 1 & \text { Introduction } & 1\end{array}$

$\begin{array}{lll}\text { Chapter } 2 & \text { Electroforming of a metal organic framework on } 25\end{array}$ porous copper hollow fibers

Chapter 3 MOFs-on-Ion Exchange Membranes: Using a 57 charge-selective interface for localized film formation

Chapter 4 Thermal evolution of polymeric gas separation membranes with embedded Metal Organic Frameworks

Chapter 5 Assessing interfacial properties of MOFs using 133 contact angle measurements: Promise and Pitfalls

Chapter 6 Reflection and Perspectives 171 



\section{Summary}

This thesis aims to highlight the importance of the interface for Metal Organic Framework (MOF) film growth, MOF/polymer compatibility and MOF/support adhesion. For MOF film growth, a precise control of the molar concentrations of the reactants is crucial to avoid MOF synthesis in the liquid bulk, and to obtain homogenous films. For polymeric membranes with embedded MOFs, the characteristics of the interface between MOF and polymer are vital for (gas) separation performance. Lastly, the interfacial properties of MOFs provide very valuable information for all the aspects of MOFs, from synthesis to applications.

Chapter 1 provides an overview to porous materials and metal organic frameworks (MOFs). A brief history of MOFs is followed by a discussion of their properties and the latest developments in the field, including a brief overview of companies involved with MOFs. Next, MOF films and their typical preparation methods (including the ones used in this thesis) and potential applications are discussed. Finally, the scope and outline of the thesis are provided.

In Chapter 2, porous copper hollow fibers have been used as both support and as a metal source for preparing thin MOF films (Cu-BTC) via electrochemical synthesis. The effect of the applied potential and the presence of a supporting electrolyte (to increase the conductivity of the organic solution) are investigated to obtain homogeneous, uniform and continuous MOF films. The adhesion of the layers, their thickness, and particle size distribution are characterized. More uniform films with smaller particles have been obtained in the absence of a supporting electrolyte and at low potentials. This is explained with the combination of pronounced electric-field driven mass transport of the organic ligand from the liquid bulk and the slower dissolution of copper due to the lower overpotentials. When supporting electrolyte is used, ligand transport is much slower and copper dissolution higher due to higher 
overpotentials resulting MOF formation in the bulk along with homogenous film growth.

Chapter 3 introduces MOF film synthesis on ion exchange membrane. MOF (ZIF-8) films have been formed on ion exchange membranes (IEMs) by using diffusion-cell set-up. IEMs are dense polymeric membranes with fixed charge groups. For MOF film growth, they have been used to separate two reservoirs containing metal and organic ligand solution in diffusion cell and allowing one reactant to pass through the membrane depending on the type of IEM (anion-exchange or cation-exchange). The effect of the solvent type, crystallization time and type of IEM have been investigated to form pure ZIF-8 films, which are characterized with SEM and XRD. Using IEMs helps to control the local molar concentrations of the reactants at the interface in a way to favor ZIF-8 synthesis (deprotonation of 2-methylimidazole (HMIM) and the $\mathrm{Zn}(\mathrm{HMIM}) n^{+}(n=1-4)$ complexes and excess molar ratio of HMIM). Pure ZIF-8 films have been obtained using a methanol-based synthesis approach with an anion-exchange membrane (AEM) barrier. Methanol mitigates the side reactions, such as hydrolysis and the dissociation of zinc, due to the lower dielectric constant, AEM provides a lower zinc concentration at the membrane interface due to Donnan exclusion. Moreover, protonated HMIM molecules, $\mathrm{H}_{2} \mathrm{MIM}^{+}$which are inactive for the ZIF- 8 reaction, are excluded. On the contrary, when CEM is used, the interface is enriched with $\mathrm{Zn}^{2+}$ ions, which does not favor ZIF-8 crystallization, and $\mathrm{H}_{2} \mathrm{MIM}^{+}$is also capable of passing between solution reservoirs. In aqueous synthesis, the formation of $\mathrm{Zn}(\mathrm{OH})_{2}$ is observed as a side reaction. In order to facilitate the deprotonation of HMIM and $\mathrm{Zn}(\mathrm{HMIM})_{n}{ }^{+}(n=1-4)$ complexes, ammonium hydroxide is used as a typical deprotonation agent. However, it destroys the IEMs used in this work due to high $\mathrm{pH}$. Chapter 3 describes possible advantages for controlled local synthesis of MOFs on IEMs, through control of the local concentrations of the reactants and opens up new opportunities in terms of both MOF film synthesis and applications of these films. 
In Chapter 4, the effect of post-thermal treatment on polymeric gas separation membranes with embedded metal organic frameworks (mixed matrix membranes $(\mathrm{MMMs})$ ) is investigated. For this, a highly permeable polymer, 6FDA-DAM, and three different MOFs (ZIF-8, sod-ZMOF, $\mathrm{K}^{+}$sod-ZMOF) have been selected. The thermal treatments have been employed based on the boiling point of the solvent and the glass transition temperature $\left(T_{\mathrm{g}}\right)$ of the polymer, and involve inert (nitrogen) or oxidative (air) conditions. The findings for the pure polymer membranes indicate that the thermal treatment above the $T_{\mathrm{g}}$ under nitrogen mainly causes physical changes in free volume of the polymer and results in a permeability increase, shifting the performance to close to the latest upper bound. On the other hand, thermal treatments in air cause oxidation phenomena, possibly combined with crosslinking, leading to amplified selectivity values and drastic decreases in permeability. Thermal treatments on MMMs result in inferior performance as compared to pure polymeric membranes. Only MMMs that are heated to $315{ }^{\circ} \mathrm{C}$ in air show a healing effect on the leaky interfaces by shifting the performance towards the 2008 upper bound in the Robeson plot. Possible amorphization of MOFs may enhanced the interactions between the polymer and MOFs. Post-thermal treatment strategies can allow fine tuning gas separation membranes.

The focus in Chapter 5 is to investigate interfacial properties of MOF (ZIF-8) films via contact angle measurements of multiple probe liquids. Films are characterized with FTIR, ellipsometry, atomic force microscopy and white light interferometry. The films are found macroscopically flat. The effect of the sample preparation and measurement techniques (vibration vs. no vibration, repeated cycles of advancing-receding contact angles) on the contact angle measurements are identified. The most stable contact angle measurements (achieved with piezoactuation) are used to estimate surface energy components (dispersive, polar: electron acceptor/donor). The most stable water contact angle of $91.0 \pm 2.5^{\circ}$ is in the limit of hydrophilicity and hydrophobicity despite its well-known reported hydrophobic characteristic, which may be related to the chemical heterogeneities in the MOF films. Dispersive and polar components are estimated by using diiodomethane and ethylene glycol contact angle values. Electron 
acceptor/donor subdivision of the polar components cannot be estimated due to the large spreads in the water contact angle values found for ZIF-8 films. The contact angle is a facile method to explore the surface characteristics of a material however it is also quite challenging. Interfacial properties of MOFs promise extremely valuable information on solvent choice for well-dispersion, designing compatible MOFpolymer-solvent systems, substrate choice, etc. The findings in Chapter 5 are important steps to understand MOF interfacial properties and their behavior in many applications.

Chapter 6 reflects the work described on this thesis along with the future directions. Next, challenges that have been come across during the thesis, so called "negative results" have been presented and discussed. This chapter provides general perspectives to the MOF field and the results presented in this thesis. 


\section{Samenvatting}

Dit proefschrift adresseert belang van het grensvlak voor metaal-organisch raamwerk (Metal Organic Framework (MOF)) filmgroei, MOF/polymeer compatibiliteit en $\mathrm{MOF} /$ substraat adhesie. Voor de groei van MOF-films is het cruciaal om de molaire concentraties van reactanten nauwkeurig te controleren om zo MOF-synthese in de bulk te voorkomen en homogene films te verkrijgen. Voor polymeer membranen met ingebedde MOF's zijn de eigenschappen van het grensvlak tussen MOF en polymeer essentieel voor (gas) scheidingsprestaties. Uiteindelijk bieden de grensvlak eigenschappen van MOF's zeer waardevolle informatie voor alle aspecten van MOF's, van synthese tot toepassingen.

Hoofdstuk 1 geeft een overzicht van poreuze materialen en MOF's. Een korte beschrijving van de geschiedenis van MOF's wordt gevolgd door een bespreking van hun eigenschappen en de nieuwste ontwikkelingen in het vakgebied, inclusief een kort overzicht van bedrijven die betrokken zijn bij (de productie van) MOF's. Vervolgens worden MOF-films, hun gebruikelijke bereidingsmethoden (inclusief degene die in dit proefschrift worden gebruikt) en mogelijke toepassingen besproken. Ten slotte wordt het kader en de hoofdlijnen van dit proefschrift gegeven.

In Hoofdstuk 2 zijn poreuze koper holle vezels gebruikt om simultaan te dienen als substraat en metaalbron voor het vervaardigen van dunne MOF films ( $\mathrm{Cu}-\mathrm{BTC})$ via elektrochemische synthese. Het effect van de toegepaste potentiaal en de aanwezigheid van een ondersteunende elektrolyt (om de geleidbaarheid van de organische oplossing te verhogen) worden onderzocht om homogene, uniforme en continue MOF-films te verkrijgen. De hechting van de lagen, hun dikte en deeltjesgrootteverdeling worden geanalyseerd. Bij afwezigheid van een ondersteunende elektrolyt en bij lage potentialen zijn meer uniforme films met kleinere deeltjes verkregen. Dit wordt verklaard door de combinatie van een uitgesproken door een elektrisch veld aangedreven massatransport van het organische 
ligand uit de bulk en de langzamere dissociatie van koper vanwege de lagere overpotentialen. Wanneer een ondersteunend elektrolyt wordt gebruikt, is het ligand transport veel langzamer en is de koper dissociatie hoger als gevolg van een hogere overpotentiaal, wat resulteert in MOF-vorming in de bulk samen met homogene filmgroei.

Hoofdstuk 3 introduceert MOF-filmsynthese op een ionenuitwisselingsmembraan. Met behulp van een diffusie cel opstelling zijn MOF-films (ZIF-8) gevormd op ionenuitwisselingsmembranen (IEM's). IEM's zijn dichte polymeer membranen met vaste ladingsgroepen. Voor MOF-filmgroei zijn ze gebruikt om twee reservoirs met metaal en organische ligandoplossing in de diffusie cel te scheiden en één reactant door het membraan te laten gaan, afhankelijk van het type IEM (anionuitwisseling of kationuitwisseling). Het effect van het type oplosmiddel, de kristallisatietijd en het type IEM zijn onderzocht om pure ZIF-8-films te vormen, die worden gekarakteriseerd met SEM en XRD. Het gebruik van IEM's helpt de lokale molaire concentraties van de reactanten aan het grensvlak te beheersen op een manier die de ZIF-8-synthese bevordert (deprotonering van 2-methylimidazol (HMIM) en een overmatige molverhouding van HMIM). Pure ZIF-8-films zijn verkregen met behulp van een synthese aanpak op basis van methanol met een anionuitwisselingsmembraan (AEM) -barrière. Methanol vermindert de nevenreacties, zoals hydrolyse en de dissociatie van zink, vanwege de lagere diëlektrische constante. AEM zorgt voor een lagere zinkconcentratie aan het membraangrensvlak als gevolg van zogenoemde Donnan uitsluiting. Bovendien zijn geprotoneerde HMIM-moleculen, die inactief zijn voor de ZIF-8-reactie, geëlimineerd. Omgekeerd, wanneer een CEM wordt gebruikt, is het grensvlak verrijkt met $\mathrm{Zn}^{2+}$-ionen, wat ZIF-8-kristallisatie niet bevordert en kunnen geprotoneerde HMIM ook tussen oplossingsreservoirs bewegen. Bij synthese in water werd de vorming van $\mathrm{Zn}(\mathrm{OH}) 2$ waargenomen als nevenreactie. Om de deprotonering van HMIM te vergemakkelijken, wordt ammoniumhydroxide gebruikt als deprotoneringsmiddel. De hoge $\mathrm{pH}$ vernietigt echter de IEM's die in dit werk worden gebruikt. Hoofdstuk 3 beschrijft mogelijke voordelen van gecontroleerde lokale synthese van MOF's op IEM's, door beheersing van de lokale concentraties van 
reactanten. Dit levert nieuwe kansen voor zowel MOF-filmsynthese als voor toepassingen van deze films.

In Hoofdstuk 4 wordt het effect van thermische nabehandeling op polymeer gasscheidingsmembranen met ingebedde MOF's (mixed matrix membranen (MMMs)) onderzocht. Hiervoor zijn een zeer permeabel polymeer, 6FDA-DAM en drie verschillende MOF's (ZIF-8, sod-ZMOF, $\mathrm{K}^{+}$sod-ZMOF) geselecteerd. De thermische behandelingen zijn toegepast op basis van het kookpunt van het oplosmiddel en de glasovergangstemperatuur $\left(\mathrm{T}_{\mathrm{g}}\right)$ van het polymeer en vinden plaats onder inerte (stikstof) of oxidatieve (lucht) omstandigheden. De resultaten voor de pure polymeermembranen geven aan dat de thermische behandeling boven de $T_{\mathrm{g}}$ onder stikstof voornamelijk fysieke veranderingen in het vrije volume van het polymeer veroorzaakt en resulteert in een verhoging van de permeabiliteit. Dit resulteert in een verschuiving van de performantie van het membraan in de richting van de 2008 'Robeson upper bound'. Anderzijds veroorzaken thermische behandelingen in de lucht oxidatieverschijnselen, mogelijk gecombineerd met vernetting van het polymeer, wat leidt tot een verhoogde selectiviteit en drastische afname van de permeabiliteit. Thermische behandelingen op MMM's resulteren in mindere prestaties in vergelijking met pure polymeer membranen. Alleen thermische behandeling van MMM's in lucht tot $315^{\circ} \mathrm{C}$ resulteerde in een helende werking op de lekkende grensvlakken tussen MOF en polymeer, waardoor een verschuiving optrad van de performantie in de richting van de 2008 Robeson upper bound. Mogelijke gedeeltelijke amorfisatie van MOF's kan leiden tot versterkte interacties tussen het polymeer en MOF's. Thermische nabehandeling strategieën kunnen het nauwkeurig afstellen van gasscheidingsmembranen mogelijk maken.

De focus in Hoofdstuk $\mathbf{5}$ is het onderzoeken van de grensvlak eigenschappen van MOF (ZIF-8) films via contacthoekmetingen met meerdere testvloeistoffen. Films zijn gekarakteriseerd met FTIR, ellipsometrie, atoomkrachtmicroscopie en interferometrie met wit licht. De films zijn macroscopisch plat bevonden. Het effect van de monstervoorbereiding en meettechnieken (trilling vs. geen trilling, herhaalde 
cycli van vooruitgang-terugwijkend contacthoekmetingen) op de contacthoekmetingen is geïdentificeerd. De meest stabiele contacthoekmetingen (bereikt met piëzoactuatie) zijn gebruikt om oppervlakte-energiecomponenten te schatten (dispersief, polair: elektronenacceptor / donor). De meest stabiele contacthoek met water van 91,0 $\pm 2,5^{\circ}$ ligt op de grens van hydrofiliciteit en hydrofobiciteit, ondanks het veelvuldig gerapporteerde hydrofobe karakter van ZIF-8. Dit houdt mogelijk verband met de chemische heterogeniteit in de MOF-films. Dispersieve en polaire componenten zijn geschat met behulp van de contacthoekwaarden van diiodomethaan en ethyleenglycol. De onderverdeling van de polaire componenten in elektronenacceptor / donor kon niet worden geschat vanwege de grote spreidingen in de watercontacthoekwaarden die werden gevonden voor ZIF8-films. De contacthoek is een gemakkelijke methode om de oppervlakte eigenschappen van een materiaal te verkennen, maar het is ook behoorlijk uitdagend. Grensvlak eigenschappen van MOF's beloven uiterst waardevolle informatie voor de keuze van oplosmiddelen voor een goede dispersie, het ontwerpen van compatibele MOF-polymeer-oplosmiddelsystemen, substraatkeuze, enz. De bevindingen in hoofdstuk 5 zijn belangrijke stappen om MOF-grensvlak eigenschappen en hun gedrag in veel toepassingen te begrijpen.

Hoofdstuk 6 reflecteert op het werk dat in dit proefschrift wordt beschreven en op mogelijke toekomstige richtingen voor vervolgonderzoek. Vervolgens zijn de tegengekomen uitdagingen, de zogenaamde 'negatieve resultaten', gepresenteerd en besproken. Ten slotte, biedt dit hoofdstuk algemene perspectieven op het MOFvakgebied en op de resultaten die in dit proefschrift worden gepresenteerd. 
CHAPTER 1

Introduction 


\subsection{Porous materials}

The history of porous materials goes back to 3700 BC in Egypt where people used charcoal to produce bronze via the reduction of different metals. The early history continued with the discovery of the adsorption properties of charcoal, which was used to adsorb odorous vapors from wounds and purification of water with carbon materials. ${ }^{1}$ Today, porous materials are considered attractive for academic and industrial applications due to their potential as a bulk material to interact with other species. ${ }^{2}$ The common applications of porous materials include separation, adsorption, catalysis, drug delivery, etc. ${ }^{3}$ Common porous materials include activated carbon, mesoporous silicas, zeolites, and metal-organic frameworks (MOFs).4,5 Mesoporous silicas have pore diameters in the nanometer range with pore surface chemistries that are interesting for drug delivery, gas separation, and storage. ${ }^{3}$ Zeolites are inorganic crystalline porous materials with rigid frameworks and well defined pore sizes. These properties make them attractive for many applications. For example, thin LTA-type zeolite membranes are commercially used in dehydration of solvents due to their hydrophilicity and small pore size. ${ }^{6}$ The extensive knowledge related to zeolites aids industrial applications such as gas separation, and has also created a tool box for further porous materials. ${ }^{6,7}$ MOFs are porous crystalline materials that are based on coordination bonds, instead of covalent bonds, between metal nodes and organic linkers. They are a recent addition to the porous materials community, arriving in the 1990 and since then the number of the MOF structures registered in Cambridge Structural Database has exceeded 8o,ooo. ${ }^{8}$

\subsection{Metal-organic frameworks}

Metal organic frameworks (MOFs) consist of metal ions or clusters connected by organic ligands in a crystalline infinite coordination network (Fig. 1.1). Since the term MOF was introduced by Yaghi for the first time, ${ }^{9}$ the MOF field has extensively grown in many different directions: involving new MOF discoveries, synthesis methods, characterization methods, applications, etc. Their unique properties such as high surface area, pore size and designable framework render them distinct from other 
porous materials..$^{10}$ It has been proposed that it is possible to design new MOFs with the combination of 86 different metals and more than 1000 organic ligands. ${ }^{11}$ The number of MOFs can increase even further with usage of multiple metals in one MOF and synthesizing different organic ligands. The diversity in MOFs also helps to bring different properties for different applications. It is possible to design the porosity, particle size and surface area (in theory) of MOFs. Designing MOF with a highest surface area and specific volume was accomplished with NU-109 and NU-110 MOFs $\left(\sim 7000 \mathrm{~m}^{2} \mathrm{~g}^{-1}\right)$, followed by DUT-6o with $\sim 8000 \mathrm{~m}^{2} \mathrm{~g}^{-1.12,13}$ The adjustable pore size lays between 0-98 Ångstrom and the particle size is between 1.6-10,00o nm. ${ }^{11}$ All these unique material properties make MOFs attractive for industrial applications such as gas adsorption, gas storage, gas separation, hydrogen catalysis, biomedical imaging and sensing, semiconductors, drug delivery systems, carbon capture, detection and sensing, etc. ${ }^{14}$

In 2019, IUPAC selected ten chemistry innovations that will likely change the world; MOFs and porous materials for water harvesting were included in this list. ${ }^{15}$ Selective adsorption of molecules with the porous nature of MOFs, drug delivery, gas purification and capture are conventional potential applications for MOFs. The latest studies of Yaghi on harvesting 2.8 liter of water per kilogram of MOF at $20 \% \mathrm{RH}$ is considered one of the innovations that can change the world. ${ }^{16}$

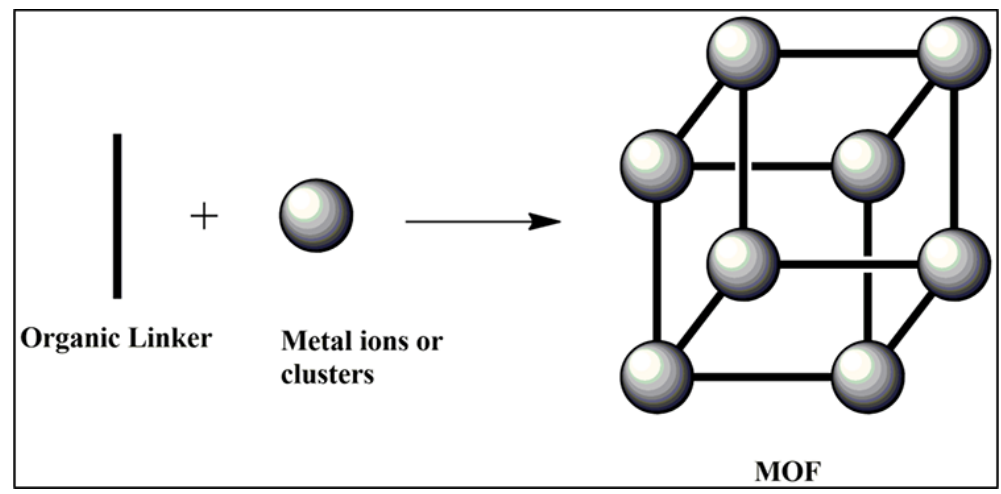

Figure 1.1 MOF structure. ${ }^{17}$ ( 2016 , Eram Sharmin and Fahmina Zafar. Originally published in Metal Organic Frameworks under Creative Commons Attribution 3.o License. Available from: 10.5772/64797 
Presently, MOFs have not (yet) changed the world in terms of commercial applications. However, emerging developments in new synthetic production methods has led to two new MOF products: TruPick and ION-X. (Fig. 1.2) TruPick is a postharvest freshness management tool for fruits and vegetables. A cooperation with Decco Worldwide Post-Harvest Holdings and MOF Technologies, a spin-off company based in Queens University Belfast initiated this product. ${ }^{18}$ TruPick uses a MOF adsorbent to store and release 1-methylcyclopropene (1-MCP), which inhibits the release of ethylene that is released by the ripened fruits and accelerates their ripening. The use of 1-MCP helps fruits to stay fresh up to nine months. This product is registered with the US Environmental Protection Agency and is used in the USA and followed by next in Turkey. Using MOFs for food applications was only possible due to the development of mechanochemical syntheses that eliminating usage of organic solvent. ${ }^{18-20}$ The second product, ION-X is for storage of hazardous gases and can be used in the electronics industry. It enables safer handling of the gases thanks to vacuum storage conditions. ${ }^{18-21}$ This product has been launched by NuMAT Technologies, a spin-off company of Northwestern University. Besides these exciting MOF products, BASF, as a main supplier of powder MOFs, ${ }^{22,23}$ has been working on MOF-based natural gas storage systems for the transportation industry. These have not been commercialized yet. ${ }^{24}$

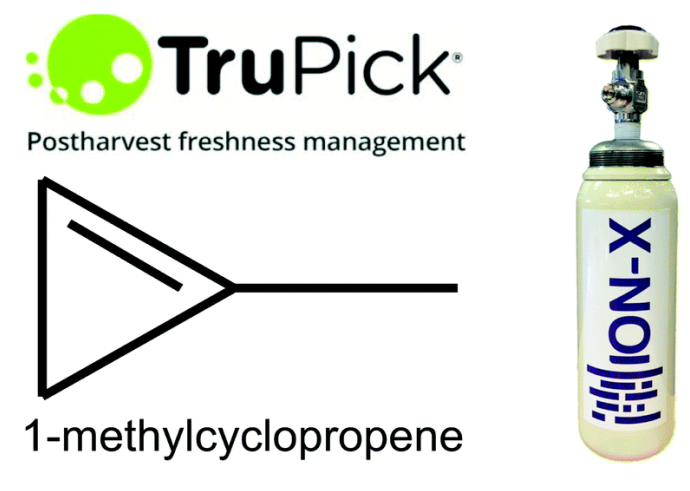

Figure 1.2 Commercial MOF products: TruPick and ION-X. ${ }^{20}$ Reproduced by permission of The Royal Society of Chemistry. 
Notwithstanding their potential in various fields MOF commercialization requires a higher production volume to satisfy the markets. Research has been focused on discovering new materials while the production scales were limited to only mg-levels. In addition, the synthesis methods can be very complex and requires days, high temperatures, and/or very expensive chemicals. Presently, the gaps between lab-scale and commercial applications are becoming smaller. Developments in electrochemical synthesis, flow synthesis, mechanochemical synthesis, and spray drying are vital to promote increases in the numbers of MOF companies, with more products released to the markets.3,20,25-29 The university-borne new spin-off companies or the strong collaboration between universities and companies open new directions towards (valorization of) more applied-research. Some of these companies (together with the established year, the University collaboration and the field) are listed below:

* Atomis - 2015 - Kyoto University - gas separation applications

* Framergy - 2011 - Texas A\&M University and École Normale Supérieure - Absorbent technologies

* Immaterial - 2015 - University of Cambridge - MOF production

* Immondo Tech - 2013 - Georgia Institute of Technology - MOF production

* MOFapps - 2013 - CNRS - MOF production

* MOF Technologies - 2012 - Queen's University Belfast - MOF production

* Mosaic Materials - 2014 - University of California - Gas separation

* NovoMOF - 2017 - Swiss Federal Institute of Technology, Paul Scherrer Institute, École Polytechnique Fédérale de Lausanne and Fachhochschule Nordwestschweiz - MOF production

* NuMat Technologies - 2013 - Northwestern University - Gas storage

* ProfMOF - 2015 - University of Oslo - MOF production

* Promethean Particles - 2007 - The University of Nottingham - MOF production 
* Main MOF suppliers in the market: BASF, Aldrich, Dresden Materials Center, Merck, STREM and TCI.

Based on the latest report by Global Info Research, the MOF market is expected to grow at a compound annual growth rate (CAGR) of roughly $34.3 \%$ over the next five years, from 70 million US\$ in 2019 to 410 million US\$ in $2024 \cdot{ }^{30}$ As mentioned above, commercialization of MOFs has been dependent on strong collaboration between academia and industry. An expected growth in the MOF market requires intensified relationships between these parties. Academia is in the hearth of discovering new MOFs along with different properties, new production techniques such as green chemistries, and large-scale productions. I am convinced that when the broad knowledge and experience of the academia meets with the industrial commercialization mindset, new MOF products will enter the market based on their diverse properties.

\subsection{MOF films}

The interest in MOF film preparation has started 10 years after Yaghi and Li has reported the MOF for the first time. In 2005, Fisher and coworkers has prepared MOF5 films on functionalized Au substrate. ${ }^{31}$ Since then, many effort have spent to prepare MOF films to be used in different applications. The main advantage of using thin films compared to powders is faster diffusion of guest molecules through shorter diffusion paths. ${ }^{32}$ MOFs offer a porous nature along with designable chemical functionality. ${ }^{33}$ Many different type of MOFs with various properties can potentially be used in a wide range of applications. ${ }^{34}$ In general, MOF films are used either as a supported thin layers (deposition of already-synthesized MOFs or direct-growth on substrate) or as a hybrid MOF-polymer films e.g. mixed matrix membranes (MMMs). ${ }^{19}$ Different substrates with different geometries have been used to grow/deposit MOF films. The knowledge from zeolites, polymers and coordination polymers has been adopted for the development of MOF preparation techniques. Although the MOF film properties vary based on the final application, the main focus is to obtain homogenous MOF films and control the thickness. For example, obtaining defect-free, continuous, intergrown 
MOF membranes are required for separation applications. Moreover, long term (hydrothermal) stability and durability are needed for industrial applications. 35 Beside the main applications such as gas storage, separation and catalysis, MOF films have been also the interest of more advanced technologies such as electronic, photonic, and sensing devices. ${ }^{33}$ MOF device fabrication is possible with homogenous, monolithic, defect free, dense and oriented MOF coating with permanent localization and patterning ${ }^{14}$ There are also other challenges such as film roughness, pinholes, interfacial properties (cohesion, adhesion to the substrate), mechanical properties, stability, density and size of crystals, alignment, etc. These challenges for the MOF research community have hindered use in applications. In order to tackle these challenges and fulfill the requirements, many different MOF film preparation methods have been developed in the last 15 years. Here, the most common ones are shortly presented together with their advantages and disadvantages.

\subsubsection{MOF film preparation techniques}

Powder MOF-based deposition (PMD) - This is a straightforward MOF film preparation method in which already-synthesized MOF powders (via conventional solvothermal and hydrothermal methods) are deposited onto a substrate. ${ }^{34}$ Deposition can be done via spin-coating, ${ }^{36}$ dip-coating, ${ }^{37}$ electrospraying, ${ }^{38}$ supersonic spray ${ }^{39}$, and hot-pressing. $4^{\circ}$ The main advantages of this technique include that existing knowledge for MOF powder synthesis can be directly used for adjusting properties of the final MOF films. Controlled over the thickness can be achieved via generally well-known process parameters of the deposition process, such as the composition (concentration/size distribution) of the colloidal nanoparticles solutions, speed and the number of the coating steps. Compared to the other MOF film preparation techniques, coating of already-synthesized MOF particles does not involve chemical reactions, mitigating the production of unwanted components. Using as-synthesized MOFs colloids, without drying the particles and redispersion, shows better results in terms of adhesion as compared to the use of dried powders ${ }^{41}$ and possible formation of defects can be overcome via applying multiple layers. 
However, for thin MOF film formation, crystal grain boundaries remain as a challenge due to the limitation of preparing intergrown MOF films. The PMD methods are also utilized for seeding the substrates for secondary-growth MOF growth. ${ }^{42}$

Another way to use to already-synthesized MOF powders is as a dispersion within a polymer matrix. Combination of nanoporous materials and polymers are considered attractive to achieve combined synergistic properties of the two materials. ${ }^{43} \mathrm{MOFs}$ have been used as fillers for mixed matrix membranes (MMMs) prepared by dispersing inorganic fillers into the polymer matrix, specifically for gas separation applications. Their diversity with respect to pore sizes, high surface areas, chemical and thermal stability, and enhanced compatibility with polymers due to their hybrid nature have motivated many MOF-based MMMs studies. However, as was found for zeolites, the MOF-polymer interface characteristics remain a major challenge. Polymer-MOF interfaces can be leaky or rigidified, which has strong effects on the gas separation performances of the derived membranes. Therefore, theoretically predicted MMM separation performances have not been achieved. Efforts have been directed to chemically modifying the interface, synthesizing MOFs in the polymer matrix, development of complex preparation techniques, using wet MOF suspensions instead of dried ones, etc. ${ }^{41,44}$ However, interfacial morphology incompatibility problems and reproducibility issues remain challenging in such complex systems. ${ }^{45}$

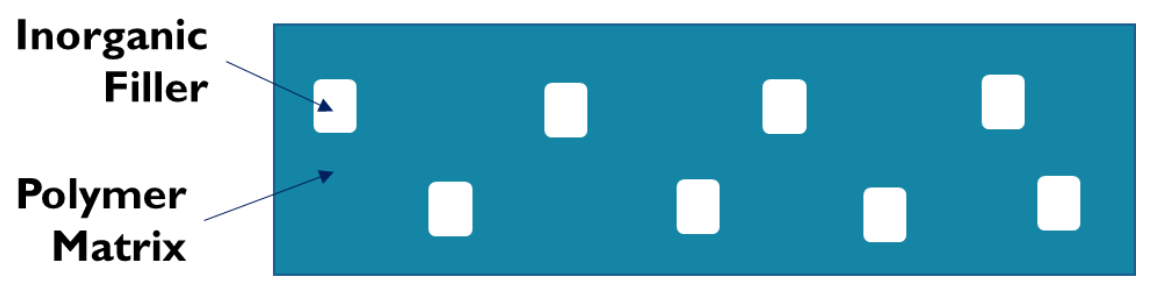

Figure 1.3 Schematic representation of mixed matrix membranes.

Thin film nanocomposite membranes have been also prepared by incorporation of MOF particles into polyamide layer that is formed with interfacial polymerization on substrates for separation applications. ${ }^{46,47}$ Electrospinning, spin-coating, dipcoating are other preparation ways of MOF-polymer mixtures. ${ }^{37,48}$ 
Solvothermal synthesis - This technique can be subdivided into i) in-situ, and ii) secondary growth. ${ }^{34,35}$ Both methods are adopted from general MOF crystallization methods, in the presence of a substrate placed vertically in an autoclave. With the insitu solvothermal method intergrown MOF films can be obtained. Concentration, time, temperature, and cooling rate are the main parameters to control the film properties. Some other approaches are also developed to further affect the film properties, such as microwave assisting, use of modified supports and use of additives. ${ }^{49-52}$ The main drawbacks are the required high temperature and pressure, along with scale-up concerns. Secondary-seeded-growth is based on controlling the nucleation by introducing nanocrystals as a seed on the surface. The seeding procedures can be dip coating, spin coating, thermal seeding, etc. (Fig. 1.4 (a))

Interfacial synthesis - Liquid-liquid interfacial synthesis of MOF films is based on the reaction between the metal source from one liquid with the organic ligand in a separate solvent that is immiscible with the other (such as water-hexane), thus localizing the crystallization reaction to the liquid-liquid interface. 53 With this method, defect-free continuous MOF film preparation is possible in considerably milder conditions as compared to the solvothermal technique. Many MOF films on different substrates have been formed via this technique. ${ }^{54-58}$ Localized formation of MOF films as either inner- or outer-layer of polymeric hollow fibers have been developed by Brown et al. ${ }^{59}$ Interfacial synthesis is also possible at air-liquid interfaces. Self-standing ZIF-8 films can be formed at the water surface. ${ }^{60}$ Solvent evaporation in the reactant mixture creates a concentration difference resulting higher concentration at the water surface. Therefore, crystallization occurs where oversaturation is reached (Fig. 1.4 (b)).

Counter-diffusion (contra-diffusion) - Counter-diffusion is one of the facile synthesis methods developed by Li et al. for MOF films. ${ }^{61}$ In this technique, the (porous) support separates the reactant solutions and in-situ synthesis occurs on the surface of the support via diffusion of the reactants. (Fig. 1.4 (b)) For this, reactant solutions were prepared in methanol with metal : organic ligand ratio of $1: 8$, which is 
a critical parameter for the ZIF-8 synthesis. Continuous ZIF-8 films were prepared on both side of porous nylon support with the thickness of $16 \mu \mathrm{m}$. In a subsequent study, aqueous ZIF-8 synthesis on a porous nylon support was demonstrated with the use of deprotonation agent, ammonium hydroxide. ${ }^{62}$ ZIF-8 films were grown on the side of the HMIM, with $2.5 \mu \mathrm{m}$ thickness. Gas separation performances exhibited the ideal selectivity of 4.6 for $\mathrm{H}_{2} / \mathrm{N}_{2}$.

The counter-diffusion technique has also been combined with hydrothermal, solvothermal, secondary-growth and anodic dissolution techniques. Combination with the secondary growth has been used to grow continuous MOF (ZIF-8) films on the inner surface of a tubular $\alpha$-alumina ceramic support. ${ }^{63,64}$ Counter-diffusion has been also used with solvothermal synthesis techniques to obtain inter-grown, defect free membranes. ${ }^{65,66}$ In the study of Kwon and Jeong, $\alpha$-alumina supports were soaked in metal solution, followed by soaking in organic ligand solution in an autoclave and synthesis took place at $120{ }^{\circ} \mathrm{C} .{ }^{65}$ The resulting $\sim 1.5 \mu \mathrm{m}$ membranes showed propylene/propane selectivity $(\sim 55)$. Anodic dissolution and counter-diffusion techniques have been utilized for Cu-BTC/PES membranes with excellent dye removal performance. ${ }^{67}$ The hydrothermal synthesis accompanied the counter-diffusion technique for the growth of Co-Zn based ZIF-8 and ZIF-7 membranes on $\mathrm{Co}_{3} \mathrm{O}_{4}$. The $\mathrm{Co}_{3} \mathrm{O}_{4}$ was used simultaneously as a support and a Co source for the mixed-MOF synthesis. ${ }^{68}$ ZIF-8 membranes were synthesized on $\alpha-\mathrm{Al}_{2} \mathrm{O}_{3}$ hollow fibers with the thickness of $40-70 \mathrm{~nm}$ on the outer surface. For this DMF-based synthesis it was shown that the temperature highly affected membrane morphology and propane/propylene separation performance. ${ }^{69}$ Nanoporous network fillers have been used for ZIF-8 films growth via counter-diffusion, resulting in films with thickness of $\sim 500 \mathrm{~nm}$ and $\mathrm{H}_{2} / \mathrm{CO}_{2}$ selectivity of $43 .^{70} \mathrm{ZIF}-8$ films have been grown on $\mathrm{SiO}_{2}$ nanofibers via counter-diffusion, aiming at application in particulate matter removal. ${ }^{71}$ Surface modification strategies have improved the adhesion between films and supports. ${ }^{72}$ The counter-diffusion concept has been applied to different MOFs: ZIF71,73 ZIF-7,, ${ }^{52,65}$ SIM-1, ${ }^{52,65} \mathrm{Cu}-\mathrm{BTC},{ }^{74}$ and ZIF-90. ${ }^{52}$ 
Layer-by-layer (LbL) (or Liquid-phase epitaxy (LPE)) LbL is an in-situ MOF film formation technique where the metal source and organic ligand solutions are alternatingly applied to the substrate in a stepwise manner. ${ }^{75}$ Ultimate control over the film thickness can be achieved via the number of the cycles. The main disadvantage of LbL is the limitation to use only paddle-wheel structure metal linkers with available coordination sites, while there is no limitation in the organic linker. ${ }^{34}$ The application of the layers can be performed in different manners: dip-coating, spincoating, immersion, pumping, spraying..$^{6-78}$ It is possible to obtain highly oriented uniform thin films on functionalized surfaces, also called as SUR-MOFs.75,79 These functional groups are used to connect metal or organic linker and initiating the growth of thin films, preferably in an oriented structure. Orientation can be controlled by the use of various functional groups.

Electrochemical deposition (ED) - ED has been developed by BASF for the full-scale production of MOF powders. ${ }^{22,23}$ The main advantages of this synthesis method are the use of pure metals without counterions such as nitrates, the milder synthesis conditions (lower temperatures), and the short synthesis time. ${ }^{80}$ This well-established method has been also adapted for thin MOF film deposition. ${ }^{81}$ The anodic dissolution technique pioneered by BASF is based on using metal substrate as a working electrode dipped in an organic ligand solution. Metal ions are released from the electrode with the applied electric potential and react with the organic linker available in the solution. The use of a two- or three-electrode configuration, applied potential, concentration of the organic linker, use of supporting electrolyte, and synthesis time are some of the critical parameters affecting the final MOF (film) properties. ${ }^{21,80}$ In the cathodic deposition, reactants are in the solution together with probase, and MOF film formation takes place at the cathodic substrate surface due to the $\mathrm{pH}$ jump at the interface via probase reduction. ${ }^{82}$ Beside these two main techniques, galvanic displacement ${ }^{83}$ and electrophoretic deposition ${ }^{8,85}$ also are ED techniques. Different type of supports have been also used for ED such as, metal meshes, foils, plates, hollow fibers, glass, gold, etc. ${ }^{82,86-88}$ In order to obtain uniform, homogenous, defect-free MOF films, understanding the electrocrystallization mechanisms and their 
characterization have been the main focus in the ED field. ${ }^{82,87-89}$ Patterned MOFs, easy scale-up potential of ED, together with in-situ metrology techniques can be useful in many different potential applications such as catalysts, sensors, micro-patterned devices, etc. ${ }^{90-92}$

(a)

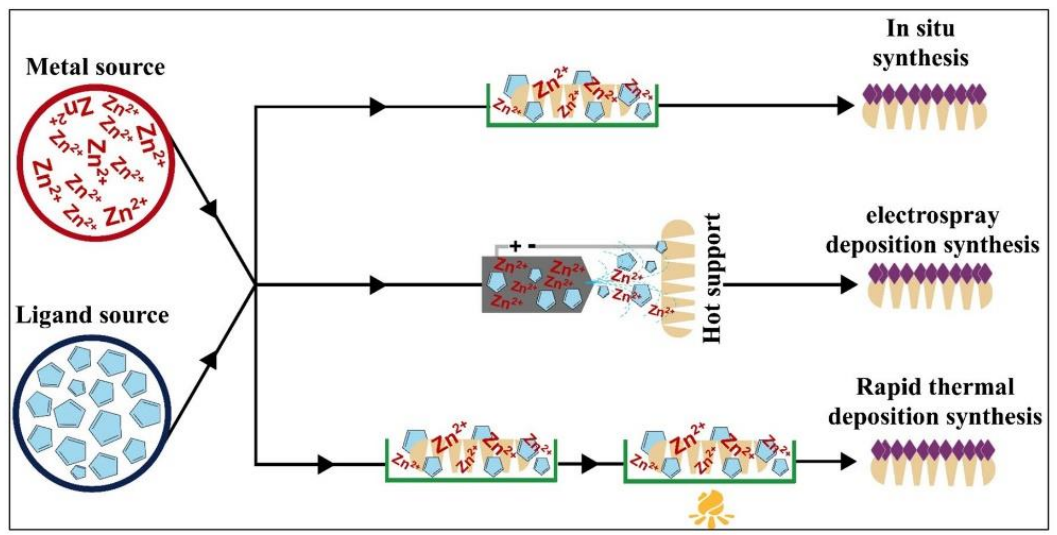

(b)

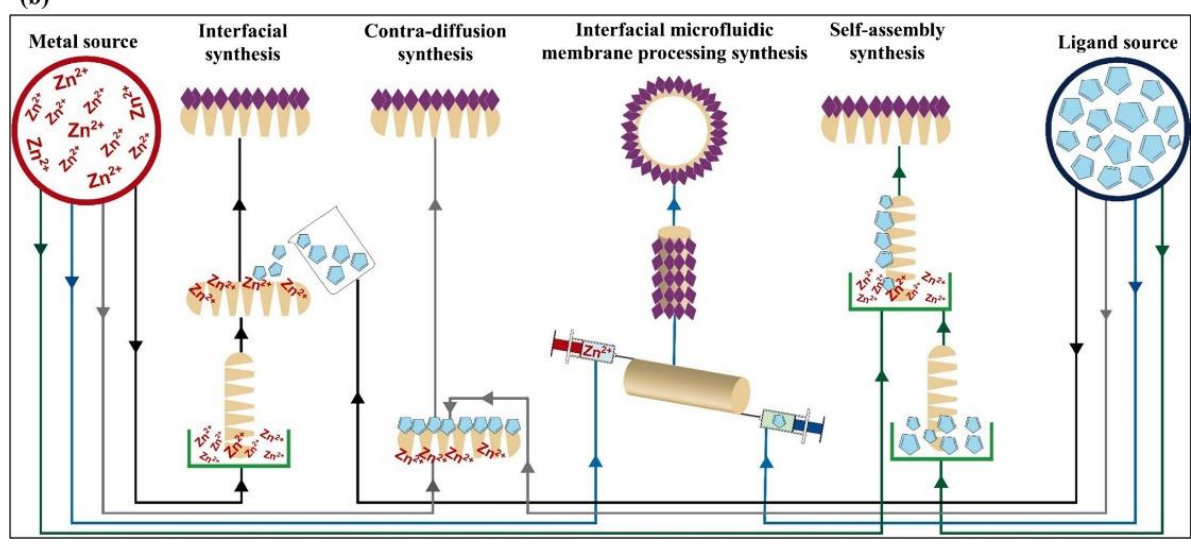

Figure 1.4 ZIF film preparation techniques a) support exposed to the mixture of reactants b) reactants exposed to each other at the interface. ${ }^{93}$ Reproduced by permission from Springer Nature publishing group, copyright 2020.

Chemical vapor deposition (CVD) - This technique is based on the MOF synthesis at the interface of the substrate by using vaporized reactants. Precise control over the thickness of the uniformly formed films is the main advantage of this method. Ameloot et al. developed the ZIF-8 CVD preparation on substrates with complex shapes, e.g., pillar arrays thanks to the use of vaporized reactants. ${ }^{94}$ Use of high 
temperature for the deposition has been tackled in the recent work of Ameloot et al. by preparing another MOF, MAF- 6 at lower temperatures $\left(100{ }^{\circ} \mathrm{C}\right)$ than previous ZIF$8 \mathrm{CVD}$ preparation at $240^{\circ} \mathrm{C} .95$ These patterned MOF films can be used in microelectronic applications. sequential, self-saturating gas-in-surface reactions.

Atomic/molecular layer deposition (ALD/MLD) - ALD has been used for the deposition of metal oxides on substrates via sequential self-limiting reactions. ${ }^{6}{ }^{6}$ For MOF synthesis, this technique is based on sequential steps of volatile metal and organic ligand reactants deposition. ${ }^{34,97}$ Good control over the thickness is possible via the control of the number of the repeating steps. This technique has been also used with the combinations of other techniques. For example, ALD can be used for the metal deposition followed by solvothermal method for MOF synthesis or as a nucleation layer for secondary-growth crystallization. ${ }^{98,99}$ Like CVD, ALD also contributes for the patterned MOF film preparation via control over the localized metal deposition.

\subsubsection{Applications}

MOF thin films and their applications are not considered mature with its 15 years history. Preparation techniques are still under development as well as assessing the potential applications. Beside fulfilling the criteria for specific applications, in a bigger picture, reproducibility and cost efficiency are the main challenges. However, MOF thin films and MOF hybrid films would be always in the scope of separation applications due to their specific pore sizes and high surface area. As discussed above, challenges such as defect-free film formation, stability and durability hinder their commercialization. With the control over the orientation and thickness along with the developments on localized synthesis techniques, MOF thin films are also attractive for many different applications: catalysis, drug-delivery, photovoltaics, $\mathrm{CO}_{2}$ reduction, water splitting, electronic devices, bioreactors, MOF-based capacitors and batteries (Fig. 1.5). ${ }^{14,34,35,100}$ 


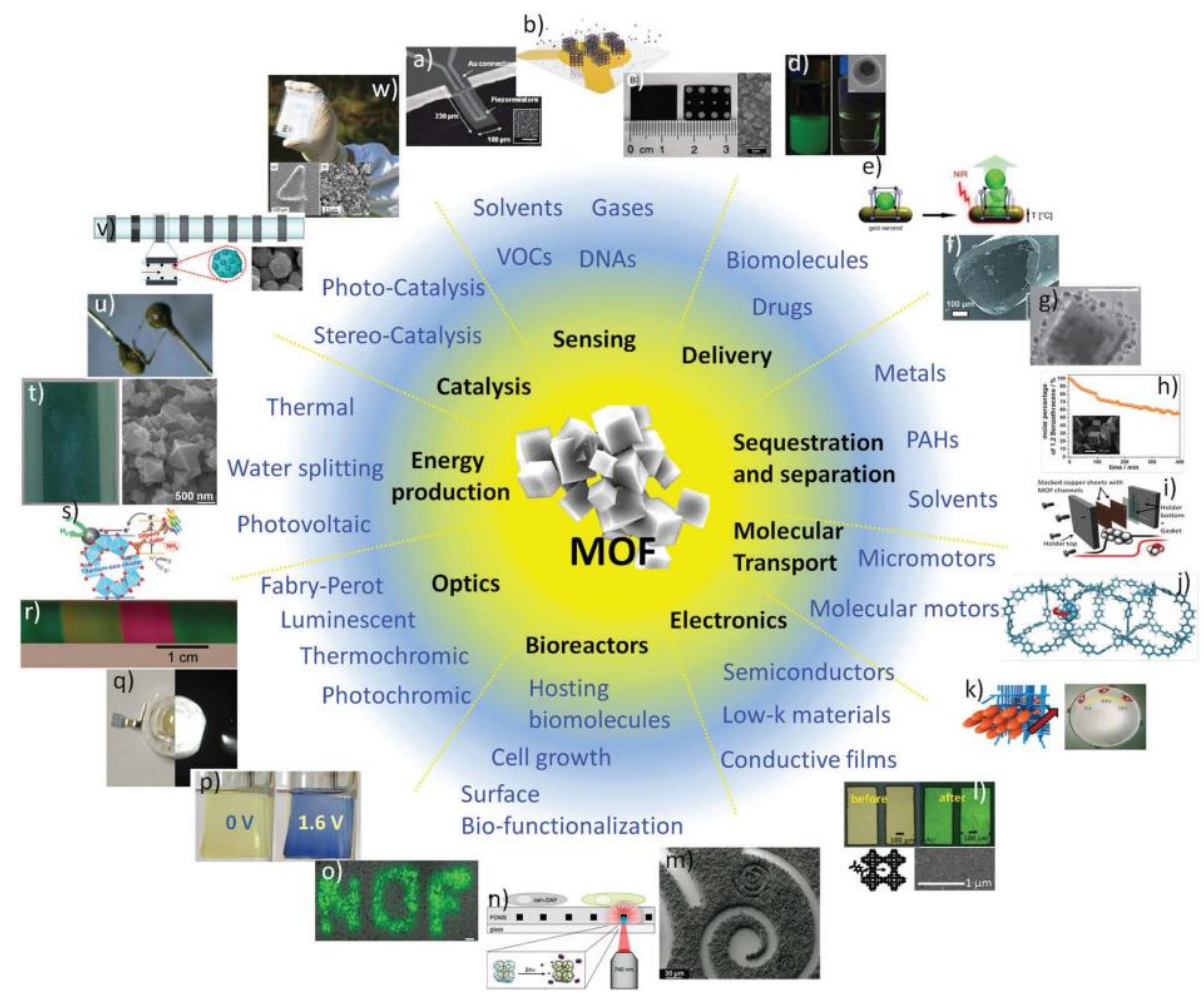

Figure 1.5 MOF applications. ${ }^{14}$ Reproduced by permission of The Royal Society of Chemistry.

\subsection{Thesis Outline}

In this thesis, the preparation of MOF films, both as surface-supported and mixed matrix membranes, was investigated. The focus was on understanding the role of the interface for synthesis and the performance of MOF based MMMs, and also efforts to quantify the interfacial properties of MOFs.

Porous copper hollow fibers used, for the first time, as a both support and a metal source for preparing thin MOF (Cu-BTC) films (Chapter 2). An electrochemical route has been chosen because it is easy, fast and side-product-free, applicable to the hollow fiber geometry, and enables the desired films characteristics. We have shown that by omitting a supporting electrolyte from the synthesis solution and by using lower potential differences thin and reproducible film formation can be 
achieved. This work is considered as an important step towards utilizing inorganic hollow fibers. ${ }^{86}$

In Chapter 3, commercial ion exchange membranes (IEM) were used both as a dense polymeric support and a selective medium to synthesize MOF (ZIF-8) films in diffusion-cell set-up. The aim is to control the transport of the reactants at the interface for localized synthesis. The influence of the different dielectric constant solvent, type of IEMs (anion exchange and cation exchange) and duration of the synthesis are investigated to obtain pure, homogenous ZIF-8 films. It was shown that pure ZIF-8 films were obtained in methanol, despite a lower dielectric constant and reduced Donnan exclusion (charge density), for anion exchange membranes in this solvent. IEMs has been introduced as a support for MOF thin films for the first time with great potential to control the local concentration and the synthesis.

In Chapter 4 MOFs embedded polymeric membranes were studied for gas separation applications. The effects of the post thermal treatment on the material properties and gas separation performance of these membranes are investigated. Three different MOFs (ZIF-8, sod-ZMOF and $\mathrm{K}^{+}$exchanged sod-ZMOF) and highly-permeable polyimide (6FDA-DAM) have been used. The performance of the membranes mainly depends on the polymer, the effect of the post-thermal treatment is investigated in detail for the polymer films. Secondly, the gas separation performance of hybrid films shows different performances based on MOF stability (stable, amorphous or oxidized) after thermal treatment. The amorphization of MOFs was shown to have a healing effect on the leaky interface between MOF and polymer. Our results show that by only changing the postthermal treatment parameter, it is possible to obtain different gas separation performance from both pure polymeric and hybrid membranes.

Chapter 5 covers analyzing and quantifying interfacial properties of MOF films (ZIF-8) via contact angle measurements. Sample preparation and measurement techniques (static, advancing-receding and most stable contact angle via 
piezoactuation) have been addressed. The most stable contact angle measurements of multiple probe liquids are used to estimate the interfacial properties of spin-coated ZIF-8 films. The challenges to analyze the surface characteristic of porous materials are conceptually and quantitatively investigated, as the interfacial aspects of MOF films are valuable information to understand any MOF-based system.

Chapter 6 reflects on the results showed in this thesis along with the possible future directions. Challenges across the thesis are discussed, with an emphasis on the so called "negative results" which were obtained during the course of this doctoral research. General perspectives on the MOF field, ranging from discovering new powders to designing films for nanotechnology applications and the contribution of this thesis to the growing field of MOFs are provided.

\section{References}

1

2

3

4

Á. Berenguer Murcia, ISRN Nanotechnol., 2013, 2013, 1-29.

M. E. Davis, Nature, 2002, 417, 813-821.

Z. Liu, J. Zhu, C. Peng, T. Wakihara and T. Okubo, React. Chem. Eng., 2019, 4, 1699-1720.

H. Yang, Z. Xu, M. Fan, R. Gupta, R. B. Slimane, A. E. Bland and I. Wright, J. Environ. Sci., 2008, 20, 14-27.

Q. Huo, in Modern Inorganic Synthetic Chemistry, Elsevier, 2011, pp. 339-373.

6 N. Rangnekar, N. Mittal, B. Elyassi, J. Caro and M. Tsapatsis, Chem. Soc. Rev., 2015, 44, 7128-7154.

7 J. Caro and M. Noack, Microporous Mesoporous Mater., 2008, 115, 215-233.

8 The Cambridge Crystallographic Data Centre (CCDC), The Cambridge Structural Database Data Update, https://www.ccdc.cam.ac.uk/support-andresources/ccdcresources/csd-2017-updates/, (accessed 16 February 2020).

O. M. Yaghi and H. Li, J. Am. Chem. Soc., 1995, 117, 10401-10402.

Io Mueller, M. Schubert, F. Teich, H. Puetter, K. Schierle-Arndt and J. Pastré, 
J. Mater. Chem., 2006, 16, 626-636.

11

novoMOF, Putting MOFs in Numbers - an Infografic, https://novomof.com/blog/putting-mofs-in-numbers-an-infografic/, (accessed 28 December 2019).

O. K. Farha, I. Eryazici, N. C. Jeong, B. G. Hauser, C. E. Wilmer, A. A. Sarjeant, R. Q. Snurr, S. T. Nguyen, A. Ö. Yazaydın and J. T. Hupp, J. Am. Chem. Soc., 2012, 134, 15016-15021.

I. M. Hönicke, I. Senkovska, V. Bon, I. A. Baburin, N. Bönisch, S. Raschke, J. D. Evans and S. Kaskel, Angew. Chemie Int. Ed., 2018, 57, 13780-13783.

P. Falcaro, R. Ricco, C. M. Doherty, K. Liang, A. J. Hill and M. J. Styles, Chem. Soc. Rev., 2014, 43, 5513-5560.

F. Gomollón-Bel, Chem. Int., 2019, 41, 12-17.

H. Kim, S. Yang, S. R. Rao, S. Narayanan, E. A. Kapustin, H. Furukawa, A. S. Umans, O. M. Yaghi and E. N. Wang, Science (80-. )., 2017, 356, 430-434.

E. Sharmin and F. Zafar, in Metal-Organic Frameworks, InTech, 2016, vol. i, p. 13 .

Nat. Chem., 2016, 8, 987-987.

J. Caro, Chemie-Ingenieur-Technik, 2018, 9o, 1759-1768.

P. A. Julien, C. Mottillo and T. Friščić, Green Chem., 2017, 19, 2729-2747.

M. Rubio-Martinez, C. Avci-Camur, A. W. Thornton, I. Imaz, D. Maspoch and M. R. Hill, Chem. Soc. Rev., 2017, 46, 3453-3480.

United States Patent, US 7,968,739 B2, 2011.

U. Mueller, M. Schubert, F. Teich, H. Puetter, K. Schierle-Arndt and J. Pastré, J. Mater. Chem., 2006, 16, 626-636.

M. Peplow, Nature, 2015, 520, 148-150.

25 J. Ren, X. Dyosiba, N. M. Musyoka, H. W. Langmi, M. Mathe and S. Liao, Coord. Chem. Rev., 2017, 352, 187-219.

D. E. Crawford and J. Casaban, Adv. Mater., 2016, 28, 5747-5754.

L. Garzón-Tovar, M. Cano-Sarabia, A. Carné-Sánchez, C. Carbonell, I. Imaz and D. Maspoch, React. Chem. Eng., 2016, 1, 533-539.

A. Carné-Sánchez, I. Imaz, M. Cano-Sarabia and D. Maspoch, Nat. Chem., 2013, 
5, 203-211.

29 M. P. Batten, M. Rubio-Martinez, T. Hadley, K. C. Carey, K. S. L. A. Polyzos and M. R. Hill, Curr. Opin. Chem. Eng., 2015, 8, 55-59.

30 Global Info Research, Global TFT-LCD Photomask Market 2018 by Manufacturers, Regions, Type and Application, Forecast to 2023, 2018.

31 S. Hermes, F. Schröder, R. Chelmowski, C. Wöll and R. A. Fischer, J. Am. Chem. Soc., 2005, 127, 13744-13745.

32 J. Cookney, University of Chemistry and Technology, 2018.

33 D. Zacher, O. Shekhah, C. Wöll and R. A. Fischer, Chem. Soc. Rev., 2009, 38, 1418.

34 J. Liu and C. Wöll, Chem. Soc. Rev., 2017, 46, 5730-5770.

35 S. Qiu, M. Xue and G. Zhu, Chem. Soc. Rev., 2014, 43, 6116-6140.

36 J. Gascon, S. Aguado and F. Kapteijn, Microporous Mesoporous Mater., 2008, $113,132-138$.

37 A. Demessence, C. Boissière, D. Grosso, P. Horcajada, C. Serre, G. Férey, G. J. A. A. Soler-Illia and C. Sanchez, J. Mater. Chem., 2010, 2o, 7676-7681.

38 V. M. Aceituno Melgar, H. T. Kwon and J. Kim, J. Memb. Sci., 2014, 459, 190196.

39 D. Y. Kim, B. N. Joshi, J. G. Lee, J. H. Lee, J. S. Lee, Y. K. Hwang, J. S. Chang, S. Al-Deyab, J. C. Tan and S. S. Yoon, Chem. Eng. J., 2016, 295, 49-56.

$40 \quad$ Y. Chen, S. Li, X. Pei, J. Zhou, X. Feng, S. Zhang, Y. Cheng, H. Li, R. Han and B. Wang, Angew. Chemie - Int. Ed., 2016, 55, 3419-3423.

41 A. Kertik, A. L. Khan and I. F. J. Vankelecom, RSC Adv., 2016, 6, 114505-114512.

42 H. Zhang, J. Hou, Y. Hu, P. Wang, R. Ou, L. Jiang, J. Zhe Liu, B. D. Freeman, A. J. Hill and H. Wang, Sci. Adv., , DOI:10.1126/sciadv.aaqoo66.

43 M. Maghami and A. Abdelrasoul, in Zeolites and Their Applications, InTech, 2018, p. 13 .

44 S. Shahid, K. Nijmeijer, S. Nehache, I. Vankelecom, A. Deratani and D. Quemener, J. Memb. Sci., 2015, 492, 21-31.

45 L. Ma, F. Svec, Y. Lv and T. Tan, Chem. - An Asian J., 2019, 14, 3502-3514.

46 S. Sorribas, P. Gorgojo, C. Téllez, J. Coronas and A. G. Livingston, J. Am. Chem. 
Soc., 2013, 135, 15201-15208.

47 J. Li, Z. Zhao, S. Yuan, J. Zhu and B. Van der Bruggen, Appl. Sci., 2018, 8, 759.

48 L. Fan, M. Xue, Z. Kang, H. Li and S. Qiu, J. Mater. Chem., 2012, 22, 25272.

49 H. Bux, F. Liang, Y. Li, J. Cravillon, M. Wiebcke and J. Caro, J. Am. Chem. Soc., 2009, 131, 16000-16001.

50 Z. Zhang, Y. Zhao, Q. Gong, Z. Li and J. Li, Chem. Commun., 2013, 49, 653-661.

51 A. Huang, Y. Chen, N. Wang, Z. Hu, J. Jiang and J. Caro, Chem. Commun., 2012, 48, 10981-10983.

52 M. Shah, H. T. Kwon, V. Tran, S. Sachdeva and H. K. Jeong, Microporous Mesoporous Mater., 2013, 165, 63-69.

53 R. Ameloot, F. Vermoortele, W. Vanhove, M. B. J. Roeffaers, B. F. Sels and D.

E. De Vos, Nat. Chem., 2011, 3, 382-387.

54 T. Tsuruoka, M. Kumano, K. Mantani, T. Matsuyama, A. Miyanaga, T. Ohhashi, Y. Takashima, H. Minami, T. Suzuki, K. Imagawa and K. Akamatsu, Cryst. Growth Des., 2016, 16, 2472-2476.

55 H. Lu and S. Zhu, Eur. J. Inorg. Chem., 2013, 2013, 1294-1300.

56 Y. Li, L. H. Wee, J. A. Martens and I. F. J. Vankelecom, J. Memb. Sci., 2017, 523, 561-566.

57 K. Eum, C. Ma, A. Rownaghi, C. W. Jones and S. Nair, ACS Appl. Mater. Interfaces, 2016, 8, 25337-25342.

58 B. P. Biswal, A. Bhaskar, R. Banerjee and U. K. Kharul, Nanoscale, 2015, 7, 72917298.

59 A. J. Brown, N. A. Brunelli, K. Eum, F. Rashidi, J. R. Johnson, W. J. Koros, C. W. Jones and S. Nair, Science (80-. )., 2014, 345, 72-75.

6 J. Su, W. Wu, Z. Li and W. Li, Dalt. Trans., 2019, 48, 11196-11199.

61 J. Yao, D. Dong, D. Li, L. He, G. Xu and H. Wang, Chem. Commun., 2011, 47, 2559 .

62 M. He, J. Yao, L. Li, Z. Zhong, F. Chen and H. Wang, Microporous Mesoporous Mater., 2013, 179, 10-16.

63 Y. Sun, R. Zhang, C. Zhao, N. Wang, Y. Xie and J. R. Li, RSC Adv., 2014, 4, 3300733012 . 
64 N. Hara, M. Yoshimune, H. Negishi, K. Haraya, S. Hara and T. Yamaguchi, J. Memb. Sci., 2014, 450, 215-223.

65 H. T. Kwon and H. K. Jeong, J. Am. Chem. Soc., 2013, 135, 10763-10768.

66 C. Li, C. Hu, Y. Zhao, L. Song, J. Zhang, R. Huang and L. Qu, Carbon N. Y., 2014, 78, 231-242.

67 X. Zhang, Y. Li, C. Van Goethem, K. Wan, W. Zhang, J. Luo, I. F. J. Vankelecom and J. Fransaer, Matter, 2019, 1, 1285-1292.

68 Y. Sun, H. Huang, X. Guo, Z. Qiao and C. Zhong, ChemNanoMat, 2019, 5, 12441250.

69 N. Hara, M. Yoshimune, H. Negishi, K. Haraya, S. Hara and T. Yamaguchi, J. Japan Pet. Inst., 2015, 58, 237-244.

$70 \quad$ S. Zhang, Z. Wang, H. Ren, F. Zhang and J. Jin, J. Mater. Chem. A, 2017, 5, 19621966.

71 Q. Zhu, X. Tang, S. Feng, Z. Zhong, J. Yao and Z. Yao, J. Memb. Sci., 2019, 581, 252-261.

72 E. Shamsaei, X. Lin, Z. X. Low, Z. Abbasi, Y. Hu, J. Z. Liu and H. Wang, ACS Appl. Mater. Interfaces, 2016, 8, 6236-6244.

73 K. Huang, Q. Li, G. Liu, J. Shen, K. Guan and W. Jin, ACS Appl. Mater. Interfaces, 2015, 7, 16157-1616o.

74 N. Hara, M. Yoshimune, H. Negishi, K. Haraya, S. Hara and T. Yamaguchi, RSC Adv., 2013, 3, 14233-14236.

75 Z. Wang and C. Wöll, Adv. Mater. Technol., 2019, 4, 1-22.

76 J. Cookney, W. Ogieglo, P. Hrabanek, I. Vankelecom, V. Fila and N. E. Benes, Chem Commun, 2014, 50, 11698-11700.

77 V. Chernikova, O. Shekhah and M. Eddaoudi, ACS Appl. Mater. Interfaces, 2016, 8, 20459-20464.

78 J. Nan, X. Dong, W. Wang, W. Jin and N. Xu, Langmuir, 2011, 27, 4309-4312.

79 Z. G. Gu and J. Zhang, Coord. Chem. Rev., 2019, 378, 513-532.

80 W. J. Li, M. Tu, R. Cao and R. A. Fischer, J. Mater. Chem. A, 2016, 4, 12356-12369.

81 R. Ameloot, L. Stappers, J. Fransaer, L. Alaerts, B. F. Sels and D. E. De Vos, Chem. Mater., 2009, 21, 2580-2582. 
82 N. Campagnol, T. R. C. Van Assche, M. Li, L. Stappers, M. Dincă, J. F. M. Denayer, K. Binnemans, D. E. De Vos and J. Fransaer, J. Mater. Chem. A, 2016, 4, 3914-3925.

83 R. Ameloot, L. Pandey, M. Van Der Auweraer, L. Alaerts, B. F. Sels and D. E. De Vos, Chem. Commun., 2010, 46, 3735.

84 H. Zhu, H. Liu, I. Zhitomirsky and S. Zhu, Mater. Lett., 2015, 142, 19-22.

85 I. Hod, W. Bury, D. M. Karlin, P. Deria, C.-W. Kung, M. J. Katz, M. So, B. Klahr, D. Jin, Y.-W. Chung, T. W. Odom, O. K. Farha and J. T. Hupp, Adv. Mater., 2014, 26, 6295-6300.

86 Ö. H. Demirel, T. Rijnaarts, P. de Wit, J. A. Wood and N. E. Benes, J. Mater. Chem. A, 2019, 7, 12616-12626.

87 P. Schäfer, A. Lalitha, P. Sebastian, S. K. Meena, J. Feliu, M. Sulpizi, M. A. van der Veen and K. F. Domke, J. Electroanal. Chem., 2017, 793, 226-234.

88 P. Schäfer, M. A. van der Veen and K. F. Domke, Chem. Commun., 2016, 52, 4722-4725.

89 S. D. Worrall, M. A. Bissett, M. P. Attfield and R. A. W. Dryfe, CrystEngComm, 2018, 20, 4421-4427.

90 S. Jabarian and A. Ghaffarinejad, J. Inorg. Organomet. Polym. Mater., 2019, 29, $1565^{-1574 .}$

91 L. Ji, J. Hao, K. Wu and N. Yang, J. Phys. Chem. C, 2019, acs.jpcc.8b10448.

92 L.-L. Jiang, X. Zeng, M. Li, M.-Q. Wang, T.-Y. Su, X.-C. Tian and J. Tang, RSC Adv., 2017, 7, 9316-9320.

93 M. S. Mirqasemi, M. Homayoonfal and M. Rezakazemi, Zeolitic imidazolate framework membranes for gas and water purification, Springer International Publishing, 2020, vol. 18.

94 I. Stassen, M. Styles, G. Grenci, H. Van Gorp, W. Vanderlinden, S. De Feyter, P. Falcaro, D. De Vos, P. Vereecken and R. Ameloot, Nat Mater, , DOI:10.1038/nmat4509.

95 T. Stassin, I. Stassen, J. Marreiros, A. J. Cruz, R. Verbeke, M. Tu, H. Reinsch, M. Dickmann, W. Egger, I. F. J. Vankelecom, D. E. De Vos and R. Ameloot, Chem. Mater., 2020, acs.chemmater.9bo3807.

96 S. M. George, Chem. Rev., 2010, 110, 111-131.

97 K. B. Lausund and O. Nilsen, Nat. Commun., 2016, 7, 1-9. 
98 K. Khaletskaya, S. Turner, M. Tu, S. Wannapaiboon, A. Schneemann, R. Meyer, A. Ludwig, G. Van Tendeloo and R. A. Fischer, Adv. Funct. Mater., 2014, 24, 4804-4811.

99 T. Xu, K. Sun, D. Gao, C. Li, X. Hu and G. Chen, Chem. Commun., 2019, 55, 7651-7654.

100 I. Stassen, N. Burtch, A. Talin, P. Falcaro, M. Allendorf and R. Ameloot, Chem. Soc. Rev., 2017, 46, 3185-3241. 


\section{CHAPTER 2}

\section{Electroforming of a metal organic framework on porous copper hollow fibers}

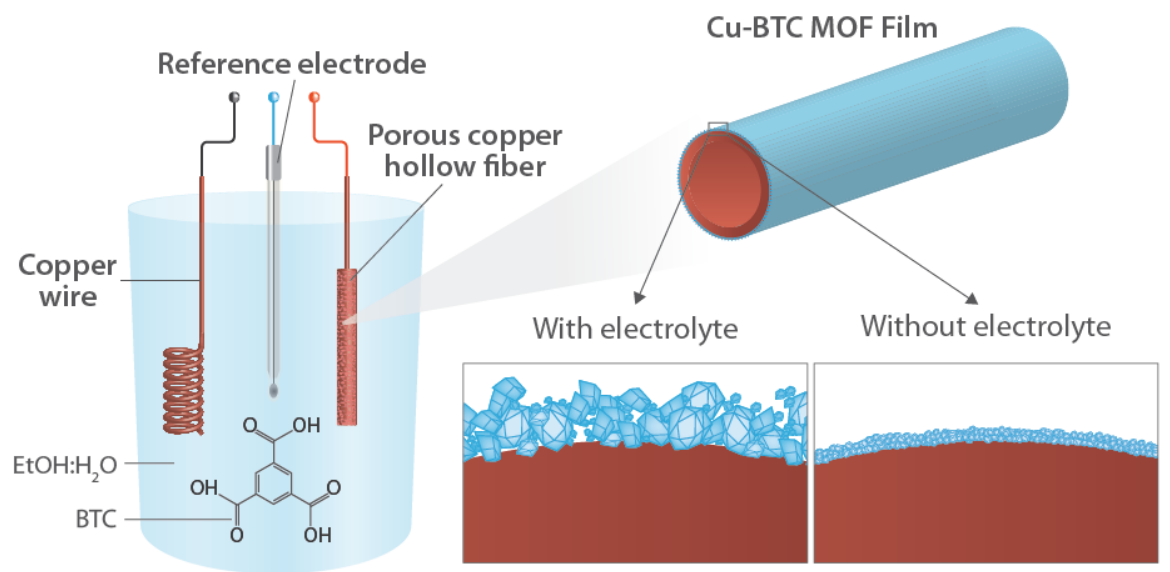

This chapter is adapted from:

Özlem H. Demirel, Timon Rijnaarts, Patrick de Wit, Jeffery A. Wood, Nieck E. Benes, Electroforming of a metal organic framework on porous copper hollow fibers, Journal of Materials Chemistry A 2019, 7, 12616-12626, DOI: 10.1039/C8TA11296G 


\section{Abstract}

Porous copper hollow fibers have been used, for the first time, as both a support structure and as a metal source for preparing thin metal organic framework $(\mathrm{Cu}-$ BTC) film via a fast, facile and direct electrochemical route. Our focus was on the effects of supporting electrolyte and magnitude of the applied electrical potential on the formation and the morphology of the films. In the absence of a supporting electrolyte, and at low potential, more uniform films with smaller particles are obtained. This is attributed to the more pronounced electric-field driven mass transport of the organic ligand from the liquid bulk towards the surface of electrode combined with the slower dissolution of copper due to the lower overpotentials. In the presence of a supporting electrolyte the ligand transport is much slower and copper dissolution higher due to higher overpotentials; this results in the formation of less homogeneous films and the growth of metal organic framework crystals in the liquid bulk. The localized formation of thin metal organic framework films on metal porous hollow fibers with high surface area to volume ratio is an important step towards various applications, including membranes, microfluidic devices, sensors and heterogeneous catalysts. 


\subsection{Introduction}

Metal-organic frameworks (MOFs) are hybrid materials consisting of inorganic metal centers connected by organic linkers. This nature gives MOFs synergetic properties of both inorganic and organic porous materials. MOFs have been studied for many different applications over the past decade due to their high surface area and porosity, relatively good thermal and chemical stability, designable framework, flexibility, sorption capacities, and functionalizability. ${ }^{1-6}$ For example, MOF thin films have attracted attention for separations, sensors, electric devices, and catalytic coatings. ${ }^{7-11}$ Efforts towards controlling MOF localized synthesis, morphology and thickness have become crucial for these applications. MOF films can be prepared by multiple methods, including in-situ and secondary growth, ${ }^{12}$ dip coating, ${ }^{13}$ layer by layer growth ${ }^{14}$ and electrochemical fabrication methods. ${ }^{15}$ After the electrochemical fabrication method was first developed for MOF powder synthesis by BASF in 2005, preparation of MOF films via electrochemical route has been also explored. ${ }^{16,17}$ The electrochemical method has a number of advantages versus other techniques. Firstly, it is a facile technique that offers the advantages of using lower temperatures than those needs for traditional methods. Secondly, by using a pure metal source instead of a metal salt, the formation of undesirable by-products, such as nitrates, is prevented..$^{18}$ Thirdly, the time required for electrochemical synthesis is typically on the order of minutes while for other approaches can be hours or days. ${ }^{19}$

Until now, 14 different MOFs have been electrochemically synthesized as thin films. ${ }^{20}$ Among them, Cu-BTC $\left(\mathrm{Cu}_{3}(\mathrm{BTC})_{2}\right.$, HKUST-1, BTC=benzene-1,3,5-tricarboxylate $)$ is the most studied electrochemically synthesized type of MOF in the literature. There are different electrochemical fabrication techniques, including anodic oxidation, ${ }^{17-19,21-}$ ${ }^{25}$ cathodic deposition, ${ }^{26,27}$ galvanic displacement, ${ }^{28}$ and electrophoretic deposition. ${ }^{29,30}$ Anodic oxidation is the most common and the most straightforward technique. In this method, a working electrode (anode) is used both as a metal source and a support for the MOF films. By applying a potential difference between the working electrode and a counter electrode, metal ions are released and react with the organic linker available in the synthesis solution and the MOF film is formed. Under the right synthesis 
conditions the formation of the MOF occurs on the surface of the working electrode and a thin film is formed. Often, a supporting electrolyte is used to enhance the conductivity of the organic solution due to its high resistivity. ${ }^{19}$

Efforts have been made to investigate the crystallization mechanism, the reaction mechanism and the factors affecting the MOF film thickness and the quality. It has been shown that dense, thin MOF films can be prepared on a partially oxidized support without damaging it by controlling the applied potential, time and the use of supporting electrolyte. ${ }^{18}$ In the anodic dissolution method, MOF formation consists of four different steps: i) initial nucleation, ii) growth of islands, iii) intergrowth and iv) detachment. ${ }^{25}$ The reaction mechanism of the synthesis has been found to be a twostep oxidation mechanism. ${ }^{24}$ Firstly, the presence of oxygen and water initiate the oxidation of $\mathrm{Cu}^{\circ}$ to $\mathrm{Cu}^{+1}$ as form of $\mathrm{Cu}_{2} \mathrm{O}$. Secondly, $\mathrm{Cu}_{2} \mathrm{O}$ in the presence of organic linker solution leads to formation of $\mathrm{Cu}_{3}(\mathrm{BTC})_{2}$. Cyclic voltammetry $(\mathrm{CV})$ of $\mathrm{Cu}-\mathrm{BTC}$ synthesis have been studied using $\mathrm{Au}(111)$ as a substrate to shed a light on the mechanism. ${ }^{31}$ After the deposition of copper to the Au surface, the interaction between the organic linker and copper in ethanol has been investigated. The oxidation of copper shifted to higher potentials due to the adlayer (adsorbed layer) of the organic linker on the copper surface. This may explain the good attachment of MOFs to the copper surface. It is also found that $\mathrm{Cu}$ oxidation occurs at low potentials (o.18 V in the presence of BTC) whereas a very large range of applied potential have been used in the literature $\left(0.5^{-25} \mathrm{~V}\right) .{ }^{17,31}$ This can be also related to the use of a two-electrode or three-electrode electrochemical cell. In a three-electrode cell, the applied potential between the working and reference electrode can be controlled precisely, whereas in a two-electrode cell it is not possible to know the exact potential applied to the working electrode since it is not versus a reference electrode. ${ }^{15}$ Solutions suffer from high (ionic) resistivity due to usage of an organic solvent, which limits charge transport and thus electron transfer at the surface. In order to decrease the Ohmic (resistance) drop in the solution and increase the efficiency of the synthesis, a supporting electrolyte is typically added to the synthesis solution. Some studies have found that the supporting electrolyte has a strong effect on the kinetics of the 
reaction. ${ }^{18,32}$ This can cause some cracks or defects on the substrate and it has been found that MTBS (tributylmethylphosphonium methyl sulphate), a supporting electrolyte commonly used in the organic solutions, can be trapped in the pores of the MOF and cause a decrease in the pore volume and specific surface area. ${ }^{33}$

Up to now, there have been various studies to obtain MOF films on various copper supports such as plate, disk, mesh, bead and copper coated silicon wafers, using gold and glass carbon electrodes. $15,16,18,31,34-36$ However, to the best of our knowledge, electrochemical deposition of MOFs directly on porous hollow fibers (HFs) has not been previously reported. HFs are attractive for many industrial applications due to their high surface area to volume ratio and easy scale-up features. Therefore, MOF HFs have gained many interest as mixed matrix HF membranes, ${ }^{37-39}$, MOF films coated onto polymeric $\mathrm{HFs}^{40,41}$ or ceramic HFs incorporated with MOFs. ${ }^{42}$ In this work, we have prepared $\mathrm{Cu}$-BTC-coated $\mathrm{Cu}$ HFs via an electrochemical synthesis route. It is shown that electrochemical synthesis can be used for MOF film formation on the outer surface of the metal HFs as a fast, simple and efficient direct synthesis technique. We investigated different synthesis conditions in order to obtain homogeneous, uniform and continuous MOF films and characterized based on the adhesion of the layers, their thickness, and their particle size distribution.

\subsection{Experimental}

\subsubsection{Preparation of Cu-BTC-coated Cu HFs}

Cu-BTC-coated $\mathrm{Cu}$ HFs were prepared using a three-electrode electrochemical cell. (Fig. 2.1) As a starting point, an adapted procedure of Van Assche, 2012 and Schäfer, 2016 with different substrates (e.g. copper mesh, copper plate) was followed. ${ }^{18,24} \mathrm{~A}$ copper HF, with a wall thickness of ca. $0.25 \mathrm{~mm}$, an inner diameter ca. $1 \mathrm{~mm}$ and an average length $10 \mathrm{~cm}$ was used as a working electrode (WE). (Fig. 2.1(c)) The preparation of copper HFs via non-solvent induced phase separation is described in detail elsewhere. ${ }^{43}$ A copper wire $(r=0.23 \mathrm{~mm})$ was polished using 240 grit sandpaper and used as a counter electrode (CE). As a reference electrode (RE), a saturated 
calomel electrode (SCE) (from SI Analytics) was used. ${ }^{44}$ All the reported electrical potential values were based on standard hydrogen electrode (SHE). The synthesis mixture was prepared by adding the organic linker, benzene-1,3,5-tricarboxylic acid (trimesic acid, BTC) (Sigma Aldrich, $\geq 95 \%$ ) and the supporting electrolyte methyltributylammonium methyl sulfate (MTBS) (Santa Cruz Biotechnology, >\%98) both with the concentration of $16 \mathrm{~g} \mathrm{~L}^{-1}$ into a mixture of purified ethanol (EtOH, $\geq 99.9$ $\%$, EMSURE $\left.{ }^{\circ}\right)$ and water $\left(\mathrm{H}_{2} \mathrm{O}\right.$, purified by a Milli Q system, Millipore) (EtOH: $\mathrm{H}_{2} \mathrm{O}$ $65: 35 \mathrm{v} / \mathrm{v})$.

All the electrodes were placed in the solution. The cell was heated to $50^{\circ} \mathrm{C}$ by immersing the assembly in a hot water bath. A PGSTAT204 potentiostat (Metrohm Autolab, B.V., The Netherlands) was used to apply a potential difference across the electrodes. For a given experiment, the desired potential was applied to the samples and synthesis allowed to take place over a given time (30 minutes). The current was recorded during the synthesis and was reported as an average over time (Fig. S2.1 and Table 2.1). After electrochemical synthesis, the MOF-HFs were rinsed in ethanol for 2 days followed by drying at ambient temperatures for further analysis. Effect of the presence of the supporting electrolyte in the synthesis solution and the effect of the applied potential (o.5 - $5 \mathrm{~V}$ vs SHE) were investigated. The Cu-BTC-coated Cu HF samples synthesized in the presence of the electrolyte and in the electrolyte free solution were called E-(applied potential) and F-(applied potential), respectively.

\subsubsection{Materials characterization}

The Cu-BTC-coated Cu HFs were investigated using an SM-6o1o (JEOL) scanning electron microscope equipped with an energy dispersive X-ray spectrometer (EDS). MOF thin layer deposition was essentially uniform on the HF surface, with only slight differences that may be attributed to the effect of the curvature of the HF and the local electric-field distribution. Consequently, in the analysis variations based on position were not considered. Cross-sections and the outer surface of fibers were sputtered with a $5 \mathrm{~nm}$ chromium coating (Quorum Q150T ES) prior to analysis. The XRD patterns of the samples were determined by powder X-ray diffraction (XRD) on a 
Bruker D2 PHASER operated at $10 \mathrm{~mA}$ and $30 \mathrm{kV}$ using a $\mathrm{CuK} \alpha$ source with a wavelength $(\lambda)^{1 / 4} 1.54 \AA$ at room temperature. Scans were made at variable angle, ranging from 5 to $50^{\circ}$ with a $2 \theta$ step size of $0.02^{\circ}$ and a scan speed of 1 s per step. The MOF sample for XRD analysis was obtained by scratching the outer surface of the fibers. Thermogravimetric analysis (TGA) was performed using a STA 449 F3 Jupiter

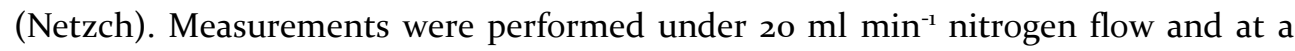
heating rate of $5{ }^{\circ} \mathrm{C} \mathrm{min}^{-1}$, starting from room temperature up to $800^{\circ} \mathrm{C}$. Temperature correction by melting standard and a blank correction with an empty cup were carried out prior to the measurements.

\subsection{Particle size and film thickness analysis}

Particle size and film thickness were determined by image analysis (ImageJ software ) using outer surface and cross-sectional SEM images, respectively. ${ }^{45}$ The particle size analysis was performed for each sample using at least two outer surface images and for more than 300 particles in total. A minimum threshold was set at 5 particles per bin (bins $0.2 \mu \mathrm{m}$ in width), bins containing fewer than this number were not included in the analysis. The particle size was fitted to a Gaussian distribution using least squares regression. The thickness of the MOF films was calculated by taking more than 10 measurements per cross-sectional SEM image. The mean particle size, the spread and thickness data are reported along with the standard error.

\subsection{Results and discussion}

Here, MOF film formation on the outer surface of the copper HF via electrochemical route is investigated. We considered two cases: with and without supporting electrolyte. In the first case, with supporting electrolyte, electrical potential gradients in the bulk are reduced or negligible due to the higher conductivity of the synthesis solution. In the second case, larger electrical potential gradients can exist in the bulk that can favor the transport of charged species to and from the electrodes via electromigration. From the perspective of electrocrystallization, MOF film formation via electrochemical method is a surface reaction that takes place in the electrical 
double layer (near the electrode surface). Partial oxidation of the copper HF support and transport of BTC in order to react and form the MOF layer are then the critical parameters controlling the properties of MOF film.

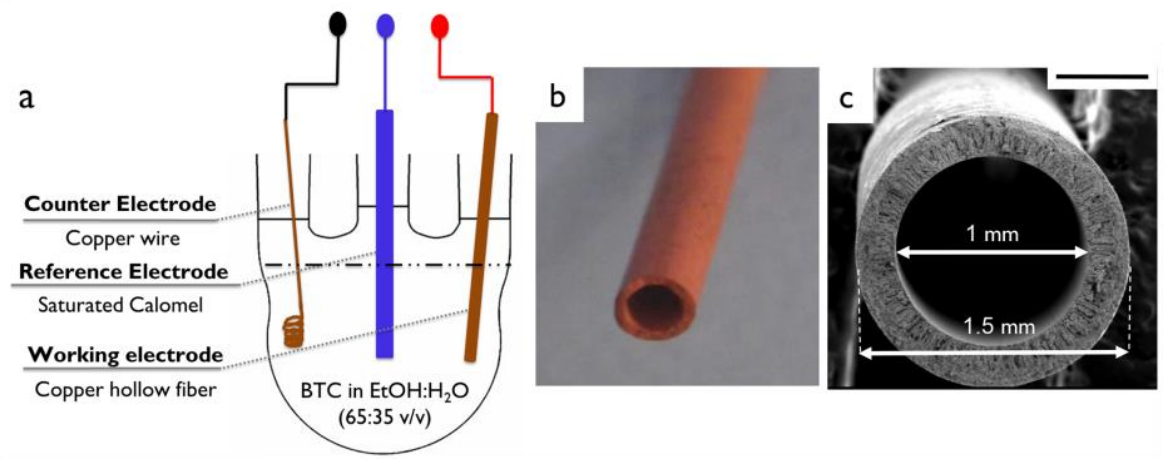

Figure 2.1 a) Schematic overview of the three-electrode cell. b) Porous copper HF c) Cross-sectional image of copper HF. Scale bar, $500 \mu \mathrm{m}$.

\subsubsection{Cu-BTC MOF films characterization}

Fig. 2.2 shows that on the outer surface of the HF films of Cu-BTC MOF crystals with the typical octahedral shape. In Fig. 2.3 the EDS data depicts the atomic composition of the films, revealing the presence of a uniform $\mathrm{Cu}$-BTC MOF structure containing both organic $(\mathrm{C})$ and metal $(\mathrm{Cu})$ components. The X-ray diffraction patterns of the MOF films that were prepared with and without supporting electrolyte are in good agreement with simulated Cu-BTC (Fig. 2.4(a)), from the study of Zhou (2013) et al., CCDC $943009 .{ }^{46}$ Powder XRD patterns $\left(2 \theta=7-50^{\circ}\right)$ confirm the crystal structure of the $\mathrm{Cu}-\mathrm{BTC}$, indicating the successful synthesis of $\mathrm{Cu}-\mathrm{BTC}$ films on the $\mathrm{Cu}$ HFs. The total weight change $(3.5 \%)$ between $50-800^{\circ} \mathrm{C}$ in the TGA analysis corresponds to the thin MOF films on the outer surface of the fiber (Fig. 2.4 (b)). The initial weight loss between $50-200^{\circ} \mathrm{C}(0.7 \%)$ is attributed to the residual ethanol, adsorbed water on the surface, and coordinated water molecules in the MOF structure. 47 The TGA results show that MOF is stable up to $280^{\circ} \mathrm{C}$ and the decomposition of the organic ligand, trimesic acid, starts at temperatures in excess of $280^{\circ} \mathrm{C}$. 

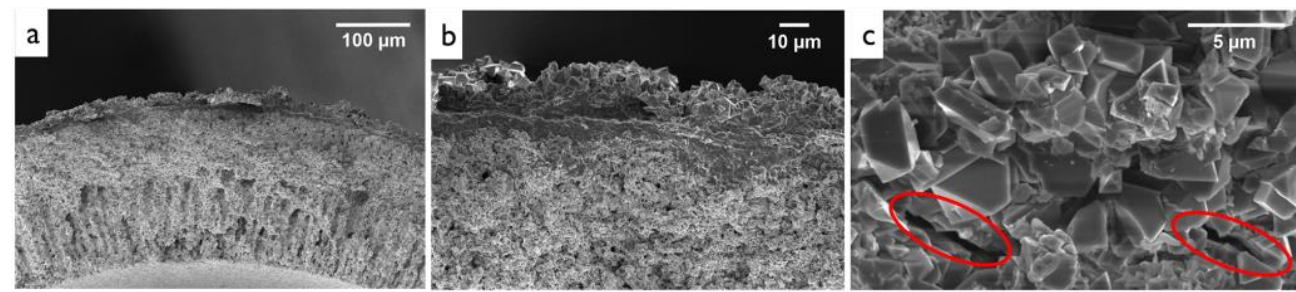

Figure 2.2 Formation of Cu-BTC MOF films (E-1) a) and b) SEM images of the crosssectional image of the $\mathrm{Cu}$-BTC-coated Cu HFs. c) The outer surface of the HF. Red circles indicate cracks present.
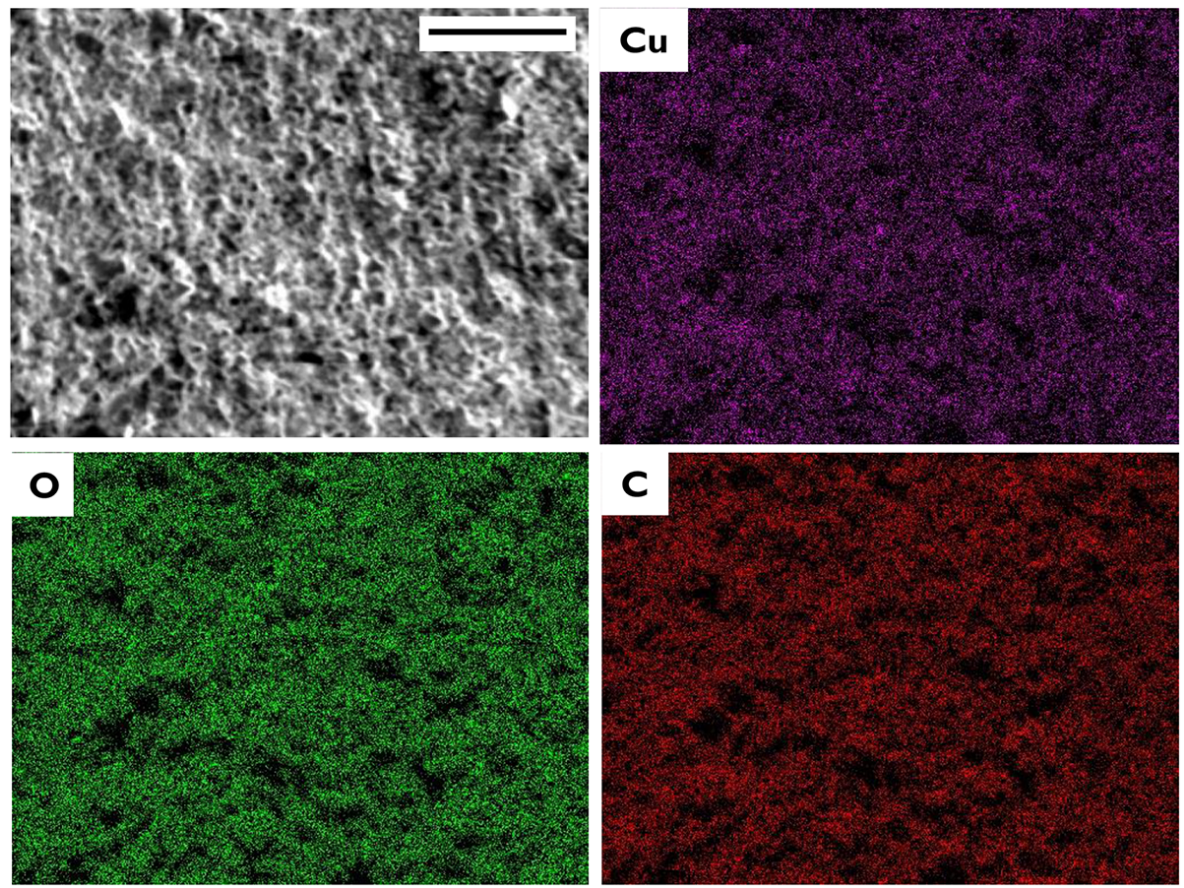

Figure 2.3 SEM image of the outer surface of the Cu-BTC-coated Cu HF (F-o.5). EDS map showing copper, oxygen and carbon distribution. Scale bar, $30 \mu \mathrm{m}$. 

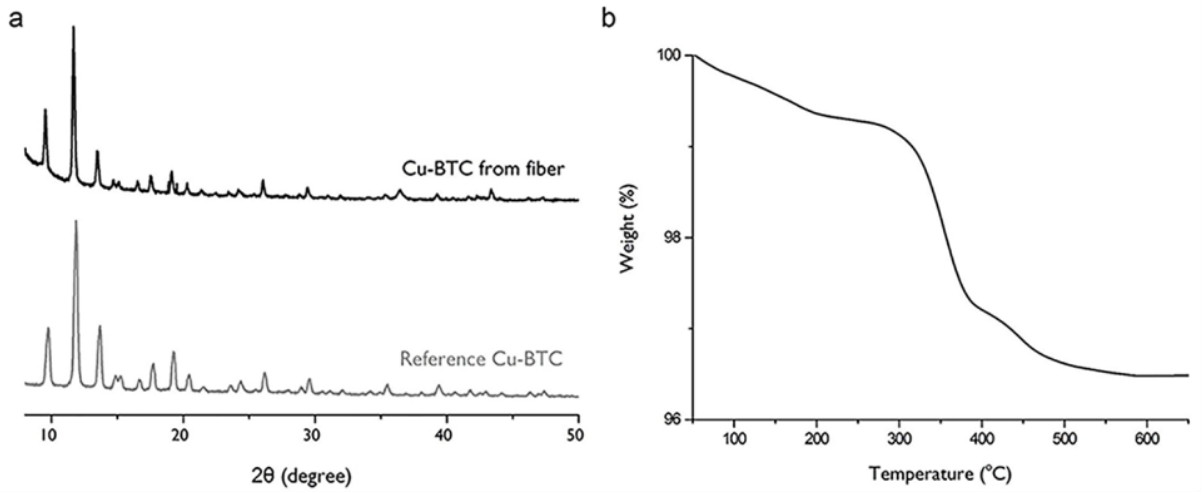

Figure 2.4 a) XRD patterns of $\mathrm{Cu}$-BTC sample scratched from fibers and simulated Cu-BTC powders (data is taken from the study of Zhou (2013) et al., CCDC 943009, [6]). b) TGA curve of $\mathrm{Cu}$-BTC-coated $\mathrm{Cu}$ HFs under continuous nitrogen flow.

Some MOF formation within the pores of the fiber is also observed, specifically close to the outer surface of the HF (Fig. S2.2). Electrochemical reactions occur at the interface between the surface of the working electrode and the solution. ${ }^{8}$ Due to the porous nature of the HF, the reaction occurs in the pores as the organic ligand (BTC) solution can diffuse into the pores. The acidity of the BTC solution $(\mathrm{pH}=3)$ can possibly enable the dissolution of the copper ions in the pores while there is a negligible electric potential gradient within the pores driving transport. ${ }^{15}$ BTC molecules can react with these copper ions and form $\mathrm{Cu}-\mathrm{BTC}$ MOF in the pores of the HF as well. Dissolution of metal substrates with the combination of acidity effect and high temperature (higher than $110^{\circ} \mathrm{C}$ ) has been also reported previously. ${ }^{32}$

\subsubsection{Effect of the supporting electrolyte}

Introducing supporting electrolyte into the synthesis can help to overcome the high electrical resistance of the organic solvent and hence aid reduction of the Ohmic drop of the solution. An organic supporting electrolyte, MTBS is often used in the electrochemical synthesis of MOFs. ${ }^{49}$ The release of the copper ions occurs much faster in an supporting electrolyte solution as all the electrical potential drop occurs close to the surface so that the efficiency of the electrochemical MOF powder synthesis is improved. ${ }^{20}$ However, in this case we have observed some disadvantages 
of using an supporting electrolyte based synthesis solution for thin film MOF formation on HFs.

Cracks: During the formation of the MOF film, cracks were observed on the copper HF surface as indicated by red circles in Fig. 2.2(c). The porous copper HF is used both as a substrate and as a metal source for the MOF film synthesis. The growth of the MOF particles on the outer surface of the HF may create internal stress and result as cracks on the substrate, especially when the reaction occurs fast with the help of the supporting electrolyte (MTBS). When the applied potential was increased to $5 \mathrm{~V}$, the effects of the presence of the supporting electrolyte are larger as can be seen in Fig. 2.5 (c-d). The detachment of the MOF spikes and the rapid release of the $\mathrm{Cu}$ ions causes damage to the $\mathrm{Cu}$ HF support. A similar phenomenon on a copper mesh substrate was also reported by Van Assche (2012) and was attributed to the presence of supporting electrolyte and its effect on kinetics. ${ }^{18}$

Blue solution: During the synthesis with the supporting electrolyte, MTBS, we have observed that the reaction solution turned blue within seconds. This color change is characteristic of $\mathrm{Cu}$-BTC MOF powders..$^{50}$ This can be the result of both powder synthesis in liquid bulk, as well as a detachment of the MOF films into the solution. By decreasing the resistance of the organic solvent through introducing MTBS, the faster release of the copper ions promotes the diffusion of these ions into the liquid bulk and synthesis of MOF particles in suspension. The use of supporting electrolyte on the reaction kinetics also promoted the detachment of the MOF films formed on the surface. Copper ions migrating through the MOF films creating voids below the MOF films results in poor adhesion of the films on the HF, as previously observed. ${ }^{25}$ When this phenomenon occurs on a wide area, the MOF films are easily detached from the surface during the synthesis. As can be seen in Fig. 2.5 (a) and (b), large MOF branch-like structures have been observed on the outer surface of the fiber when a potential difference of $2 \mathrm{~V}$ applied in a supporting electrolyte solution. These structures are not physically stable and show poor attachment to the surface of the $\mathrm{Cu}$ HF. They can be easily detached from the surface and dispersed in the solution, as can 
be seen in the corner of the Fig. 2.5 (b) where the synthesis solution is partially blue. As the applied potential is increased to $5 \mathrm{~V}$, the synthesis solution became a deeper blue color (corner of the Fig. 2.5 (d)). The branch-like structures formed at this potential have completely detached from the surface and damage to the HF support has been also observed (Fig. 2.5 (d)). The presence of supporting-electrolyte allows for a very rapid synthesis of the MOF on the surface.
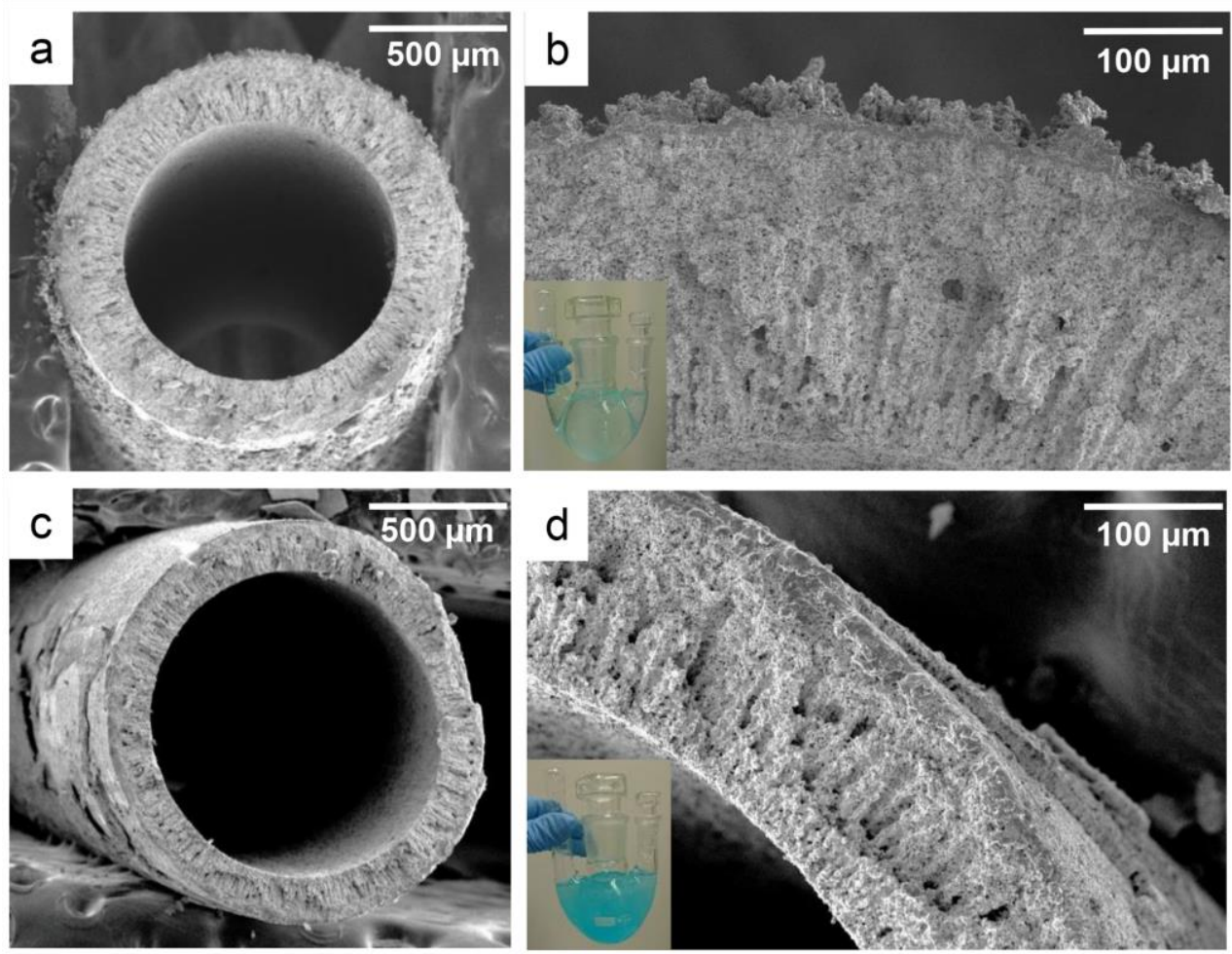

Figure 2.5 The effect of applied potential higher than $1 \mathrm{~V}$ on the structure of the $\mathrm{Cu}$ BTC-coated $\mathrm{Cu}$ HFs a) low and b) high magnification SEM images of the sample E-2 with the insets showing solution after synthesis. c) Low and d) high magnification SEM images of the sample E- 5 with the insets showing solution after synthesis. (contrast and brightness adjustment has been made for Fig. 2.5 (b), (c) and (d)).

Gas formation: Formation of gas bubbles at the counter electrode has been observed in the presence of supporting electrolyte at the applied potential higher than $1 \mathrm{~V} .{ }^{51}$ Hydrogen evolution occurs at high current densities and causes weak adhesion during electrodeposition processes. ${ }^{52}$ The detachment of the MOF films into the solution and 
deformation on the $\mathrm{Cu}-\mathrm{BTC}$-coated $\mathrm{Cu} \mathrm{HF}$ have been observed in $\mathrm{E}-2 \mathrm{~V}$ and $\mathrm{E}-5 \mathrm{~V}$ (Fig. 2.5). The presence of a supporting electrolyte increases the current as it is shown in Table 2.1, as well as the current densities in the system.

MOF formation on the inner surface: In the samples E-2V and E-5V with supporting electrolyte, some MOF crystals have been formed on the inner surface of the HFs (Fig. S2.3). These spots with MOF are not as homogenous as the outer surface due to the absence of electric field. As a result, the migration of charged species in the electric field is limited. The porous copper HF allows BTC to diffuse through the wall of the fiber as well as the access from the bottom of the fiber. The high potential difference near the open end of the fiber can cause dissolution of the $\mathrm{Cu}$ ions near this region and followed by the formation of MOF particles.
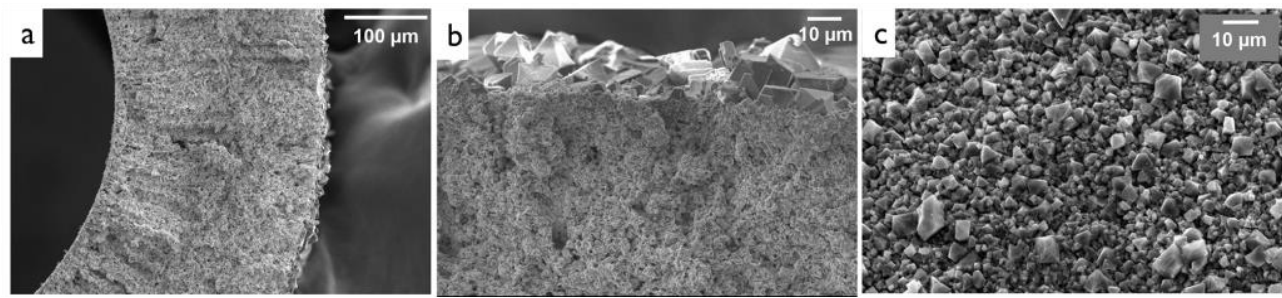

Figure 2.6 Formation of Cu-BTC MOF films (F-o.5) a) and b) SEM images of the crosssectional image of the $\mathrm{Cu}-\mathrm{BTC}$-coated $\mathrm{Cu}$ HFs. c) The outer surface of the HF. 
Table 2.1 Results of Cu-BTC-coated Cu HFs synthesis. Particle size analysis of the MOFs, determined by image analysis (by ImageJ software) of SEM image at different magnification (x100o-x750o). The thickness of MOF films - synthesized for 30 min for both set of experiments ( $\mathrm{E}$ and $\mathrm{F}$ ) - was calculated by taking more than 10 measurements per cross-sectional SEM image at different magnification (x500$\mathrm{x2000)}$. The data are presented as mean +- standard error (SE).

\begin{tabular}{ccccccc}
\hline Sample & Electrolyte & $\begin{array}{c}\text { Applied } \\
\text { Potential }\end{array}$ & Current & $\begin{array}{c}\text { Mean } \\
\text { Particle } \\
\text { Size }\end{array}$ & Spread & Thickness \\
& & $(\mathrm{V})$ & $(\mathbf{m A})$ & $(\mu \mathrm{m})$ & $(\mu \mathrm{m})$ & $(\mu \mathrm{m})$ \\
\hline E-0.5 & MTBS & 0.5 & 5.68 & $2.30 \pm 0.18$ & $1.50 \pm 0.27$ & $25.31 \pm 1.79$ \\
E-1 & MTBS & 1 & 9.50 & $2.06 \pm 0.11$ & $1.21 \pm 0.17$ & $19.20 \pm 0.68$ \\
E-2 & MTBS & 2 & 19.82 & $2.86 \pm 0.17$ & $2.13 \pm 0.28$ & $27.93 \pm 2.67$ \\
E-5 & MTBS & 5 & 45.58 & $0.92 \pm 0.04$ & $0.61 \pm 0.06$ & $15.33 \pm 1.19$ \\
F-0.5 & - & 0.5 & 0.50 & $0.90 \pm 0.02$ & $0.43 \pm 0.02$ & $2.93 \pm 0.39$ \\
F-1 & - & 1 & 0.76 & $0.98 \pm 0.03$ & $0.45 \pm 0.04$ & $4.19 \pm 0.26$ \\
F-2 & - & 2 & 0.96 & $1.32 \pm 0.09$ & $1.19 \pm 0.13$ & $8.88 \pm 1.10$ \\
F-5 & - & 5 & 2.21 & $2.10 \pm 0.03$ & $1.10 \pm 0.05$ & $15.76 \pm 1.19$ \\
\hline
\end{tabular}




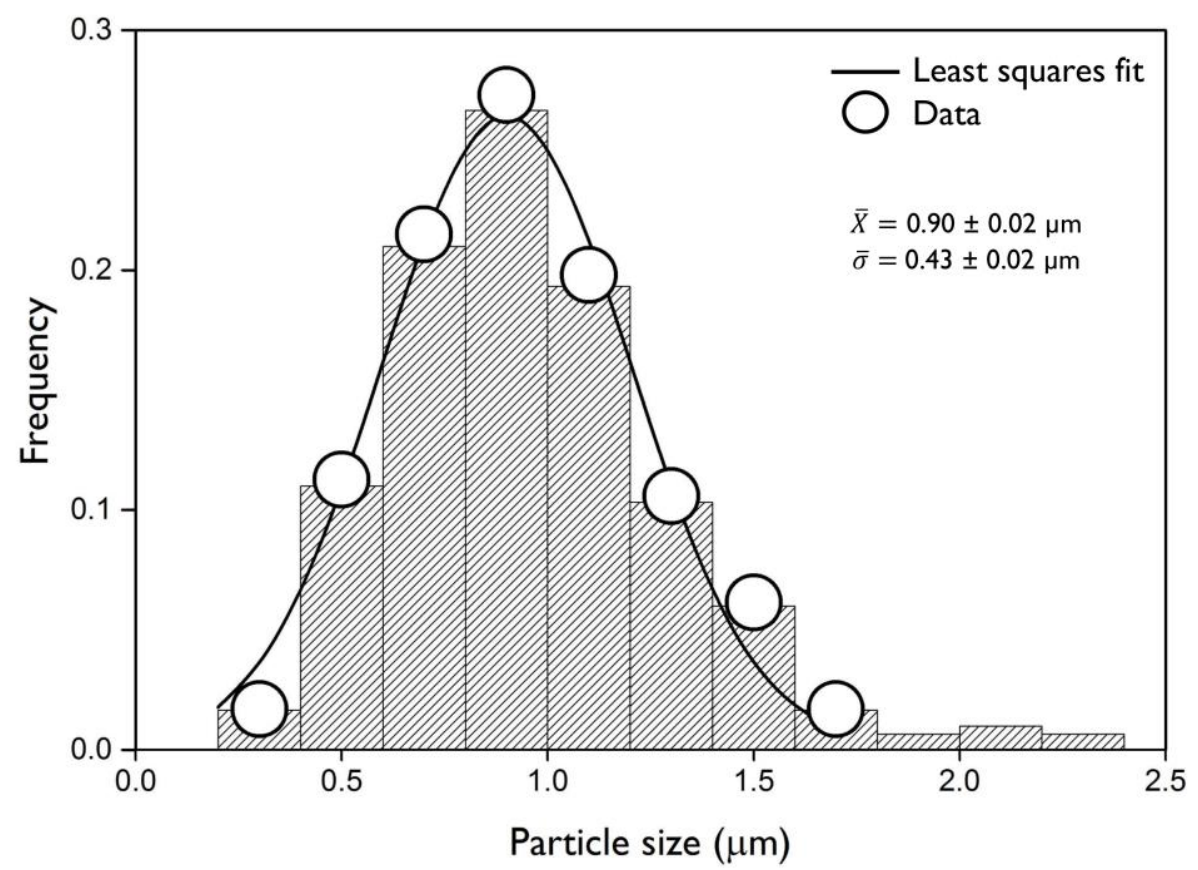

Figure 2.7 Gaussian distribution of particle size of sample F-0.5 with least squares fit, along wit larger aggregates. Mean particle size $(\overline{\boldsymbol{X}})$ and the spread $(\overline{\boldsymbol{\sigma}})$ values are shown in the graph.

\subsubsection{Electrolyte-free synthesis}

By omitting the supporting electrolyte (MTBS) from the synthesis solution more uniform films with smaller particles are obtained on top of the HF (Fig. 2.6). These smaller particles exhibit better attachment to the Cu HF surface (Fig. 2.6 (b)). As compared to the synthesis with supporting electrolyte, the same applied potentials now result in substantially lower current values due to the high resistance of the organic solution (Table 2.1). The low current indicates slower the reaction kinetics, evidently favouring more reproducible films. The lack of color change of the synthesis solution during and after the synthesis indicated that the MOF formation primarily occurs on the surface, without substantial detachment from the surface. When MTBS is excluded from the synthesis solution, the cracks and damage on $\mathrm{Cu}$-BTC-coated $\mathrm{Cu}$ HFs observed when using supporting electrolyte solution are not apparent (see Fig. 2.6). 

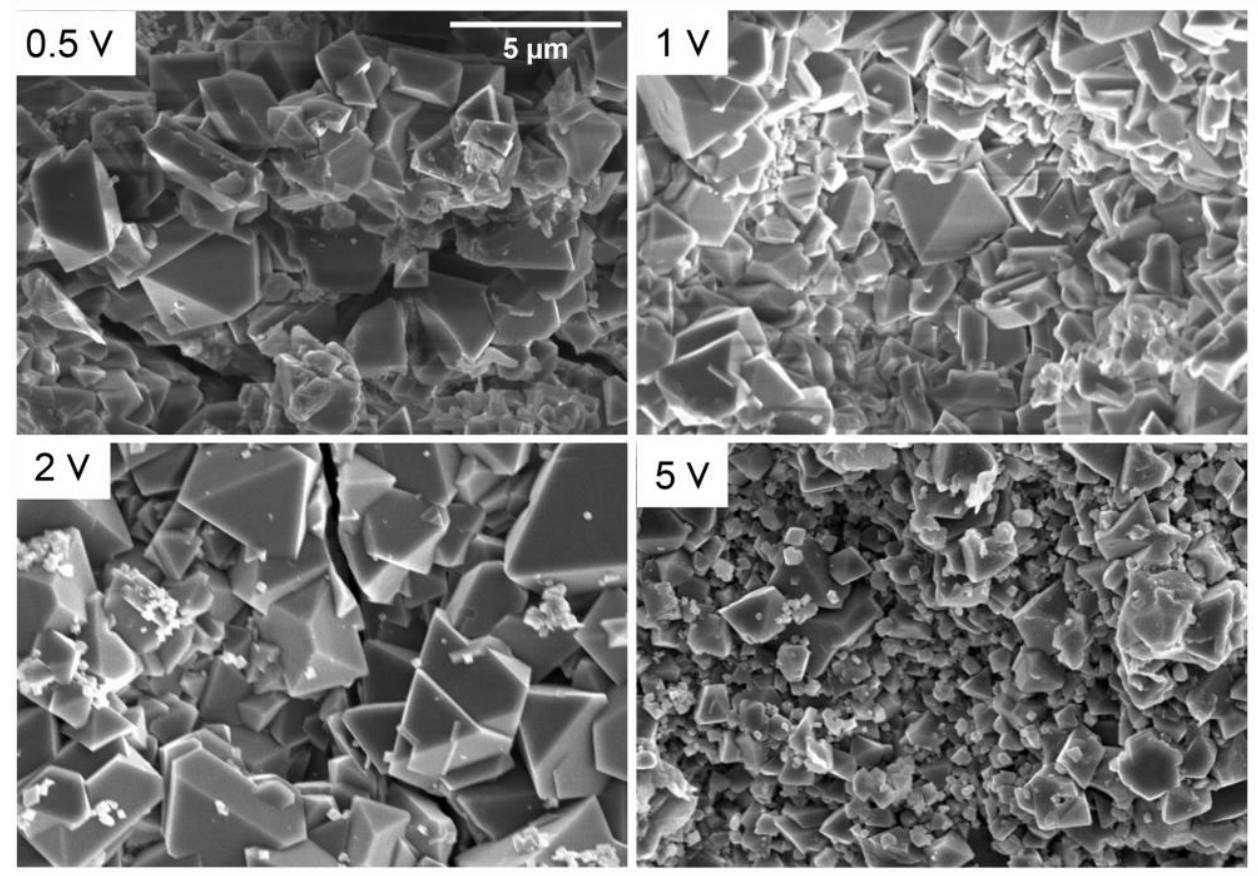

Figure 2.8 SEM images of the outer surface of the Cu-BTC-coated Cu HFs: E-o.5, E1, E-2, E-5.

The electrochemical crystallization occurs at the electrode/solution interface and the limiting factor is the ion transport from the liquid bulk to the electric double layer (EDL).53 Movement of the ligand species is based on the gradients in the electric potential (migration) and chemical potential (diffusion), and the motion of the bulk fluid. In the absence of stirring the motion of the bulk fluid can be considered minimal and any potential convective contributions be neglected. Therefore, assuming that the mixture is thermodynamically ideal, net transport of species $i$ can be described via the Nernst-Planck equation as: $5^{2}$

$$
\begin{aligned}
& \text { Flux }=\text { Diffusion }+ \text { Electromigration } \\
& J_{i}=-D_{i} \nabla c_{i}-\frac{z_{i} F}{R T} D_{i} c_{i} \nabla \Phi
\end{aligned}
$$

where $J_{i}$ is the flux of species $i$ in $\mathrm{mol} \mathrm{m}^{-2} \mathrm{~s}^{-1}, D_{i}$ is the diffusion coefficient of species $i$ in $\mathrm{m}^{2} \mathrm{~s}^{-1}, c_{i}$ is the concentration of species $i$ in $\mathrm{mol} \mathrm{m}^{-3}, \mathrm{z}_{i}$ is the charge number of the 
species $i$ (dimensionless), $F$ is Faraday's constant in $\mathrm{C} \mathrm{mol}^{-1}, R$ is the gas constant in J $\mathrm{mol}^{-1} \mathrm{~K}^{-1}, T$ is the temperature in $\mathrm{K}$, and $\Phi$ is the electric potential in $\mathrm{V}$.

In this study, electroformation of MOF films occurs at the interface between porous copper working electrode and the synthesis solution. By applying an electric potential, copper ions are released from the surface while BTC molecules diffuse or migrate to the EDL from bulk. The migration of BTC molecules in the bulk depends on the electric potential gradient in the system. In supporting electrolyte-free solution, there is a drastic Ohmic drop in the solution due to use of organic solution, ethanol. This Ohmic drop means there is an electric-field in the bulk (potential gradient) and transport of the BTC molecules would be facilitated with both migration and diffusion. Therefore, BTC transport to the EDL would be enhanced in electrolyte-free synthesis. In addition, a low current implies that copper dissociation on the pure copper HF is slow. The combined faster supply of BTC at the EDL surface and the slow and controlled release of the copper at this location results in the formation of the thin and homogenous MOF films comprising small crystals. A similar phenomenon was observed for hydrothermal synthesis of Cu-BTC on an alumina support previously; a low concentration of the precursors was suggested to result in small crystals and controlled layer formation. ${ }^{54}$

Addition of a supporting electrolyte minimizes the electric potential drop in the bulk meaning there is limited contribution from electromigration. With the addition of the electrolyte, nearly all the change in electric potential occurs very close to the electrode surface. The transport of BTC molecules will then be primarily due to diffusion associated with a concentration gradient. Based on the free water diffusion coefficients, $\mathrm{Cu}^{2+}$ ions $\left(1.43 \times 10^{-9} \mathrm{~m}^{2} \mathrm{~s}^{-1}\right)$ diffuse faster than the BTC molecules $\left(7.6 \times 10^{-}\right.$ $\left.{ }^{10} \mathrm{~m}^{2} \mathrm{~s}^{-1}\right) .35,55$ The limited supply of the BTC at the electrode will lead to a less controlled film formation. This will become more pronounced when more copper is generated on the surface, i.e., at higher values of the current. When there is a large excess of copper ions, growth of $\mathrm{Cu}$-BTC in the bulk fluid will become more apparent. 
Combined with the diffusion limitations of BTC, this can also result as non-uniform concentration distribution around the growing crystals. ${ }^{53}$

Another mechanism that affects the film properties is the adsorption of BTC on the copper HF surface. The presence of a molecular adlayer of BTC molecules, on copper surfaces, was previously reported by Schäfer, 2017. ${ }^{31}$ This layer would initiate the first layer of Cu-BTC MOF films. By applying higher potentials, the adlayer thickness would also then increase which explains the thicker MOF films obtained at higher potentials. The presence of the supporting electrolyte may also influence the adsorption of BTC by limiting the transport of BTC to the electrode surface that results as nonhomogenous and non-uniform MOF films.
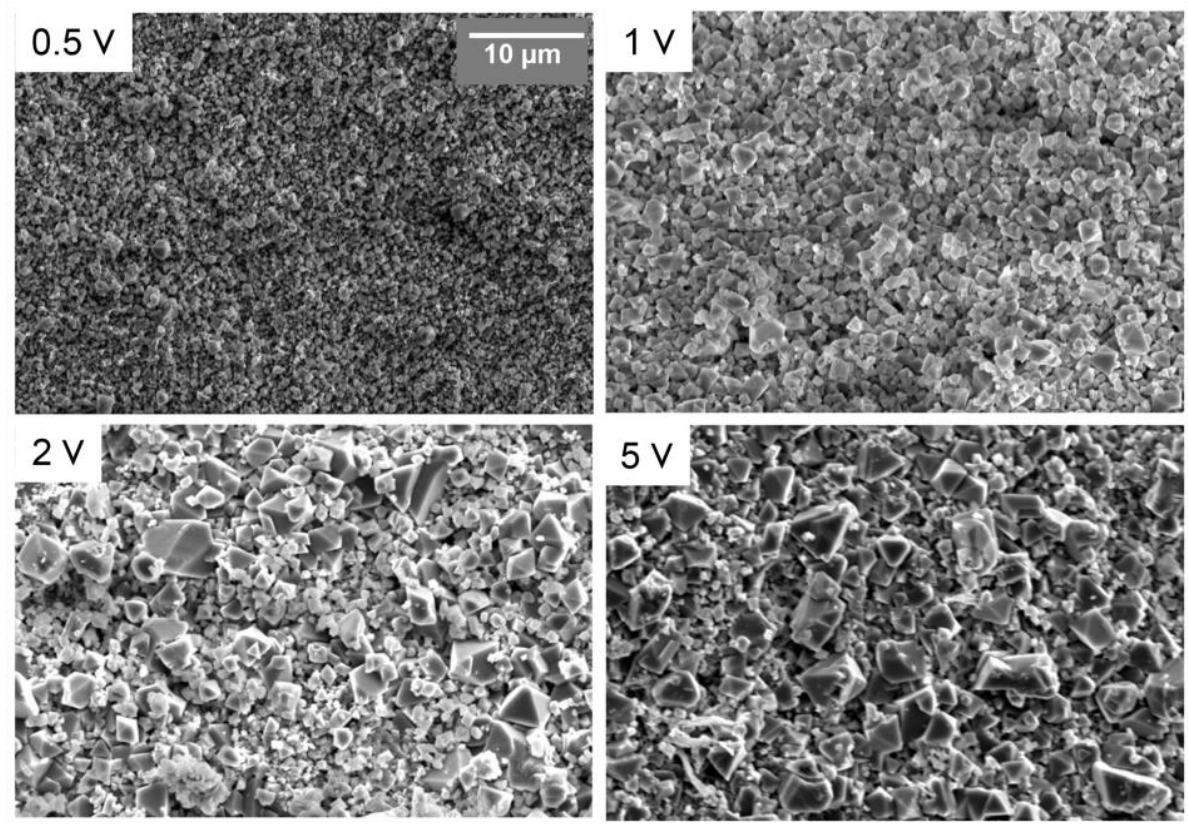

Figure 2.9 SEM images of the outer surface of the Cu-BTC-coated $\mathrm{Cu}$ HFs: F-o.5, F1, F-2, F-5.

\subsubsection{Particle size}

The particle size histogram, data and corresponding least squares fit are depicted in Fig. 2.7 for a representative sample for without electrolyte synthesis (and in Fig. S2.4 
for with supporting electrolyte synthesis). The results of the particle size analysis, including mean particle size and the spread of the MOF crystals and the thickness of the MOF films, are reported in Table 2.1. The results show that the mean particle size and the spread decrease after removing the supporting electrolyte from the synthesis solution. A slight increase of the particle size with increasing the applied potential can be observed for experiment without the supporting-electrolyte. When a potential higher than $1 \mathrm{~V}(\mathrm{E}-2, \mathrm{E}-5)$ is applied to the copper HF, with supporting electrolyte, either the MOF films are detached from the surface of the HF or MOF powders are formed in the solution. It can be also seen from the SEM images in Fig. 2.5 (c) and (d) that the HF is damaged at $5 \mathrm{~V}$. SEM images of this sample show only the films left on the surface after the partial detachment.

Based on classical nucleation theory it is expected that a higher applied potential will results in smaller crystals. ${ }^{22}$ Ameloot (2009) et al. observed a decrease in the particle size by increasing the applied potential from $2.5 \mathrm{~V}$ to $25 \mathrm{~V}$ in an supporting electrolyte system. ${ }^{17}$ By increasing the voltage, a higher dissolution rate and higher concentration of copper ions on the surface are obtained, which leads to higher nucleation rate and smaller crystals. ${ }^{17}$ Van Assche (2012) et al. also observed the same behavior for film formation in a smaller applied potential range $(0.2-4 \mathrm{~V})$ by explaining it with the relationship between high current densities and high concentration of metal ions near the surface..$^{22}$ However, Joaristi (2012) et al. observed that the large current densities did not result in a large number of nuclei and small crystals. ${ }^{19}$ In this study, we have also observed that lower applied potential and lower current densities (without supporting electrolyte) lead to smaller crystals. It is important to note that crystal growth is also a function of supersaturation. ${ }^{5-58}$ In electrochemical crystallization processes, the extent of supersaturation is directly related to the potential difference between the equilibrium potential and the applied potential, i.e., the overpotential.53 Overpotential impacts copper oxidation on the copper HF surface. The higher the overpotential, the higher the amount of copper ions released from the surface. In the electrolyte-free synthesis, overpotential can be considered to be lower vs. the case with supporting electrolyte, because more of the potential drop occurs within the bulk 
rather than near to surface. Lower supersaturation (or lower overpotential) means slower nucleation and potentially relatively faster crystal growth which can result in larger crystals. ${ }^{57}$ However, for the MOF film formation, not only copper oxidation but also the BTC transport to the EDL plays a crucial role. In the electrolyte-free synthesis, the enhanced transport of BTC via electromigration and diffusion supplies more BTC to the surface of the nucleus and this evidently contributes to the uniformity of the particle size. As a result, supplying less copper but in a slow and controlled manner along with the enhanced transport of BTC ensures MOF film formation on the surface with uniform layer and smaller crystals. In addition, electrochemical adsorption is also another important part of the crystallization..$^{31,53,59}$ Nucleation starts with the adsorbed molecules on the surface. More uniform nucleation sites might be created in the electrolyte-free synthesis. With the use of MTBS, there is also an additional chance that the anionic part can be adsorbed on the surface of the copper HF along with BTC molecules. In the supporting electrolyte synthesis, the adlayer of BTC initiates the nucleation process, while MTBS adsorbed sites cause non-uniformity and large spread in the particle size of the $\mathrm{Cu}$-BTC crystals. In the electrolyte-free synthesis, nucleation points can be created in a controlled manner and favors formation of smaller particles in the desired location.

\subsubsection{Thickness}

As depicted in Table 2.1, the thickness of the MOF films increases when a supporting electrolyte is used in the synthesis solution. In the presence of supporting electrolyte, potential drop occurs primarily near to the surface due to smaller resistance in the bulk which indicates higher overpotential than electrolyte-free synthesis. When a potential difference is applied, dissociation of the copper starts immediately. This was observed during the synthesis; within seconds of applied potential, the HF starts to change color to characteristic blue of $\mathrm{Cu}$-BTC. The activation energy for the crystallization is overcome much faster than supporting-electrolyte-free synthesis. ${ }^{19}$ These fast kinetics allow the MOF crystals to grow as a thick film because more copper is generated with the help of the high overpotential. Sample E-5V has much thinner 
MOF films due to the removal of the particles to the solution. This makes it difficult to compare the data with the rest of the samples. The sample E-2V shows agglomerated branch-like MOFs instead of a MOF film. Therefore, the effect of the applied potential on the samples with the supporting electrolyte can not be fully understood, mainly due to the detachment of the MOF film into the bulk. For applied potentials smaller than $2 \mathrm{~V}$, MOF films were obtained. In the electrolyte-free synthesis, the thickness of the obtained MOF films has been decreased. Homogenous and thin MOF films were obtained, as it can be seen in Table 2.1. By increasing the applied potential, more copper is oxidized and the thickness of the MOF films increased.

MOF particles that separated from the surface turn the synthesis solution blue, which is a characteristic color of $\mathrm{Cu}-\mathrm{BTC} \mathrm{MOF}$. The increase in the thickness results in a detachment of the particles from the surface, as can be seen in Fig. 2.6. After drying of the samples, it has been observed that some MOF particles were not well attached to the surface and were also removed. As the diffusion limitations control the transport of copper and BTC in the case with supporting electrolyte, the relative diffusivities of copper and BTC play more of a role. Copper moves much faster compare to BTC based on their ionic size (diffusion coefficients), which hinders formation of MOF near to the surface.

Table 2.1 also shows an increase of the thickness by increasing the applied potential in the electrolyte-free synthesis along with the increase in the overpotential. More copper ions are generated at the surface and all of these copper ions react with the organic linker, BTC, with the increase of the overpotential which results in thicker MOF films. Neither colour change nor detachment was observed for this set of experiments.

\subsection{Effect of applied potential}

The effect of the applied potential in the range of $0.5^{-5} \mathrm{~V}$ vs. SHE is discussed for solutions with and without supporting electrolyte. As is depicted in Fig. 2.8 and 2.9, and is reported in Table 2.1, a comparison between electrolyte-free and with- 
electrolyte samples shows that the standard error $(S E)$ and spread values decreased drastically in supporting electrolyte-free solutions, indicating more uniform MOF particles with relatively narrower distributions are formed. The mean particle size increases with increasing potential. Based on the nucleation theory, higher applied potentials should result in the smaller crystals. ${ }^{17}$ By increasing the voltage, higher dissolution rate and higher concentration of copper ions on the surface are obtained, which lead to a higher nucleation rate and smaller crystals. ${ }^{60}$ However, the porous nature of the copper $\mathrm{HF}$ electrode also allows more $\mathrm{Cu}$ ions to release to the surface and react with the organic linker ions even at lower voltages. The study of Joaristi (2012) et al, also has showed theoretically that only $0.124 \mathrm{~V}$ is necessary to overcome the nucleation activation energy of $71.6 \mathrm{~kJ} \mathrm{~mol}^{-1}$ for Cu-BTC MOF. ${ }^{19}$ All the applied potentials in this study are above this nucleation activation energy barrier. As also described above, overpotential as the replacement of the supersaturation is the key factor to explain the electrocrystallization of MOF films. By increasing the applied potential, overpotential is also increased. The critical $\mathrm{Cu}$ ion concentration for the MOF formation is reached rapidly and this allows crystals to grow for a longer time.

The current values were decreased by a factor of more than 10 times by omitting supporting electrolyte from the synthesis. The current is directly proportional to the oxidation at the anode so that the current and time give a qualitative estimate of the crystal growth and the film thickness. In the electrolyte-free synthesis, the thickness increases in direct proportion to the applied potential. In the case of using supporting electrolyte, by increasing the thicknesses of synthesized films, the attachment of the films to the surface also becomes weaker and results in easier removal from the surface to the bulk that ultimately results in thinner and discontinuous films in the analysis. The current is lower due to the resistance of the organic linker solution in waterethanol mixture. Most of the applied potential is used to overcome the Ohmic drop of the solution. ${ }^{19}$ Higher current usually refers to higher reaction efficiency and yield. ${ }^{18,19}$ It is crucial to remind of the distinct difference between MOF powder synthesis and film formation. ${ }^{17,18,22,24,31,35,61-63}$ Our results show that a decrease in the current is not detrimental but can result in formation of more uniform films. $\mathrm{Cu}$-BTC-coated $\mathrm{Cu}$ 
HF prepared without supporting electrolyte are promising candidates for the future applications such as gas separation or catalysis.

We found that applying only 0.5 V vs SHE applied potential in both electrolyte-free and electrolyte containing systems was sufficient to obtain thin MOF films. In the early studies of electroforming MOF films, the applied potential has been varied between 2.5-25 V. ${ }^{17}$ However, this was done using a two-electrode system instead of three-electrode cell. In a two-electrode cell, it is not possible to control the exact applied potential to the surface of the working electrode which can limit the reproducibility of the experiments. A third electrode is needed to standardize the potential with respect to a reference electrode so that the potential on the working electrode can be controlled. ${ }^{48,52}$ Secondly, to synthesize MOF powders, higher applied potentials are necessary as the goal is to oxidize the anode and release metal ions into the bulk where MOF particles are formed. To electrochemically form MOF films, the anode must be partially oxidized and not damaged, so that the dissociated metal ions should not migrate to the bulk and stay near to the surface in order to form MOF films. By increasing the potential, the migration of metal ions away from the surface is also promoted. As mentioned above, the efficiency of the MOF film fabrication is not directly related with the high concentration of metal ions, high potential-current, etc.. A precise control of the kinetics of the reaction and crystallization is more important. To support our results, it is necessary to repeat that only $0.124 \mathrm{~V}$ is theoretically necessary to overcome the nucleation activation energy. Cyclic voltammetry studies have also show that the copper oxidized at $0.18 \mathrm{~V}$ in the presence of a trimesic acid, which is in reasonable agreement with theoretical calculations. ${ }^{31}$

\subsection{Conclusions}

In this chapter, we have prepared $\mathrm{Cu}-\mathrm{BTC}$ MOF coated HFs by a partial anodic dissolution electrochemical route. We have used porous copper HFs as anode, metal source and support simultaneously for the fabrication of the MOF films. The successful formation of $\mathrm{Cu}$-BTC MOF films onto porous copper HFs is confirmed by SEM, EDS, XRD and TGA. The effects of supporting electrolyte and applied potential 
on the electro-synthesis of MOF films have been quantified. A supporting electrolyte is typically used to increase the conductivity of the synthesis solution and enhance the electron transfer during electrochemical synthesis of MOF powders. However, we found that usage of supporting electrolyte for MOF film formation has numerous disadvantages. It results in cracks on the MOF films, detachment of MOF films, the formation MOF particles in the bulk, and gas formation at the counter electrode. By increasing the conductivity of the synthesis solution, controlling the electroformation of MOF films on the fiber becomes more challenging.

Alternatively, using an electrolyte-free solution and lower potential differences we have obtained thinner and more reproducible $\mathrm{Cu}-\mathrm{BTC}$ films. The potential drop primarily occurs near the electrode surface with supporting electrolyte, while without supporting electrolyte (electrolyte-free) this potential drop is mainly in the bulk. The lower potential drop at the electrode surface in the electrolyte-free case lowers the rate of copper ion generation while also enhancing the transport of BTC, the slower diffusing molecule, to the surface for a higher degree of control of the MOF film formation. In order to obtain thin, dense and uniform MOF films, control of kinetics and synthesis location is crucial compared to the bulk synthesis. The applied potential changes the overpotential in the system, which is related to the release of copper ions available for the synthesis. Therefore, an increase in the particle size and film thickness have been observed for higher applied potentials. Utilization of electrochemical synthesis for MOF formation on a HF support is a straightforward and fast synthesis compared to the conventional methods e.g. solvothermal synthesis. ${ }^{42}$ The synthesized HFs in our work are promising for numerous applications, in particular gas separation ${ }^{64,65}$ or catalysis ${ }^{66,67}$ due to their high surface areas, porosity and scalability for wide-scale usage. This work represents an important first step towards utilizing these HFs, after further work on improving the adhesion and mechanical properties. 


\section{Acknowledgments}

The authors acknowledge the contribution of Fleur Sebek (University of Twente) to this work and the technical support of the Photo Catalytic Synthesis (PCS) group from University of Twente. The authors declare no conflict of interest.

\section{References}

1 H. Furukawa, N. Ko, Y. B. Go, N. Aratani, S. B. Choi, E. Choi, A. O. Yazaydin, R. Q. Snurr, M. O’Keeffe, J. Kim and O. M. Yaghi, Science, 2010, 329, 424-428.

2

H. Furukawa, K. E. Cordova, M. O’Keeffe and O. M. Yaghi, Science, 2013, 341, 1230444-1230444.

3

4

5

6

H. Li, M. Eddaoudi, M. O’Keeffe and O. M. Yaghi, Nature, 1999, 402, 276-279.

S. K. Elsaidi, M. H. Mohamed, D. Banerjee and P. K. Thallapally, Coord. Chem. Rev., 2018, 358, 125-152.

D. Zhao, D. J. Timmons, D. Yuan and H.-C. Zhou, Acc. Chem. Res., 2011, 44, 123-133.

A. Schneemann, S. Henke, I. Schwedler and R. A. Fischer, ChemPhysChem, 2014, 15, 823-839.

H. Li, K. Wang, Y. Sun, C. T. Lollar, J. Li and H.-C. Zhou, Mater. Today, 2018, 21, 108-121.

L. E. Kreno, K. Leong, O. K. Farha, M. Allendorf, R. P. Van Duyne and J. T. Hupp, Chem. Rev., 2012, 112, 1105-1125.

M. D. Allendorf, A. Schwartzberg, V. Stavila and A. A. Talin, Chem. - A Eur. J., 2011, 17, 11372-11388.

T. Granato, F. Testa and R. Olivo, Microporous Mesoporous Mater., 2012, 153, $236-246$.

R. Jin, Z. Bian, J. Li, M. Ding and L. Gao, Dalt. Trans., 2013, 42, 3936.

Z. Y. Yeo, S.-P. Chai, P. W. Zhu and A. R. Mohamed, RSC Adv., 2014, 4, 5432254334 .

J. Cookney, W. Ogieglo, P. Hrabanek, I. Vankelecom, V. Fila and N. E. Benes, Chem. Commun., 2014, 50, 11698-11700.

4 R. Makiura, S. Motoyama, Y. Umemura, H. Yamanaka, O. Sakata and H. Kitagawa, Nat. Mater., 2010, 9, 565-571.

W.-J. Li, M. Tu, R. Cao and R. A. Fischer, J. Mater. Chem. A, 2016, 4, 1235612369.

U. Mueller, M. Schubert, F. Teich, H. Puetter, K. Schierle-Arndt and J. Pastré, J. Mater. Chem., 2006, 16, 626-636. 
17 R. Ameloot, L. Stappers, J. Fransaer, L. Alaerts, B. F. Sels and D. E. De Vos, Chem. Mater., 2009, 21, 2580-2582.

18 T. R. C. Van Assche, G. Desmet, R. Ameloot, D. E. De Vos, H. Terryn and J. F. M. Denayer, Microporous Mesoporous Mater., 2012, 158, 209-213.

19 A. Martinez Joaristi, J. Juan-Alcañiz, P. Serra-Crespo, F. Kapteijn and J. Gascon, Cryst. Growth Des., 2012, 12, 3489-3498.

M. Rubio-Martinez, C. Avci-Camur, A. W. Thornton, I. Imaz, D. Maspoch and M. R. Hill, Chem. Soc. Rev., 2017, 46, 3453-3480.

I. Buchan, M. R. Ryder and J.-C. Tan, Cryst. Growth Des., 2015, 15, 1991-1999.

T. R. C. Van Assche, N. Campagnol, T. Muselle, H. Terryn, J. Fransaer and J. F. M. Denayer, Microporous Mesoporous Mater., 2016, 224, 302-310.

23 S. D. Worrall, H. Mann, A. Rogers, M. A. Bissett, M. P. Attfield and R. A. W. Dryfe, Electrochim. Acta, 2015, 197, 228-240.

24 P. Schäfer, M. A. van der Veen and K. F. Domke, Chem. Commun., 2016, 52, 4722-4725.

25 N. Campagnol, T. Van Assche, L. Stappers, J. F. M. Denayer, K. Binnemans, D. E. De Vos and J. Fransaer, ECS Trans., 2014, 61, 25-40.

M. Li, M. Dincă and M. Dinc, J. Am. Chem. Soc., 2011, 133, 12926-12929.

M. Li and M. Dincă, Chem. Sci., 2014, 5, 107-111.

28 R. Ameloot, L. Pandey, M. Van Der Auweraer, L. Alaerts, B. F. Sels and D. E. De Vos, Chem. Commun., 2010, 46, 3735.

H. Zhu, H. Liu, I. Zhitomirsky and S. Zhu, Mater. Lett., 2015, 142, 19-22.

I. Hod, W. Bury, D. M. Karlin, P. Deria, C.-W. Kung, M. J. Katz, M. So, B. Klahr, D. Jin, Y.-W. Chung, T. W. Odom, O. K. Farha and J. T. Hupp, Adv. Mater., 2014, 26, 6295-6300.

31 P. Schäfer, A. Lalitha, P. Sebastian, S. K. Meena, J. Feliu, M. Sulpizi, M. A. van der Veen and K. F. Domke, J. Electroanal. Chem., 2017, 793, 226-234.

32 N. Campagnol, T. Van Assche, T. Boudewijns, J. Denayer, K. Binnemans, D. De Vos and J. Fransaer, J. Mater. Chem. A, 2013, 1, 5827.

33 M. Hartmann, S. Kunz, D. Himsl, O. Tangermann, S. Ernst and A. Wagener, Langmuir, 2008, 24, 8634-8642.

34 U. Mueller, H. Puetter, M. Hesse, M. Schubert, H. Wessel, J. Huff and M. Guzmann, United States Patent, US 7,968,739 B2, 2011.

35 N. Campagnol, T. R. C. Van Assche, M. Li, L. Stappers, M. Dincă, J. F. M. Denayer, K. Binnemans, D. E. De Vos and J. Fransaer, J. Mater. Chem. A, 2016, 4, 3914-3925.

36 S. Yadnum, J. Roche, E. Lebraud, P. Négrier, P. Garrigue, D. Bradshaw, C. Warakulwit, J. Limtrakul and A. Kuhn, Angew. Chemie Int. Ed., 2014, 53, 4001- 
4005 .

37 Y. Zhang, I. H. Musselman, J. P. Ferraris and K. J. Balkus, J. Memb. Sci., 20o8, 313, 170-181.

38 J. Dechnik, C. J. Sumby and C. Janiak, Cryst. Growth Des., 2017, 17, 4467-4488.

39 M. Etxeberria-Benavides, O. David, T. Johnson, M. M. Łozińska, A. Orsi, P. A. Wright, S. Mastel, R. Hillenbrand, F. Kapteijn and J. Gascon, J. Memb. Sci., 2018, 550, 198-207.

40 S. Brown, Andrew J; Brunelli, Nicholas A.; Eum, Kiwon; Rashidi, Fereshteh; Johnson, J. R.; Koros, William J.; Jones, Christopher W.; Nair, Science, 2014, 345, 72-75.

41 A. M. Marti, W. Wickramanayake, G. Dahe, A. Sekizkardes, T. L. Bank, D. P. Hopkinson and S. R. Venna, ACS Appl. Mater. Interfaces, 2017, 9, 5678-5682.

42 N. Abdullah, M. A. Rahman, M. H. Dzarfan Othman, J. Jaafar and A. A. Aziz, J. Memb. Sci., 2018, 563, 162-174.

43 R. Kas, K. K. Hummadi, R. Kortlever, P. de Wit, A. Milbrat, M. W. J. LuitenOlieman, N. E. Benes, M. T. M. Koper and G. Mul, Nat. Commun., 2016, 7, 10748.

44 T. J. Smith and K. J. Stevenson, in Handbook of Electrochemistry, ed. C. G. Zoski, Elsevier, 2007, pp. 73-110.

45 C. A. Schneider, W. S. Rasband and K. W. Eliceiri, Nat. Methods, 2012, 9, 671675 .

46 A. A. Yakovenko, J. H. Reibenspies, N. Bhuvanesh and H. C. Zhou, J. Appl. Crystallogr., 2013, 46, 346-353.

47 W. W. Lestari, I. D. Winarni and F. Rahmawati, Electrosynthesis of MetalOrganic Frameworks (MOFs) Based on Nickel(II) and Benzene 1,3,5-Tri Carboxylic Acid (H3BTC): An Optimization Reaction Condition, IOP Conference Series: Materials Science and Engineering, Purwokerto, 2017.

48 M. Atobe, in Fundamentals and Applications of Organic Electrochemistry, ed. M. Fuchigami, Toshio; Inagi, Shinsuke; Atobe, John Wiley \& Sons, Ltd, Weinheim, 1st ed., 2014, pp. 1-10.

49 H. Al-Kutubi, J. Gascon, E. J. R. Sudhölter and L. Rassaei, ChemElectroChem, 2015, 2, 462-474.

50 R. Senthil Kumar, S. Senthil Kumar and M. Anbu Kulandainathan, Microporous Mesoporous Mater., 2013, 168, 57-64.

51 P. Atkins and J. de Paula, Physical Chemistry, Oxford University Press, Oxford, 1oth ed., 2014.

52 A. J. Bard and L. R. Faulkner, Electrochemical methods, fundamentals and applications, Wiley, New York, 2nd ed., 2001. 
53 A. Milchev, Electrocrystallization Fundamentals of Nucleation And Growth, Kluwer Academic Publishers, Dordrecht, 2002.

54 J. Gascon, S. Aguado and F. Kapteijn, Microporous Mesoporous Mater., 2008, 113, 132-138.

55 R. L. Hershey and W. Fereday, Laboratory Experiments to Evaluate Matrix Diffusion of Dissolved Organic Carbon Carbon-14 in Southern Nevada Fractured-rock Aquifers, Las Vegas, 2016.

56 S. Dodds, J. A. Wood and P. A. Charpentier, Ind. Eng. Chem. Res., 2007, 46, 8009-8017.

57 H. Grön, A. Borissova and K. J. K. Roberts, Ind. Eng. Chem. Res., 2003, 42, 198206.

58 T. Vetter, M. Iggland, D. R. Ochsenbein, F. S. Hänseler and M. Mazzotti, Cryst. Growth Des., 2013, 13, 4890-4905.

59 J. Mostany and B. Scharifker, in Encyclopedia of Electrochemistry, ed. A. J. Bard, Wiley-VCH Verlag GmbH \& Co. KGaA, Weinheim, Germany, 2007, pp. 512540 .

$60 \quad$ W.-J. Li, J. Lü, S.-Y. Gao, Q.-H. Li and R. Cao, J. Mater. Chem. A, 2014, 2, 1947319478.

61 L.-L. Jiang, X. Zeng, M. Li, M.-Q. Wang, T.-Y. Su, X.-C. Tian and J. Tang, RSC Adv., 2017, 7, 9316-9320.

62 S. Sachdeva, M. R. Venkatesh, B. El Mansouri, J. Wei, A. Bossche, F. Kapteijn, G. Q. Zhang, J. Gascon, L. C. P. M. de Smet and E. J. R. Sudhölter, Small, 2017, 13, 1604150.

63 L. Ji, J. Wang, K. Wu and N. Yang, Adv. Funct. Mater., 2018, 28, 1706961.

64 Y. Mao, J. Li, W. Cao, Y. Ying, L. Sun and X. Peng, ACS Appl. Mater. Interfaces, 2014, 6, 4473-4479.

65 Y. Mao, L. Shi, H. Huang, W. Cao, J. Li, L. Sun, X. Jin and X. Peng, Chem. Commun., 2013, 49, 5666-5668.

66 A. Sachse, R. Ameloot, B. Coq, F. Fajula, B. Coasne, D. De Vos and A. Galarneau, Chem. Commun., 2012, 48, 4749.

67 J. Lee, O. K. Farha, J. Roberts, K. A. Scheidt, S. T. Nguyen and J. T. Hupp, Chem. Soc. Rev., 2009, 38, 1450. 


\section{Supporting Information}

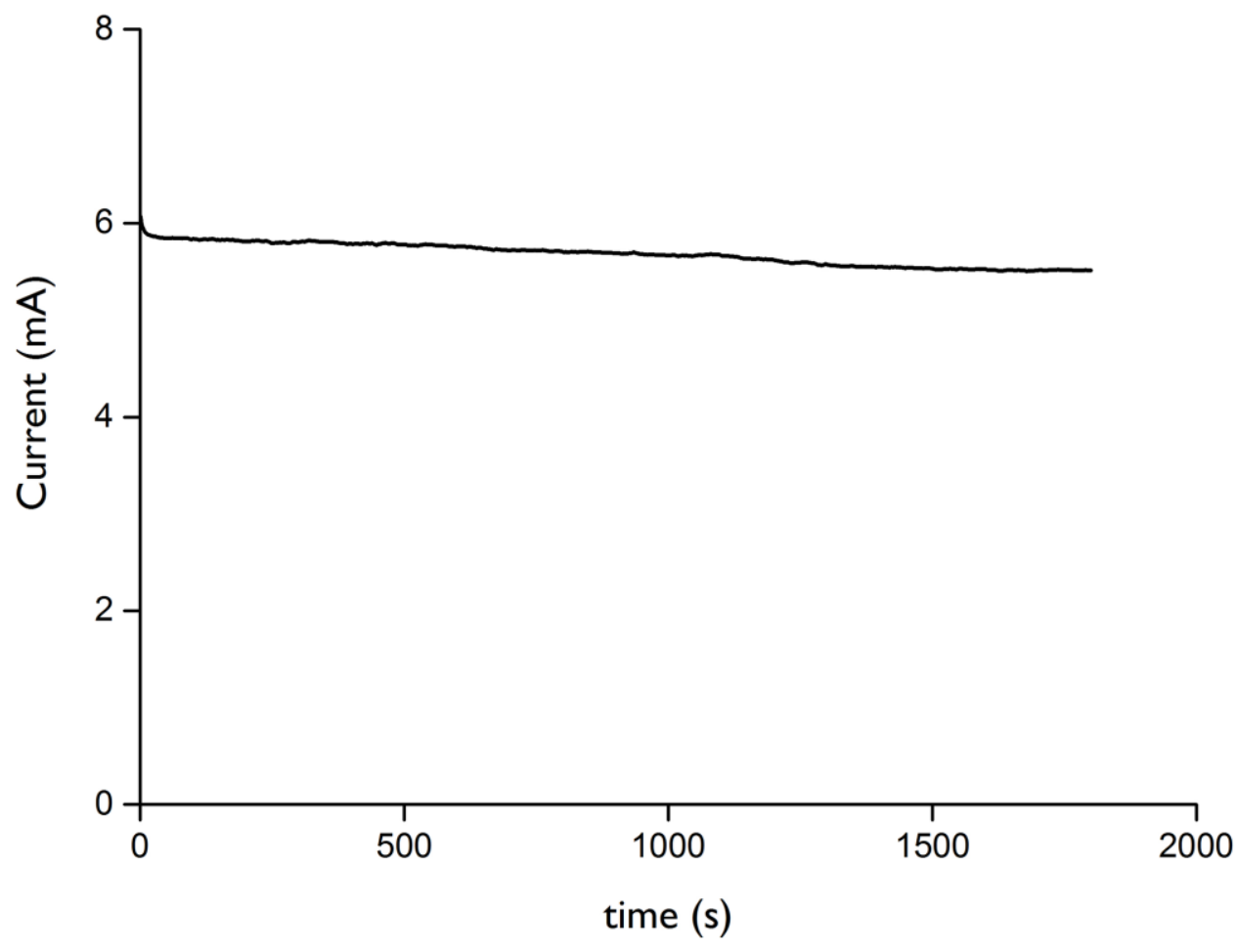

Figure S2.1 Current-time graph during the synthesis of sample E-0.5V 

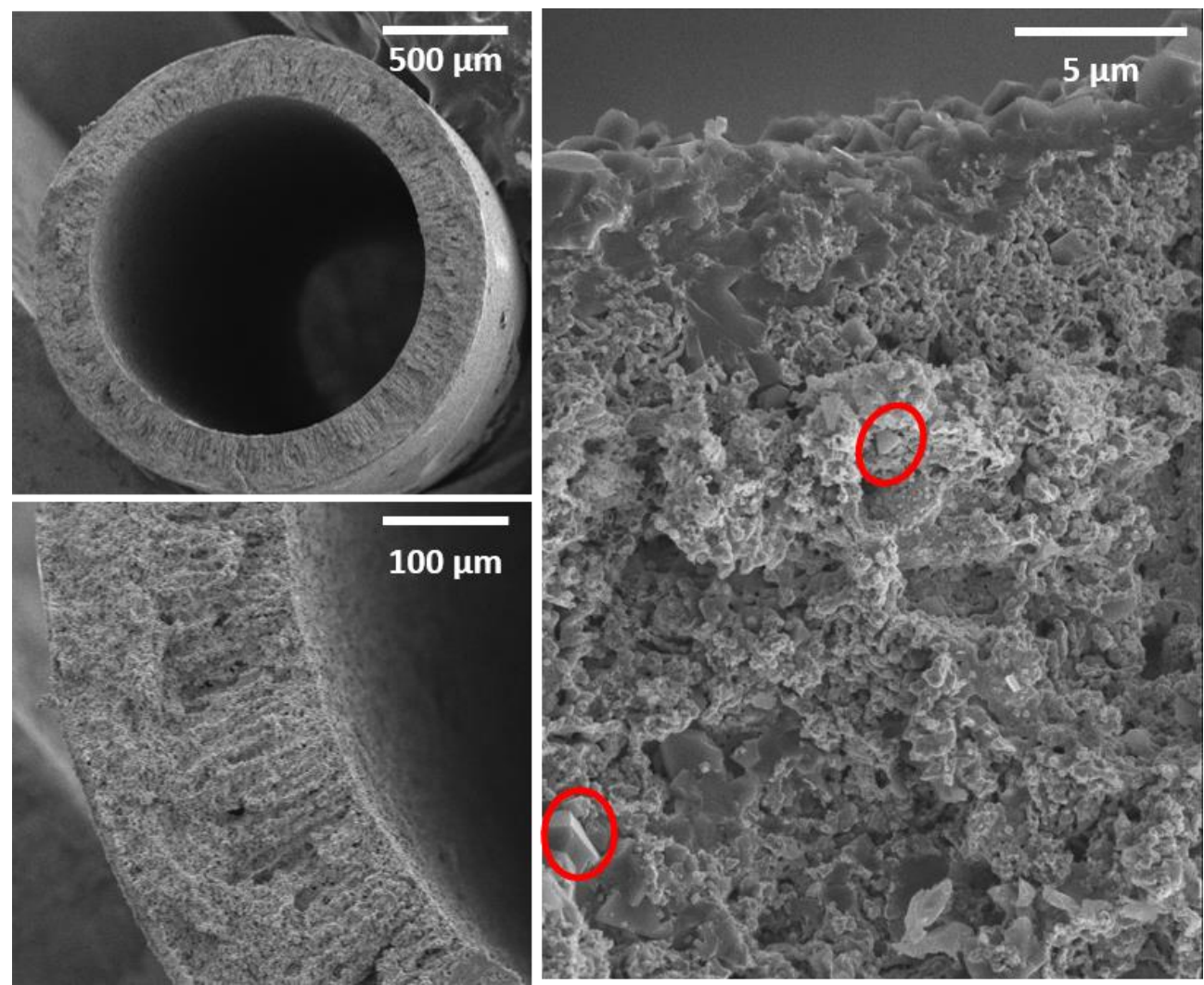

Figure S2.2 Cu-BTC MOF crystal formation in the interior of the hollow fiber. SEM images of the cross-section of the $\mathrm{Cu}$-BTC coated $\mathrm{Cu}$ HFs. Red circles indicate octahedral Cu-BTC MOF crystals. 

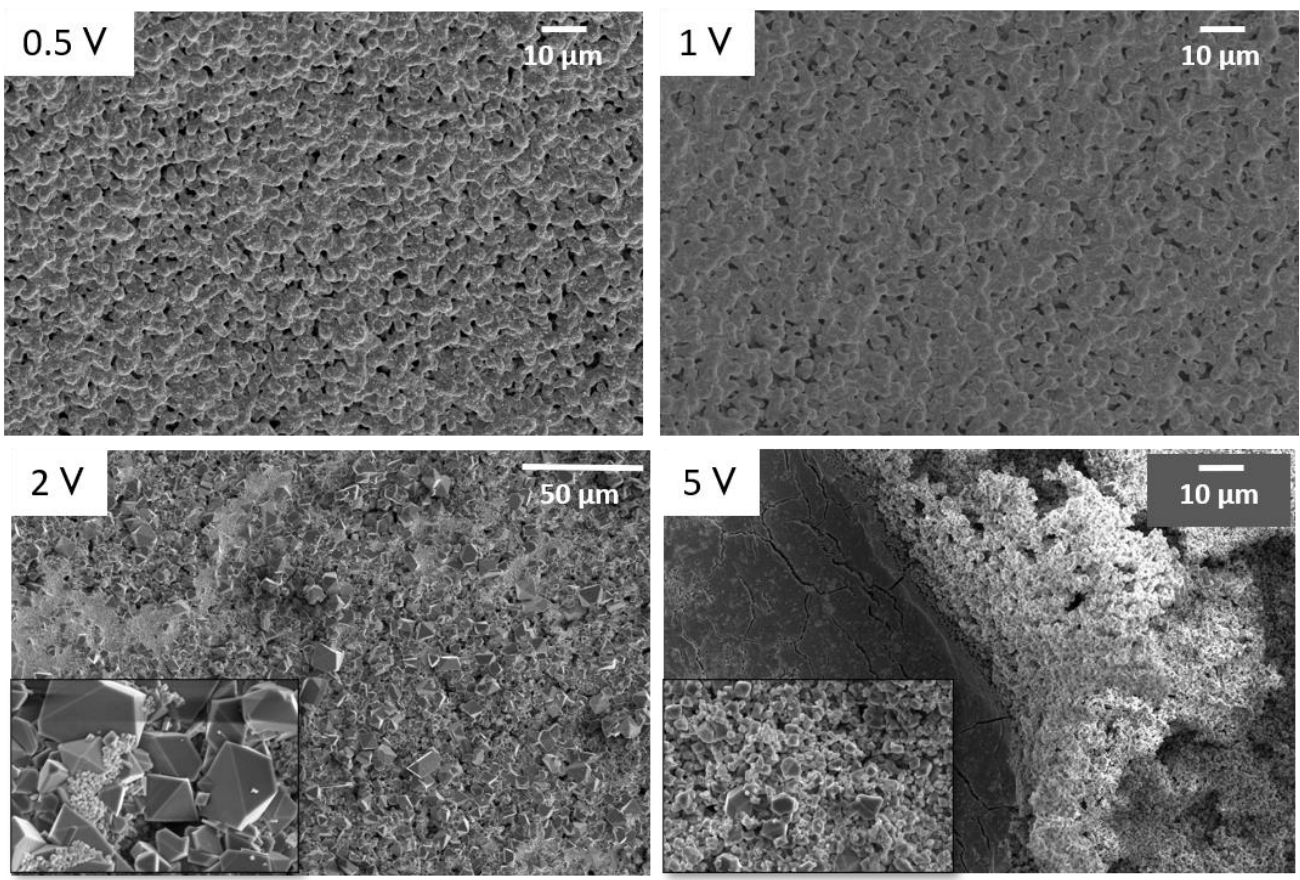

Figure S2.3 SEM images of the inner surface of Cu-BTC-coated Cu HFs: E-o.5, E-1, E2, E-5. 


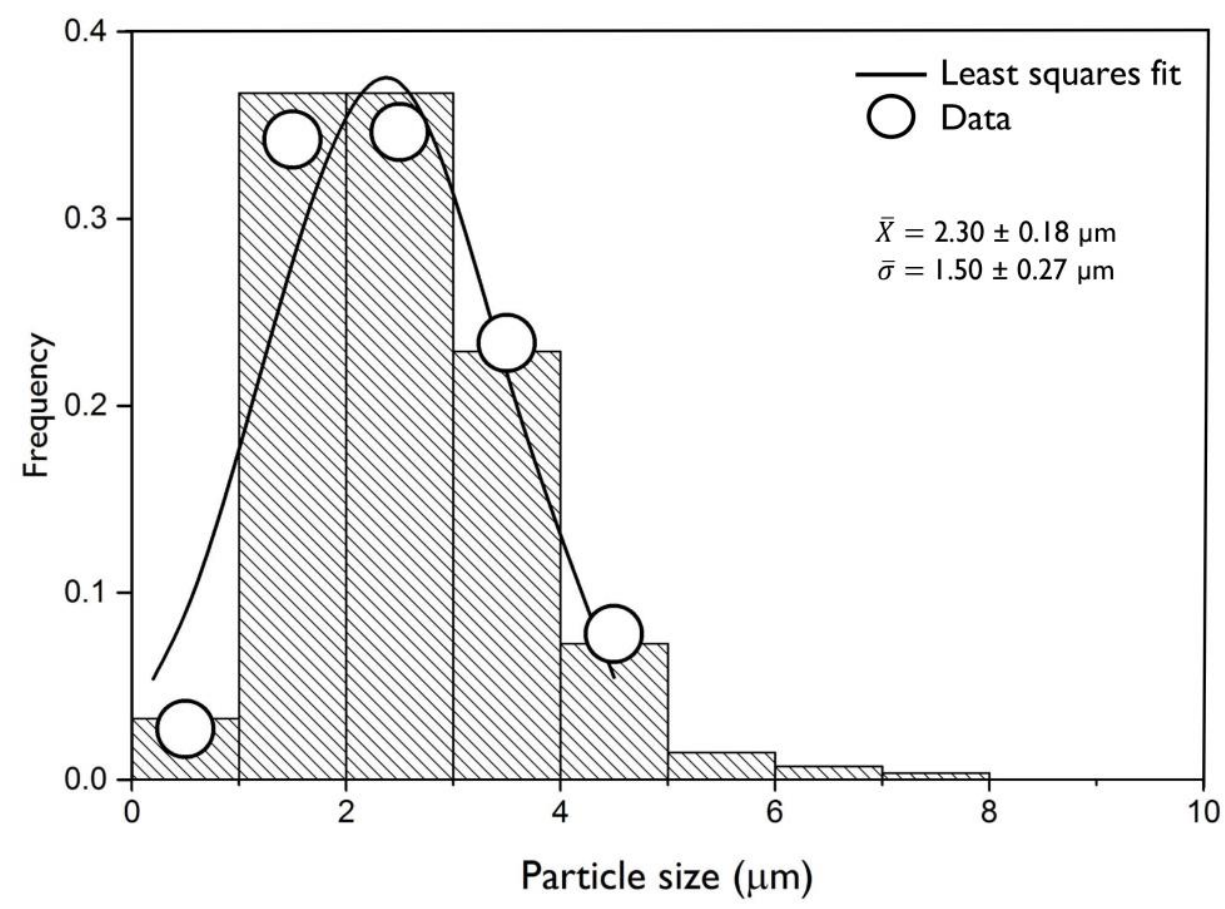

Figure S2.4 Gaussian distribution of particle size of sample E-0.5 with least squares fit, along with larger aggregates. Mean particle size $(\overline{\boldsymbol{X}})$ and the spread $(\overline{\boldsymbol{\sigma}})$ values are shown in the graph. 


\section{CHAPTER 3}

\section{MOFs-on-Ion Exchange Membranes: \\ Using a charge-selective interface for localized film formation}

This chapter is adapted from:

Özlem H. Demirel, Tom van der Meer, Harmen Zwijnenberg, Nieck E. Benes, Jeffery A. Wood, MOFs-on-Ion Exchange Membranes: Using a chargeselective interface for localized film formation, Manuscript in preparation. 


\section{Abstract}

Pure ZIF-8 films have been formed on ion exchange membranes (IEM) by using diffusion-cell set-up, for the first time. The IEMs function as both a dense polymeric support and selectively regulate the transport of the reactants to allow for controlled localized film formation. The synthesis of ZIF-8 requires the deprotonation of the 2-methylimidazole (HMIM) and $\mathrm{Zn}(\mathrm{HMIM})_{n}{ }^{+}(n=1-4)$ complexes that can be achieved by the use of deprotonation agent or an excess of the organic ligand (2-methylimidazole, HMIM) or to create a sufficiently basic environment. When using IEMs, local molar concentrations of the (charged) reactants at the interface can be controlled in a way to favor ZIF-8 crystallization. The influence of solvents with different dielectric constants and the type of the IEM was investigated to explore the possibilities to control the formation of MOF films, which are characterized with SEM and XRD. The highest quality ZIF-8 films have been obtained using a methanol-based synthesis approach with an anion exchange membrane (AEM) barrier. In methanol, hydrolysis reactions of reactants are inhibited, while the dissociation of zinc into charged form is also somewhat reduced due to the lower dielectric constant. The use of an AEM also ensures a lower zinc concentration at the membrane interface due to Donnan exclusion, although this charge-exclusion is reduced as compared to the case of a pristine IEM in water (a high dielectric constant solvent). The ion selective nature of AEM also helps to ensure that any protonated organic ligand $\left(\mathrm{H}_{2} \mathrm{MIM}^{+}\right)$is hindered in crossing that favors ZIF-8 synthesis. When CEM is used, the interface is enriched with $\mathrm{Zn}$ ions, which is not desired for ZIF-8 crystallization, and $\mathrm{H}_{2} \mathrm{MIM}^{+}$is also capable of passing between solution reservoirs. In aqueous synthesis, formation of $\mathrm{Zn}(\mathrm{OH})_{2}$ was observed as a side reaction of $\mathrm{Zn}^{2+}$. The use of a conventional deprotonation agent in ZIF-8 synthesis, ammonium hydroxide, destroyed the IEMs used in this work due to high $\mathrm{pH}$. This study demonstrates possible advantages for controlled local synthesis of MOFs on IEMs, through control of the local concentrations of the reactants and opens up new opportunities in terms of both MOF film synthesis and applications of these films. 


\subsection{Introduction}

Metal organic frameworks (MOFs) are a class of nanoporous materials consisting of metal centers connected with organic ligands. ${ }^{1}$ Their chemical and thermal stability, high surface area and porosity attracted interest in many different applications. Early studies have focused on obtaining powder materials. ${ }^{2-5}$ However, as the application spectrum has expended to film-based sensors, electrical devices and separation membranes, a great deal of research has been focused on the preparation of MOF films. ${ }^{6}$ Different techniques have been utilized to form thin MOF film on various substrates such as: in-situ synthesis, ${ }^{7-}$ 9 secondary growth, ${ }^{10-12}$ microwave irradiation, ${ }^{13,14}$ layer-by-layer, ${ }^{15,16}$ dip coating, ${ }^{1718}$ electrochemical synthesis, ${ }^{19}$ counter-diffusion ${ }^{20-22}$ and interfacial synthesis, ${ }^{23-26}$ etc. Zeolitic imidazolate frameworks (ZIFs) are a sub-class of MOFs, consisting of divalent zinc ions connected with imidazolate based linkers with crystal structures similar to zeolites. ${ }^{27}$ As one of the most studied ZIFs, ZIF8 synthesis is considered a 'simple' process but remains complicated at the same time. Deprotonation of 2-methylimidazole (HMIM) $(\mathrm{pKa}=14.2)$ and $\mathrm{Zn}(\mathrm{HMIM}) \mathrm{n}^{+}$ $(\mathrm{n}=1-4) \quad(\mathrm{pKa}=10.3)$ complexes requires a basic environment to initiate the formation of ZIF- 8 crystals..$^{52}$ In order to increase the $\mathrm{pH}$, use of excessive organic ligand $^{28-30}$ or deprotonation agent such as ammonium hydroxide is necessary. ${ }^{22,31,32}$ In aqueous media, due to the hydrolysis reaction of HMIM and $\mathrm{Zn}^{2+}$ the reaction becomes more complicated than in an organic solvent, mainly due to the uncontrolled hydrolysis. ${ }^{33}$

The preparation of thin-films of ZIFs has been studied extensively, especially for ZIF-8. ${ }^{22,34}$ Yao et al. showed contra-diffusion ZIF-8 synthesis on a flexible porous polymer (nylon) membrane as a support. Two reactant solutions in methanol were separated with the support and the ZIF-8 film was formed on the membrane surface through contra-diffusion of the solutions. ZIF-8 crystals were formed on both side of the support. And different morphologies have been obtained due to different local molar ratios. On the metal solution side the ratio of organic ligand to metal ion was approaching zero, resulting in the formation of big crystals. On the organic ligand 
solution side, the molar ratio was greater than the original molar ratios and the MOF crystallization was more controlled. ${ }^{20}$ Interfacial microfluidic membrane processing has been used for the synthesis of ZIF-8 films using immiscible solvents (octanol for $\mathrm{Zn}^{2+} /$ water for imidazole) on hollow fiber membranes. Control over the synthesis locations, e.g., the inner or outer surface was possible via the choice of the solvents. ${ }^{35}$ Li et al. used porous polyethersulfone (PES) supports soaked overnight in an aqueous metal solution, followed by exposing these to an organic ligand solution in hexane (with a small amount of ethanol as co-solvent) in order to form ZIF-8 membranes via interfacial synthesis. ${ }^{36}$ Abdul Hamid et al. coined the term polymer-modificationenabled in situ metal-organic framework formation (PMMOF) for the preparation of ZIF-8 films. ${ }^{7}$ Metal doped polymer substrates were prepared for solvothermal synthesis of continuous and densely packed ZIF-8 films. Substrates were soaked in aqueous $\mathrm{Zn}$ solution for $1 \mathrm{~h}$ followed and placed in autoclave with organic ligand solution in methanol for solvothermal synthesis. Through metal doping, localized synthesis was possible to generate complex patterns of MOFs. Matrimid ${ }^{\circ}$ hollow fibers with ZIF-8 membranes were prepared via PMMOF method under a continuous microfluidic flow of a growth solution. These membranes showed promising results for propane/propylene separation when coated with PDMS as a protective top layer. ${ }^{7}$ In addition to different porous polymer supports mentioned above, up to now no use of dense ion exchange membranes as a support for pure ZIF-8 films has been reported. Only in one study, a dense commercial cation exchange membrane has been used to study the effect of incorporating ZIF-8 particles in a skin layer of polyamine that was formed by interfacial polymerization. ${ }^{37}$ This nanocomposite films containing ZIFs on cation exchange membranes have been used for monovalent ion separation, to demonstrate that nanoporous MOFs can show selectivity for monovalent ions, as well as mono vs. higher valence ions. ${ }^{3}$ IEMs are interesting candidates as a dense polymeric support for the MOF film formation due to their selective ion transport nature. An IEM allows counter-ions to permeate through the membrane while co-ions are excluded based on the anionic/cationic fixed charges. The possibility to control the interface concentration of the metal source via Donnan exclusion offers another 
control parameter for ensuring high organic to metal ratios and localized film synthesis. 39

In this study, we explore the use of Fujifilm Type 1 ion exchange membranes for ZIF8 film formation. These membranes are made of dense polymeric (aliphatic polyamide) membranes with fixed charge groups and inert polyolefin fibers for the mechanical strength. Fujifilm Type 1 Anion-exchange membranes (AEMs) are functionalized with $-\left(\mathrm{CH}_{3}\right)_{3} \mathrm{~N}^{+}$and Cation-exchange membranes (CEMs) with sulfo groups, $-\mathrm{SO}_{3}{ }^{-40}$ These membranes are used in various applications, such as electrodialysis. ${ }^{41}$ For the case of ZIF-8 film formation, IEMs are used to separate two reservoirs containing a metal and organic ligand solution respectively in diffusion cell and allowing one reactant to diffuse through the membrane depending on which type of IEM is used. We have investigated different synthesis conditions (time, solvent and combination of solvents, influence of deprotonation agent, IEM type) in order to obtain pure and controlled synthesis of ZIF-8 films, which are characterized by XRD and SEM in terms of the crystal structures and morphology.

\subsection{Experimental}

\subsubsection{Materials}

The chemicals used for ZIF-8 film preparation consist of zinc nitrate hexahydrate $\left(\mathrm{Zn}\left(\mathrm{NO}_{3}\right)_{2} \cdot 6 \mathrm{H}_{2} \mathrm{O}\right.$, Sigma Aldrich, $\left.\geq 99 \%\right)$, and 2-methylimidazole (HMIM, Sigma Aldrich, $\geq 99 \%)$, ammonium hydroxide $\left(\mathrm{NH}_{4} \mathrm{OH}\right.$, Sigma-Aldrich, $28-30 \%$ aqueous solution), methanol (Merck KGaA, 99.8\%) and water $\left(\mathrm{H}_{2} \mathrm{O}\right.$, purified using Milli Q system, Millipore). All the chemicals were used as received. The dense ion exchange membranes (IEMs) were purchased from FUJIFILM Europe B.V., The Netherlands. Type 1 Anion-exchange (AEM) (in $\mathrm{OH}^{-}$form) and Cation-exchange membranes (CEM) (in $\mathrm{Na}^{+}$form) were used as a support and a selective transport facilitator for ZIF-8 film synthesis. IEMs were cut into $\sim 7 \mathrm{~cm}$ diameter samples for use in a diffusion cell with diameter of $4 \mathrm{~cm}$. The membranes were pre-soaked in the solvent (methanol, water or $0.025 \mathrm{M} \mathrm{Zn}\left(\mathrm{NO}_{3}\right)_{2}$ solution) prior to the synthesis. 


\subsubsection{Preparation of MOF films on ion exchange membranes}

For only methanol based synthesis, $0.05 \mathrm{M} \mathrm{Zn}\left(\mathrm{NO}_{3}\right)_{2} \cdot 6 \mathrm{H}_{2} \mathrm{O}$ solution, as a metal source and 0.4 M HMIM solution, as an organic ligand source were prepared in methanol and stirred for one hour. The molar ratio of Zn:HMIM was 1:8. The IEM was placed in between two chambers of a diffusion cell. One chamber was filled with the metal solution and the other with the organic ligand solution. The synthesis durations investigated as 16, 24 and 72 hours. After the synthesis, the samples were washed with methanol and stored in methanol. (Table 3.1) For the water based synthesis $0.025 \mathrm{M}$ $\mathrm{Zn}\left(\mathrm{NO}_{3}\right)_{2} \cdot 6 \mathrm{H}_{2} \mathrm{O}$ and $0.5 \mathrm{M}$ HMIM solution for $\mathrm{Zn}$ :HMIM ratio of 1:20 were prepared. In order to increase the $\mathrm{pH}$ and deprotonate HMIM, ammonium hydroxide solution was added to HMIM solution with Zn:HMIM: $\mathrm{NH}_{4}{ }^{+}$molar ratios of 1:2:64 and 1:2:32 as per the conventional approach of He et al. ${ }^{22}$ The samples prepared in water were washed with water and also stored in water. More details can be found in Table S3.1.

Sample naming convention is as follows: IEM type-Solvent type-the duration of the synthesis. As an example, sample code A-MeOH-16h means that ZIF-8 films were grown on AEM support for $16 \mathrm{~h}$ and both metal and organic ligand solutions were prepared in methanol. When the solvent type is written as $\mathrm{MeOH} / \mathrm{W}$, it means metal solution was prepared in methanol and organic ligand was prepared in water.

\subsubsection{Materials characterization}

The membranes were dried overnight in a vacuum oven at $30^{\circ} \mathrm{C}$ for the analysis. The ZIF-8 films on IEM were investigated using an SM-6o1o (JEOL) scanning electron microscope (SEM) equipped with an energy dispersive X-ray spectrometer (EDS). Samples were sputtered with a $5 \mathrm{~nm}$ chromium coating (Quorum Q150T ES) prior to analysis. The XRD patterns of the samples were determined by powder X-ray diffraction (XRD) on a Bruker D2 PHASER operated at $10 \mathrm{~mA}$ and $30 \mathrm{kV}$ using a $\mathrm{CuK} \alpha$ source with a wavelength $(\lambda)^{1 / 4} 1.54 \AA$ at room temperature. Scans were made at variable angle, ranging from 5 to $40^{\circ}$ with a $2 \theta$ step size of $0.2-0.02^{\circ}$ and a scan speed of $1 \mathrm{~s}$ per step. 


\subsection{Results and discussion}

In this study, we have explored two solvent systems for ZIF-8 film formation on IEMs: $\mathrm{MeOH}$-based and aqueous-based. In $\mathrm{MeOH}$, due to its lower dielectric constant relative to water, the dissociation of zinc from zinc nitrate is somewhat less favored. However, it is still dissociated to a substantial degree. The effective ion-exchange capacity of an IEM is also lowered by the use of a lower dielectric constant solvent as some of the fixed charge groups within the membrane will not dissociate, but in methanol $(\varepsilon=32.7)$ charge-selectivity is still maintained. The advantage of methanol comes in limiting hydrolysis reactions, as well as potentially allowing more of the neutral HMIM to permeate the membrane vs. the case of a highly-charged dense polymeric membrane in water. In aqueous system, IEM is expected to facilitate the transport of the reactants at the interface due to higher Donnan exclusion and ion exchange capacity in water. However, in the aqueous-based synthesis the $\mathrm{pH}$ stability of the IEMs and hydrolysis of $\mathrm{Zn}^{2+}$ limited the formation of ZIF-8.

\subsubsection{MEOH-based synthesis}

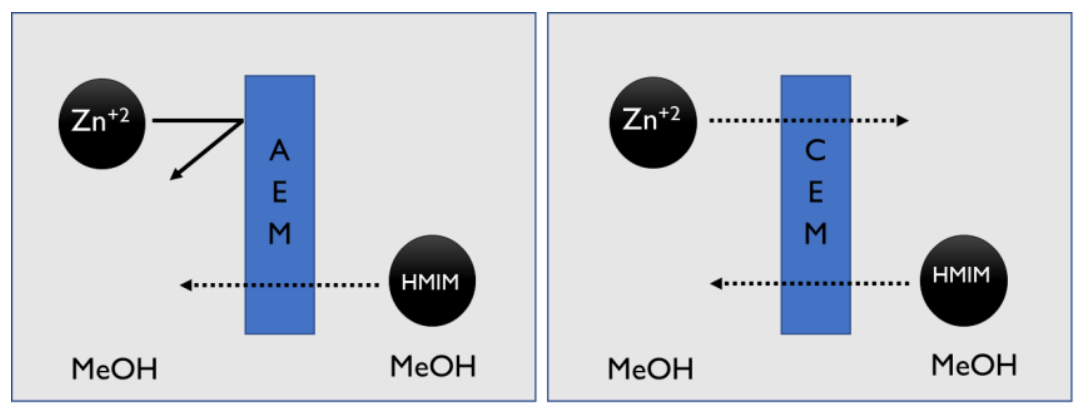

Scheme 3.1 Schematic image of the ZIF-8 formation in MeOH based synthesis. 
Table 3. 1 The experimental details for MeOH based synthesis of ZIF-8 films.

\begin{tabular}{cccc}
\hline Sample & IEM & Solvent (Zn/HMIM) & Pretreatment \\
\hline A-MeOH-(X)h & AEM & $\mathrm{MeOH} / \mathrm{MeOH}$ & $\mathrm{MeOH}$ \\
$\mathbf{C - M e O H}-(\mathbf{X}) \mathbf{h}$ & $\mathrm{CEM}$ & $\mathrm{MeOH} / \mathrm{MeOH}$ & $\mathbf{0 . 0 2 5} \mathrm{M} \mathrm{Zn}\left(\mathrm{NO}_{3}\right)_{2}$ \\
A-MeOH/W-(X)h & AEM & $\mathrm{MeOH} / \mathrm{H}_{2} \mathrm{O}$ & $\mathrm{H}_{2} \mathrm{O}$ \\
C-MeOH/W-(X)h & $\mathrm{CEM}$ & $\mathrm{MeOH} / \mathrm{H}_{2} \mathrm{O}$ & $\mathrm{MeOH}$ \\
A-W/MeOH-(X)h & AEM & $\mathrm{H}_{2} \mathrm{O} / \mathrm{MeOH}$ & $\mathrm{MeOH}$ \\
C-W/MeOH-(X)h & $\mathrm{CEM}$ & $\mathrm{H}_{2} \mathrm{O} / \mathrm{MeOH}$ & $0.025 \mathrm{M} \mathrm{Zn}\left(\mathrm{NO}_{3}\right)_{2}$ \\
\hline
\end{tabular}

$\mathrm{A}=\mathrm{AEM}, \mathrm{C}=\mathrm{CEM}, \mathrm{W}=\mathrm{H}_{2} \mathrm{O}, \mathrm{X}=$ synthesis time (16h, 24h, 72h)

$\mathrm{Zn:HMIM}$ ratio of 1:8 is used for all the samples.

In $\mathrm{MeOH}$-based synthesis, $\mathrm{Zn}$ ions are rejected by the positive charge of the AEM and vice versa for CEM. Therefore, ZIF-8 formation is expected on the $\mathrm{Zn}$ side for AEM, and on the HMIM side for CEM. However, these membranes are not $100 \%$ selective and the transport of the reactants to both sides can be also considered. Donnan exclusion would also contribute to control the local concentrations of the $\mathrm{Zn}^{2+}$ (as well as any protonated $\mathrm{HMIM}\left(\mathrm{H}_{2} \mathrm{MIM}^{+}\right)$in $\mathrm{MeOH}$, another potential advantage). At the interface, where film formation occurs, there will be increase in the concentration of the counter-ions and decrease of co-ions based on the charge of the membrane. For instance, low Zn/HMIM ratios can be reached at the Zn-solution side of the AEM interface. However, care should be taken with the molar ratios of the reactants calculated directly from the solution molar ratios, as $\mathrm{Zn}^{+2}$ shows a partial dissociation of $\sim 70 \%$ in methanol. ${ }^{42}$ Based on Donnan exclusion this ratio would shift even more favorably to higher organic to metal locally at the AEM interface on the metal-rich solution side. ${ }^{42}$ Even though the methanol system has a lower ion exchange capacity and Donnan exclusion compared to water due to the same dissociation effect, in this case it led to very controlled synthesis of ZIF-8 films without observing any crossover 
of synthesis between compartments. The experimental details of the MeOH-based synthesis can be found in Table 3.1.
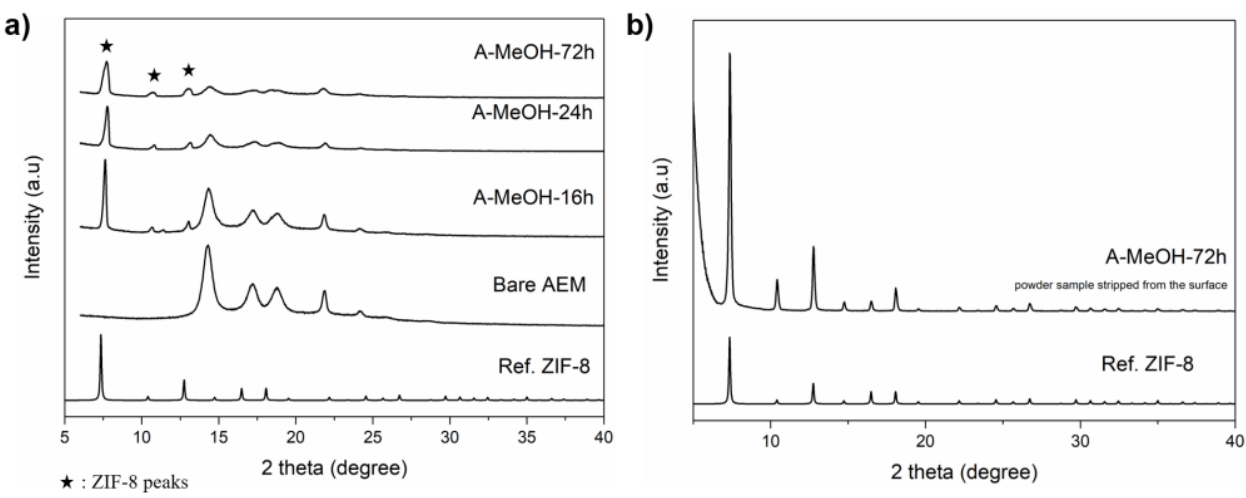

Figure 3. 1 XRD patterns of ZIF-8 films a) A-MeOH samples with different synthesis times, stars showing the characteristic peaks of ZIF-8 and b) A-MeOH-72h, powder sample stripped from the surface.

Fig.3.1 (a) shows the XRD results of the ZIF-8/AEM membranes with the characteristic peaks at (110), (200) and (211) planes, as it is indicated with stars. XRD patterns of IEMs also shows some peaks at the same location as ZIF-8 characteristic peaks (Fig. 3.1 (a) and Fig. S3.2). The origin of these diffraction peaks is the polyolefin fibers exist in both AEM and IEM for reinforcement. ${ }^{43}$ In order to confirm the ZIF-8 structure, some films were stripped from the surface of AEM. The powder XRD results in Fig. 3.1 (b) are consistent with the reference ZIF-8 (CCDC 602542), which proofs that ZIF-8 films are obtained without any other phases. During the synthesis, there was no color change in any of the compartments of the diffusion cell for $16 \mathrm{~h}$. When the synthesis time increases, Zn side slightly turns into milky color to indicate that ZIF-8 particles are also formed in the bulk or detached from the surface. (Fig. S3.3)

SEM images show that as the synthesis time increases the ZIF-8 particle size also increases (Fig. 3.2). In A-MeOH-16h, small size ZIF-8 grains are obtained. With the increase of the synthesis time, rhombic dodecahedra ZIF-8 crystals are observed on the surface. While intercrystalline gaps are still visible in A-MeOH-24h, wellintergrown MOF films are obtained in A-MeOH-72h. As HMIM permeates through 
$\mathrm{AEM}$, at the interface the $\mathrm{Zn} / \mathrm{HMIM}$ ratio will be less than the original reactant solutions. Rejection of the metal ions by the AEM also contributes into increase of HMIM concentration more than the $\mathrm{Zn}$ ions. This is due to Donnan exclusion at the interface, as the positively charged $\mathrm{Zn}^{2+}$ ions are excluded from the interface between membrane and the bulk. Thus, lower $\mathrm{Zn} / \mathrm{HMIM}$ ratio favors the formation of the ZIF8 and the crystallization occurs on the Zn side of the AEM.8,34,44 As the synthesis time increases, more HMIM permeates through the membrane forming ZIF-8 films as an intergrown structure. Due to the different crystal growth rates on the surface, there is a non-uniform particle size distribution. The increase in the thickness can be seen in the decrease in the intensity of the polymer peaks in the XRD results Fig. 3.1 (a). Bigger crystals were washed off from the surface. Adhesion between the MOF films and AEMs was found to be good based on the scratching the surface for XRD analysis.

\section{Bare AEM}

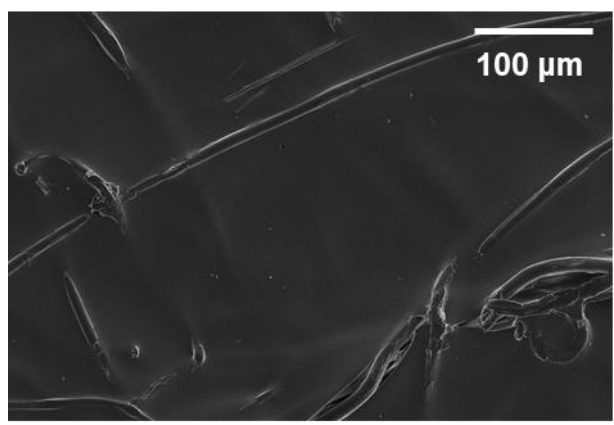

$24 \mathrm{~h}$

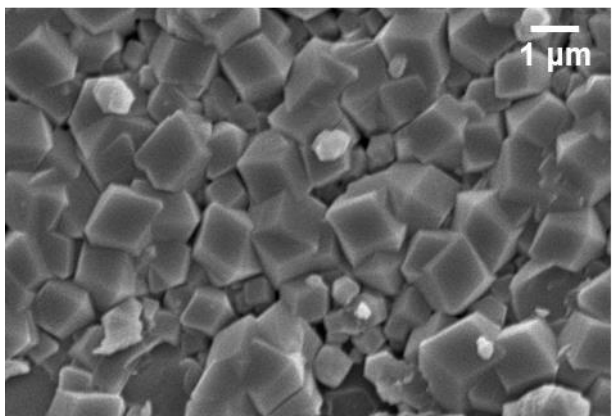

$16 \mathrm{~h}$

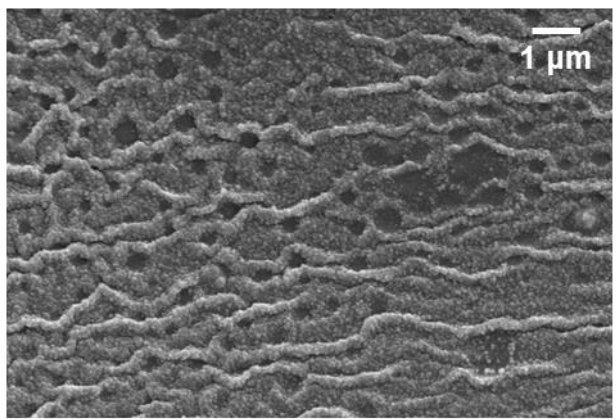

$72 \mathrm{~h}$

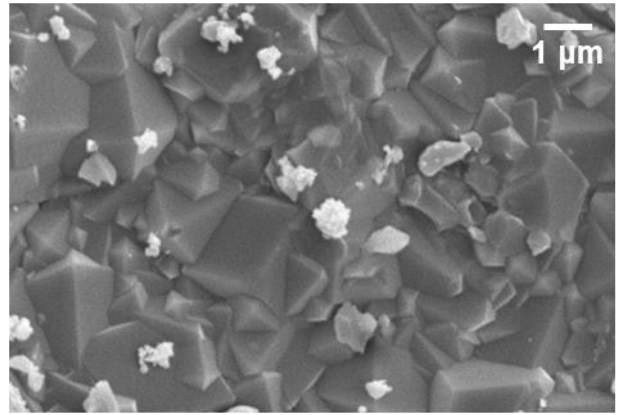

Figure 3. 2 Top surface (Zn side) SEM images of A-MeOH membranes with bare AEM and different synthesis time. 
In methanol, HMIM molecules form an equilibrium between protonated and neutral form and deprotonation of HMIM is initiated with the gain of lattice energy by ZIF-8 crystallization. ${ }^{44}$ The dissociation of $\mathrm{Zn}\left(\mathrm{NO}_{3}\right)_{2}$ is around $70 \%$ in methanol indicating that it is largely ionic. In order to favor synthesis, excess HMIM is used to create a basic environment for the deprotonation of $\mathrm{Zn}(\mathrm{HMIM})^{+2}$ complexes and change equilibrium for the neutral HMIM.33 In an AEM system, positively charged protonated HMIM $\left(\mathrm{H}_{2} \mathrm{MIM}^{+}\right)$cannot easily permeate through the positively charged AEM implying transport of predominantly neutral HMIM; this also favors synthesis.

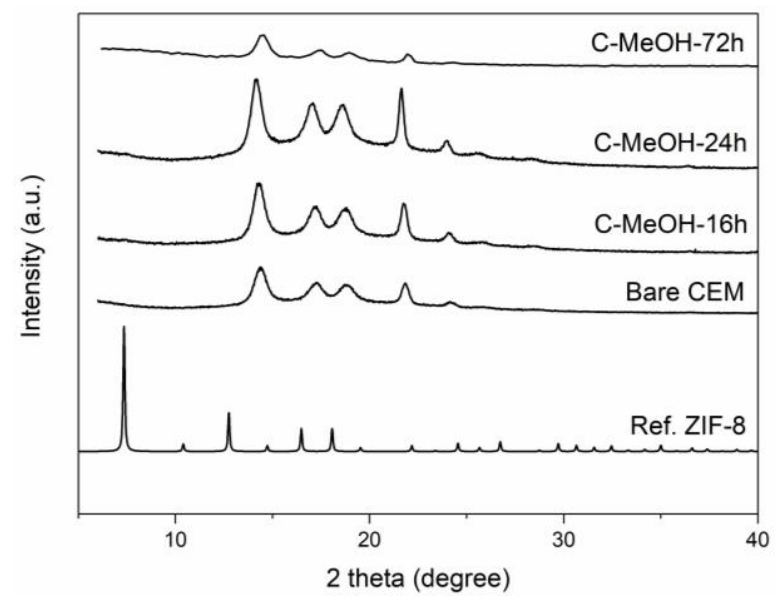

Figure 3. $3 \mathrm{XRD}$ patterns of $\mathrm{C}-\mathrm{MeOH}$ with different synthesis times.

When CEM is used as a support for the synthesis, there was no color change during the synthesis of all durations (16h, $24 \mathrm{~h}$ and $72 \mathrm{~h}$ ). This is also confirmed with the XRD results in Fig. 3.3 indicating that there is no evidence of any crystal formation on the surface. We also monitored the $\mathrm{pH}$ of the HMIM solution before and after the synthesis, there was also no change in the $\mathrm{pH}$ values $(\mathrm{pH}=9)$ indicating no reaction. SEM analysis also did not show any trace of the synthesis on both sides of the membrane. Smooth polymer films are observed, as is the case for bare IEMs. (Fig. S3.1 and Fig. S3.4) The cracks are due to swelling of IEMs in a solvent and drying under vacuum for SEM sample. The pretreatment step of exchanging cations with $\mathrm{Zn}^{2+}$ prior to the synthesis may affect the $\mathrm{Zn}^{2+}$ transport through the membrane. By introducing metal source to the membrane could start nucleation points for the ZIF-8 synthesis. 
On the other hand, saturating CEMs in pretreatment solution of $\mathrm{Zn}\left(\mathrm{NO}_{3}\right)_{2}$ in water and placing this in a methanol solution leads to a preference for $\mathrm{Zn}^{2+}$ to be retained within the higher dielectric constant environment (CEM with water), at least initially. ${ }^{45}$ CEMs also facilitate the transport of any protonated HMIM $\left(\mathrm{H}_{2} \mathrm{MIM}^{+}\right)$, which is not favorable for ZIF-8 synthesis.

\section{MeOH/Water-based synthesis:}
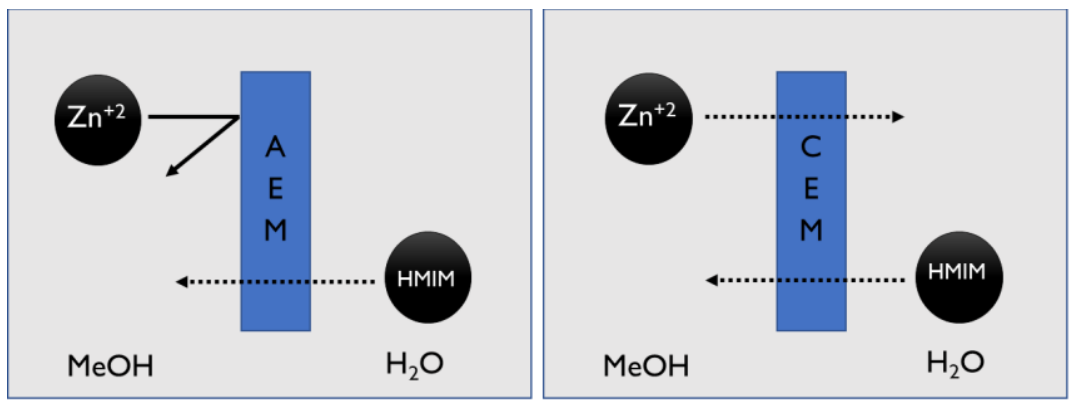

Scheme 3.2 Schematic image of the ZIF-8 formation in MeOH/Water based synthesis.
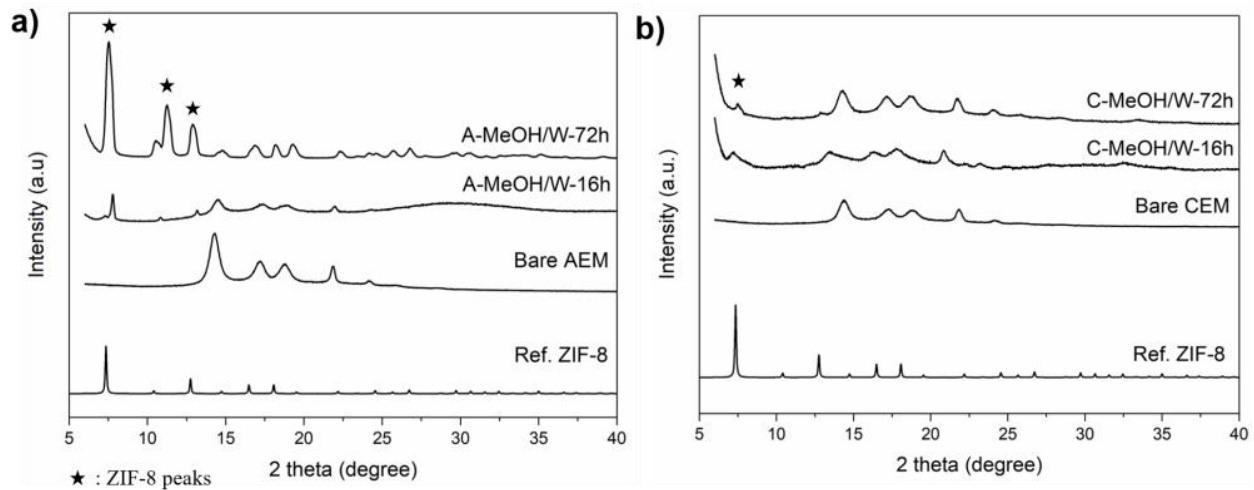

Figure 3. $4 \mathrm{XRD}$ patterns of a) A-MeOH/W and b) $\mathrm{C}-\mathrm{MeOH} / \mathrm{W}$ at different synthesis times.

In $\mathrm{MeOH} /$ Water based synthesis, the methanol is replaced with water for the organic ligand, HMIM solution. As pretreatment, we choose the solvent of the reactant that can permeate through the membrane. AEM membranes are soaked in water prior to the synthesis, to promote HMIM transport through the membrane and CEM in methanol, as $\mathrm{Zn}^{2+}$ ions in principle will be the mobile reactant in that case. By choosing 
water for the organic ligand and organic solvent for the metal source, it is aimed to facilitate the transport of the reactants to the solvent where it is more favorably to dissolved. There is also water and methanol exchange in the system. Due to its high dielectric constant, water is more favorable for ions compared to methanol. Therefore, uncharged HMIM transport in AEM may be easier to the repelled Zn.

$16 \mathrm{~h}$

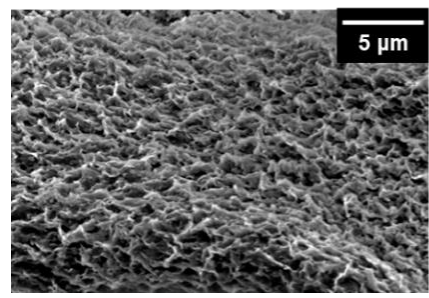

$24 \mathrm{~h}$

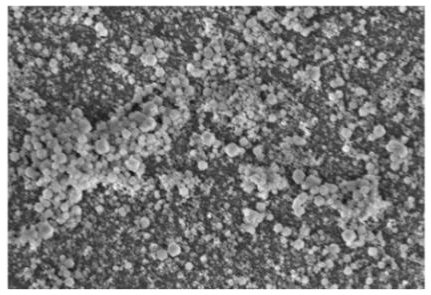

$72 \mathrm{~h}$

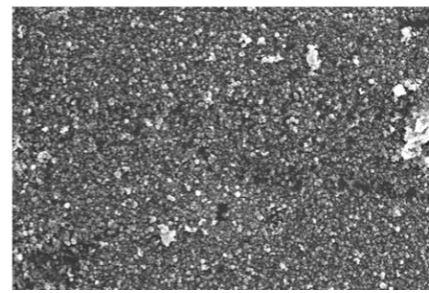

Figure 3. 5 Top surface (Zn side) SEM images of A-MeOH/W with different synthesis times.

In Fig. 3.4(a), A-MeOH/W-16h and -72h samples show the characteristic peaks of ZIF8. Although, an extra shoulder at $10^{\circ}$ might be an indication of an impurity for $72 \mathrm{~h}$ synthesis, the rest of the pattern is compatible with the reference ZIF-8. SEM images show the ZIF-8 crystal growth at different reaction times (Fig. 3.5). As the reaction times increase, ZIF-8 crystal morphology changes from flake-like structure to a smaller-grain-like intergrown structure. The flake like ZIF-8 structure were reported when flake-like $\mathrm{ZnO}$ is used as a metal source for the solvent free synthesis of ZIF-8 films..$^{46}$ In this study, due to the counter diffusion of water, at the interface different side reactions of Zn may have resulted as different morphologies of ZIF-8. Increasing the synthesis time allows more supply of the metal source for the crystal growth, resulting in the morphology of the crystals to change from flake-like to grain-like. Fig. 3.5 presents more uniform and smaller crystals for A-MeOH/W-72h compared to $-24 \mathrm{~h}$. From our observations on the diffusion cell set-up, both Zn and HMIM side solutions had a characteristic milky appearance of ZIF-8, instead of the precipitation of $\mathrm{Zn}(\mathrm{OH})_{2}$ crystals directly at the bottom of the cell. Therefore, the uniformity of the particles in $\mathrm{A}-\mathrm{MeOH} / \mathrm{W}$ might be due to the detachment of the big particles to the bulk. The color 
change in both sides indicates the membrane is not less selective in this condition and both reactants can permeate through the membrane.

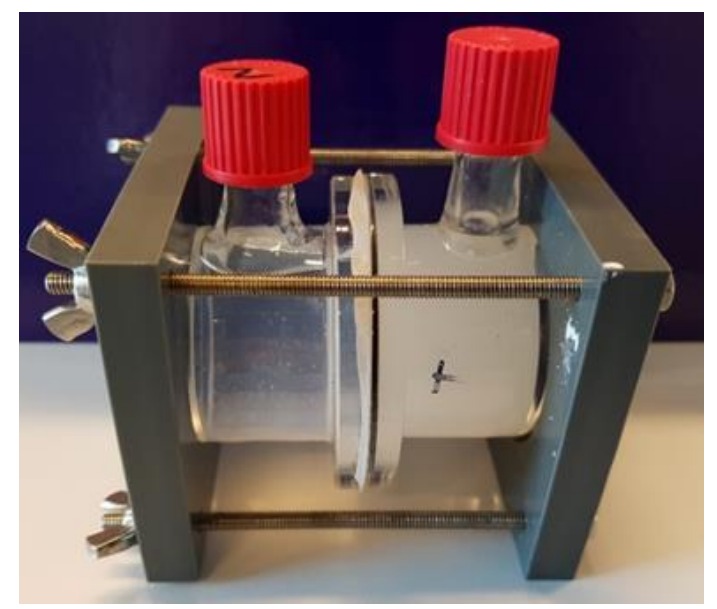

Figure 3.6 C-MeOH/W-72h after the synthesis. HMIM side turns into a milky appearance after synthesis.
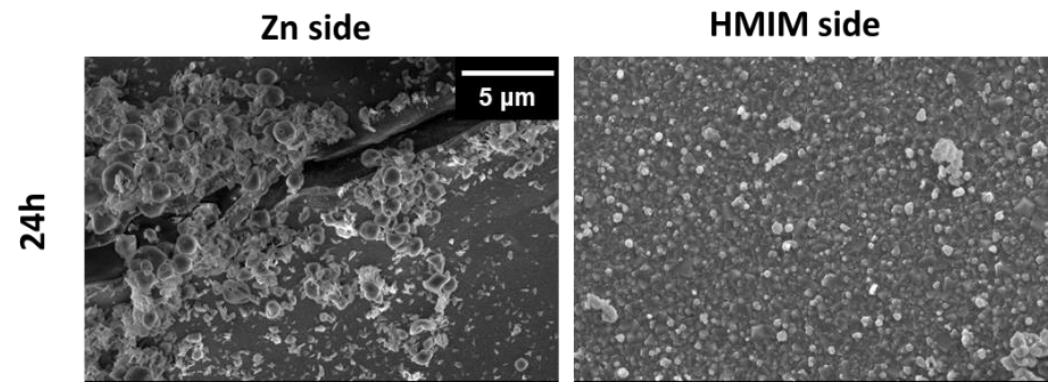

Figure 3. 7 SEM image of C-MeOH/W-24h, top surface facing Zn side and HMIM side in the diffusion cell.

When the AEM is changed to the CEM the synthesis occurs mainly in HMIM side, as can be seen in Fig. 3.6. However, the milky color represents either a reaction in the bulk or the detachment of (big) crystals to the bulk. According to the SEM images in Fig. 3.7 the deposition of intergrown ZIF-8 particles, with a few agglomerated large particles, is observed. Therefore, the color of the bulk might be due to the detachment of large ZIF-8 crystals. Even though the CEM is slightly more selective (in terms of synthesis) compared to AEM based on the control over the localized synthesis, there was still a layer of ZIF-8 crystals formed on both sides of the CEM. At the HMIM side 
of the membrane, a large number of aggregates was present at the surface, more than at the zinc side as determined by visible inspection. These particles could be washed off with methanol after the synthesis. The SEM images show that on the Zn side there is a random formation of crystals, while the HMIM side is well-covered with a ZIF-8 film. (Figure 3.7) In CEM, the Donnan exclusion at the surface does not favor the formation of ZIF-8, as the positively charged ions including protonated HMIM $\left(\mathrm{H}_{2} \mathrm{MIM}^{+}\right)$, are enriched at the interface. However, the bulk conditions are more in favor of the ZIF-8 formation. The molar ratio of permeated $\mathrm{Zn}^{2+} / \mathrm{HMIM}$ is much higher than original ratio of $1 / 8$. Therefore, the detachment or the synthesis in the bulk could be dominant over a stable film formation at the interface.

\section{Water/MeOH - based synthesis:}

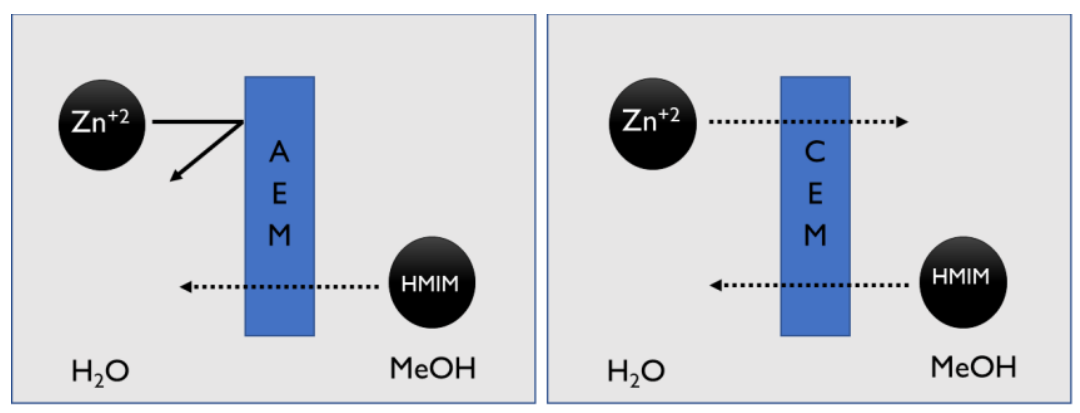

Scheme 3.3 Schematic image of the ZIF-8 formation in Water/MeOH based synthesis.

In this case water is used as the solvent for the metal source and methanol for the organic ligand, to explore the effect of solubility of the reactants. As mentioned before, water favors the dissociation of $\mathrm{Zn}^{2+}$ ions more than methanol; IEMs in water should have a higher effective charge-density (meaning a higher selectivity and a higher Donnan exclusion at the interface). However, the control over the side reactions of $\mathrm{Zn}^{2+}$ can be a limiting factor for the ZIF-8 synthesis and for the conditions studied here this appears to be the case. ${ }^{31}$

Fig. 3.8 (a) shows ZIF-8 characteristic peaks on A-W/MeOH samples, along with extra peaks at around $20-21^{\circ}$ and $27-28^{\circ}$ when the crystallization time is longer than $16 \mathrm{~h}$. This is also confirmed with the XRD results of samples stripped from the surface of 
AEMs. In Fig. 3.8 (b), XRD patterns of A-W/MeOH-16h is compatible with the reference ZIF-8. On the other hand, A-W/MeOH-72h exhibits ZIF-8 and $\mathrm{Zn}(\mathrm{OH})_{2}$ multiple phase formation. (Fig. 3.8 (b)) Two consecutive peaks around $20-21^{\circ}$ and $27^{-}$ $28^{\circ}$ are the indication of the $\mathrm{Zn}(\mathrm{OH})_{2}$ formation in the XRD analysis of films, shown with triangle index. ${ }^{47-49}$ SEM images also demonstrates the non-uniform, random formation of a different phase with very large crystals in the long time synthesis (24h and 72h). In contrary, A-W/MeOH-16h depicts a small particle size ZIF-8 crystal film formation with intergrown structure. (Fig. 3.9)

Similar to the previous cases, in AEM, ZIF-8 films are formed on the Zn side thanks to the high local concentration of HMIM at the interface. However, use of water as a solvent for the $\mathrm{Zn}^{2+}$ solution results in uncontrolled hydrolysis reaction of $\mathrm{Zn}^{2+}$ ions with water. $\mathrm{Zn}(\mathrm{OH})_{2}$ formation is observed for $24 \mathrm{~h}$ and $72 \mathrm{~h}$ synthesis. ${ }^{31}$ As it can be seen in Fig. 3.9, multiple phases have grown on the surface. Hydrolysis of $\mathrm{Zn}^{2+}$ is a critical problem for crystallization of ZIF-8 and any potential advantages in using water as the medium with IEMs is evidently outweighed by this. 

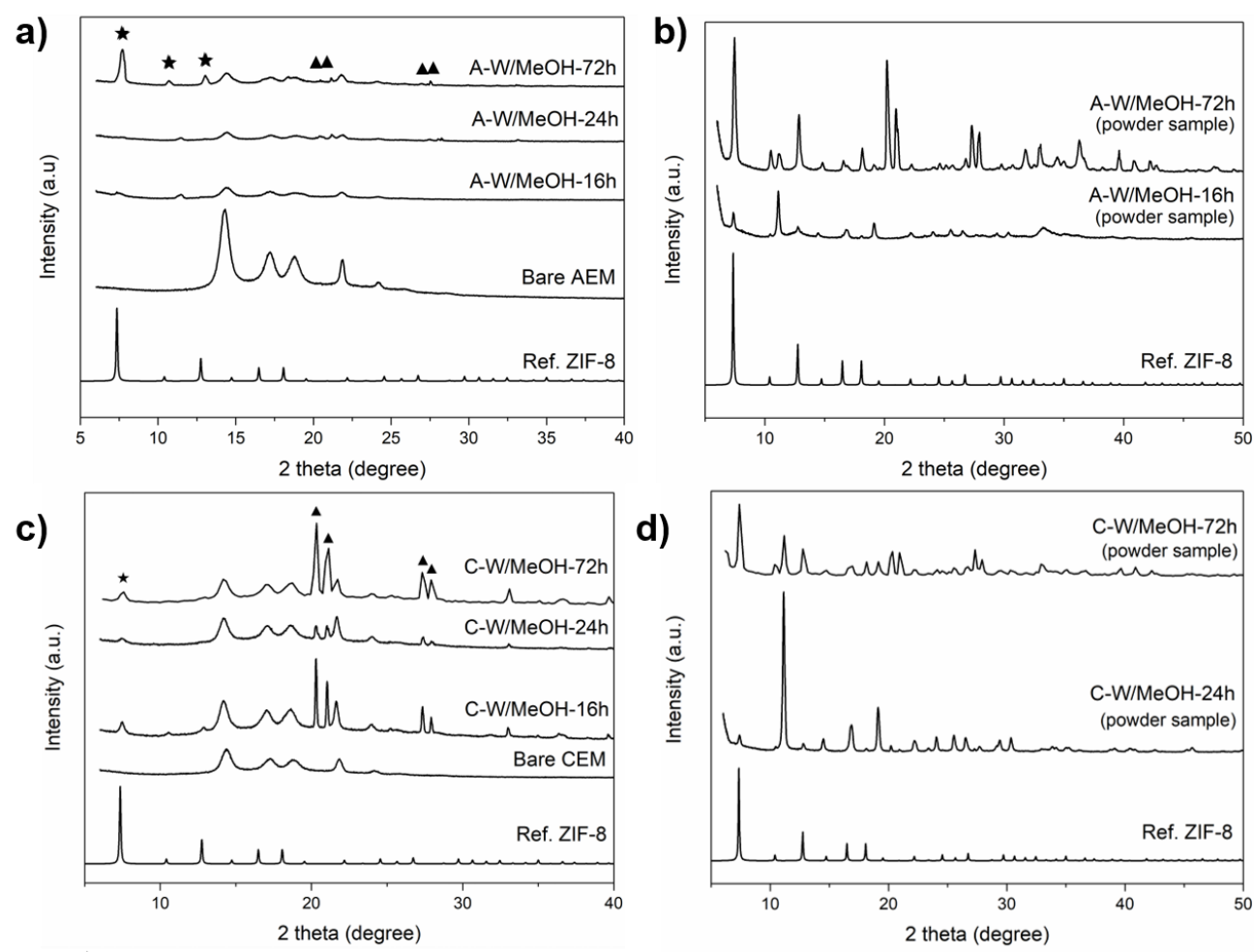

$\star$ : ZIF-8 peaks

$\boldsymbol{\Delta}: \mathrm{Zn}(\mathrm{OH})_{2}$ peaks

Figure 3. $8 \mathrm{XRD}$ patterns of ZIF-8 films a) A-W/MeOH at different synthesis times b) powder stripped from $\mathrm{A}-\mathrm{W} / \mathrm{MeOH}-16 \mathrm{~h}$ and $72 \mathrm{~h}, \mathrm{c}) \mathrm{C}-\mathrm{W} / \mathrm{MeOH}$ at different synthesis times and d) powder stripped from $\mathrm{C}-\mathrm{W} / \mathrm{MeOH}-24 \mathrm{~h}$ and $72 \mathrm{~h}$. 

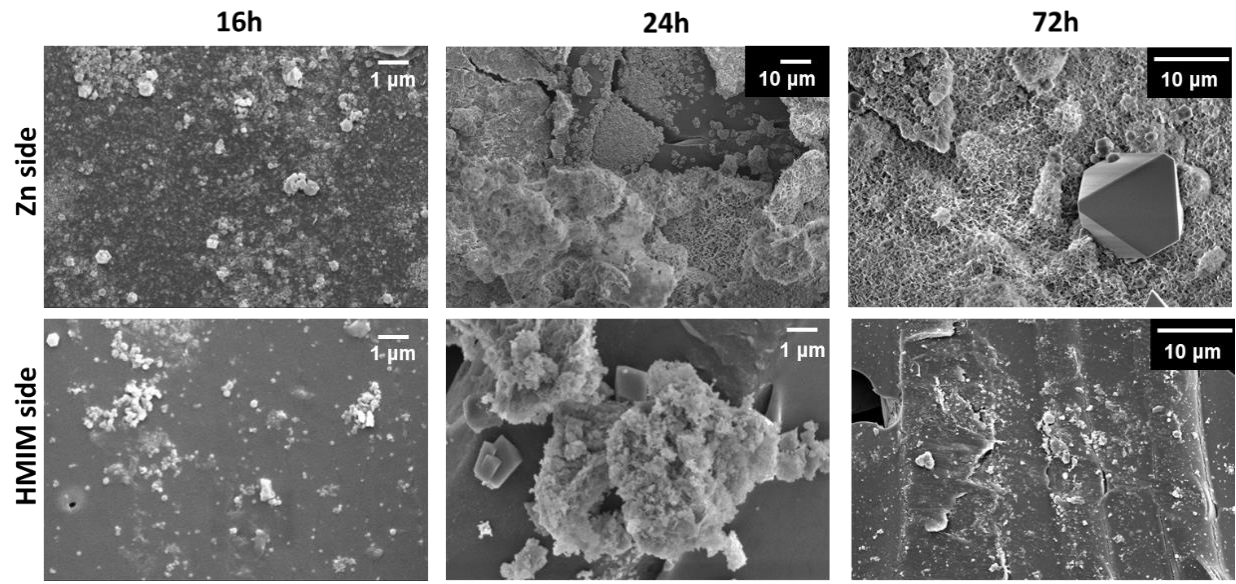

Figure 3. 9 Top surface SEM images of A-W/MeOH with different synthesis times.

CEM studies also show similar uncontrolled and undesired phase formation on the surface. The $\mathrm{Zn}$ side shows open flake like structure, while denser structures are observed on the HMIM side. (Fig. 3.10) XRD results reveals $\mathrm{Zn}(\mathrm{OH})_{2}$ formation all the samples. (Fig.3.9 (c) $\mathrm{Zn}(\mathrm{OH})_{2}$ formation could be more favored for CEM samples due to the pretreatment of the CEMs in Zn solution overnight. As the membrane already soaked in water for a long time.

To summarize, ZIF-8 films has been formed on Zn side of AEMs when MeOH has been used as a solvent for both reactants. Using water as a solvent for the metal source causes uncontrolled side reactions of $\mathrm{Zn}^{2+}$, that limits the ZIF-8 formation. Use of pretreatment for CEM in metal solution in water, restricts $\mathrm{Zn}$ permeation to the methanol-based solution as dissociation in water is more favorable than methanol. When pretreatment of CEM takes place in methanol, the formation of ZIF-8 powders or detachment of the films are observed in the bulk. This can be explained by the fact that Donnan exclusion at the interface is not favorable for ZIF-8 formation, whereas low Zn/HMIM ratio in the bulk accelerates the ZIF-8 crystallization. 
$16 \mathrm{~h}$
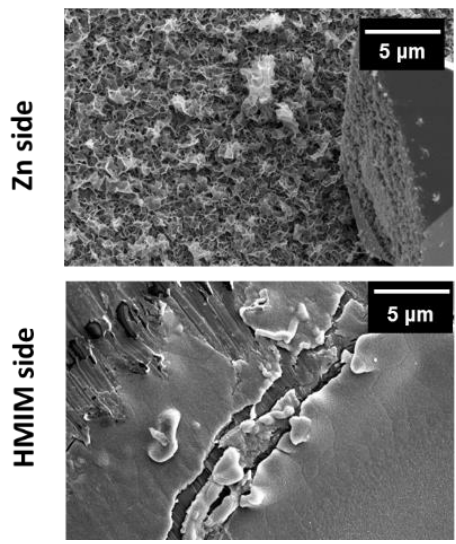

$24 \mathrm{~h}$
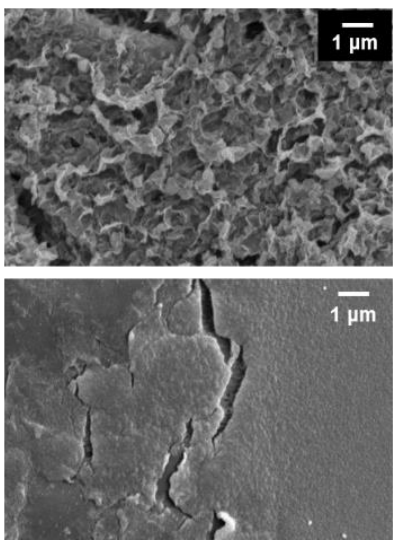

$72 \mathrm{~h}$

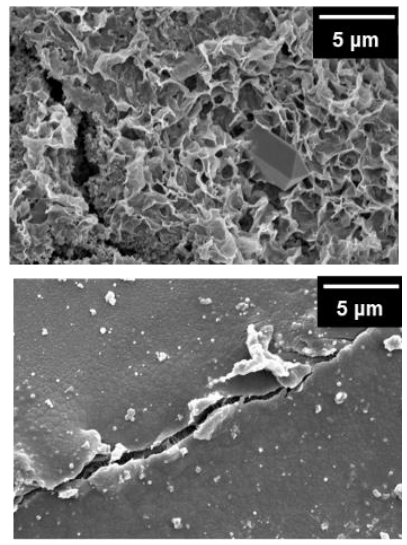

Figure 3. 10 Top surface SEM images of $\mathrm{C}-\mathrm{W} / \mathrm{MeOH}$ with different synthesis times.

\subsubsection{Limitations of aqueous synthesis}

To further confirm that aqueous synthesis of ZIF-8 on IEMs is unfavorable, we tested ZIF-8 film formation on IEMs in all aqueous systems. Although, aqueous conditions are more favorable for IEM performance, the improvement for the ZIF-8 synthesis does not reflect to the ZIF-8 synthesis. A major disadvantage (hydrolysis) has already been discussed but also the need for the use of deprotonation agent leads to $\mathrm{pH}$ stability issues for the IEMs considered. Experimental details of the aqueous synthesis can be found in Table $S_{3.1}$

\section{With deprotonation agent}

In aqueous ZIF-8 (bulk) synthesis, use of the stochiometric ratio of Zn:HMIM (1:2) is not very common. The stochiometric ratio can be only used effectively at conditions that are sufficiently basic for the deprotonation of HMIM (pKa=14.2). Use of a deprotonation agent such as ammonium hydroxide $\left(\mathrm{NH}_{4} \mathrm{OH}\right)$ in aqueous synthesis of ZIF-8 is a conventional method to deprotonate HMIM..$^{22,31,32,50}$ Here, the addition of $\mathrm{NH}_{4} \mathrm{OH}$ to the HMIM solution has been tested for ZIF-8 formation on IEMs with Zn:HMIM: $\mathrm{NH}_{4}{ }^{+}$molar ratio of 1:2:64. For both AEM and CEM, the $\mathrm{Zn}^{2+}$ solution turns to turbid appearance within the first minutes of the synthesis. (Fig. S3.6) Therefore, longer synthesis durations were not tried for this case. As it can be seen in the XRD 
patterns of both AEM and CEM, the diffraction peaks of the polymer are not visible as they are not pH stable. (Fig. S3.7) SEM images show that different morphologies have been observed. In HMIM side of AEM, some deformation of the polymer can be seen. (Fig. S3.8) With the addition of $\mathrm{NH}_{4} \mathrm{OH}, \mathrm{pH}$ of the HMIM solution is increased from 10 to 12 . However, the $\mathrm{pH}$ stability of AEM is between 2-10 and CEM is between 4-12.40 Therefore, IEMs were not acting as a selective membrane but a diffusion barrier. When $\mathrm{Zn}: \mathrm{HMIM}: \mathrm{NH}_{4}{ }^{+}$molar ratio is decreased to 1:2:32 from 1:2:64 in the synthesis solution, the $\mathrm{pH}=11.5$ remained high for the stability of the IEM, especially for AEM. Moreover, at $\mathrm{pH}=12, \mathrm{NH}_{4} \mathrm{OH}$ was in the form of $100 \%$ ammonia $\left(\mathrm{NH}_{3}\right.$ (aq.) $)$ and not $\mathrm{NH}_{4}{ }^{+} .{ }^{11}$ Here, the synthesis did not occur immediately. Some particle formation in the solution and the wall of the containers were observed. For CEM, homogenous thick white layers were formed on CEM. XRD results show that these particles are $\mathrm{Zn}(\mathrm{OH})_{2}$. For AEM, another phase was obtained for $72 \mathrm{~h}$ while no other peaks than the bare AEM were observed for $16 \mathrm{~h}$ and $24 \mathrm{~h}$. (Fig. S3.9-10)

\section{Without deprotonation agent}

In this part, aqueous ZIF-8 synthesis on CEM with excess use of HMIM (Zn:HMIM ratio of 1:20) has been tested. ZIF-8 film formation has not been observed on CEM. XRD results presenting the formation of $\mathrm{Zn}(\mathrm{OH})_{2}$ due to the hydrolysis of $\mathrm{Zn}$. (Fig. S3.11(a)) The peaks are very distinct in $16 \mathrm{~h}$ and $24 \mathrm{~h}$ samples. At C-W-72h sample, intensity decreased due to the possible detachment of the large crystal into the bulk from surface. When the powder has been stripped from the surface, the formation of $\mathrm{Zn}(\mathrm{OH})_{2}$ can be clearly seen from XRD results. (Fig. S3.11(b)) SEM images shows weblike structure on the Zn side and some crystal growth on the HMIM side. (Fig. S3.12) Homogenous $\mathrm{Zn}(\mathrm{OH})_{2}$ coating on the $\mathrm{Zn}$ side of CEMs are visually observed. During the synthesis, $\mathrm{pH}$ of HMIM solution stays constant ( $\mathrm{pH}=11$ ) indicating no consumption of HMIM. Aqueous synthesis with high Zn:HMIM molar ratio was also tested with AEM. After $16 \mathrm{~h}$ synthesis of crystallization, XRD patterns of A-W-16h is identical to the bare AEM. When the crystallization time increased to $24 \mathrm{~h}$ and $72 \mathrm{~h}$, only $\mathrm{Zn}(\mathrm{OH})_{2}$ has been deposited on the AEM surface. (Fig. S3.13) SEM images show that web-like 
structures are more clustered in this case on the Zn side of the AEM. (Fig. S3.14) At the HMIM side, beside the cracks occurred due to the drying, no formation has been observed. It is also important to note that using excessive HMIM alone increases the $\mathrm{pH}$ of the solution to 11.0 and AEM is not stable at this $\mathrm{pH}$.

\subsection{Discussion}

Our incentive is to control the transport of $\mathrm{Zn}$ ions by using CEM as a support and to form ZIF-8 locally in the HMIM side and the vice versa for the case of AEM. Exploring different synthesis conditions allow us to explain the complexity of transport mechanism. There is a summary of the main conclusions along with more detail discussion on transport mechanism and equilibrium.

(i) AEM vs. CEM - In this study, better control over the synthesis was achieved using AEMs compared to CEMs. In AEM, Zn cations are excluded by the membrane and in principle only neutral HMIM can permeate through (protonated HMIM $\left(\mathrm{H}_{2} \mathrm{MIM}^{+}\right)$is also excluded based on charge). In CEM, positively charged ions can permeate through the membrane while anions are rejected by the membrane. When CEMs were soaked in $\mathrm{Zn}^{2+}$ solution overnight prior to the synthesis, the ZIF-8 films were not formed. Since the pre-treatment is done in aqueous solution, ions are in a more favorable environment with the CEM vs. in the reservoirs when using methanol as the medium (due to the lower dielectric constant). Thus, during the synthesis, transport of positively charged ions was highly limited, since methanol is less favorable for charged species. If we look to the interface, the local concentration of $\mathrm{Zn}$ and positively charged HMIM $\left(\mathrm{H}_{2} \mathrm{MIM}^{+}\right)$would be much higher than the neutral (HMIM) when using a CEM that hinders the ZIF-8 formation. In the case of C-MeOH/W samples that soaked with methanol only. Here the ZIF-8 formation has been observed on the HMIM side of the membrane.

AEM samples are only soaked in the solvent used for metal solution as a pretreatment. For an $\mathrm{AEM} \mathrm{Zn}^{2+}$ transport is limited through the membrane while neutral HMIM transport is facilitated. Due to the jump on the Donnan equilibrium, at the interface 
of the AEM, the concentration of $\mathrm{Zn}^{2+}$ ions is reduced vs. the bulk concentration and thereby a high ratio of organic to metal is obtained near the AEM interface on the metal side. This is the desired condition for the ZIF-8 synthesis. Although the deprotonation of HMIM not be fully completed, in principle with an AEM this issue is also reduced as protonated HMIM $\left(\mathrm{H}_{2} \mathrm{MIM}^{+}\right)$is not favored to cross a positivelycharged membrane. When HMIM is neutral, the transport to the $\mathrm{Zn}^{2+}$ side is still possible driven by the chemical potential gradient (concentration gradient) between each reservoir. Use of a different organic ligand (negatively charged) than HMIM may ease the complexity of the transport of MOF reactants.

(ii) Methanol is a more favorable solvent than water for ZIF-8 synthesis - Both solvents are conventionally used for synthesis of ZIF-8 crystals. ${ }^{29,44}$ However, ZIF-8 film formation by using IEM in a diffusion cell is different than the bulk synthesis. Here, slower and more controlled transport is desired in order to obtain homogenous films. Long crystallization times have been chosen for this study, considering the slow kinetics across the membrane (due to the dense polymeric nature). This long synthesis time increases the influence of side reactions of $\mathrm{Zn}^{2+}$, e.g. hydrolysis of $\mathrm{Zn}^{2+}$ to $\mathrm{Zn}(\mathrm{OH})_{2}$ when water is chosen as a solvent for the $\mathrm{Zn}$ nitrate solution. ${ }^{31}$ We have observed formation of pure $\mathrm{Zn}(\mathrm{OH})_{2}$ or formation of both $\mathrm{Zn}(\mathrm{OH})_{2}$ and $\mathrm{ZIF}-8$ during this study. Beside Zn solution, HMIM also hydrolyzed and protonated in the aqueous solution. ${ }^{52}$ Methanol is a polar organic solvent with lower dielectric constant than water and the dissociation of the $\mathrm{Zn}$ ions is somewhat reduced ( $30 \%)$ compared to the water. This helps to obtain a lower metal/organic ligand ratio that is favorable for the ZIF-8 formation. Additionally, the IEM loses some degree of its charge-density but evidently this loss of Donnan exclusion is compensated by transport of more neutral HMIM or certainly through avoiding hydrolysis.

(iii) Limitations of IEMs - The $\mathrm{pH}$ stability of the IEMs used in this study was a limiting factor for the ZIF-8 film formation. Increasing the $\mathrm{pH}$ can potentially be beneficial for the aqueous ZIF-8 synthesis, as it would ensure deprotonation. However, it is not possible to go higher than $\mathrm{pH} 10$ and $\mathrm{pH} 12$ for AEM and CEM, respectively. It would 
be interesting to consider the use of more stable IEMs such as Fujifilm Type 10 or Fumasep ${ }^{\circ}$ IEMs with a wider range of working $\mathrm{pHs}$ for future synthesis strategies.

\subsection{Conclusion}

In this study, we have prepared ZIF-8 films on IEMs by controlling the selective transport of the reactants based on their charge. IEMs were used both as a dense polymeric support and selective ion facilitator for the control of the synthesis. We have tried different configurations with different solvents and conditions. The successful formation of pure ZIF-8 films has been achieved when methanol was used as a solvent for both metal and organic ligand source. The benefits of using methanol as a solvent for ZIF-8 film formation are: (i) slower transport due to low dielectric constant and (ii) prevention of the hydrolysis side reactions of $\mathrm{Zn}^{2+}$. When water is used as a solvent for the metal source, the side reactions and deposition of $\mathrm{Zn}(\mathrm{OH})_{2}$ is inevitable for both AEM and CEM. Suppressing the ionic dissociation and hydrolysis is only possible when methanol is used a solvent with lower dielectric constant. Our attempts to use a deprotonation agent (ammonium hydroxide) in aqueous synthesis, failed due to low $\mathrm{pH}$ stability of IEMs. Alternatively, using lower Zn/HMIM ratios $(1 / 20)$ in water has also ended as formation of $\mathrm{Zn}(\mathrm{OH})_{2}$. The transport mechanism also depends on Donnan exclusion. For the MOF film formation, it is desired to have a control over the concentrations of the reactants at the interface of the support. Therefore, IEMs are very attractive candidates to accommodate MOF films. Donnan exclusion creates an interface with counter-ions rich with exclusion of co-ions interface. Thus, lower Zn/HMIM interface locally can be obtained in the case of AEM. Our results also confirmed a better controlled of the ZIF-8 film formation on AEM than CEM when methanol is used as a solvent. ZIF-8 synthesis is more complex despite it is one of the most studied MOF. Deprotonation of the organic ligand, 2methylimidazole (HMIM) and the $\mathrm{Zn}(\mathrm{HMIM}) n^{+}(n=1-4)$ complexes, avoiding side reaction of the metal source, $\mathrm{Zn}^{2+}$, adjusting the $\mathrm{pH}$ of the solution and use of excess HMIM are some of the crucial parameters for the synthesis. Considering the complexity of ZIF-8 system, this concept can be applied to the synthesis of numerous 
different MOFs, potentially very advantageously in the case of MOFs with negatively charged organic ligands such as dicarboxylic acids, tricarboxylic acids and tetracarboxylic acids. These MOF films can be utilized in separation based applications to selectively tune the ion selectivity and modify the properties.

\section{Acknowledgements}

We would like to thank to Timon Rijnaarts for the useful discussions.

\section{References}

1

2

O. M. Yaghi and H. Li, J. Am. Chem. Soc., 1995, 117, 10401-10402.

O. M. Yaghi, M. O’Keeffe, N. W. Ockwig, H. K. Chae, M. Eddaoudi and J. Kim, Nature, 2003, 423, 705-714.

M. J. Rosseinsky, Microporous Mesoporous Mater., 2004, 73, 15-30.

S. Kitagawa, R. Kitaura and S. Noro, Angew. Chemie Int. Ed., 2004, 43, 23342375 .

J. L. C. Rowsell and O. M. Yaghi, Microporous Mesoporous Mater., 2004, 73, 314.

J. Liu and C. Wöll, Chem. Soc. Rev., 2017, 46, 5730-5770.

M. R. Abdul Hamid, S. Park, J. S. Kim, Y. M. Lee and H. K. Jeong, J. Mater. Chem. A, 2019, 7, 9680-9689.

M. Shah, H. T. Kwon, V. Tran, S. Sachdeva and H. K. Jeong, Microporous Mesoporous Mater., 2013, 165, 63-69.

C. Wang, T. Zheng, R. Luo, C. Liu, M. Zhang, J. Li, X. Sun, J. Shen, W. Han and L. Wang, ACS Appl. Mater. Interfaces, 2018, 10, 24164-24171.

Y. Sun, R. Zhang, C. Zhao, N. Wang, Y. Xie and J. R. Li, RSC Adv., 2014, 4, 3300733012.

N. T. Tran, J. Kim and M. R. Othman, Microporous Mesoporous Mater., 2019, 285, 178-184.

R. L. Papporello, E. E. Miró and J. M. Zamaro, Microporous Mesoporous Mater., 2015, 211, 64-72.

T. Tsuruoka, M. Kumano, K. Mantani, T. Matsuyama, A. Miyanaga, T. Ohhashi, 
Y. Takashima, H. Minami, T. Suzuki, K. Imagawa and K. Akamatsu, Cryst. Growth Des., 2016, 16, 2472-2476.

14 Y. Li, F. Liang, H. Bux, W. Yang and J. Caro, J. Memb. Sci., 2010, 354, 48-54.

15 A. R. Abbasi, K. Akhbari and A. Morsali, Ultrason. Sonochem., 2012, 19, 846852 .

16 S. Lawson, A. A. Rownaghi and F. Rezaei, Energy Technol., 2018, 6, 694-701.

17 J. Cookney, W. Ogieglo, P. Hrabanek, I. Vankelecom, V. Fila and N. E. Benes, Chem. Commun., 2014, 50, 11698-11700.

18 K. Tao, L. Cao, Y. Lin, C. Kong and L. Chen, J. Mater. Chem. A, 2013, 1, 1304613049.

19 Ö. H. Demirel, T. Rijnaarts, P. de Wit, J. A. Wood and N. E. Benes, J. Mater. Chem. A, 2019, 7, 12616-12626.

20 J. Yao, D. Dong, D. Li, L. He, G. Xu and H. Wang, Chem. Commun., 2011, 47, 2559.

21 C. Li, C. Hu, Y. Zhao, L. Song, J. Zhang, R. Huang and L. Qu, Carbon N. Y., 2014, 78, 231-242.

22 M. He, J. Yao, L. Li, Z. Zhong, F. Chen and H. Wang, Microporous Mesoporous Mater., 2013, 179, 10-16.

23 Y. Li, L. H. Wee, A. Volodin, J. A. Martens and I. F. J. Vankelecom, Chem. Commun., 2015, 51, 918-920.

24 Y. Li, L. H. Wee, J. A. Martens and I. F. J. Vankelecom, J. Memb. Sci., 2017, 523, 561-566.

25 B. P. Biswal, A. Bhaskar, R. Banerjee and U. K. Kharul, Nanoscale, 2015, 7, 72917298.

26 R. Ameloot, F. Vermoortele, W. Vanhove, M. B. J. Roeffaers, B. F. Sels and D.

E. De Vos, Nat. Chem., 2011, 3, 382-387.

27 B. Chen, Z. Yang, Y. Zhu and Y. Xia, J. Mater. Chem. A, 2014, 2, 16811-16831.

28 Z. Shi, Y. Yu, C. Fu, L. Wang and X. Li, RSC Adv., 2017, 7, $29227-29232$.

29 K. Kida, M. Okita, K. Fujita, S. Tanaka and Y. Miyake, CrystEngComm, 2013, 15, 1794.

30 H. Zhang, D. Liu, Y. Yao, B. Zhang and Y. S. Lin, J. Memb. Sci., 2015, 485, 103111. 
31 R. Wu, T. Fan, J. Chen and Y. Li, ACS Sustain. Chem. Eng., 2019, 7, 3632-3646.

32 J. Yao, M. He, K. Wang, R. Chen, Z. Zhong and H. Wang, CrystEngComm, 2013, 15, 3601-3606.

33 M. Malekmohammadi, S. Fatemi, M. Razavian and A. Nouralishahi, Solid State Sci., 2019, 91, 108-112.

34 H. T. Kwon and H. K. Jeong, J. Am. Chem. Soc., 2013, 135, 10763-10768.

35 A. J. Brown, N. A. Brunelli, K. Eum, F. Rashidi, J. R. Johnson, W. J. Koros, C. W. Jones and S. Nair, Science (80-. )., 2014, 345, 72-75.

36 Y. Li, L. H. Wee, A. Volodin, J. A. Martens and I. F. J. Vankelecom, Chem. Commun., 2015, 51, 918-920.

37 J. Li, Z. Zhao, S. Yuan, J. Zhu and B. Van der Bruggen, Appl. Sci., 2018, 8, 759.

38 H. Zhang, J. Hou, Y. Hu, P. Wang, R. Ou, L. Jiang, J. Z. Liu, B. D. Freeman, A. J. Hill and H. Wang, Sci. Adv., 2018, 4, eaaqoo66.

39 T. Sata, Ion Exchange Membranes Preparation, Characterization, Modification and Application, The Royal Society of Chemistry, 2004.

40 Sarapulova, Shkorkina, Mareev, Pismenskaya, Kononenko, Larchet, Dammak and Nikonenko, Membranes (Basel)., 2019, 9, 84.

41 T. Rijnaarts, D. M. Reurink, F. Radmanesh, W. M. de Vos and K. Nijmeijer, J. Memb. Sci., 2019, 570-571, 513-521.

42 S. A. Al-Baldawi, M. H. Brooker, T. E. Gough and D. E. Irish, Can. J. Chem., 1970, 48, 1202-1208.

43 K. Chrissopoulou and S. H. Anastasiadis, Eur. Polym. J., 2011, 47, 6oo-613.

44 J. Cravillon, S. Münzer, S.-J. Lohmeier, A. Feldhoff, K. Huber and M. Wiebcke, Chem. Mater., 2009, 21, 1410-1412.

45 S. Sachdeva, S. J. H. Koper, A. Sabetghadam, D. Soccol, D. J. Gravesteijn, F. Kapteijn, E. J. R. Sudhölter, J. Gascon and L. C. P. M. De Smet, ACS Appl. Mater. Interfaces, 2017, 9, 24926-24935.

46 I. Stassen, N. Campagnol, J. Fransaer, P. Vereecken, D. De Vos and R. Ameloot, CrystEngComm, 2013, 15, 9308.

47 D. Ghica, I. D. Vlaicu, M. Stefan, L. C. Nistor and S. V. Nistor, RSC Adv., 2016, 6, 106732-106741.

48 M. Ghaedi, H. Z. Khafri, A. Asfaram and A. Goudarzi, Spectrochim. Acta Part A 
Mol. Biomol. Spectrosc., 2016, 152, 233-240.

49 M. Wang, Y. Zhang, Y. Zhou, F. Yang, E. J. Kim, S. H. Hahn and S. G. Seong, CrystEngComm, 2013, 15, 754-763.

50 B. Chen, F. Bai, Y. Zhu and Y. Xia, Microporous Mesoporous Mater., 2014, 193, 7-14.

51 A. Kunz and S. Mukhtar, Eng. Agrícola, 2016, 36, 377-386.

52 M. Jian, B. Liu, R. Liu, J. Qu, H. Wang and X. Zhang, RSC Adv., 2015, 5, 4843348441 . 


\section{Supporting Information}

\section{Bare IEMs}
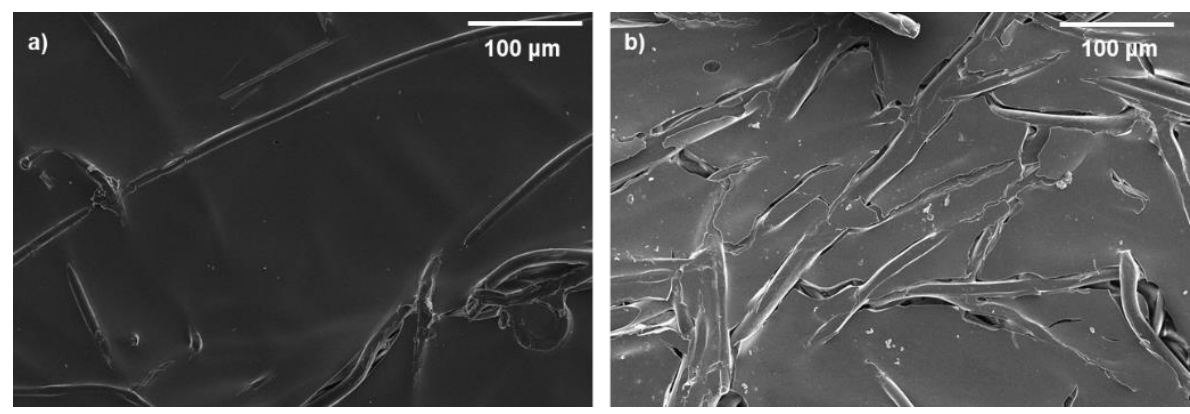

Figure S3.1 Top surface SEM images of Fujifilm Type I a) AEM and b) CEM.

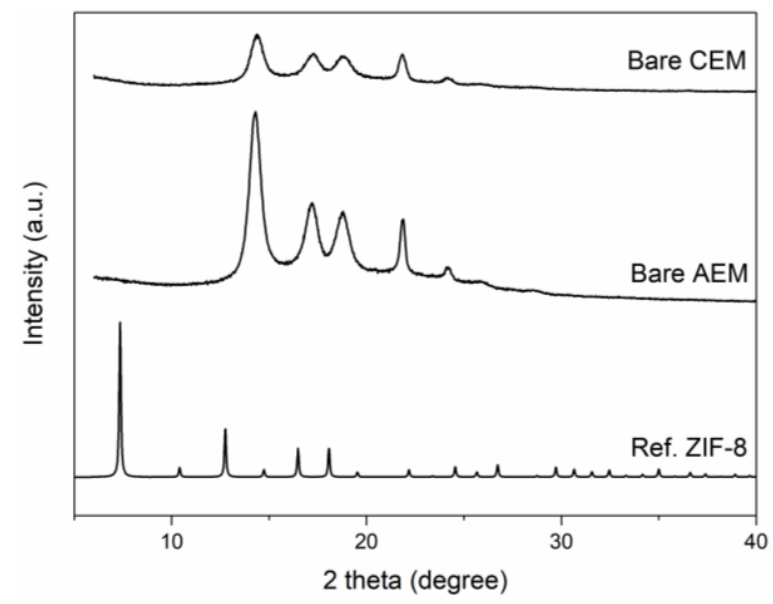

Figure S3.2 XRD patterns of reference ZIF-8 (CCDC 602542), Fujifilm Type 1 AEM and CEM. 
$16 \mathrm{~h}$

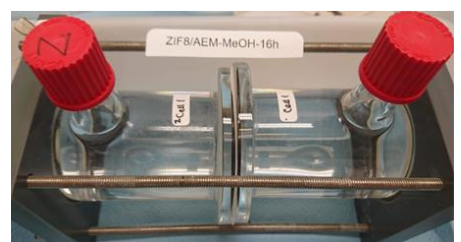

$24 h$

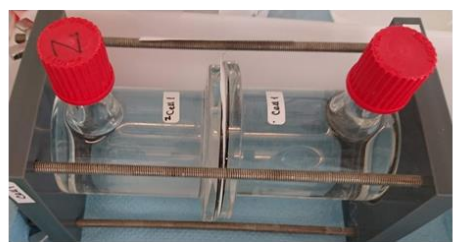

$72 \mathrm{~h}$

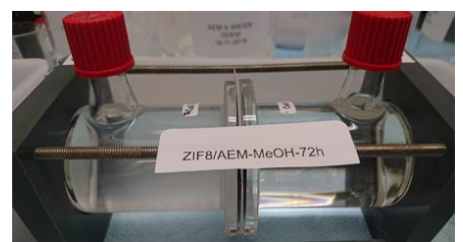

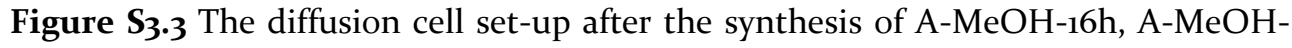
24h and A-MeOH-72h samples.
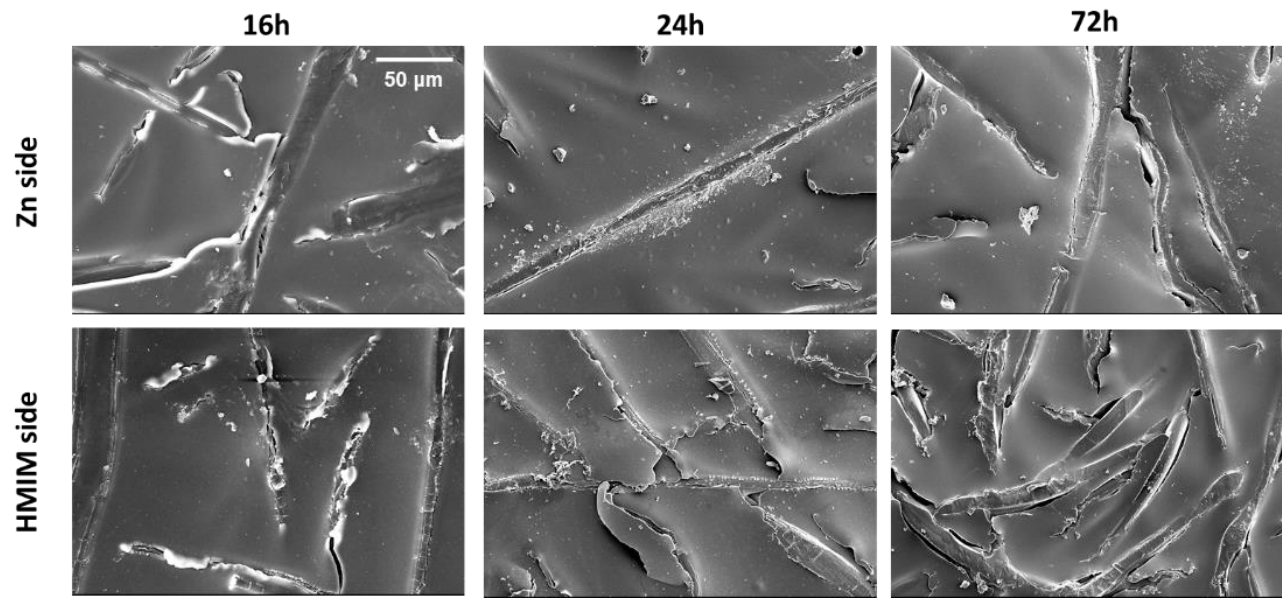

Figure S3.4 Top surface SEM images of the C-MeOH with different synthesis time. 


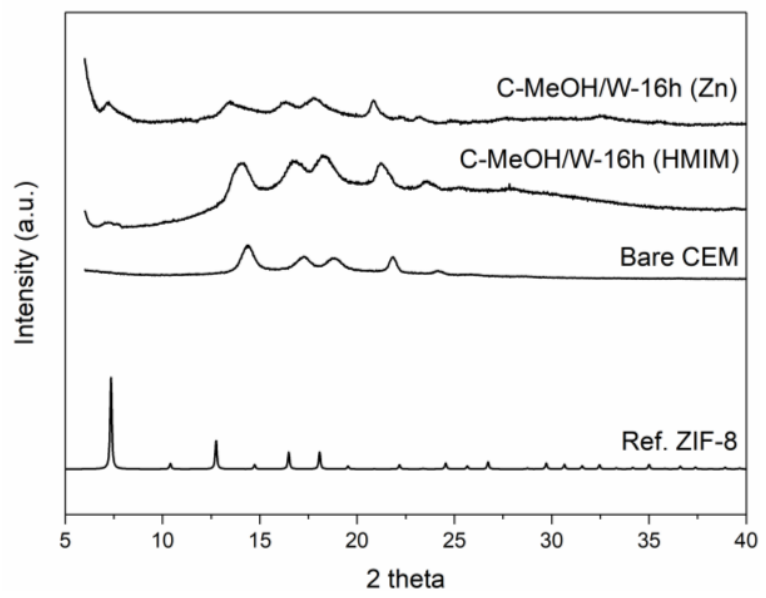

Figure S3.5 XRD patterns of C-MeOH/W-16h Zn side and HMIM side.

\section{Aqueous synthesis}

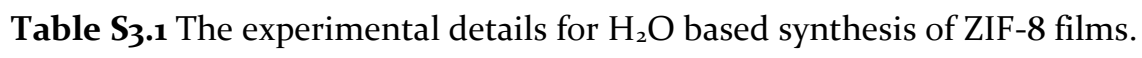

\begin{tabular}{|c|c|c|c|c|}
\hline Sample & IEM & $\begin{array}{c}\mathrm{Zn}: \mathrm{HMIM}: \mathrm{NH}_{4} \\
+\end{array}$ & $\begin{array}{c}\text { Solvent } \\
\text { (Zn/HMIM) }\end{array}$ & Pretreatment \\
\hline $\mathrm{C}-\mathrm{W} / \mathrm{NH}_{4}{ }^{+}-(\mathrm{X}) \mathrm{h}$ & AEM & $\begin{array}{l}1: 2: 64 \\
1: 2: 32\end{array}$ & $\mathrm{H}_{2} \mathrm{O} / \mathrm{H}_{2} \mathrm{O}-\mathrm{NH}_{4}^{+}$ & water \\
\hline $\mathrm{A}-\mathrm{W} / \mathrm{NH}_{4}{ }^{+}-(\mathrm{X}) \mathrm{h}$ & CEM & $\begin{array}{l}1: 2: 64 \\
1: 2: 32\end{array}$ & $\mathrm{H}_{2} \mathrm{O} / \mathrm{H}_{2} \mathrm{O}-\mathrm{NH}_{4}{ }^{+}$ & Water \\
\hline A-W-(X)h & AEM & 1:20:0 & $\mathrm{H}_{2} \mathrm{O}$ & $\begin{array}{c}0.025 \mathrm{M} \\
\mathrm{Zn}\left(\mathrm{NO}_{3}\right)_{2}\end{array}$ \\
\hline C-W-(X)h & CEM & 1:20:0 & $\mathrm{H}_{2} \mathrm{O}$ & $\begin{array}{c}0.025 \mathrm{M} \\
\mathrm{Zn}\left(\mathrm{NO}_{3}\right)_{2}\end{array}$ \\
\hline
\end{tabular}

$\mathrm{A}=\mathrm{AEM}, \mathrm{C}=\mathrm{CEM}, \mathrm{W}=\mathrm{H}_{2} \mathrm{O}, \mathrm{X}=$ synthesis time (16h, 24h, 72h) 
A-W/NH ${ }_{4}{ }^{+}-16 \mathrm{~h}$

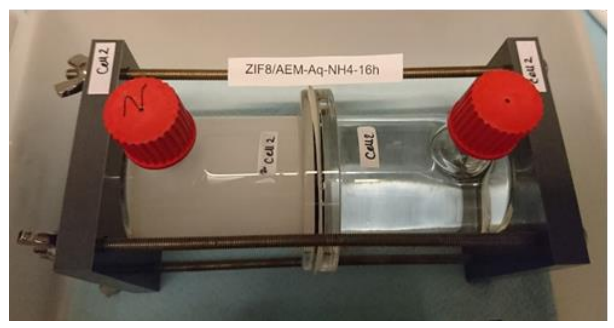

C-W/NH ${ }_{4}{ }^{+}-16 \mathrm{~h}$

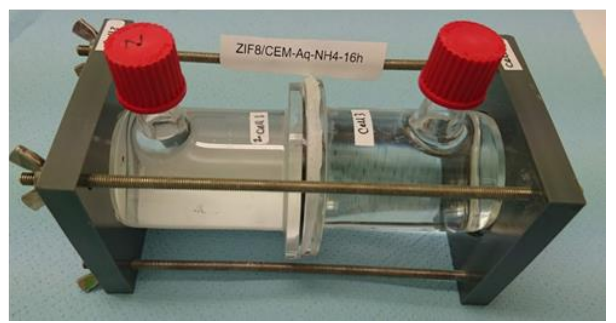

Figure S3.6 The diffusion cell set-up after the 10 min synthesis of $\mathrm{A}-\mathrm{W} / \mathrm{NH}_{4}{ }^{+}-16 \mathrm{~h}$ and C- W/ $\mathrm{NH}_{4}{ }^{+}-16 \mathrm{~h}$ samples. Zn:HMIM: $\mathrm{NH}_{4}{ }^{+}$ratio of 1:2:64

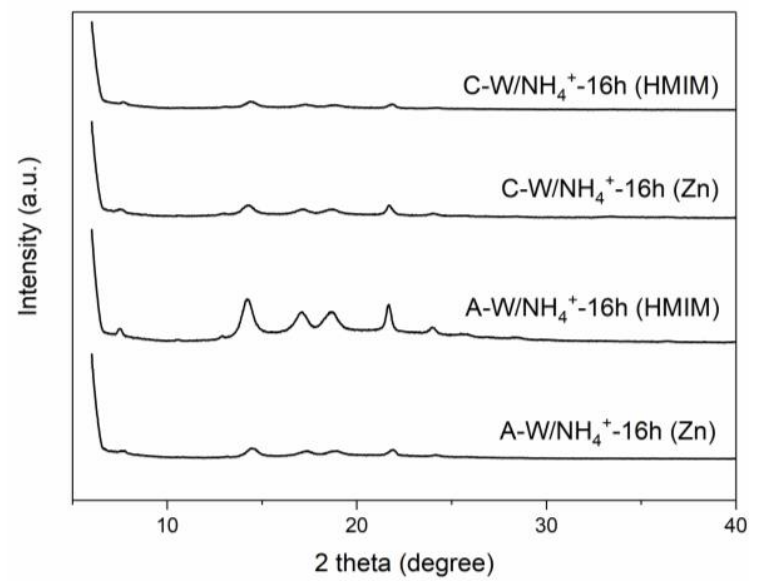

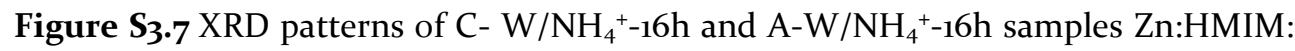
$\mathrm{NH}_{4}{ }^{+}$ratio of 1:2:64. 


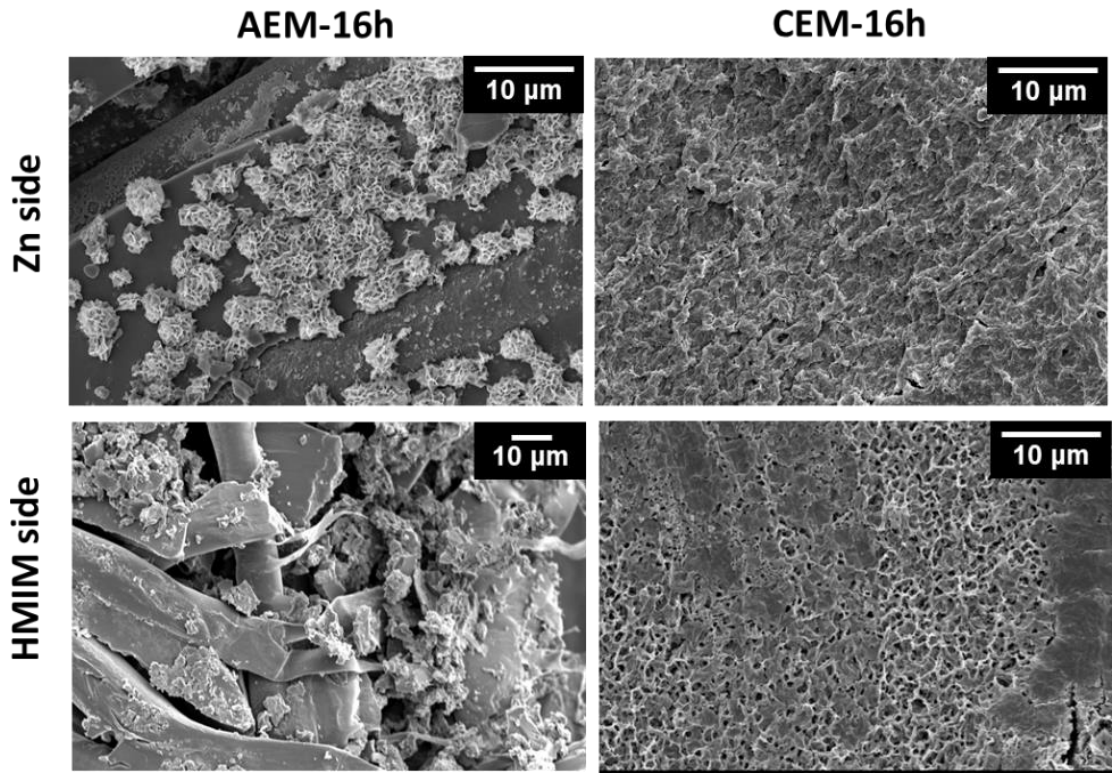

Figure S3.8 SEM images of C-W/ $\mathrm{NH}_{4}{ }^{+}-16 \mathrm{~h}$ and $\mathrm{A}-\mathrm{W} / \mathrm{NH}_{4}{ }^{+}-16 \mathrm{~h}$ samples. Both $\mathrm{Zn}$ and HMIM side with Zn:HMIM: $\mathrm{NH}_{4}{ }^{+}$ratio of 1:2:64.

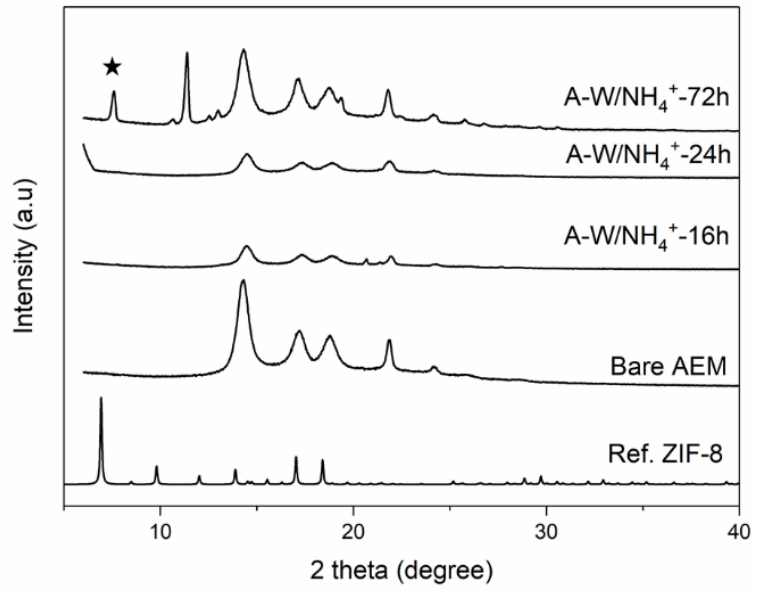

Figure S3.9 XRD patterns of A-W/ $\mathrm{NH}_{4}{ }^{+}-16 \mathrm{~h}, \mathrm{~A}-\mathrm{W} / \mathrm{NH}_{4}{ }^{+}-24 \mathrm{~h}$ and $\mathrm{A}-\mathrm{W} / \mathrm{NH}_{4}{ }^{+}-72 \mathrm{~h}$ samples with $\mathrm{Zn}: \mathrm{HMIM}: \mathrm{NH}_{4}{ }^{+}$ratio of 1:2:32. 

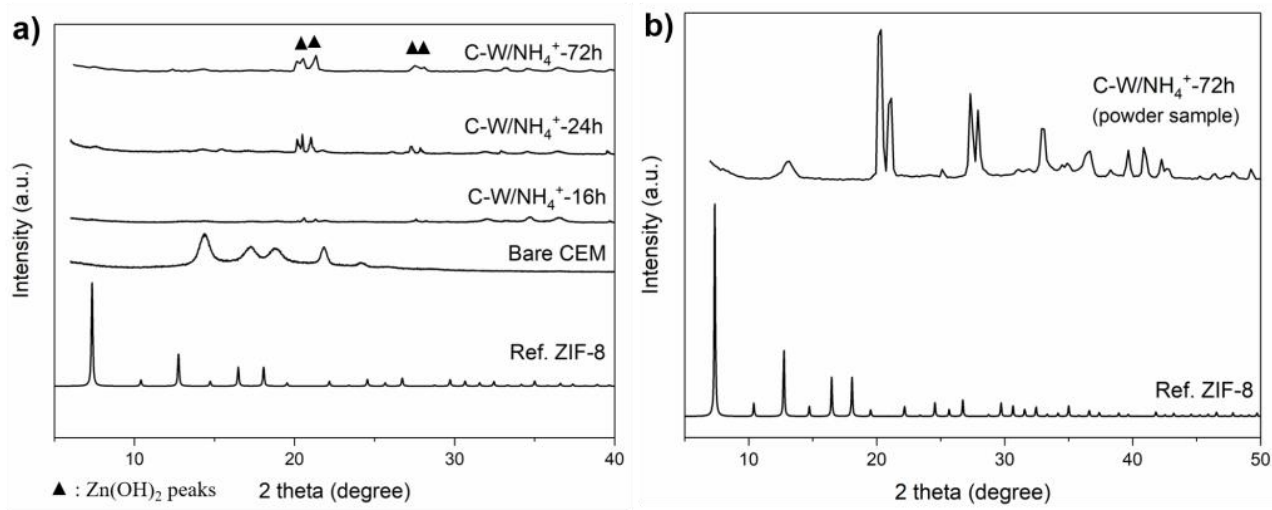

Figure S3.10 XRD patterns of a) $\mathrm{C}-\mathrm{W} / \mathrm{NH}_{4}{ }^{+}$samples with different synthesis times and b) powder stripped from C-W/ $\mathrm{NH}_{4}{ }^{+}-72 \mathrm{~h}$. $\mathrm{Zn}$ :HMIM: $\mathrm{NH}_{4}{ }^{+}$ratio of 1:2:32.
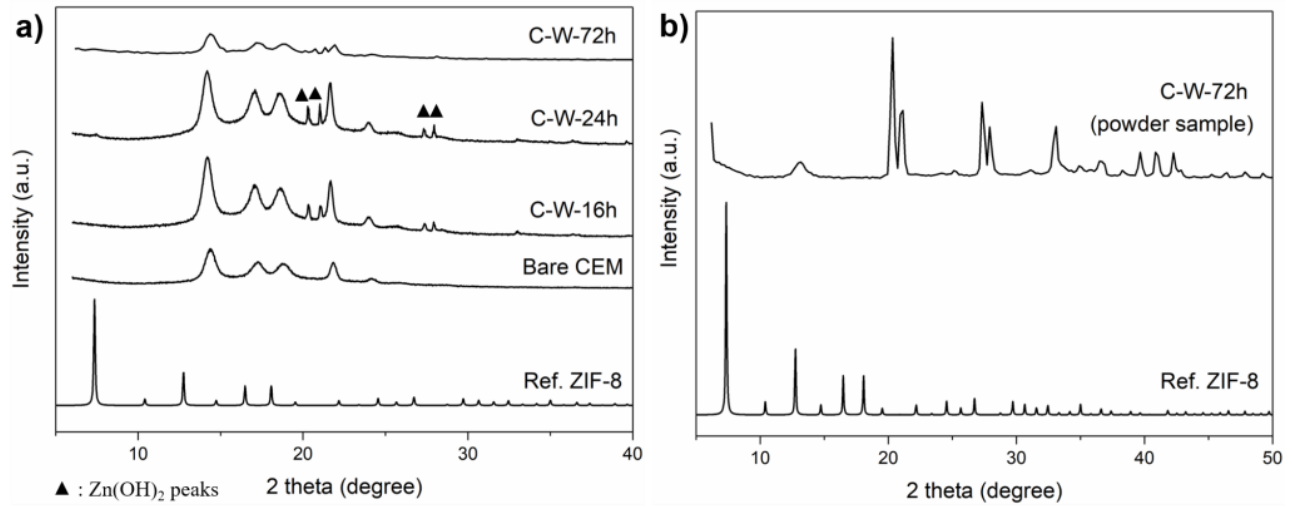

Figure S3.11 XRD patterns of ZIF-8 films a) C-W samples at different synthesis time b) powder stripped from C-W-72h. (Zn:HMIM 1:20) 

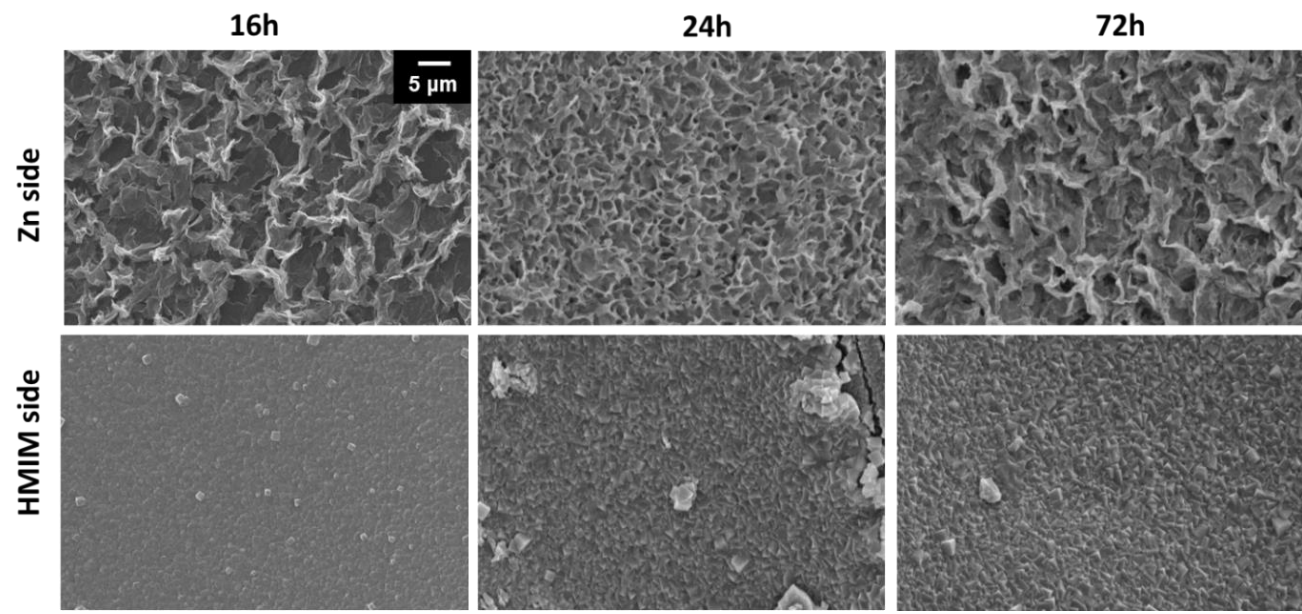

Figure S3.12 Top surface SEM images of C-W with different synthesis times. Zn:HMIM molar ratio of 1:20.

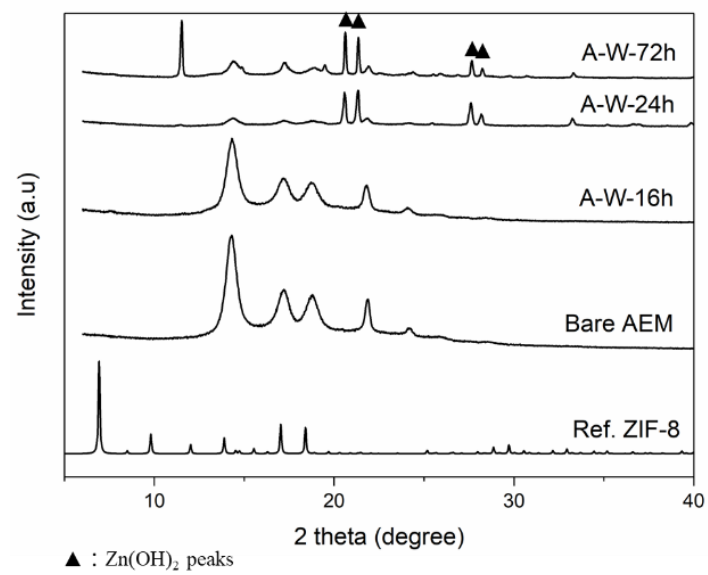

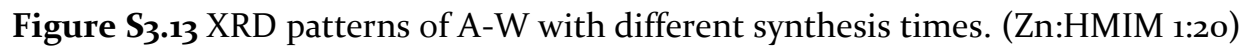



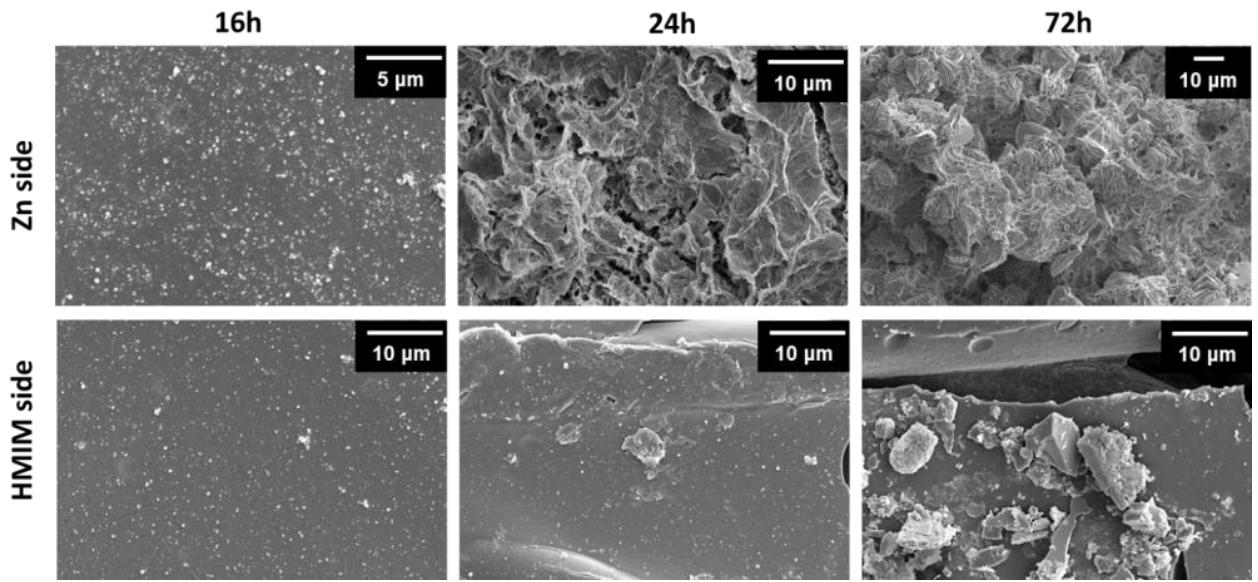

Figure S3.14 Top surface SEM images of A-W with different synthesis times. Zn:HMIM molar ratio of 1:20. 


\section{CHAPTER 4}

\section{Thermal evolution of polymeric gas}

\section{separation membranes with embedded}

\section{Metal Organic Frameworks}

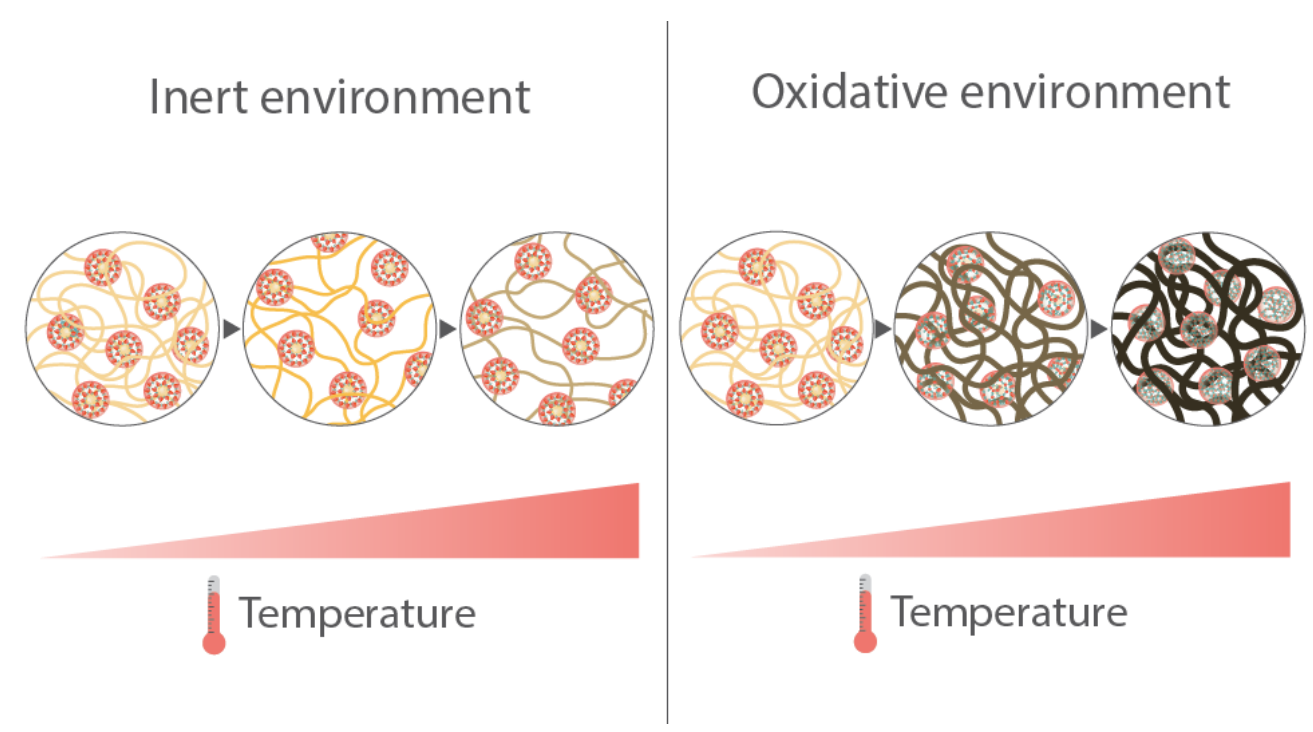

This chapter is adapted from:

Ayşe Kılıç̌, Özlem H. Demirel, Göktuğ Ahunbay, Nieck E. Benes, S. Birgül Tantekin-Ersolmaz, Thermal evolution of polymeric gas separation membranes with embedded Metal Organic Frameworks, Manuscript in preparation. 


\section{Abstract}

Polymeric gas separation membranes suffer from a trade-off between permeability and selectivity, as one increases, the other decreases. Plasticization also diminishes the performance of these membranes at elevated $\mathrm{CO}_{2}$ pressures. In order to improve these challenges many attempts have been developed especially through material science. In this study, dispersion of as-synthesized MOF fillers in the polymer matrix and post-thermal treatments have been combined to address these issues and gas separation performances of these membranes have been investigated. For this, a highly permeable polymer, 6FDA-DAM, and three different metal organic frameworks (MOFs) (ZIF-8, sod-ZMOF, $\mathrm{K}^{+}$sod-ZMOF) have been selected. The employed thermal treatment protocols are based on the boiling point of the solvent and the glass transition temperature $\left(T_{\mathrm{g}}\right)$ of the polymer, and involve inert (nitrogen) or oxidative (air) conditions. For the pure polymer membranes, the thermal treatment above the $T_{\mathrm{g}}$ under nitrogen mainly causes physical changes in free volume of the polymer and results in a permeability increase, shifting the performance to close to the latest upper bound. The thermal treatments in air cause oxidation phenomena, possibly combined with crosslinking, leading to amplified selectivity values and drastic decreases in permeability. For the mixed matrix membranes (MMMs) the performance is in general lower than that of the pure polymer membranes. Only after heat treatment in air at $315^{\circ} \mathrm{C}$ superior performances of MMMs as compared to the pure polymer membrane are observed. These improved performances are attribute to possible amorphization and oxidation of the MOF, and to enhanced interactions at the interface between the MOF particles and the polymer. The results indicate that well designed thermal treatment strategies can aid performance improvement of gas separation membranes. 


\subsection{Introduction}

$\mathrm{CO}_{2}$ separation from industrially important gas mixtures, such as natural gas, flue gas, and synthesis gas, is an urgent environmental and economic issue. ${ }^{1}$ In industry, membranes used for $\mathrm{CO}_{2}$ removal are commonly polymer-based, as these can be produced inexpensively on a large scale and have suitable properties. However, their separation performance is usually limited by a trade-off between permeability and selectivity. ${ }^{2-5}$ In addition they have a tendency to plasticize under high feed pressures of highly soluble components, such as $\mathrm{CO}_{2}$. Several techniques have been suggested to mitigate these drawbacks, such as polymer blending and thermal treatment. ${ }^{6}$ Thermal treatment can strongly affect the properties and separation performance of the membranes. Carbonization, annealing and quenching are the common thermal processes for polymeric membranes and each leads to different consequences for the transport phenomena in the membrane..$^{7-10}$ Due to the molecular rearrangement of the polymer chains, via controlled thermal treatment, the free-volume and packing density within the polymer matrix can be modified and this may lead to improvement in permeability and/or selectivity of the polymeric membranes. Moreover, chemical crosslinking may take place during the thermal treatment, which is an effective method to improve the plasticization resistance of polymeric membranes as well as to increase thermal and chemical stability ${ }^{6,10-12}$

Mixed matrix membranes (MMMs), produced by incorporating filler particles into the polymer matrix, are also promising to provide a solution to surpass the Robeson upper-bound. Here the aim is to combine the processability and mechanical stability of polymers and superior separation performance of fillers to achieve better membranes. ${ }^{2,13,14}$ Fillers reported for MMM fabrication include zeolites ${ }^{15}$, silicas ${ }^{16}$, carbon nanotubes ${ }^{17}$, carbon molecular sieves ${ }^{18}$ and metal-organic frameworks (MOFs). ${ }^{19}$ MOFs can be considered particularly attractive as their organic linkers have affinity with the polymer chains ${ }^{20-22}$, offering a good compatibility between the dispersed and continuous phases. ${ }^{23}$ They also have some unique features, such as tunable chemistry and pore structure, further aiding their potential for gas separation 
applications. ${ }^{24,25}$ Numerous studies has been reported in the literature on MOF-based MMMs for separation of several gas pairs.,14,20,26,27

Zeolitic imidazolate frameworks (ZIFs) are a sub-family of MOFs that have attracted a great deal of attention as fillers in MMMs, because of their molecular sieving properties and excellent chemical and thermal stability. ${ }^{2,28,29}$ Especially ZIF-8 is extensively studied in literature on MOF based mixed-matrix gas separation membranes. ${ }^{13,27}$ Zeolite-like metal-organic frameworks (ZMOFs) are another subset of MOFs having the same similarity to zeolite frameworks as ZIFs, but have an anionic framework with charge-compensating cations as counterions. These counterions may enhance host-guest interactions with specific gas molecules, and hence ion-exchange using alkali metal ions may enable tuning the of their adsorption properties. ${ }^{22,25,30}$ Unlike ZIFs, there is limited number of studies on ZMOF-based MMMs. ${ }^{22,25}$

This study investigates the effects of thermal treatment of 6FDA-DAM-based MMMs, in inert and oxidative environments, on $\mathrm{CO}_{2}$ separation performance. The aim is to identify the underlying structure-performance relationships. Therefore, the effects of thermal treatments of 6FDA-DAM membranes and derived MMMs with three different embedded MOFs have been examined via materials characterization and gas separation studies. 6FDA-DAM has been selected from numerous polyimides because it is commonly regarded as a high-potential material for natural gas purification. It has good intrinsic $\mathrm{CO}_{2} / \mathrm{CH}_{4}$ separation properties, high chemical and thermal stability, and high mechanical strength under aggressive feed gas conditions. ${ }^{11}$ In particular, the bulky $-\mathrm{CF}_{3}$ groups in this polymer promote a high free volume, ${ }^{5}$ and their affinity towards $\mathrm{CO}_{2}$ further amplifies $\mathrm{CO}_{2}$ transport. ${ }^{31} \mathrm{ZIF}-8$ has been selected because it has previously been shown that, when embedded in a Matrimid ${ }^{\circ}$, in-situ amorphization of this MOF is possible by thermal treatment in air. ${ }^{2}$ Kertik et al. reported remarkably high $\mathrm{CO}_{2} / \mathrm{CH}_{4}$ selectivities that have been attributed to changes in the polymer characteristics and the MOF transformation. Recently, in situ fabrication of glassy ZIF-62/6FDA-DAM composites have been reported. ${ }^{32}$ The increase in the selectivity was explained due to the healing defects via the interactions between melted ZIF and polymer. We propose to extend this new concept to the 
highly permeable polyimide 6FDA-DAM with three different MMM systems. ${ }^{33}$ In addition, the anionic indium-based sodalite-cage framework sod-ZMOF with imidazolium as a counter-ion, and its $\mathrm{K}^{+}$ion-exchanged form ( $\mathrm{K}^{+}$sod-ZMOF), have been selected. A previous simulation study suggests that competitive adsorption of $\mathrm{CO}_{2}$ over $\mathrm{CH}_{4}$ takes place in sod-ZMOF, and ion-exchanging with $\mathrm{K}^{+}$might cause a further increase in its $\mathrm{CO}_{2} / \mathrm{CH}_{4}$ separation performance. ${ }^{34}$ To the best of our knowledge, this is the first study in which $\mathrm{K}^{+}$sod-ZMOF is used as a filler in a gas separation membrane.

\subsection{Experimental section}

\subsubsection{Materials}

For the ZIF-8 synthesis, the metal source zinc nitrate hexahydrate and the organic linker 2-methylimidazole were purchased from Sigma Aldrich, with a purity of $\geq 99.0 \%$. For membrane preparation, $\mathrm{N}, \mathrm{N}$-dimethyl formamide (DMF) was purchased from Merck with a purity of $\geq 99.8 \%$. 6FDA-DAM polymer has been synthesized by MEMASEP group, ITU. Nano size sod-ZMOF and $\mathrm{K}^{+}$sod-ZMOF with particle size of $\sim 200 \mathrm{~nm}$ were kindly provided by KAUST. ${ }^{22}$

\subsubsection{ZIF-8 synthesis}

ZIF-8 was synthesized by following the procedure of Cravillion et al.35 As a metal source, zinc nitrate hexahydrate $9.9 \mathrm{mmol} \mathrm{Zn}\left(\mathrm{NO}_{3}\right)_{2} \cdot 6 \mathrm{H}_{2} \mathrm{O}$ (Sigma Aldrich, with a purity of $\geq 99.0 \%$ ) and as an organic linker, $79.1 \mathrm{mmol}$ 2-methylimidazole (SigmaAldrich, with a purity of $\geq 99.0 \%$ ) solutions were prepared in methanol (SigmaAldrich, with a purity of $99.8 \%$ ). Metal source and organic linker solutions were mixed and stirred for one hour at ambient conditions. Synthesized ZIF-8 crystals were removed by centrifuge at 6000 rpm and washed with methanol three times. After the evaporation of methanol overnight, the crystals were dried at $40^{\circ} \mathrm{C}$ in the oven for one day. The average size of the ZIF-8 crystals was $\sim 200 \mathrm{~nm}$. 


\subsubsection{Mixed matrix membrane preparation}

Prior to membrane preparation, both polymer and MOFs were dried overnight at 120 ${ }^{\circ} \mathrm{C}$ under vacuum. MMM films containing $20 \mathrm{wt} \%$ MOF were prepared with the conventional solution-casting technique..$^{36}$ The MOF loading was calculated as below:

$$
\text { Loading } w \mathrm{t} \%=100 *\left[w t_{\mathrm{MOF}} /\left(w t_{\mathrm{MOF}}+w t_{\mathrm{polymer}}\right)\right]
$$

After the prescribed amount of MOF particles were added in dimethylformamide (DMF), the suspension was mixed overnight with a magnetic stirrer. Then, the mixture was sonicated for $1 \mathrm{~h}$ to promote a good dispersion of the crystals. A wellestablished priming method for zeolites and MOFs based MMMs was implemented by adding $10 \mathrm{wt} \%$ of total required quantity of polymer in order to produce MOF particles coated with a thin layer of polymer which is thought to improve the polymer/filler interface and prevent agglomeration of filler. 37,38 After mixing the solution overnight on a magnetic stirrer and performing five cycles of stirring and sonication 10 minutes each, the remaining polymer was added to the suspension gradually as 4 equal portions. The suspension was prepared with a 15/85 polymer/solvent ratio. After the last portion of polymer was added, the film solution was allowed to stir for another night and was cast on a glass plate using a casting knife, with an initial thickness of $700 \mu \mathrm{m}$. The plate was placed in an oven at $80{ }^{\circ} \mathrm{C}$ and approximately three hours later the film was peeled off from the glass and kept in the oven at $100{ }^{\circ} \mathrm{C}$ overnight. Then it was heated to $130^{\circ} \mathrm{C}$ with $1{ }^{\circ} \mathrm{C} \mathrm{min}^{-1}$ heating rate and further annealed at this temperature for $72 \mathrm{~h}$ under vacuum to remove the residual solvent.

\subsubsection{Thermal annealing procedure}

The thermal treatment of the pure polymeric and mixed matrix membranes was carried out following the study of Kertik et al. ${ }^{2}$ Final thermal treatment temperatures were set considering the glass transition temperature $\left(T_{\mathrm{g}}\right)$ of the polymer and the boiling temperature of the solvent (DMF) used in the MMM preparation: $160{ }^{\circ} \mathrm{C}$ - 
above the boiling point of the solvent, at $315^{\circ} \mathrm{C}$ - below the $T_{\mathrm{g}}$ of the polymer and at $400{ }^{\circ} \mathrm{C}$ - just above the $T_{\mathrm{g}}$ of the polymer (Table $\mathrm{S}_{4.1}$ ). After fast initial heating from room temperature to $85^{\circ} \mathrm{C}$, the samples were heated with sequential heating steps (heating rates $1^{\circ} \mathrm{C} \mathrm{min}^{-1}$, followed by 2 -hour isothermal dwell at every $\sim 60^{\circ}$ interval steps) to the final temperature as it can be seen in Fig.4.1. After dwelling 24 hours at the final temperature, the samples were cooled down to room temperature slowly inside the switched-off furnace; or quenched by taking the samples out of the furnace and cooling in open air. For labeling the membrane samples in the rest of the paper, thermal treatment temperature and annealing condition (air or $\mathrm{N}_{2}$ ) are added in front of the membrane name e.g. 16o-air-ZIF_MMM. When the sample is quenched, "Q" is added after the annealing condition.

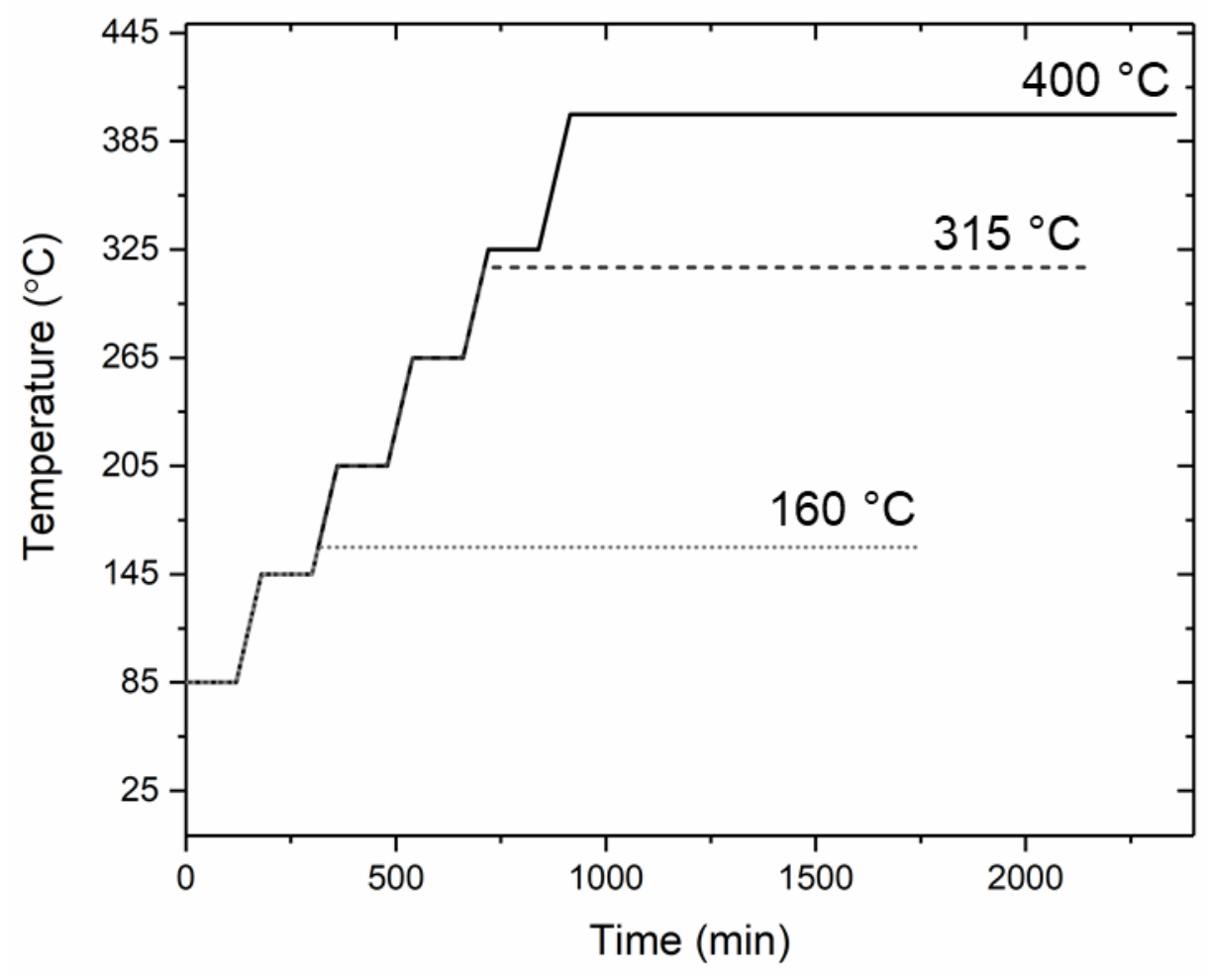

Figure 4.1 Thermal treatment programs of the membranes at 160 , 315 and $400{ }^{\circ} \mathrm{C}$. 


\subsubsection{Characterization}

The XRD patterns of the membranes and MOF crystals were determined by powder $\mathrm{X}$-ray diffraction (XRD) on a Bruker D2 PHASER operated at $10 \mathrm{~mA}$ and $30 \mathrm{kV}$ using a $\mathrm{CuK} \alpha$ source with a wavelength $(\lambda)^{1 / 2} 1.54 \AA$ at room temperature. Scans were carried out at variable angles, ranging from 5 to $80^{\circ}$ with a $2 \theta$ step size of $0.2^{\circ}$ and a scan speed of $1 \mathrm{~s}$ per step. SEM analyses were carried out using a JEOL JSM-6oioLA instrument. Membrane cross-sections were exposed by breaking the samples cryogenically in liquid nitrogen. The samples were attached on a sample holder with an adhesive carbon foil and coated with Chromium, to prevent charging of the samples. A Quorum Q150T ES sputter coater was used for coating. Samples were then characterized under high vacuum at an accelerating voltage of $5 \mathrm{kV}$. The thickness of the membranes was also confirmed by SEM images.

Thermogravimetric analyses (TGA) of the powder materials used in MMM preparation were performed using a STA $449 \mathrm{~F}_{3}$ Jupiter (Netzch). Measurements were performed under $70 \mathrm{~mL} \mathrm{~min}^{-1}$ air flow $\left(56 \mathrm{~mL} \mathrm{~min}^{-1} \mathrm{~N}_{2}\right.$ and $14 \mathrm{~mL} \mathrm{~min}^{-1} \mathrm{O}_{2}$ ) and at a heating rate of $5^{\circ} \mathrm{C} \mathrm{min}^{-1}$, starting from $35^{\circ} \mathrm{C}$ up to $800{ }^{\circ} \mathrm{C}$. Temperature correction with the melting point standard and a blank correction with an empty cup were carried out prior to the measurements. The initial sample mass was determined at the weighing scale prior to the measurements. Gases evolving during the thermogravimetric analysis were transferred to a mass spectrometer (MS, QMS 403 D Aëolos ${ }^{\circ}$, Netzsch) by a glass capillary. TGA and MS start times were synchronized; no correction was applied for the time offset caused by the transfer line time (estimated < $30 \mathrm{~s}$, systematic offset). A bar graph scan for $m / \mathrm{z}^{1 / 4} 1-100$ amu was performed to determine the evolving $\mathrm{m} / \mathrm{z}$ numbers. FTIR-ATR spectra were recorded on an ALPHA spectrometer equipped with an ATR platinum diamond crystal (Bruker, Germany) at a resolution of $4 \mathrm{~cm}^{-1}$. Spectra were averaged over the co-addition of 32 scans for each sample in the spectral range of $4000-400 \mathrm{~cm}^{-1}$. Prior to the measurements, a background spectrum was recorded at ambient conditions. Solubility tests were performed on all thermally treated membranes by keeping them in chloroform for three days to confirm the crosslinking of polymers after thermal treatment. 
Thin film polymer samples for the ellipsometry experiments were prepared using 5 wt\% solutions of 6FDA-DAM in DMF. The solutions were spin coated (Laurell WS40oB-6NPP-Lite spin coater) on a silicon wafer with a native oxide: $\sim 0.4 \mathrm{~mL}$ polymer solution was injected on the silicon wafer followed by rotating at $500 \mathrm{rpm}$ for $10 \mathrm{~s}$ (acceleration $228 \mathrm{rpm} \mathrm{s}^{-1}$ ) and then spinning at $3000 \mathrm{rpm}$ for 1 minute (acceleration $1710 \mathrm{rpm} \mathrm{s}^{-1}$ ). After spin coating, the samples were dried at $130{ }^{\circ} \mathrm{C}$ under vacuum for overnight prior to the ellipsometry measurements. The thicknesses of the polymer films were between 100-150 nm. ${ }^{39}$ Spectroscopic ellipsometer M-20ooX (J.A. Woollam Co., Inc.) equipped with a Linkam heating stage with quartz windows was used to measure temperature dependent thickness and refractive index of the spin-coated

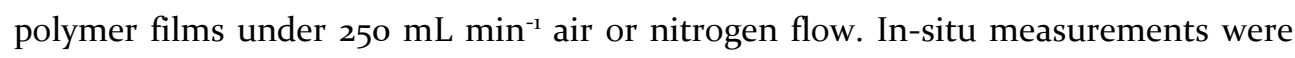
performed with light reflected at $70^{\circ}$ angle of incidence. The Complete EASE v.4.64 software package (J.A. Woollam Co., Inc.) was used to model the data in the wavelength of 370-1000 nm. 6FDA-DAM films were modelled with Cauchy dispersion (fit parameters: thickness, $A, B$ ) using the built-in temperature-dependent optical properties of silicon wafer as a substrate. Dried spin-coated polymer films were heated to $200{ }^{\circ} \mathrm{C}$ with a heating rate of $5^{\circ} \mathrm{C} \mathrm{min}^{-1}$ and held at this temperature for $1 \mathrm{~h}$ followed by heating to $450{ }^{\circ} \mathrm{C}$ with $5{ }^{\circ} \mathrm{C} \mathrm{min}^{-1}$ increment. After this step, two different cooling steps were used to represent the thermal treatments of 6FDA-DAM membranes: Quenched samples were cooled down with a heating rate of $25{ }^{\circ} \mathrm{C} \mathrm{min}^{-1}$ and others were cooled down with a heating rate of $5{ }^{\circ} \mathrm{C} \mathrm{min}^{-1}$.

\subsubsection{Gas separation measurements}

A custom-built high-pressure gas permeation setup was used for both single gas and mixed gas permeation experiments using a constant volume - variable pressure method, with vacuum at the permeate side. Each membrane was evacuated for $2 \mathrm{~h}$ after which it was placed into the stainless-steel cell and the desired feed pressure was applied at the top side of the membrane. The gas permeability values were calculated from the steady state pressure increase with time in a well calibrated volume at the permeate side. All measurements were performed at a constant temperature of $35^{\circ} \mathrm{C}$. 
While single gas measurements $\left(\mathrm{CO}_{2}, \mathrm{~N}_{2}, \mathrm{CH}_{4}\right.$ and $\left.\mathrm{He}\right)$ were performed at 4 bar transmembrane pressure, a 50:50 $\mathrm{CO}_{2}: \mathrm{CH}_{4}$ mixture was used to investigate the membrane performance under high pressure mixed gas conditions (up to 40 bar total feed pressure).

\subsection{Results and discussion}

In this study, we aim to explore the effect of the thermal evolution of the MOF embedded polymeric gas separation membranes. First, gas separation performances and materials characteristics of pure polymeric membranes that have undergone different thermal treatments are reported. Subsequently, results are presented for MMMs. To aid readability, the materials characterization results for the polymer and the MOFs can be found in Supporting Information (Fig. S4.1-4.8).

\subsubsection{Pure polymeric membranes}

\section{Gas transport results}

The $\mathrm{CO}_{2} / \mathrm{CH}_{4}$ gas mixture separation performances of pure 6FDA-DAM membranes are summarized in Figure 4.2 together with corresponding Robeson trade-off curves. All of the measured single and mixed gas permeability values are listed in Table S4.2. The membranes annealed at $160{ }^{\circ} \mathrm{C}$ (160-air-6FDA-DAM) are considered as the benchmark for comparison with membranes annealed at higher temperatures. The $\mathrm{CO}_{2}$ permeability of the pure 6FDA-DAM is 406 Barrer, which agrees well with the result (390 Barrer) reported by Bae et al. ${ }^{20}$ As separation properties are affected by several parameters, such as the molecular weight of the polymer, the solvent used for film preparation, drying temperature, measurement conditions, etc., a wide range of permeability values varying between 20 and 1000 Barrer have also been reported in different studies. ${ }^{40-42}$

Heating to just below the $T_{\mathrm{g}}$ in inert environment followed by slow cooling $\left(315-\mathrm{N}_{2}-\right.$ 6FDA-DAM) does not substantially affect the gas separation performance of the pure 
polymeric membrane, as can be seen in Figure 4.2. At temperatures below the $T_{\mathrm{g}}$, the polymer chain dynamics are too slow to allow the polymer to approach its thermodynamic equilibrium state within the timescale of the experiment. As a consequence, the non-equilibrium characteristics of the polymer, manifested by the excess free volume (EFV), are not affected by the imposed thermal treatment and the membrane performance is not changed. In contrast, when a similar thermal treatment is conducted under oxidative environment (315-air-6FDA-DAM) a substantial decrease in single gas permeabilities is observed, while the ideal $\mathrm{CO}_{2} / \mathrm{N}_{2}$ selectivity remains relatively unaffected (Table $\mathrm{S}_{4.2}$ ). The reduced permeability is not likely to be due to a reduced excess free volume, as the supplied thermal energy is comparable to that during the experiment under inert conditions. It is more likely to originate from some oxidation of the polymer. The combination of a reduction in permeability and a persisting selectivity may be explained by a very low permeability of the oxidized localities within the polymer, effectively no longer contributing to gas permeance, whereas unaffected regions maintain their properties. 


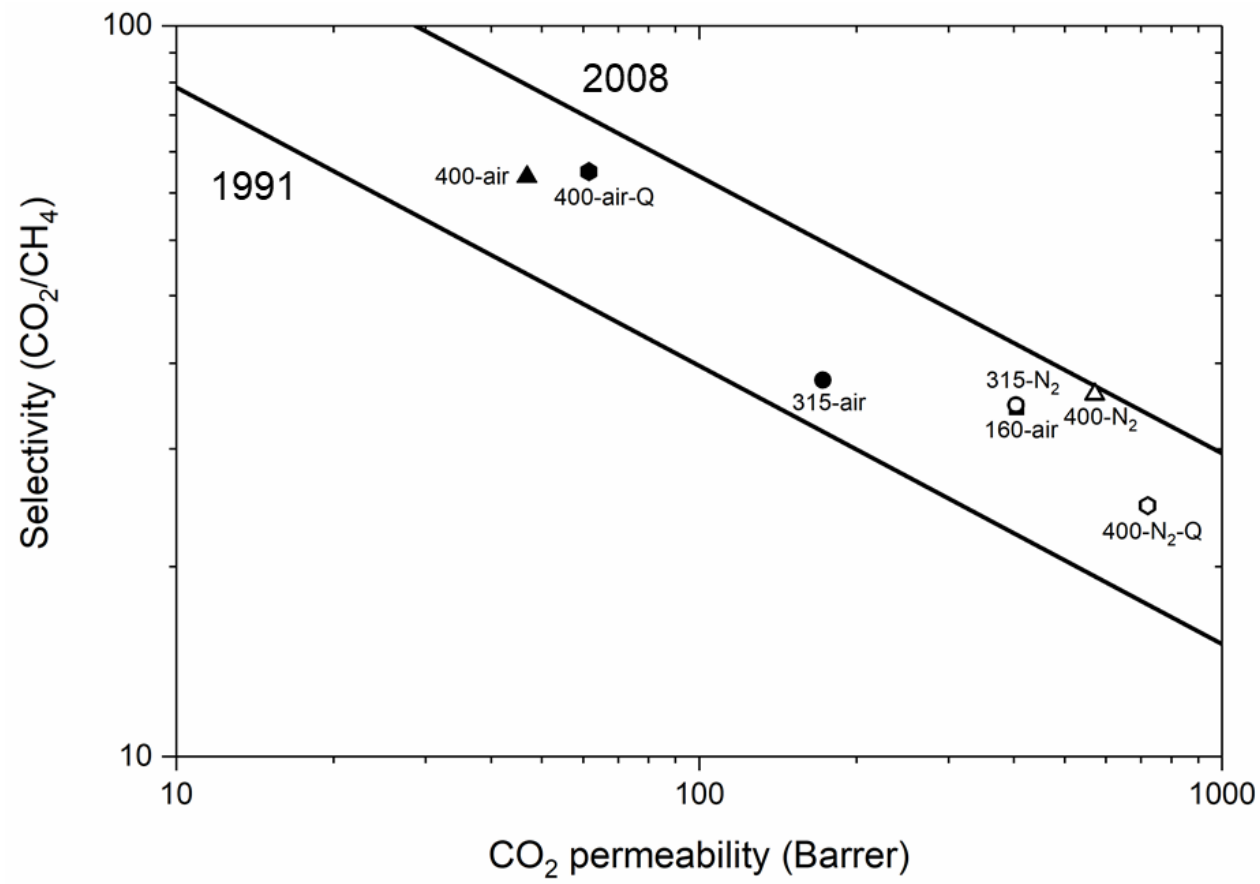

Figure 4.2 The mixed gas separation performance of the 6FDA-DAM membranes thermally annealed at different conditions as labelled on the graph, plotted against the Robeson plot of 1991 and 2008 (Q: quenched). ${ }^{43}$

Heating a membrane to $400{ }^{\circ} \mathrm{C}$, above the $T_{\mathrm{g}}$, in an inert atmosphere $\left(400-\mathrm{N}_{2}-6 \mathrm{FDA}-\right.$ DAM) results in an increase of the pure $\mathrm{CO}_{2}$ permeability of $44 \%$, with no considerable change in selectivity, positioning this membrane almost on the 2008-upper-bound in the Robeson plot. In the absence of oxidation, the changes in the gas separation performances must be explained by physical changes in the polymer structure. The enhanced permeability is associated with the increased free volume upon heating above the $T_{\mathrm{g}}$, which at least partly persists as excess free volume upon slow cooling. ${ }^{44}$ When the membrane is heated above the $T_{\mathrm{g}}$ and subsequently quenched to room temperature $\left(400-\mathrm{N}_{2}(Q)\right)$ the time for relaxations of the polymer chains becomes further shortened and a larger excess free volume remains, augmenting the permeance of both gases. The result is that, in addition to an enhanced permeability, quenching results in a distinct decrease in mixed gas selectivity. ${ }^{10}$ The results demonstrate that when the membranes are heated to just above the $T_{\mathrm{g}}$ the gas final separation 
performance is very sensitive to the cooling rates. When heating to $400{ }^{\circ} \mathrm{C}$ is done in air (400-air-6FDA-DAM) gas permeabilities strongly reduce $\left(\mathrm{CO}_{2}\right.$ : from 378 Barrer to 46.3 Barrer, $\mathrm{CH}_{4}$ : from 13.5 (calculated from mixed gas $\mathrm{CH}_{4}$ permeability) to o.1 Barrer; $\mathrm{N}_{2}$ : from 20.5 Barrer to 1.7 Barrer) and the $\mathrm{CO}_{2} / \mathrm{CH}_{4}$ mixed gas selectivity roughly doubles (from 30 up to 62 ). For $\mathrm{CO}_{2} / \mathrm{N}_{2}$ the ideal permselectivity increases $\sim 50 \%$. The results can be explained by the occurrence of oxidation reactions that, similar to when heating just below the $T_{\mathrm{g}}$, result in denser and less permeable local regions in the polymer, but also addition chemical modifications such as crosslinking that lead to further tightened polymer segmental packing. ${ }^{1,32}$ The tightened packing has a more pronounced effect on the mobility of the larger $\mathrm{CH}_{4}$ molecules than on $\mathrm{CO}_{2}$ molecules, causing the increase in selectivity. ${ }^{2,11}$ As the oxidative reactions have pronounced effects on the actual chemistry of the polymer that overshadow effects related to physical chain relaxations, the sensitivity of the membrane performance to the cooling rate is minimal; as a consequence quenching the membranes has no strong effect. The pronounced effects of the presence of oxygen during heating on the changes in polymer density are also manifested by a strong reduction in the film thickness and an increased refractive index (spectroscopic ellipsometry, vide infra).

The effects of oxidation reactions are also apparent in the gas separation behavior at elevated pressures, depicted in Figure 4.3. The $\mathrm{CO}_{2} / \mathrm{CH}_{4}$ selectivity shows the expected decrease with increasing pressure. For the thermal treatments below the $T_{\mathrm{g}}$ comparable performances are observed. Heating to $400{ }^{\circ} \mathrm{C}$ results in a much higher selectivity that is attributed to the densified structure that reduces the mobility of in particular the more bulky $\mathrm{CH}_{4}$. The plasticization behavior of the membranes is more clearly visible from the normalized $\mathrm{CH}_{4}$ permeance data in Fig. 4.3 (b). The minimum in the permeance corresponds to the so-called plasticization pressure that is similar for all three membranes. However, the changes in data for the membrane heated to $400{ }^{\circ} \mathrm{C}$ are distinctly smaller, which is in accordance with a more densified and more crosslinked macromolecular structure. Crosslinking is also confirmed with the solubility tests in chloroform. Membranes annealed at $160{ }^{\circ} \mathrm{C}$ in air dissolved completely in chloroform in solubility test indicating that no crosslinking occurred at 
this condition. On the other hand, all membranes treated at $315^{\circ} \mathrm{C}$ and $400{ }^{\circ} \mathrm{C}$ became largely insoluble in chloroform. In particular, for the membranes annealed at $400{ }^{\circ} \mathrm{C}$ in air, there were no weight loss or deformity after solubility tests indicating crosslinking was achieved.
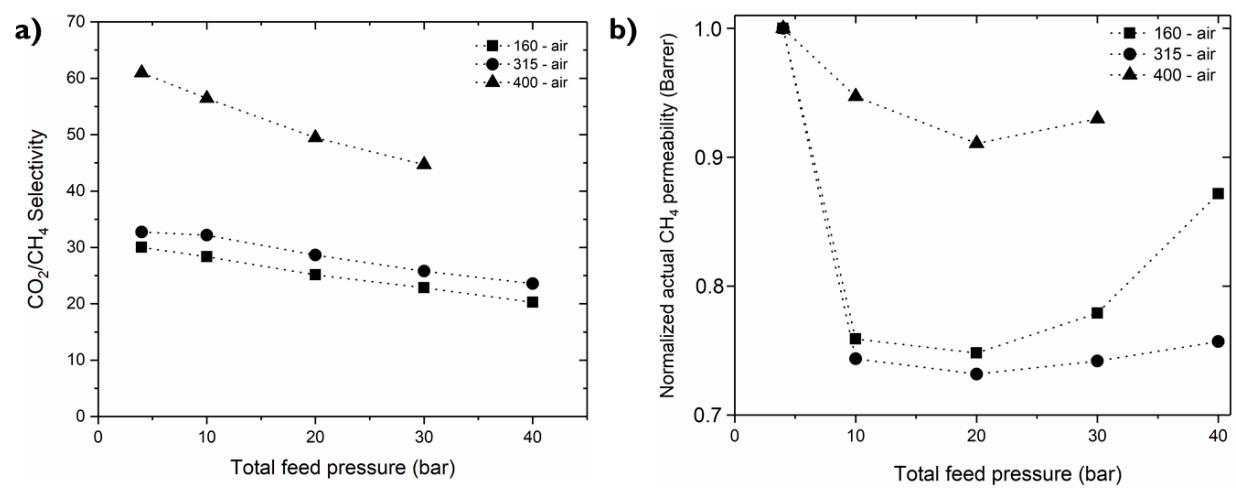

Figure 4.3 a) actual $\mathrm{CO}_{2} / \mathrm{CH}_{4}$ selectivity and b) actual normalized $\mathrm{CH}_{4}$ permeability of pure polymer membranes thermally treated at different temperatures under air against total feed pressure.

\section{Materials characterization}

The XRD patterns in Fig. S4.9 show that all polymers, before and after treatment, are amorphous. Some of the spectra reveal a broad peak that is associated with (excess) free volume. The of the peak location is correlated with the diffusivities for gases.3,7,8 The location can be expressed by $d$-spacing, where low angles correspond to elements with larger $d$-spacing. For the samples that are heated under inert conditions the variations in $d$-spacing, $\sim 0.1 \AA$, are within the experimental error. For samples treated in air a distinct behavior is observed at $400{ }^{\circ} \mathrm{C}$. The diffraction peak disappears, which indicates a pronounced reduction of the free volume in the polymer. This is in agreement with the gas transport data presented above that are also rationalized by a densification of the macromolecular make-up of the polymer due to (cross-linking) reactions. 45

The FTIR spectra for the pure polymer membranes in Fig. S4.9, shows that all the characteristic peaks of 6FDA-DAM are preserved in all samples. The spectra do not reveal distinctly visible peaks originating from the oxidation reactions that are 
postulated to cause polymer densification during heating in oxidative environment. The TGA-MS results of polymer powders in Fig. $\mathrm{S}_{4.4}$ substantiate that, in inert atmosphere, the 6 FDA-DAM based polyimide is very stable up to $\sim 500{ }^{\circ} \mathrm{C}$; the weight loss is only $5 \%$. Around $520{ }^{\circ} \mathrm{C}$, water peaks at $\mathrm{m} / \mathrm{z}=17$ and 18 , fluoride peak at $\mathrm{m} / \mathrm{z}=19$ and $\mathrm{CO}_{2}$ peak at $\mathrm{m} / \mathrm{z}=44$ are observed. At the final temperature of $800{ }^{\circ} \mathrm{C}$ the residual weight is approximately $50 \%$. Under air, the polymer is only stable up to $420^{\circ} \mathrm{C}$ and all the polymer is lost at the end of the analysis. around $520{ }^{\circ} \mathrm{C}$, carbon peak at $\mathrm{m} / \mathrm{z}=12$, water peaks at $m / z=17$ and 18 , fluoride peak at $m / z=19$ and $\mathrm{CO}_{2}$ peak at $\mathrm{m} / \mathrm{z}=44$ are observed. Fluorine containing groups are observed to leave the materials only at temperatures exceeding those employed in the thermal treatments of the membranes. Peaks for $\mathrm{COF}_{3}, \mathrm{CF}_{3}$ and $\mathrm{HCF}_{2}$ are located above $500{ }^{\circ} \mathrm{C}$. Under nitrogen the peaks of $\mathrm{COF}_{3}, \mathrm{CF}_{3}$ and $\mathrm{HCF}_{2}$ groups are all visible while under air $\mathrm{COF}_{3}$ is predominantly visible (Fig. $\mathrm{S}_{4.5}$ ). The preservation of $\mathrm{CF}_{3}$ groups is important for high-performance, because these bulky groups are known to enhance the free volume and the affinity for $\mathrm{CO}_{2}{ }^{31}$

Data for in-situ study of the thermal evolution of thin polymer films via spectroscopic ellipsometry are shown in Fig. 4.4 ( $a$ and b). In the absence of chemical reactions and changes to the polymer structure it is expected that thermal expansion will cause the film thickness to increase with temperature, and the refractive index to decrease with temperature. Above the $T_{\mathrm{g}}$ of the polymer the trends should be complete reversible, and below the $T_{\mathrm{g}}$ some hysteresis will result from the developing excess free volume. This behavior is observed for samples treated in inert conditions. It should be noted that the observed hysteresis here represents the thermal history of the polymer and hence is also due to the stresses in the polymer originating from the sample preparation. To prove this, multiple heat treatment steps between $200-450{ }^{\circ} \mathrm{C}$ were performed and the observed hysteresis became progressively less (Fig. S4.11 and S4.12). For the samples treated under air, the thickness variation is much more pronounced (Fig. 4.4 (c and d)). The evident hysteresis, and the final decrease in thickness and increase in refractive index are all indicative of progressive irreversible changes in the polymer during the heating in an oxygen containing environment. The importance of 
reactions is also clear from the effect of the time; when the samples are quenched less time is available for the reactions to occur and the extent of the observed changes is smaller. In contrast to heat treatment in inert conditions, repeating the ellipsometry experiments for the same sample in air indeed results in continuing changes in the film thickness and the refractive index. These results are in agreement with the observed altered gas separation performance of the membranes, which indicate that the oxidative environment promotes crosslinking of the polymer.
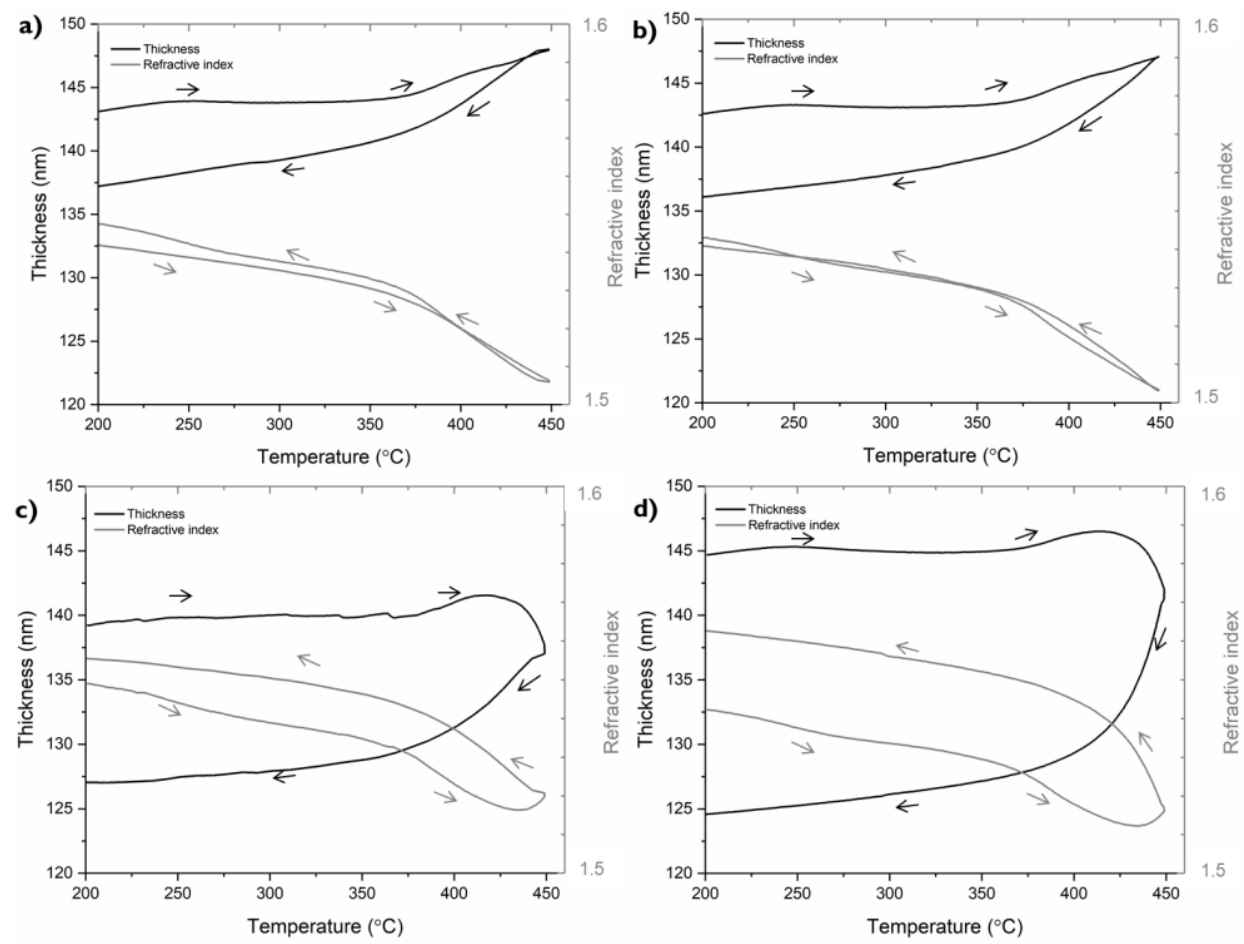

Figure 4.4 Ellipsometry results of 6FDA-DAM films on silicon wafer a) under $\mathrm{N}_{2}$ quenched b) under $\mathrm{N}_{2}$-slow cooling, c) under air-quenched and d) under air-slow cooling.

\subsubsection{Mixed-matrix membranes}

When the heat treatment protocols are applied to MMMs, the membrane performance can also be affected by degradation/oxidation and amorphization of the embedded MOF particles, and changes in the characteristics of the MOF/polymer 
interface etc. Fig. 4.5 depicts the thermal evolution of the individual constituents of the MMMs (the neat polymer and the MOF) in air and inert atmosphere. The results show that the polymer is stable in the entire temperature range of the thermal treatments of the membranes (up to $400{ }^{\circ} \mathrm{C}$ ), in both air and nitrogen. Of the MOFs, ZIF-8 clearly has the highest thermal stability and displays only minor mass loss in the temperature range of the thermal treatments, both in air and nitrogen. Only in air the mass of ZIF-8 finally reaches a plateau, representing the oxidation of the material to zinc oxide. The sod-MOFs display inferior thermal stability and already degrade substantially at temperatures exceeding $\sim 200{ }^{\circ} \mathrm{C}$. For these MOFs, the presence of oxygen in the ambient appears to have only relatively small influence on the degradation behavior. This can be attributed to the presence of water surrounding the cation counter-ions in these frameworks, which provides an additional source for oxidation. This is substantiated by the water release peaks in the MS-TGA at higher temperatures than $100{ }^{\circ} \mathrm{C}$ (Fig. $\mathrm{S}_{4.7}$ and $\mathrm{S}_{4} .8$ ). These results imply that thermal treatment of the MMM with embedded sod-MOFs will likely not be successful.
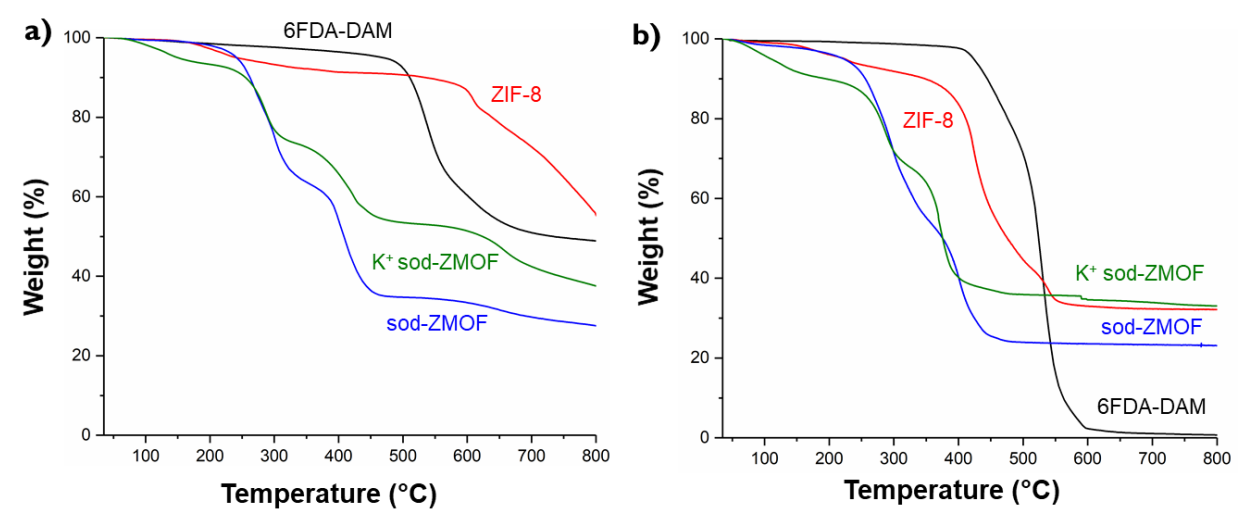

Figure 4.5 TGA curve of the powder 6FDA-DAM, ZIF-8, sod-ZMOF and $\mathrm{K}^{+}$sod-ZMOF a) under continuous nitrogen flow b) under continuous air flow.

\section{MMMs with embedded ZIF-8}

For ZIF_MMM, the SEM images in Fig. 4.6 (a) show that after thermal treatment at $160^{\circ} \mathrm{C}$ there is a homogeneous particle distribution of MOF particles in 6FDA-DAM, with no apparent particle agglomeration. The image reveals no significant voids at the 
polymer/filler interface, which is indicative of compatibility between the surface of the MOF crystals and the polymer. After thermal treatment at $315{ }^{\circ} \mathrm{C}$ in air a slightly altered morphology can be seen (Fig. 4.6 (b)) and heating to $400{ }^{\circ} \mathrm{C}$ in either air or nitrogen results in a quite distinct morphology (Fig. 4.6 (c) and (d), relatively).

The separation performance of ZIF_MMM is depicted in Fig. 4.7 (a). When comparing the results for the pure polymer and the ZIF_MMM treated at $160^{\circ} \mathrm{C}$ it is clear that the addition of the MOF causes an increase in permeability and a decrease selectivity. This is indicative of a more 'open' character of the material, possibly at the interface between the ZIF and the polymer. Upon heating under nitrogen the permeability remains unchanged, but a further reduction in selectivity is observed. When compared to the pure polymer membrane treated at the same temperatures the ZIF_MMM has inferior performance. Surprisingly, heating to $315{ }^{\circ} \mathrm{C}$ in air results in a higher selectivity and permeability as compared to the pure polymer treated in the same conditions. It has been reported previously that polymer embedded ZIF-8 might be thermally amorphized under these conditions, ${ }^{2}$ but it is also possible that (amorphous) zinc oxide may be formed within the polymer matrix. ${ }^{46}$ The XRD results in Fig. S4.13 shows possible amorphization of ZIF-8 at $315^{\circ} \mathrm{C}$. The improvement with respect to the pure polymer does suggest that a selective MOF structure, possibly amorphous, persists and that the interface between the polymer and the MOF is no longer non-selective, perhaps due to crosslinking between polymer and the amorphous MOF and healing the defects at the interface between MOF and polymer. ${ }^{2,32}$ It was not possible to measure the gas permeability of 400 - air ZIF_MMM membranes. During the thermal treatment the ZIF-8 partly transforms to zinc oxide. This causes the polymer particle structure to become fragile. In addition, the gases evolving from the oxidation reaction cause pinholes in the structure, as is also evident from the SEM images in Fig. S4.16. 

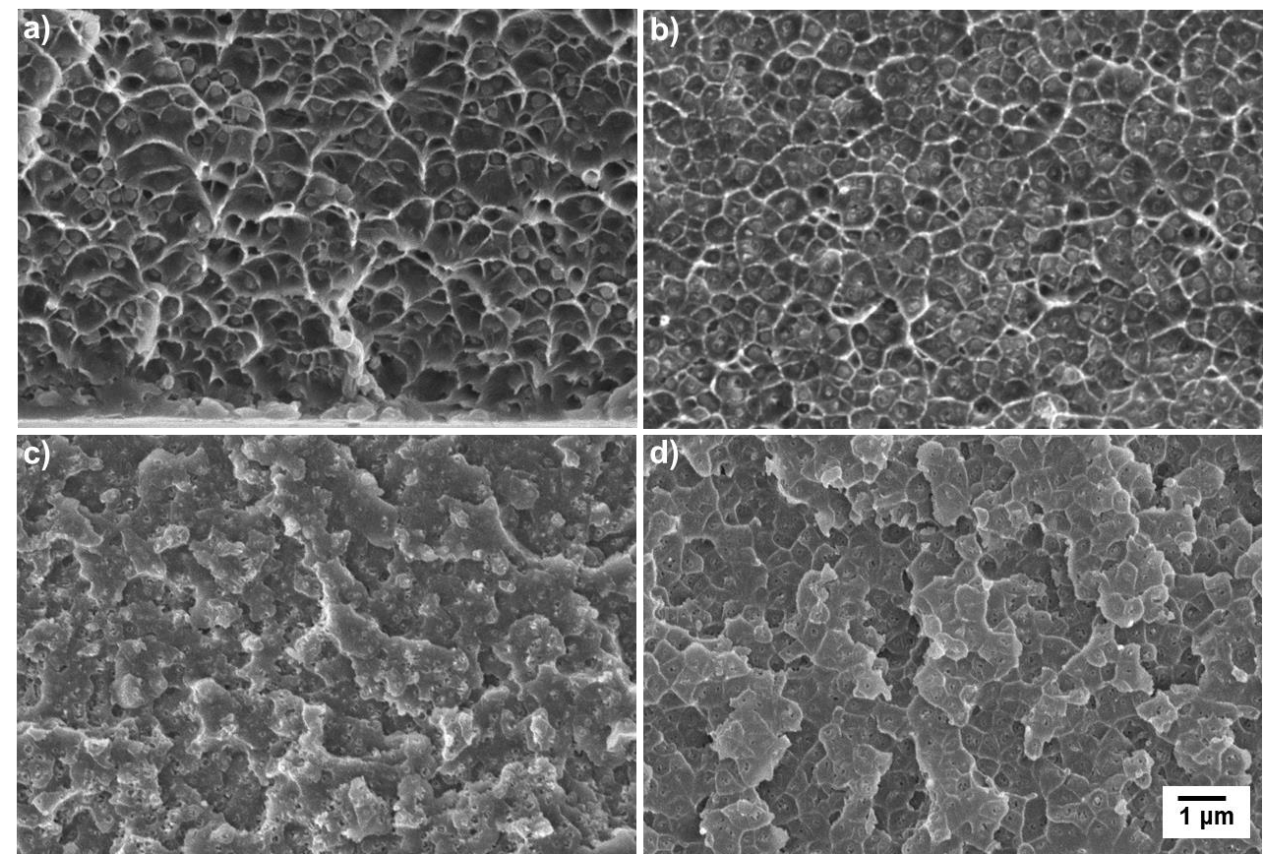

Figure 4.6 Cross-sectional SEM images of the thermally annealed MMM samples a) 160 - air - ZIF_MMM, b) 315 - air - ZIF_MMM, c) 400 - air - ZIF_MMM and d) 400 $\mathrm{N}_{2}$ - ZIF_MMM. Scale bar is $1 \mu \mathrm{m}$ and the magnification is 10,000 for all the images. 

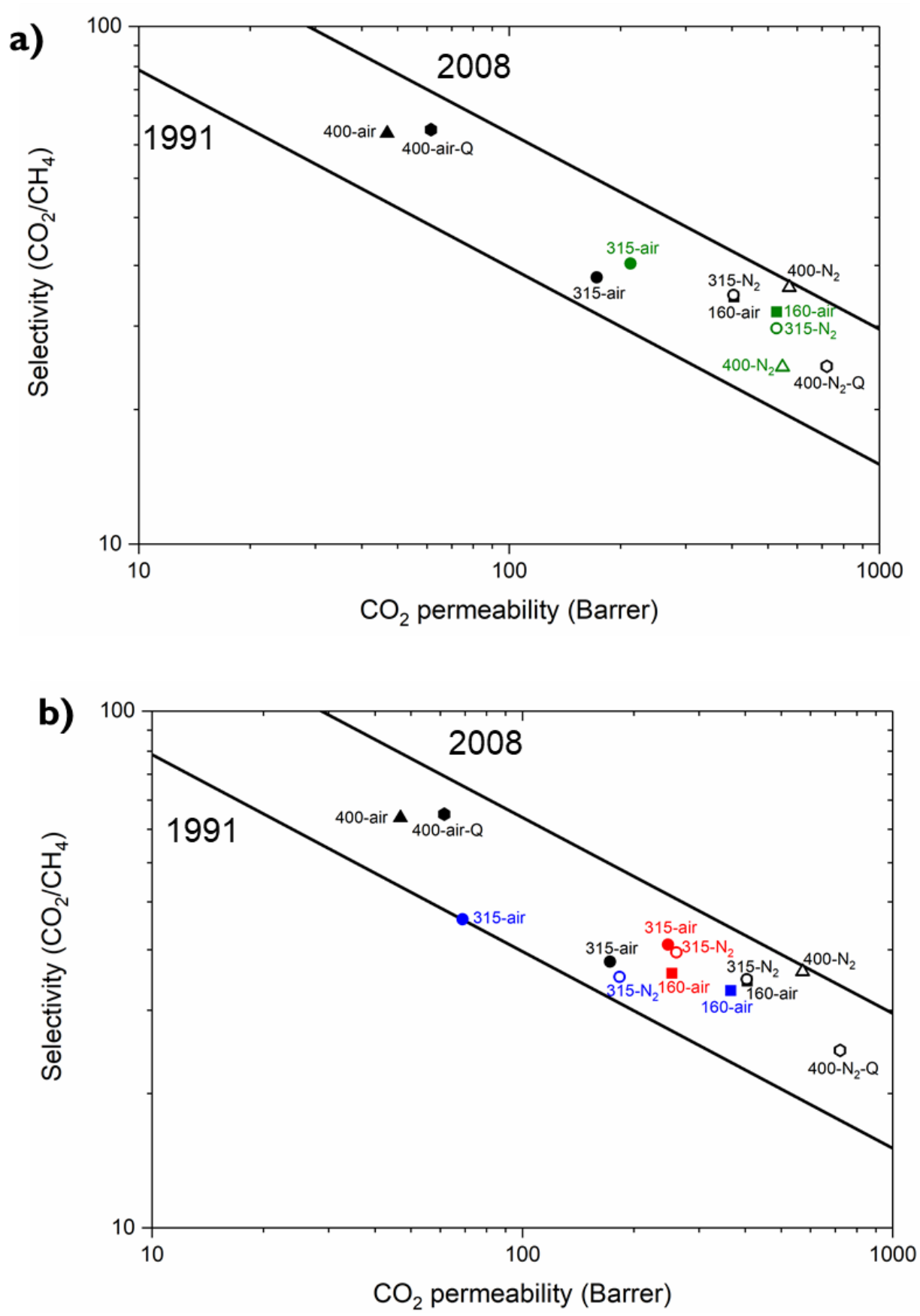

Figure 4.7 The gas separation performance of the a) ZIF_MMMs and b)sod_MMMs and K+sod_MMMs, plotted against the Robeson plot of 1991 and 2008.43 (Black: 6FDADAM benchmark, green: ZIF-8, red: sod-ZMOF and blue: $\mathrm{K}^{+}$sod-ZMOF). 


\section{MMMs with embedded sod-ZMOFs}

For the $\mathrm{K}^{+}$sod_MMMs, no improvements in performance are observed when comparing the MMM with the pure polymer, after both have received the same thermal treatment. The $\mathrm{K}^{+}$sod_MMM treated at $160{ }^{\circ} \mathrm{C}$ has comparable selectivity as the benchmark, but a lower permeability. When thermal treatment is conducted at $315{ }^{\circ} \mathrm{C}$ the permeability shows a strong decrease that shifts the performance towards the 1991 instead of the 2008 upper bound. For the non-ion exchanged sod-MOF treatment at $160{ }^{\circ} \mathrm{C}$ results in a low permeability without gain in selectivity. Heating to $315{ }^{\circ} \mathrm{C}$ does not appear to affect the permeability, but slightly enhances the selectivity. As compared to the pure polymer, treatment at $315{ }^{\circ} \mathrm{C}$ in air shifts performance towards the upper bound. Again, the rationale for this could be enhanced interactions between polymer and MOF particles, as was observed for the ZIF based MMMs. $^{2,32}$

\subsection{Conclusions}

The effects of thermal treatment of 6FDA-DAM polyimide gas separation membranes and the derived ZIF-8, sod-ZMOF and $\mathrm{K}^{+}$sod-ZMOF mixed matrix membranes are presented. The results indicate that the separation performance of the membranes can be improved via thermal treatment. SEM images of MMMs reveal a uniform dispersion of MOF particles in the polymer matrix. The performance of the MMMs was generally inferior to that of the pure polymer membranes. Only MMMs that were heated to 315 ${ }^{\circ} \mathrm{C}$ in air showed a shift in performance towards the 2008 upper bound in the Robson plot. The upward shift is attributed to the superior selectivity of the, possible amorphous, MOF as compared to the polymer, combined with enhanced interactions between the polymer and the surface of the MOF particles. Overall, the results demonstrate that thermal treatment strategies can allow fine tuning of polymer and MMM gas separation membranes. 


\section{Acknowledgements}

We would like to thank MEMASEP group at Istanbul Technical University for synthesizing 6FDA-DAM polymer and providing sod-ZMOFs thanks to their collaboration with KAUST; Mariël Elshof for her guidance with ellipsometry analyses; Alberto Tena and Oğuz Karvan for their useful discussions.

\section{References}

1 J. Yuan, H. Zhu, J. Sun, Y. Mao, G. Liu and W. Jin, ACS Appl. Mater. Interfaces, 2017, 9, 38575-38583.

2 A. Kertik, L. H. Wee, M. Pfannmöller, S. Bals, J. A. Martens and I. F. J. Vankelecom, Energy Environ. Sci., 2017, 10, 2342-2351.

3 M. Safak Boroglu and A. B. Yumru, Sep. Purif. Technol., 2017, 173, 269-279.

4 A. Perea-Cachero, J. Sánchez-Laínez, Á. Berenguer-Murcia, D. CazorlaAmorós, C. Téllez and J. Coronas, J. Memb. Sci., 2017, 544, 88-97.

5 S. Velioğlu, M. G. Ahunbay and S. B. Tantekin-Ersolmaz, Sep. Purif. Technol., 2017, 178, 90-104.

6 Y. Zhang, J. Sunarso, S. Liu and R. Wang, Int. J. Greenh. Gas Control, 2013, 12, 84-107.

7 M. E. Dose, M. Chwatko, I. Hubacek, N. A. Lynd, D. R. Paul and B. D. Freeman, Polymer (Guildf)., 2019, 161, 16-26.

8 Z. Tian, B. Cao and P. Li, J. Memb. Sci., 2018, 56o, 87-96.

9 C. Zhang, B. Cao and P. Li, J. Memb. Sci., 2018, 546, 90-99.

$10 \quad$ J. U. Wieneke and C. Staudt, Polym. Degrad. Stab., 2010, 95, 684-693.

11 W. Qiu, C.-C. Chen, L. Xu, L. Cui, D. R. Paul and W. J. Koros, Macromolecules, 2011, 44, 6046-6056.

K. Vanherck, G. Koeckelberghs and I. F. J. Vankelecom, Prog. Polym. Sci., 2013, 38, 874-896.

13 B. Seoane, J. Coronas, I. Gascon, M. E. Benavides, O. Karvan, J. Caro, F. Kapteijn and J. Gascon, Chem. Soc. Rev., 2015, 44, 2421-2454.

14 R. Castro-Muñoz, V. Fíla, V. Martin-Gil and C. Muller, Sep. Purif. Technol., 2019, 210, 553-562. 
A. E. Amooghin, M. Omidkhah and A. Kargari, RSC Adv., 2015, 5, 8552-8565.

M. Barooah and B. Mandal, J. Appl. Polym. Sci., 2018, 135, 46481.

B. Zhang, J. Fu, Q. Zhang, C. Yi and B. Yang, J. Appl. Polym. Sci., 2019, 47848, 112.

B. Seoane, J. Coronas, I. Gascon, M. E. Benavides, O. Karvan, J. Caro, F. Kapteijn and J. Gascon, Chem. Soc. Rev., 2015, 44, 2421-2454.

M. Z. Ahmad, M. Navarro, M. Lhotka, B. Zornoza, C. Téllez, W. M. de Vos, N. E. Benes, N. M. Konnertz, T. Visser, R. Semino, G. Maurin, V. Fila and J. Coronas, J. Memb. Sci., 2018, 558, 64-77.

T.-H. Bae, J. S. Lee, W. Qiu, W. J. Koros, C. W. Jones and S. Nair, Angew. Chemie Int. Ed., 2010, 49, 9863-9866.

X. Dong, Q. Liu and A. Huang, J. Appl. Polym. Sci., 2016, 133, 43485.

G. Liu, Y. Labreche, V. Chernikova, O. Shekhah, C. Zhang, Y. Belmabkhout, M. Eddaoudi and W. J. Koros, J. Memb. Sci., 2018, 565, 186-193.

J. Zhao, G. He, G. Liu, F. Pan, H. Wu, W. Jin and Z. Jiang, Prog. Polym. Sci., 2018, 80, 125-152.

M. Ahmadi, E. Tas, A. Kılıç, V. Kumbaracı, N. Talınlı, M. G. Ahunbay and S. B. Tantekin-Ersolmaz, ACS Appl. Mater. Interfaces, 2017, 9, 35936-35946.

A. Kılıç, Ç. Atalay-Oral, A. Sirkecioğlu, B. Tantekin-Ersolmaz and M. G. Ahunbay, 2015, 489, 81-89.

Y. Zhang, I. H. Musselman, J. P. Ferraris and K. J. Balkus, J. Memb. Sci., 20o8, 313, 170-181.

C. Zhang and W. J. Koros, ACS Appl. Mater. Interfaces, 2015, 23407-23411.

M. J. C. Ordoñez, K. J. Balkus, J. P. Ferraris and I. H. Musselman, J. Memb. Sci., 2010, 361, 28-37.

H. Yang, H. Du, L. Zhang, Z. Liang and W. Li, 2015, 10, 1420-1433.

C. Chen, J. Kim, D.-A. Yang and W.-S. Ahn, Chem. Eng. J., 2011, 168, 1134-1139.

Y.-S. Bae, O. K. Farha, J. T. Hupp and R. Q. Snurr, J. Mater. Chem., 2009, 19, 2131.

R. Lin, J. Hou, M. Li, Z. Wang, L. Ge, S. Li, S. Smart, Z. Zhu, T. D. Bennett and V. Chen, Chem. Commun., , DOI:10.1039/DoCCoo664E. 
33 W. Qiu, L. Xu, C.-C. Chen, D. R. Paul and W. J. Koros, Polymer (Guildf)., 2013, $54,6226-6235$.

34 B. Demir and M. G. Ahunbay, J. Phys. Chem. C, 2013, 117, 15647-15658.

35 J. Cravillon, S. Münzer, S.-J. Lohmeier, A. Feldhoff, K. Huber and M. Wiebcke, Chem. Mater., 2009, 21, 1410-1412.

36 A. Kiliç, Ç. Atalay-Oral, A. Sirkecioğlu, S. B. Tantekin-Ersolmaz and M. G. Ahunbay, J. Memb. Sci., 2015, 489, 81-89.

37 R. Mahajan and W. J. Koros, Ind. Eng. Chem. Res., 2000, 39, 2692-2696.

38 R. Lin, B. Villacorta Hernandez, L. Ge and Z. Zhu, J. Mater. Chem. A, 2018, 6, 293-312.

39 K. Tempelman, University of Twente, 2019.

40 W. Qiu, C. C. Chen, L. Xu, L. Cui, D. R. Paul and W. J. Koros, Macromolecules, 2011, 44, 6046-6056.

41 M. Safak Boroglu and A. B. Yumru, Sep. Purif. Technol., 2017, 173, 269-279.

42 G. Liu, Y. Labreche, V. Chernikova, O. Shekhah, C. Zhang, Y. Belmabkhout, M. Eddaoudi and W. J. Koros, J. Memb. Sci., 2018, 565, 186-193.

43 L. M. Robeson, J. Memb. Sci., 2008, 320, 390-400.

44 H. B. Park, S. H. Han, C. H. Jung, Y. M. Lee and A. J. Hill, J. Memb. Sci., 2010, 359, 11-24.

45 J. Su and A. C. Lua, J. Memb. Sci., 2007, 305, 263-270.

46 E. Samuel, B. Joshi, M. W. Kim, Y. Il Kim, S. Park, T. G. Kim, M. T. Swihart, W. Y. Yoon and S. S. Yoon, J. Power Sources, 2018, 395, 349-357. 


\section{Supporting Information}

- Material characterization results of powder materials

a)

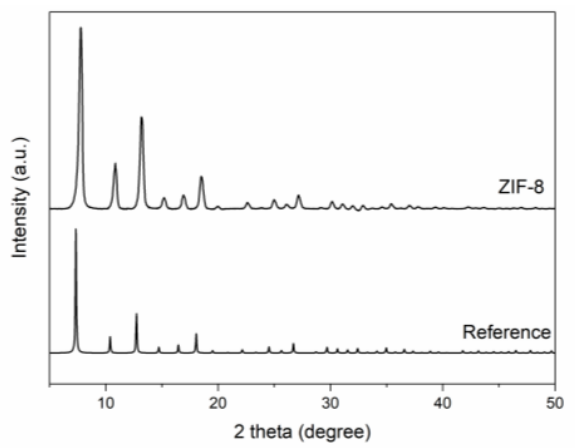

b)

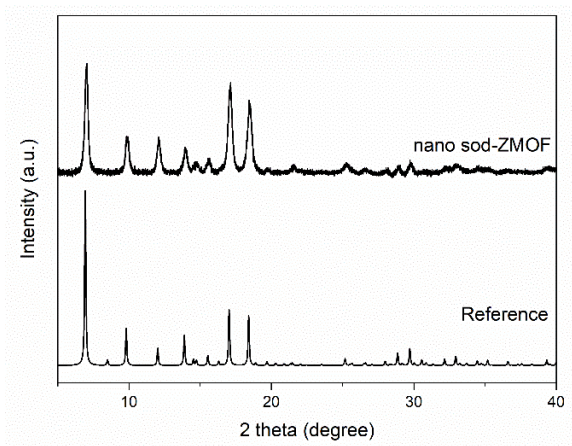

Figure S4.1 XRD pattern of as-synthesized a) ZIF-8 with reference CCDC 602542 and b) sod-ZMOF particles with reference CCDC 294664.

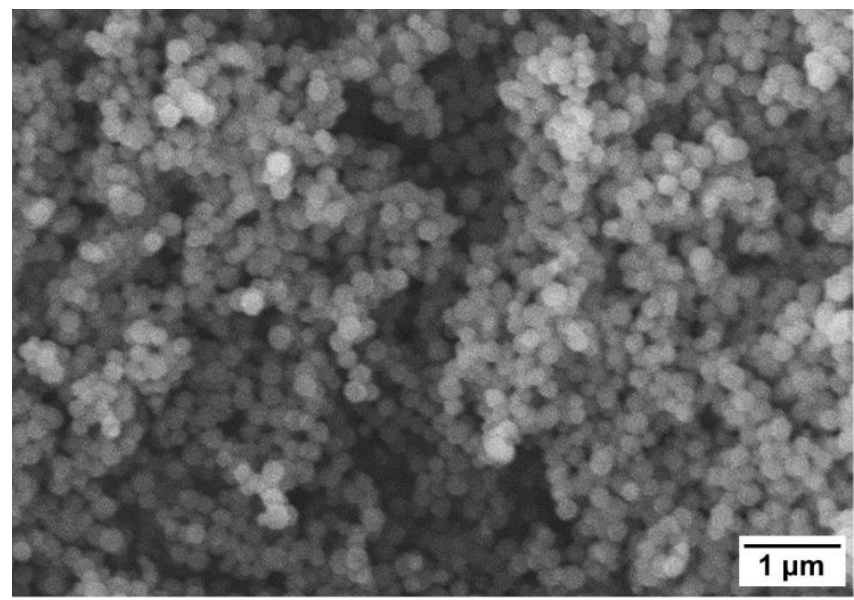

Figure $\mathbf{S}_{\mathbf{4} .2}$ SEM image of the as-synthesized ZIF-8 powder samples. Scale bar is $1 \mu \mathrm{m}$ and the magnification is 14,000 . 

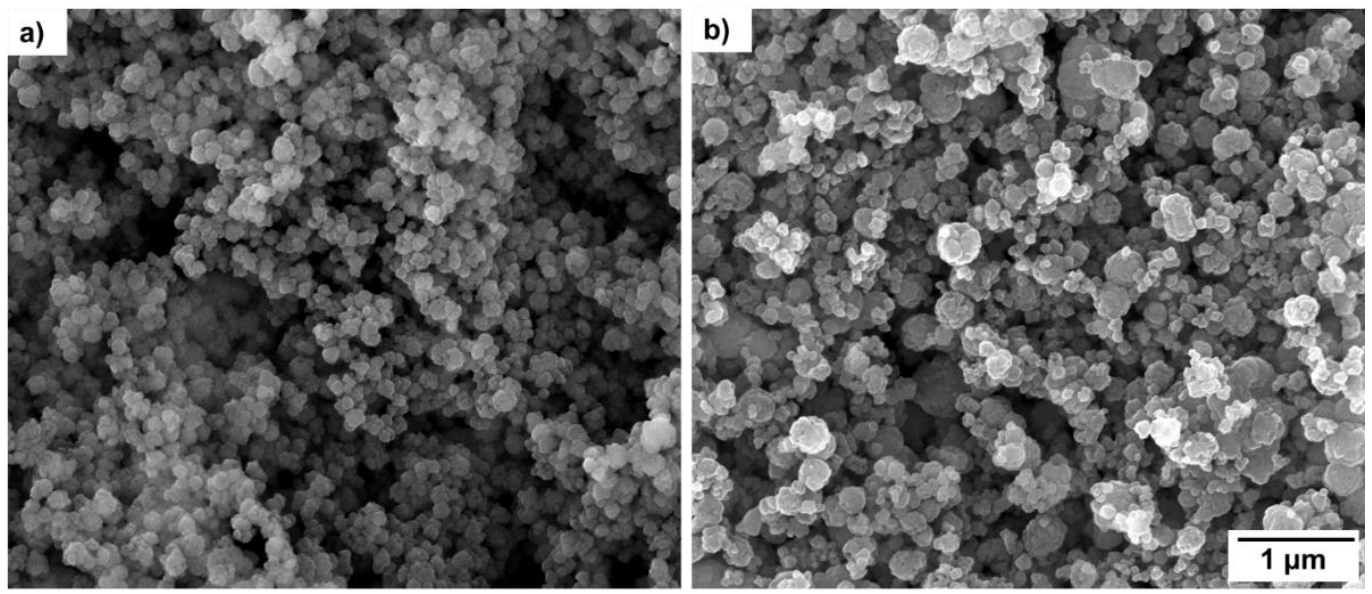

Figure $\mathbf{S 4}_{4} 3 \mathrm{SEM}$ images of the as-synthesized a) sod-ZMOF powder and b) $\mathrm{K}^{+}$sodZMOF powder samples. Scale bar is $1 \mu \mathrm{m}$ and the magnification is 50,000 for all the images.
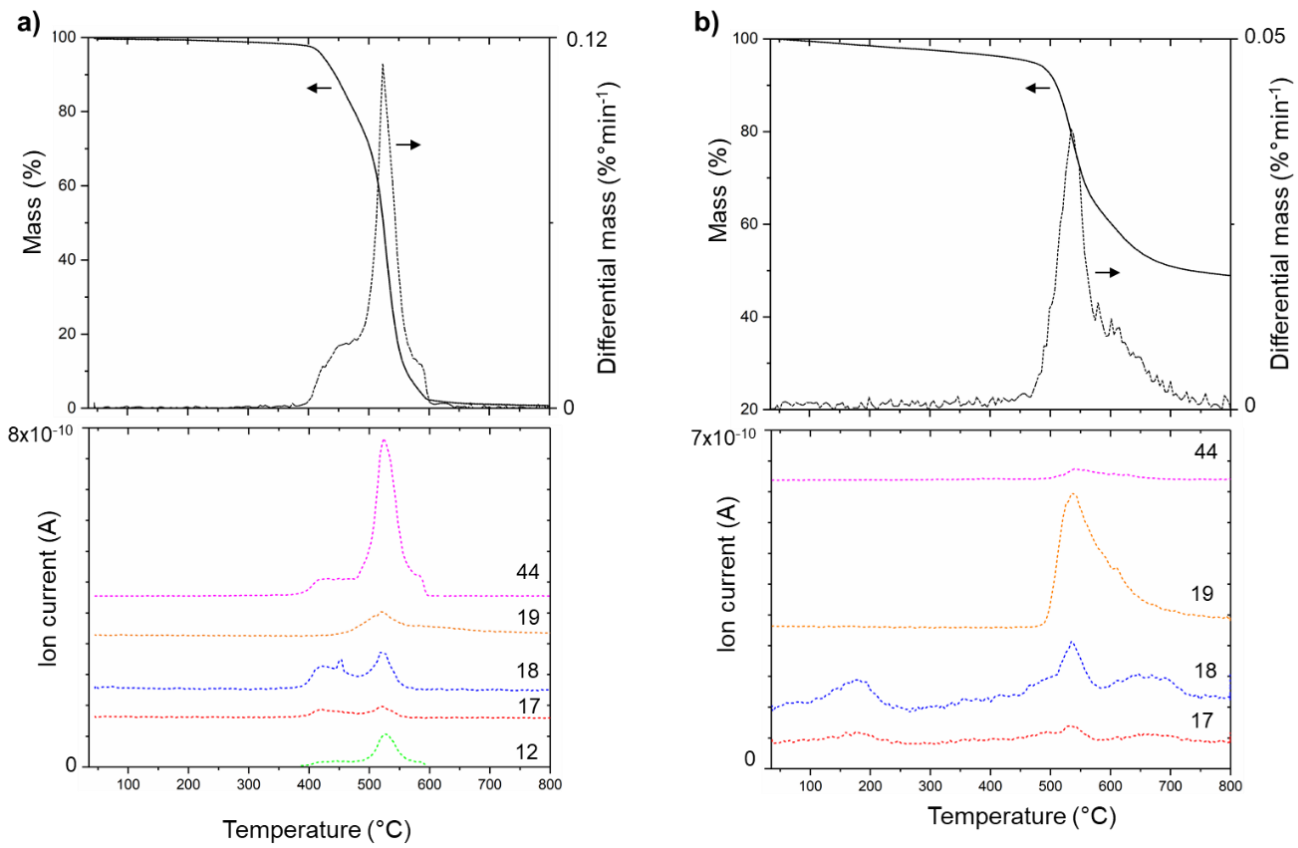

Figure S4.4 TGA-MS results of pure 6FDA-DAM powder a) under air and b) under nitrogen flow with a heating rate of $5^{\circ} \mathrm{C} \mathrm{min}^{-1}$. 

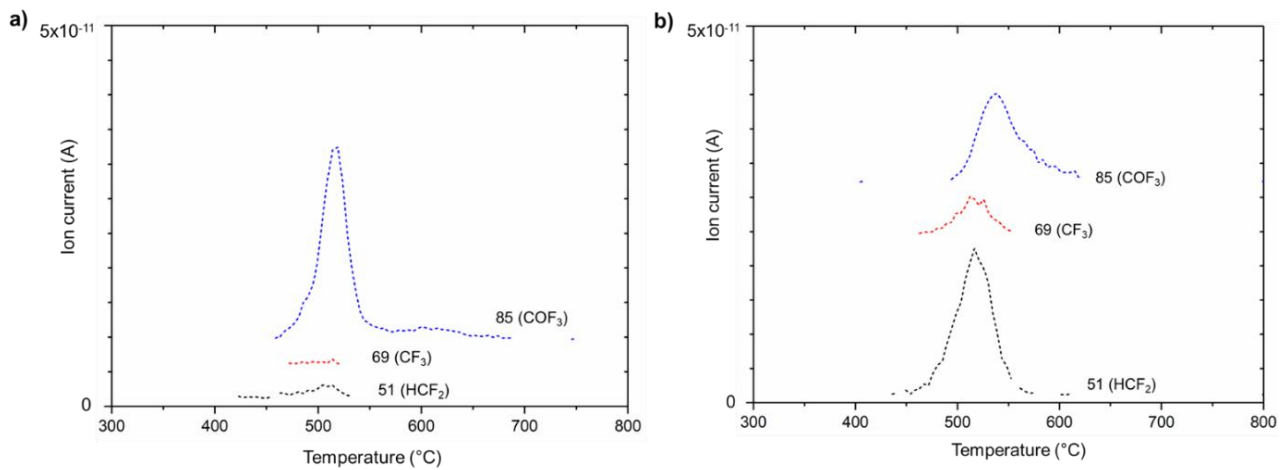

Figure S4.5 TGA-MS results of 6FDA-DAM a) under air and b) under nitrogen with a heating rate of $5^{\circ} \mathrm{C} \mathrm{min}^{-1}$.
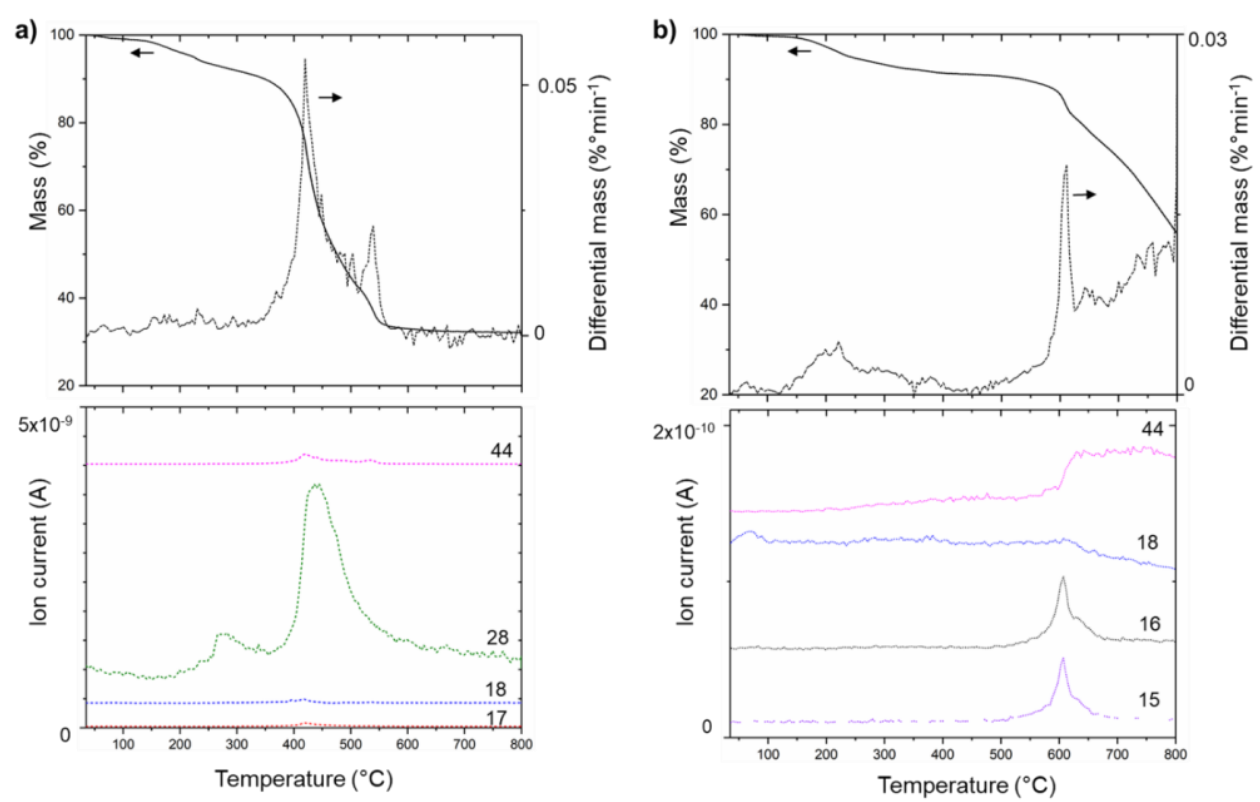

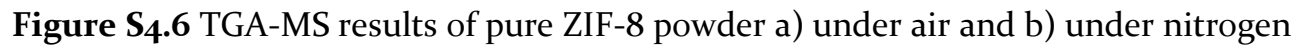
flow with a heating rate of $5^{\circ} \mathrm{C} \mathrm{min}^{-1}$. 

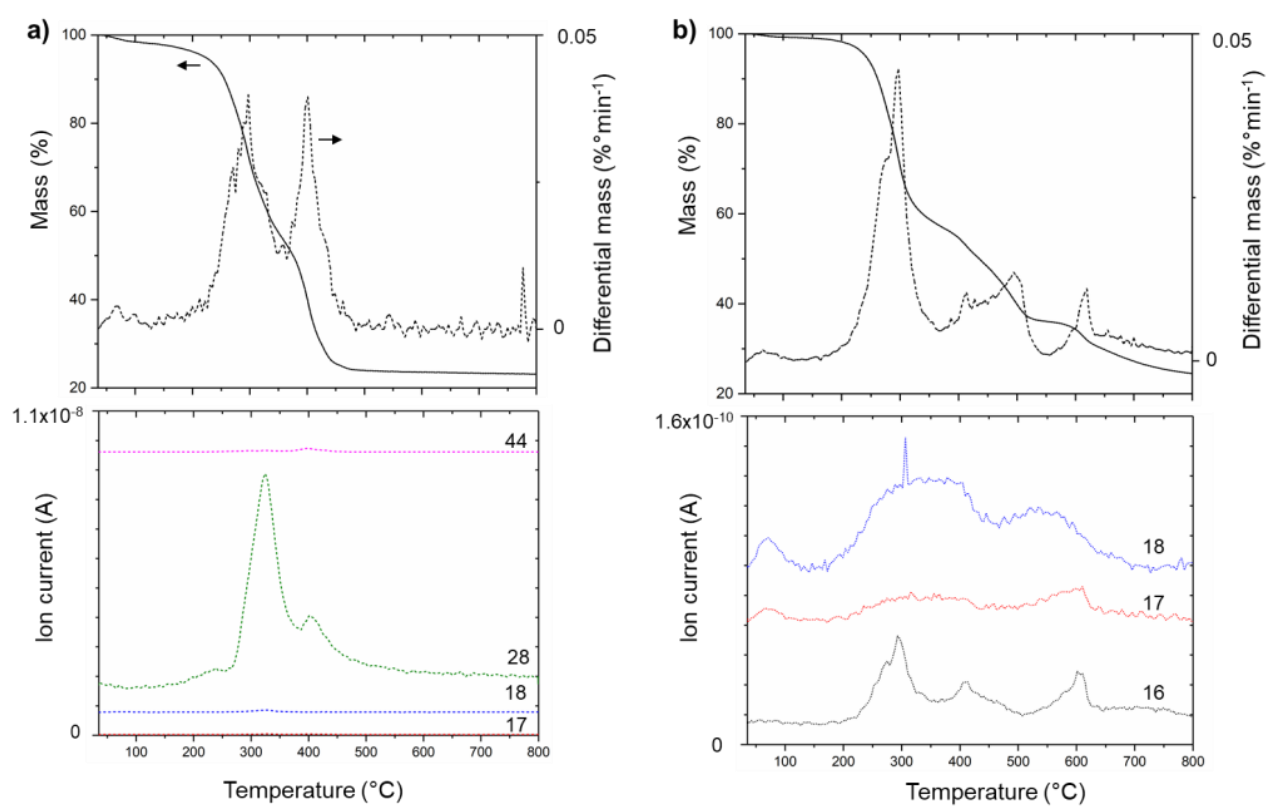

Figure $\mathbf{S}_{4.7}$ TGA-MS results of pure sod-ZMOF powder a) under air and b) under nitrogen flow with a heating rate of $5^{\circ} \mathrm{C} \mathrm{min}^{-1}$.
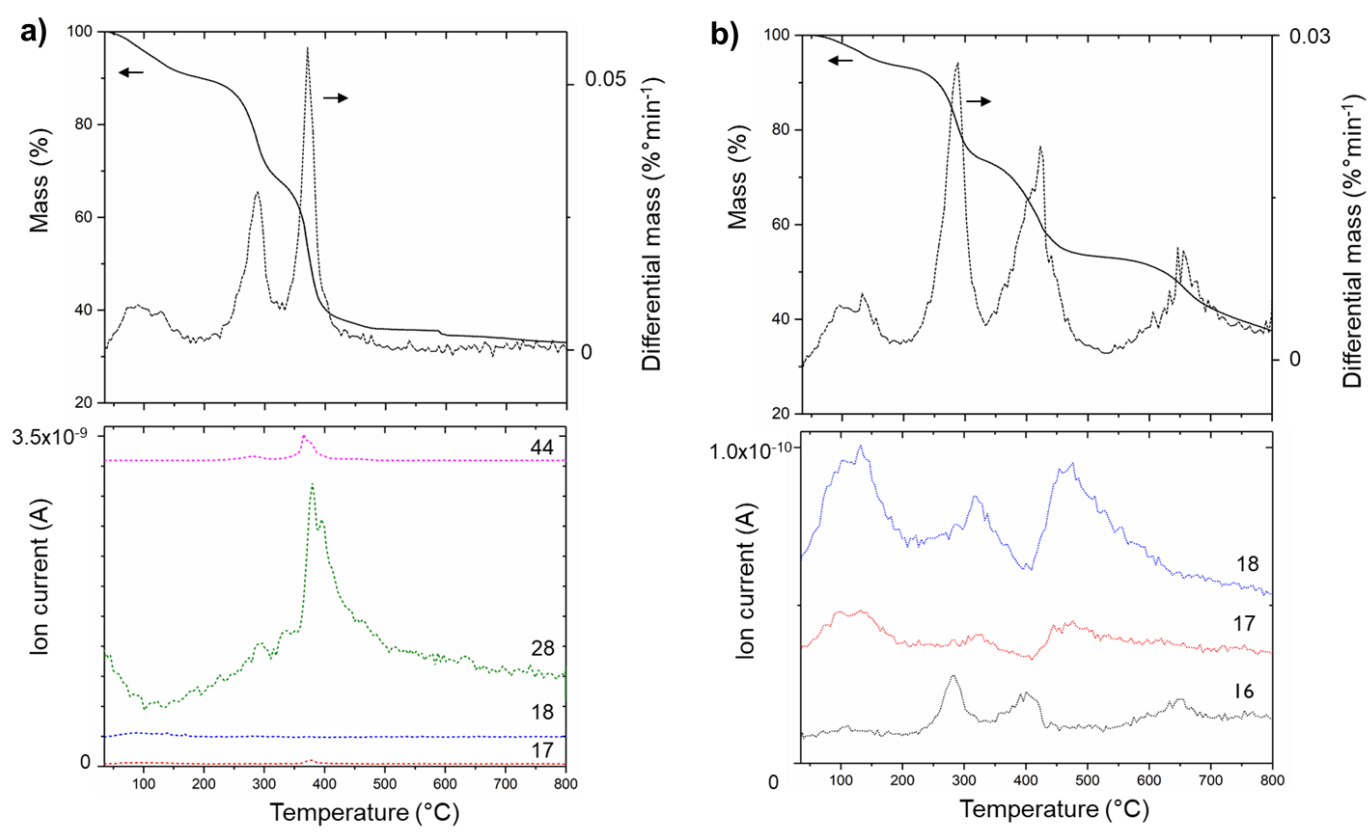

Figure S4.8 TGA-MS results of pure K+sod-ZMOF powder a) under air and b) under nitrogen flow with a heating rate of $5{ }^{\circ} \mathrm{C} \mathrm{min}{ }^{-1}$. 
- Thermal annealing and membrane characterization

Table S4.1 The membrane samples list including the thermal annealing conditions. For $\mathrm{N}_{2}$ environment $150 \mathrm{ml} \mathrm{min}{ }^{-1}$ gas flow is used, no additional flow is used for the samples in air.

\section{Samples}

\begin{tabular}{|c|c|c|}
\hline \multirow{5}{*}{ pure 6FDA-DAM } & above boiling point $\left(160^{\circ} \mathrm{C}\right)$ & air \\
\hline & below $\operatorname{Tg}\left(315^{\circ} \mathrm{C}\right)$ & air \\
\hline & below $\operatorname{Tg}\left(315^{\circ} \mathrm{C}\right)$ & $\mathrm{N}_{2}$ \\
\hline & above $\operatorname{Tg}\left(400^{\circ} \mathrm{C}\right)$ & air \\
\hline & above $\operatorname{Tg}\left(400^{\circ} \mathrm{C}\right)$ & $\mathrm{N}_{2}$ \\
\hline \multirow{5}{*}{ ZIF-8/6FDA-DAM } & above boiling point $\left(160^{\circ} \mathrm{C}\right)$ & air \\
\hline & below $\operatorname{Tg}\left(315^{\circ} \mathrm{C}\right)$ & air \\
\hline & below $\operatorname{Tg}\left(315^{\circ} \mathrm{C}\right)$ & $\mathrm{N}_{2}$ \\
\hline & above $\operatorname{Tg}\left(400^{\circ} \mathrm{C}\right)$ & air \\
\hline & above $\operatorname{Tg}\left(400^{\circ} \mathrm{C}\right)$ & $\mathrm{N}_{2}$ \\
\hline \multirow{5}{*}{ sod-ZMOF/6FDA-DAM } & above boiling point $\left(160^{\circ} \mathrm{C}\right)$ & air \\
\hline & below $\operatorname{Tg}\left(315^{\circ} \mathrm{C}\right)$ & air \\
\hline & below $\operatorname{Tg}\left(315^{\circ} \mathrm{C}\right)$ & $\mathrm{N}_{2}$ \\
\hline & above $\operatorname{Tg}\left(400^{\circ} \mathrm{C}\right)$ & air \\
\hline & above $\operatorname{Tg}\left(400^{\circ} \mathrm{C}\right)$ & $\mathrm{N}_{2}$ \\
\hline \multirow{5}{*}{$\mathrm{K}^{+}$sod-ZMOF/6FDA-DAM } & above boiling point $\left(160^{\circ} \mathrm{C}\right)$ & air \\
\hline & below $\operatorname{Tg}\left(315^{\circ} \mathrm{C}\right)$ & air \\
\hline & below $\operatorname{Tg}\left(315^{\circ} \mathrm{C}\right)$ & $\mathrm{N}_{2}$ \\
\hline & above $\operatorname{Tg}\left(400^{\circ} \mathrm{C}\right)$ & air \\
\hline & above $\operatorname{Tg}\left(400^{\circ} \mathrm{C}\right)$ & $\mathrm{N}_{2}$ \\
\hline
\end{tabular}

\section{Thermal annealing condition}


Table S4.2 Separation performance of thermally treated membranes. The permeability and selectivity data are presented as mean \pm standard deviation (SD)) and if it is available together with duplicate measurements.

\begin{tabular}{|c|c|c|c|c|c|c|c|c|}
\hline \multirow{3}{*}{ Membrane } & \multicolumn{5}{|c|}{ Single gas permeation } & \multicolumn{3}{|c|}{$\begin{array}{c}\text { Mixed gas permeation } \\
\left(50: 50 \mathrm{CO}_{2}: \mathrm{CH}_{4} \text { molar ratio) }\right.\end{array}$} \\
\hline & \multicolumn{4}{|c|}{ Permeability (Barrer) } & \multirow{2}{*}{$\begin{array}{c}\text { Ideal } \\
\mathrm{CO}_{2} / \mathrm{N}_{2} \\
\text { selectivity }\end{array}$} & \multirow{2}{*}{$\begin{array}{c}\mathrm{CH}_{4} \\
\text { permeability } \\
\text { (Barrer) }\end{array}$} & \multirow{2}{*}{$\begin{array}{l}\mathrm{CO}_{2} \\
\text { permeability } \\
\text { (Barrer) }\end{array}$} & \multirow{2}{*}{$\begin{array}{c}\text { Actual } \\
\mathrm{CO}_{2} / \mathrm{CH}_{4} \\
\text { selectivity }\end{array}$} \\
\hline & $\mathrm{CH}_{4}$ & $\mathrm{~N}_{2}$ & $\mathrm{CO}_{2}$ & $\mathrm{He}$ & & & & \\
\hline 16o - air- 6FDA-DAM & - & $\begin{array}{c}20.5 \pm \\
0.07\end{array}$ & $378 \pm 2.88$ & $315 \pm 1.17$ & 18.5 & $13.5 \pm 0.24$ & $406 \pm 2.96$ & $30.1 \pm 0.63$ \\
\hline 16o - air- 6FDA-DAM - 2 & - & $\begin{array}{c}22.0 \pm \\
0.23\end{array}$ & $368 \pm 3.90$ & $305 \pm 2.71$ & 16.7 & $13.3 \pm 0.33$ & $400 \pm 2.84$ & $30.1 \pm 0.72$ \\
\hline $315-\mathrm{N}_{2}-6$ FDA-DAM & - & $21.7 \pm 0.13$ & $389 \pm 2.55$ & $331 \pm 2.73$ & $17 \cdot 9$ & $13.3 \pm 0.16$ & $404 \pm 3.04$ & $30.3 \pm 0.37$ \\
\hline $315-\mathrm{N}_{2}-6$ FDA-DAM - 2 & - & $22.8 \pm 0.17$ & $401 \pm 2.00$ & $343 \pm 3.19$ & 17.6 & $14.3 \pm 0.32$ & $436 \pm 1.31$ & $30.6 \pm 0.70$ \\
\hline 315 - air- 6FDA-DAM & $6.94 \pm 0.05$ & $9.49 \pm 0.11$ & $177 \pm 1.04$ & $179 \pm 0.67$ & 18.6 & $5.29 \pm 0.10$ & $173 \pm 1.79$ & $32.7 \pm 0.40$ \\
\hline $400-\mathrm{N}_{2}-6$ FDA-DAM & - & $\begin{array}{c}30.0 \pm \\
0.46\end{array}$ & $545 \pm 2.21$ & $\begin{array}{c}452 \pm \\
3.90\end{array}$ & 18.2 & $18.2 \pm 0.33$ & $571 \pm 2.99$ & $31.4 \pm 0.57$ \\
\hline
\end{tabular}




\begin{tabular}{|c|c|c|c|c|c|c|c|c|}
\hline $400-\mathrm{N}_{2}-6$ FDA-DAM - Q & - & $\begin{array}{c}44 \cdot 3 \pm \\
0.41\end{array}$ & $708 \pm 3 \cdot 50$ & $\mathrm{~N} / \mathrm{A}$ & 16.0 & $32.5 \pm 0.89$ & $751 \pm 4 \cdot 58$ & $23.1 \pm 0.70$ \\
\hline 400 - air - 6FDA-DAM & $\begin{array}{l}0.882 \pm \\
0.018\end{array}$ & $\begin{array}{c}1.69 \pm \\
0.02\end{array}$ & $\begin{array}{c}46.3 \pm \\
0.47\end{array}$ & $108 \pm 0.91$ & $27 \cdot 3$ & $0.754 \pm 0.013$ & $46.9 \pm 0.81$ & $62.2 \pm 1.16$ \\
\hline 400 - air - 6FDA-DAM - 2 & - & - & - & - & - & $0.816 \pm 0.025$ & $49.7 \pm 0.16$ & $61.8 \pm 1.89$ \\
\hline 400 - air - 6FDA-DAM - Q & - & $\begin{array}{c}3.98 \pm \\
0.08\end{array}$ & $\begin{array}{c}86.7 \pm \\
0.76\end{array}$ & $189 \pm 2.14$ & 21.7 & $0.975 \pm 0.031$ & $61.5 \pm 0.59$ & $63.1 \pm 2.03$ \\
\hline 16o - air - ZIF-8/6FDA-DAM & - & $\begin{array}{l}25.0 \pm \\
0.24\end{array}$ & $493 \pm 2.19$ & $445 \pm 6.19$ & 19.8 & $18.8 \pm 0.26$ & $528 \pm 1.46$ & $28.1 \pm 0.32$ \\
\hline $315-\mathrm{N}_{2}-\mathrm{ZIF}-8 / 6 \mathrm{FDA}-\mathrm{DAM}$ & - & $33.2 \pm 0.14$ & $531 \pm 2.93$ & $501 \pm 3.09$ & 16.0 & $20.3 \pm 0.48$ & $526 \pm 1.88$ & $25.9 \pm 0.61$ \\
\hline $315-\mathrm{N}_{2}-\mathrm{ZIF}-8 / 6 \mathrm{FDA}-\mathrm{DAM}-2$ & - & $\begin{array}{c}34.7 \pm \\
0.23\end{array}$ & $548 \pm 4 \cdot 51$ & $\begin{array}{c}492 \pm \\
4.20\end{array}$ & 15.8 & $22.7 \pm 0.67$ & $592 \pm 3.27$ & $26.1 \pm 0.78$ \\
\hline 315 - air - ZIF-8/6FDA-DAM & - & $\begin{array}{c}10.6 \pm \\
0.08\end{array}$ & $200 \pm 1.51$ & $198 \pm 1.63$ & 18.8 & $6.12 \pm 0.06$ & $213 \pm 0.85$ & $34.8 \pm 0.37$ \\
\hline 315 - air - ZIF-8/6FDA-DAM - 2 & - & $\begin{array}{l}9.06 \pm \\
0.06\end{array}$ & $179 \pm 1.64$ & $214 \pm 1.56$ & 19.8 & $5.15 \pm 0.10$ & $193 \pm 1.33$ & $37 \cdot 5 \pm 0.64$ \\
\hline $400-\mathrm{N}_{2}-\mathrm{ZIF}-8 / 6 \mathrm{FDA}-\mathrm{DAM}$ & - & $\begin{array}{c}35.2 \pm \\
0.30\end{array}$ & $528 \pm 3.25$ & $419 \pm 3 \cdot 37$ & 15.0 & $24 \cdot 9 \pm 0.47$ & $547 \pm 1.86$ & $22.0 \pm 0.38$ \\
\hline 16o - air - sod-ZMOF/6FDA-DAM & - & $12.3 \pm 0.10$ & $241 \pm 1.57$ & $\begin{array}{c}207 \pm \\
2.30\end{array}$ & 19.6 & $8.15 \pm 0.19$ & $253 \pm 0.57$ & $31.1 \pm 0.77$ \\
\hline
\end{tabular}




\begin{tabular}{|c|c|c|c|c|c|c|c|c|}
\hline $\begin{array}{l}160 \text { - air - sod-ZMOF/6FDA-DAM - } \\
2\end{array}$ & - & $12.5 \pm 0.12$ & $246 \pm 2.11$ & $205 \pm 1.14$ & 19.6 & $8.63 \pm 0.19$ & $259 \pm 1.17$ & $30.0 \pm 0.72$ \\
\hline $315-\mathrm{N}_{2}-$ sod-ZMOF/6FDA-DAM & - & $13.4 \pm 0.05$ & $252 \pm 0.92$ & $270 \pm 1.33$ & 18.8 & $7.64 \pm 0.13$ & $260 \pm 0.74$ & $34.1 \pm 0.60$ \\
\hline $\begin{array}{l}315-\mathrm{N}_{2}-\text { sod-ZMOF/6FDA-DAM - } \\
2\end{array}$ & - & $14.2 \pm 0.12$ & $265 \pm 2.51$ & $263 \pm 2.01$ & 18.6 & $8.47 \pm 0.22$ & $290 \pm 1.73$ & $34 \cdot 3 \pm 0.82$ \\
\hline 315 - air - sod-ZMOF/6FDA-DAM & - & $\begin{array}{c}12.9 \pm \\
0.06\end{array}$ & $240 \pm 1.14$ & $237 \pm 2.23$ & 18.6 & $7.01 \pm 0.06$ & $247 \pm 0.89$ & $35 \cdot 3 \pm 0.26$ \\
\hline $\begin{array}{l}315 \text { - air - sod-ZMOF/6FDA-DAM - } \\
2\end{array}$ & - & $11.6 \pm 0.09$ & $224 \pm 1.24$ & $\begin{array}{c}262 \pm \\
2.64\end{array}$ & 19.2 & $6.60 \pm 0.11$ & $238 \pm 1.59$ & $36.0 \pm 0.72$ \\
\hline 16o - air - K+sod-ZMOF/6FDA-DAM & - & $19.0 \pm 0.21$ & $35^{2} \pm 2.51$ & $260 \pm 1.72$ & 18.6 & $12.7 \pm 0.21$ & $365 \pm 1.55$ & $\begin{array}{c}28.8 \pm \\
0.48\end{array}$ \\
\hline $\begin{array}{l}\text { 16o- air - K+sod-ZMOF/6FDA-DAM } \\
-2\end{array}$ & - & $19.7 \pm 0.15$ & $369 \pm 2.36$ & $275 \pm 3 \cdot 39$ & 18.7 & $13.9 \pm 0.20$ & $392 \pm 1.44$ & $28.2 \pm 0.36$ \\
\hline $315-\mathrm{N}_{2}-\mathrm{K}^{+}$sod-ZMOF/6FDA-DAM & - & $9.5 \pm 0.16$ & $177 \pm 1.71$ & $178 \pm 1.52$ & 18.7 & $5 \cdot 97 \pm 0.16$ & $183 \pm 0.85$ & $30.7 \pm 0.89$ \\
\hline 315 - air - K+sod-ZMOF/6FDA-DAM & - & $\begin{array}{l}3.72 \pm \\
0.09\end{array}$ & $\begin{array}{c}64.2 \pm \\
0.60\end{array}$ & $115 \pm 1.05$ & 17.2 & $1.74 \pm 0.02$ & $69.0 \pm 0.70$ & $39.5 \pm 0.22$ \\
\hline
\end{tabular}




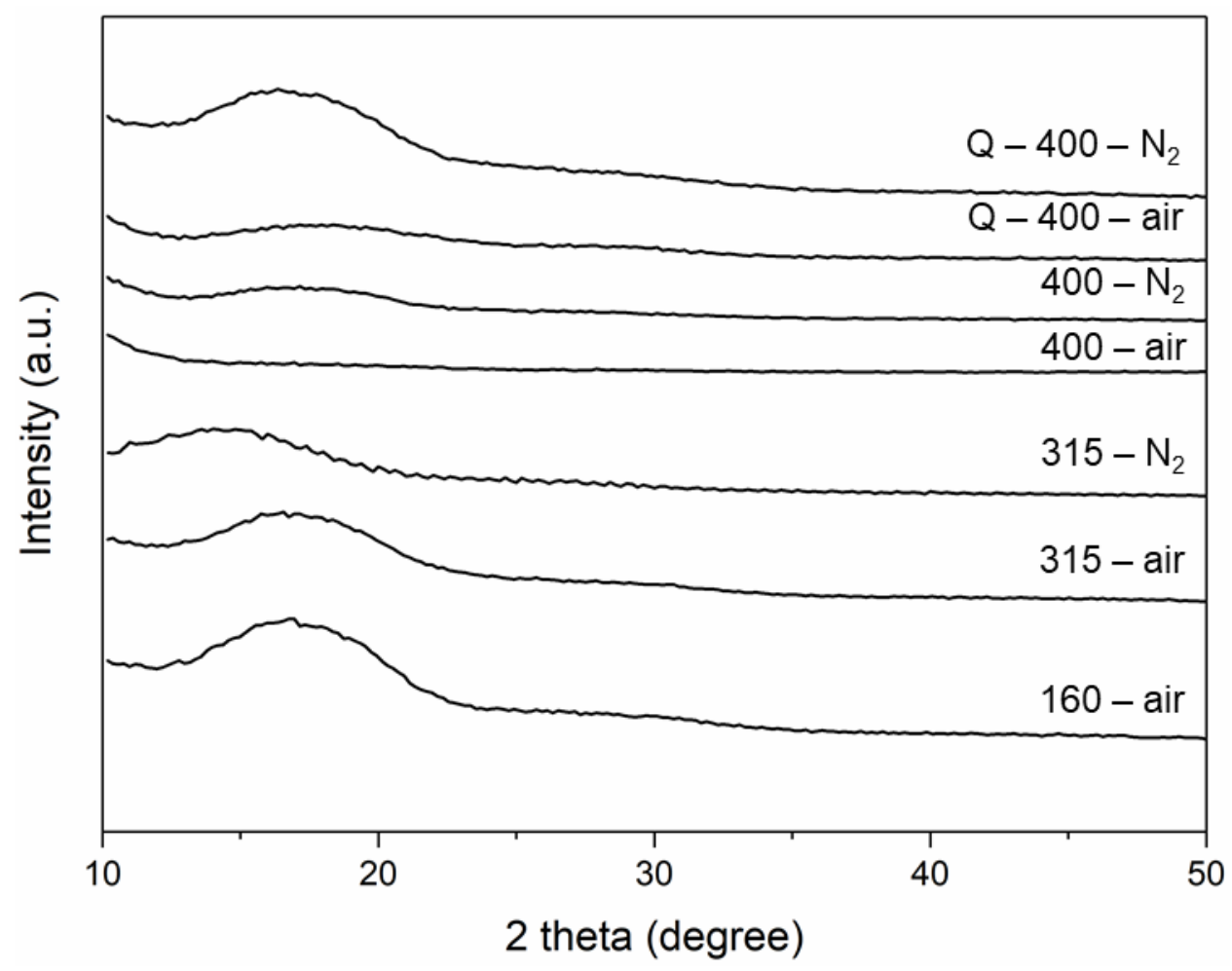

Figure S4.9 XRD patterns of pure 6FDA-DAM membranes thermally annealed at different conditions. (Q: quenched) 


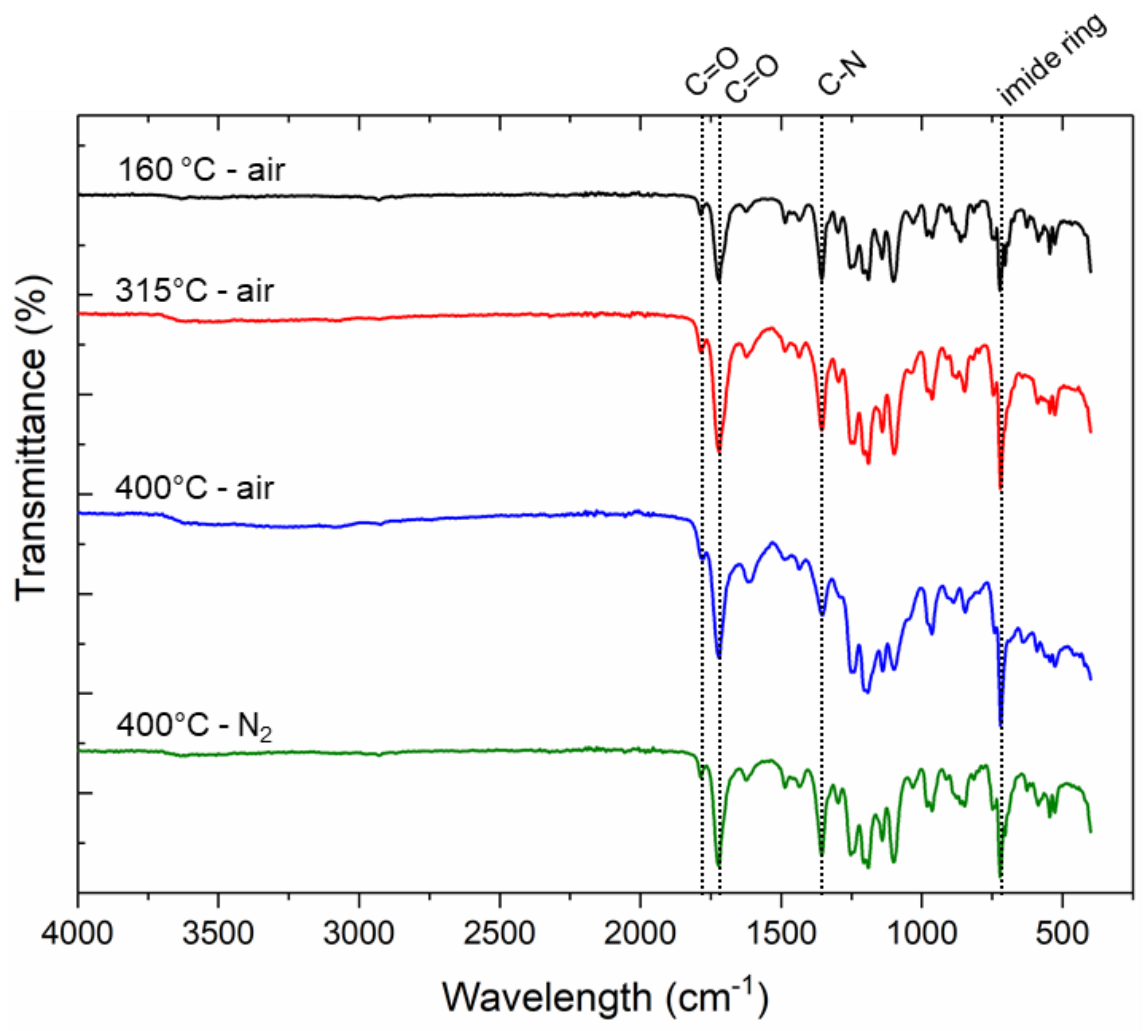

Figure S4.10 FTIR results of 6FDA-DAM membranes thermally annealed at different conditions: black: $160^{\circ} \mathrm{C}$ - air, red: $315^{\circ} \mathrm{C}$ - air, blue: $400^{\circ} \mathrm{C}$ - air, green: $400^{\circ} \mathrm{C}-\mathrm{N}_{2}$

a)

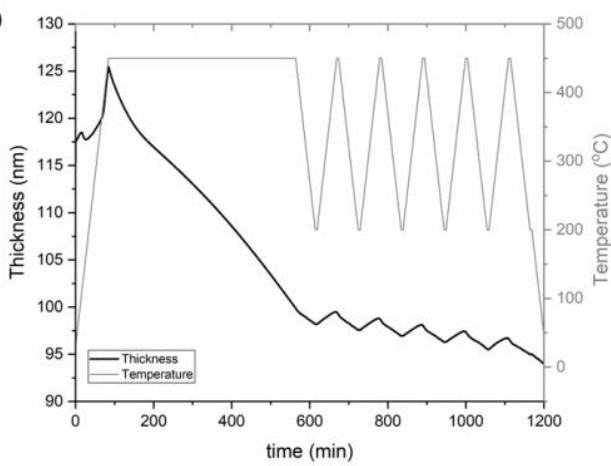

b)

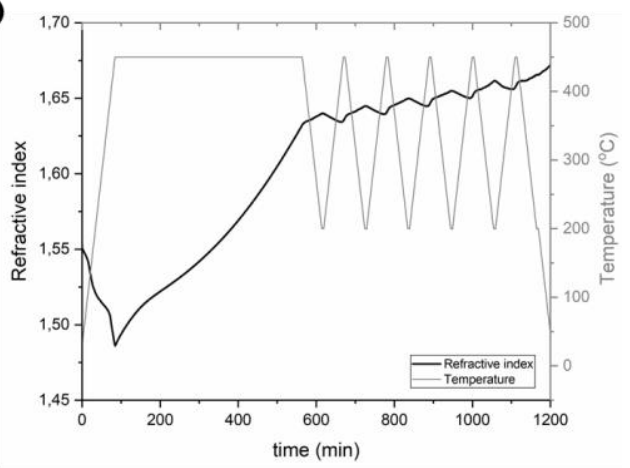

Figure $\mathbf{S}_{4.11}$ Ellipsometry results under $\mathrm{N}_{2}$ a) thickness b) refractive index. 
a)

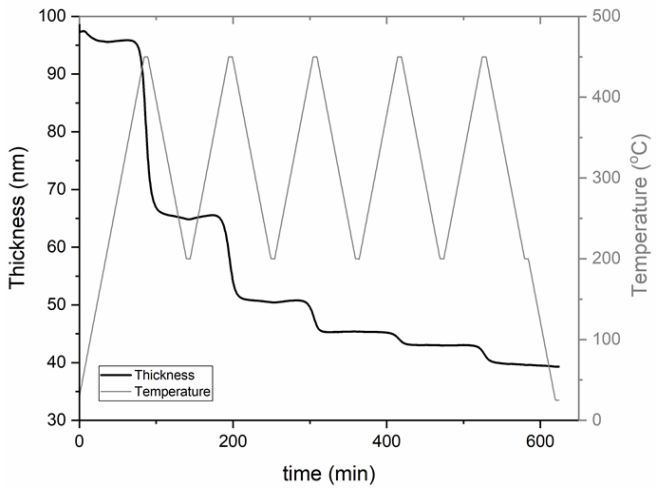

b)

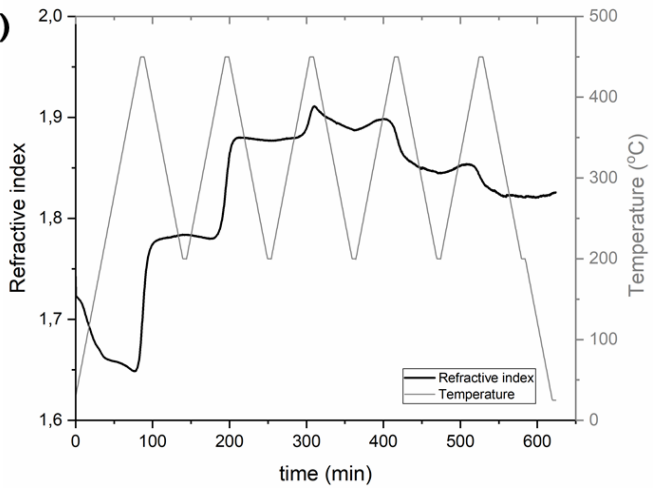

Figure S4.12 Ellipsometry results under $\mathrm{N}_{2}$ a) thickness b) refractive index.

a)

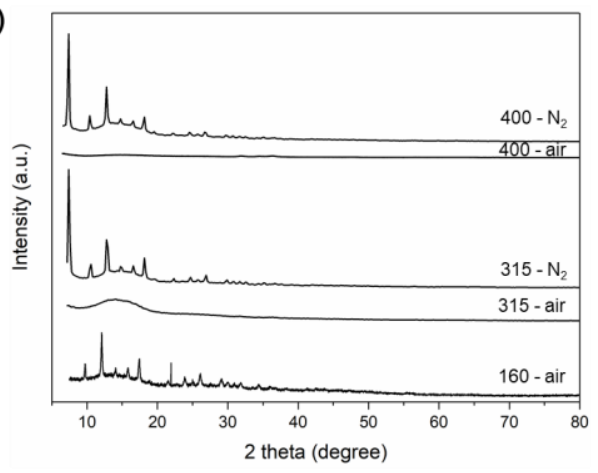

b)

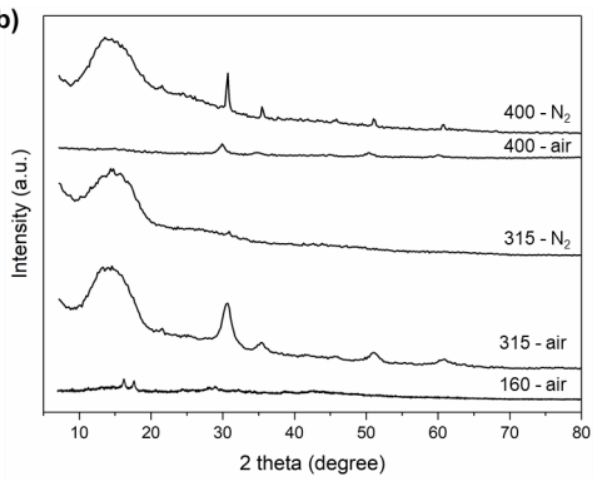

c)

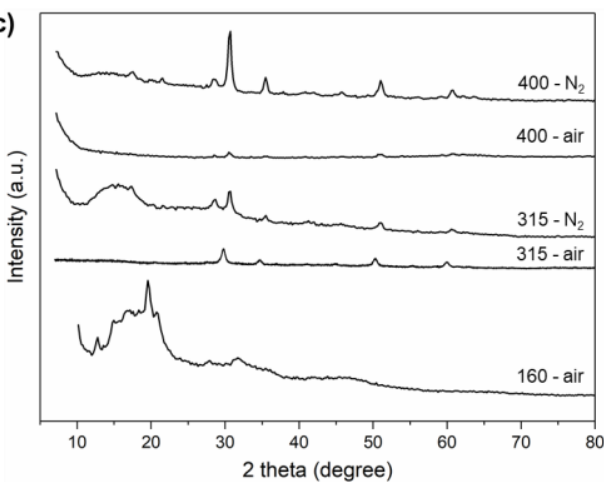

Figure S4.13 XRD patterns of MMMs a) ZIF_MMM, b) sod_MMM and c) K+sod_MMM thermally annealed at different conditions. (Q: quenched). 

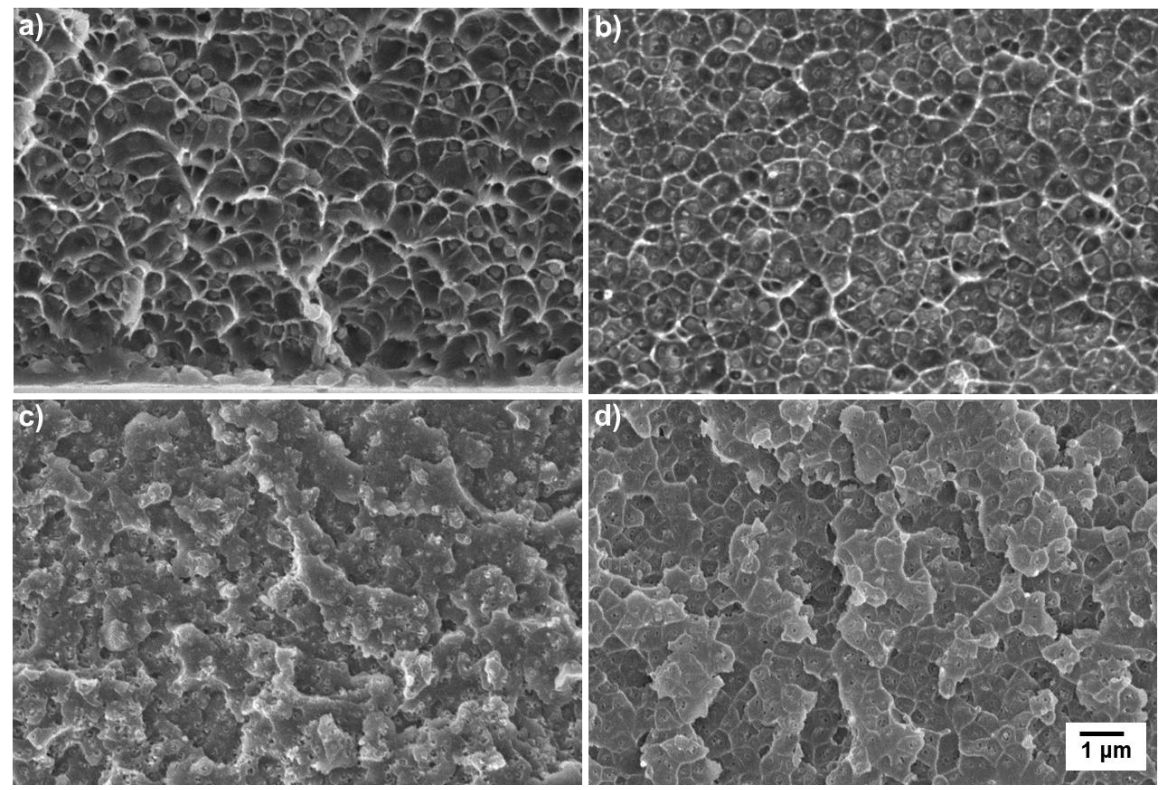

Figure $\mathbf{S 4 . 1 4}$ Cross-sectional SEM images of the thermally annealed MMM samples a) 160 - air - ZIF_MMM, b) 315 - air - ZIF_MMM, c) 400 - air - ZIF_MMM and d) 400 $\mathrm{N}_{2}$ - ZIF_MMM. Scale bar is $1 \mu \mathrm{m}$ and the magnification is 10 ,ooo for all the images. 

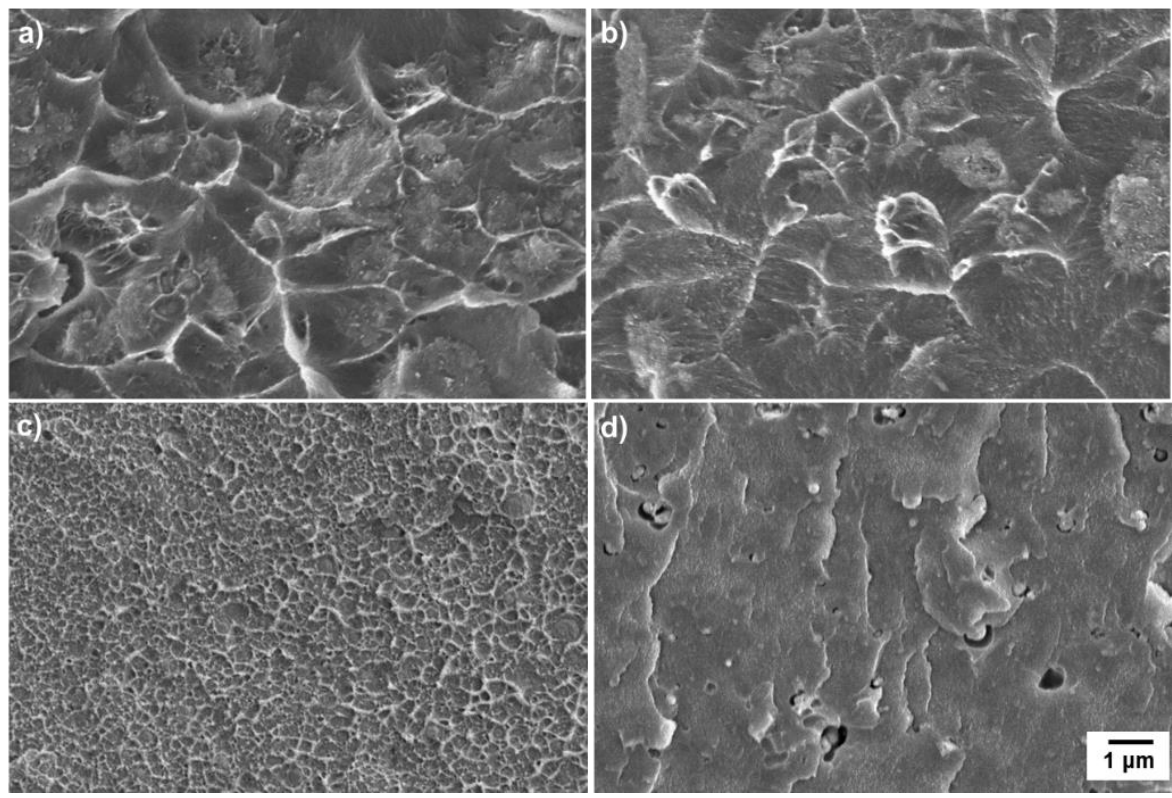

Figure S4.15 Cross-sectional SEM images of the thermally annealed MMM samples a) 160 - air - sod_MMM, b) 315 - air - sod_MMM, c) 160 - air - K'sod_MMM and d) 315 - air - K+sod_MMM. Scale bar is $1 \mu \mathrm{m}$ and the magnification is 10,000 for all the images.
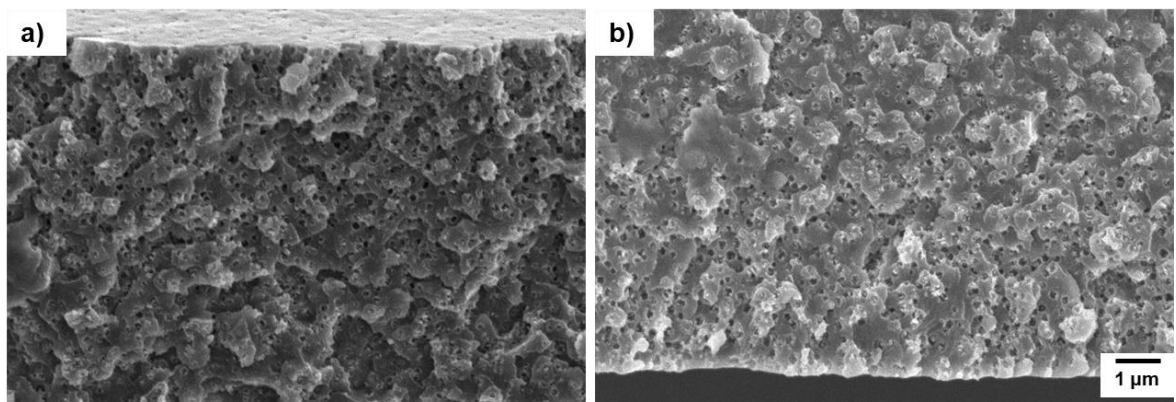

Figure S4.16 Cross-sectional SEM images of 400 - air - ZIF-8/6FDA-DAM close to a) top and b) bottom surfaces showing the pinholes occurred after the thermal treatment. Scale bar is $1 \mu \mathrm{m}$ and the magnification is 10,ooo for all the images. 

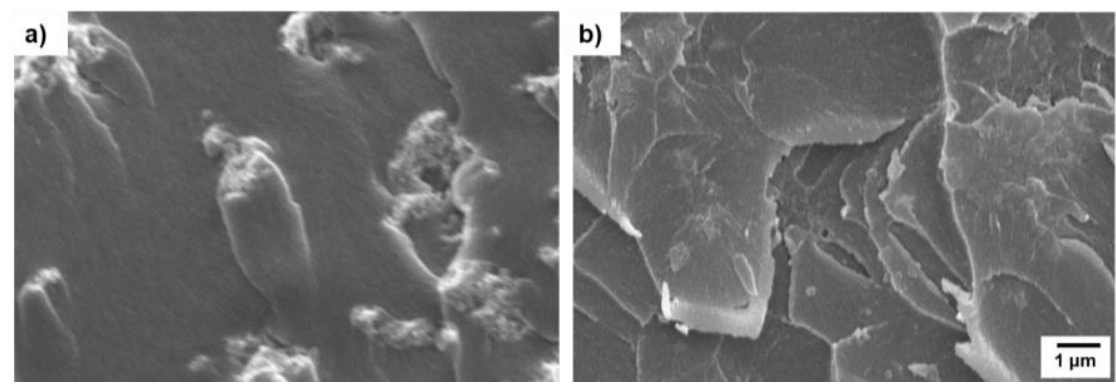

Figure $\mathbf{S}_{4.17}$ Cross-sectional SEM images of the thermally annealed a) 400 - air - sodZMOF/6FDA-DAM and b) $400-\mathrm{N}_{2}$ - sod-ZMOF/6FDA-DAM MMM samples. Scale bar is $1 \mu \mathrm{m}$ and the magnification is 10,0oo for all the images.
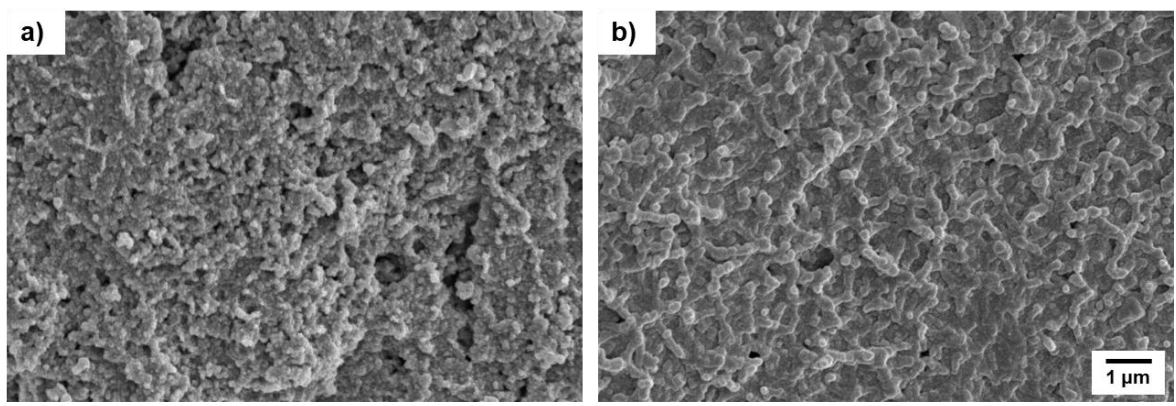

Figure S4.18 SEM images of the thermally annealed a) 400 - air - K+sod-ZMOF/6FDADAM (powder) and b) $400-\mathrm{N}_{2}-\mathrm{K}^{+}$sod-ZMOF/6FDA-DAM (cross-section) MMM samples. Scale bar is $1 \mu \mathrm{m}$ and the magnification is 10,0oo for all the images.
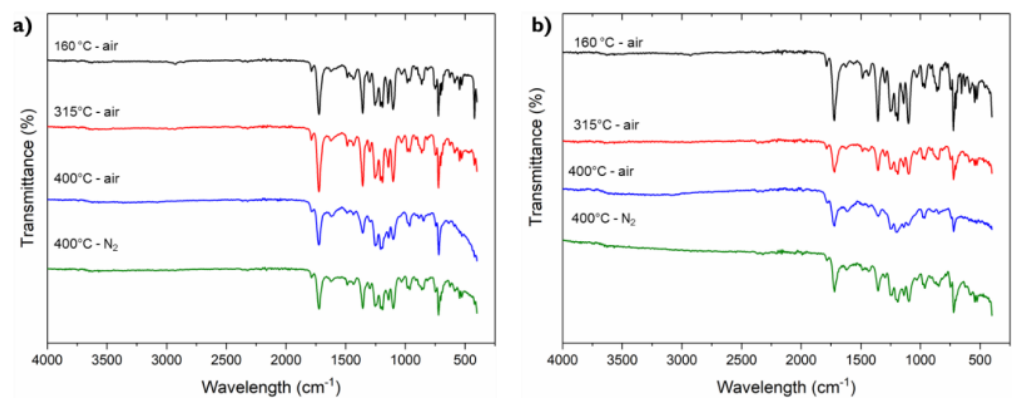

Figure S4.19 FTIR results of a) ZIF-8/6FDA-DAM and b) sod-ZMOF/ 6FDA-DAM membranes thermally annealed at different conditions: black: $160^{\circ} \mathrm{C}$ - air, red: $315^{\circ} \mathrm{C}$ air, blue: $400^{\circ} \mathrm{C}$ - air, green: $400^{\circ} \mathrm{C}-\mathrm{N}_{2}$. 


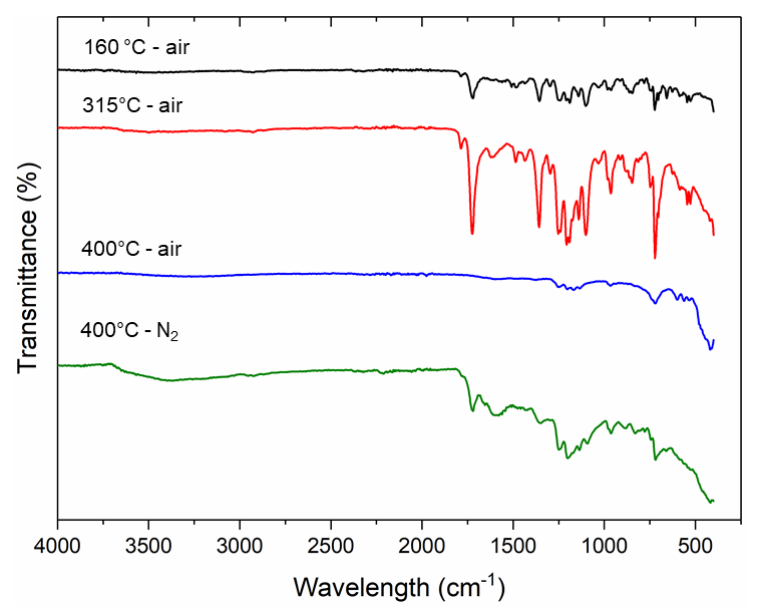

Figure S4.20 FTIR results of $\mathrm{K}^{+}$sod_MMM membranes thermally annealed at different conditions: black: $160{ }^{\circ} \mathrm{C}$ - air, red: $315{ }^{\circ} \mathrm{C}$ - air, blue: $400{ }^{\circ} \mathrm{C}$ - air, green: $400{ }^{\circ} \mathrm{C}-\mathrm{N}_{2}$. 


\section{CHAPTER 5}

\section{Assessing interfacial properties of MOFs using contact angle measurements: Promise and Pitfalls}

This chapter is adapted from:

Özlem H. Demirel, Nieck E. Benes, Jeffery A. Wood, Assessing interfacial properties of MOFs using contact angle measurements: Promise and Pitfalls, Manuscript in preparation. 


\section{Abstract}

Interfacial properties of metal-organic frameworks (MOFs), such as adhesion and wetting properties, play an important role for synthesizing powder MOFs (colloidal stability), preparation of pure and hybrid MOF films and their eventual application. Despite this, relatively few studies have been focused on quantifying the interfacial properties of MOFs. Here, we have systematically investigated the interfacial properties of spin-coated ZIF-8 films through contact angle measurements of multiple probe liquids. Films have been characterized with FTIR, ellipsometry, atomic force microscopy (AFM), white light interferometry (WLI). The effect of drying and waiting time have been found as critical parameters for the static contact angle measurements, highlighting the importance of the sample preparation and measurement techniques. The water contact angle hysteresis measured with advancing-receding method shows a wide variability between maximum and minimum contact angle can be obtained for this system. This is attributed to the separate hydrophilic and hydrophobic domains of the ZIF-8 films or possible instability of ZIF-8 in water. The most stable contact angle values have been achieved by using piezoactuation as a mechanical stimulus, showing large deviation with the apparent 'static' angle. Despite its well-known reported hydrophobic characteristic, average water contact angle values of $91 \pm 2.5^{\circ}$ on ZIF-8 films were found implying this material is on the boundary between hydrophobicity and hydrophilicity. Using most stable contact angle measurements, the surface tension components of ZIF-8 films were estimated. Diiodomethane (DIM) as a non-polar probe liquid has been used to calculate the dispersive surface energy component of the ZIF-8 films as $46.8 \mathrm{mN} \mathrm{m}^{-1}$ which is also found consistent with the estimated theoretical value. The polar component of surface tension has been estimated by using both diiodomethane and ethylene glycol contact angle measurements simultaneously. Polar contributions of $0.4 \mathrm{mN} \mathrm{m}^{-1}$ were estimated, substantially lower vs. dispersive contributions. Calculating the electron acceptor/donor subdivision of the polar component was not possible in this case due to the large spreads in the water contact angle values found for ZIF-8. The interfacial properties of MOFs are very valuable piece of information as a tool box for designing 
MOF synthesis and applications. Here we have shown a way to asses these properties together with the challenges involved in carrying out measurements as well as interpretation. This work highlights the utility of these measurements towards understanding MOF interfacial properties and is an important step to understanding the behavior of MOFs in numerous applications.

\subsection{Introduction}

Metal organic frameworks (MOFs) are hybrid crystalline materials consisting of metal centers connected with organic ligands. Since their discovery, they have been considered attractive due to their high surface area to volume ratio, amongst other properties, for use in various applications such as gas separation/storage, catalysis, sensing, etc. The flexibility from the ability to use different metals and organic ligands to create a MOF allows for tuning properties of a synthesized MOF for a given application. MOFs can be in the form of powders, colloids in suspension, ${ }^{1}$ films on a substrate or embedded within a polymer as a composite material ${ }^{2-4}$ to try to provide additional functionality, such as in a mixed matrix membrane. ${ }^{5}$ In all these cases, the adhesion (or interfacial energy) of the MOF and substrate or surrounding material and the MOF with itself is a crucial parameter governing performance. ${ }^{3,6,7}$ As it is also shown in this thesis, the adhesion between the $\mathrm{Cu}$-BTC MOF films and copper hollow fiber support (Chapter 2), ZIF-8 MOF films and IEMs (Chapter 3), and the MOFpolymer interface in mixed matrix membranes affects the formation of the MOF films and the performance of the MMMs applications (Chapter 4).

However, despite the importance of adhesion properties, there is a limited literature on this topic. Most studies to date have focused on hydrophilicity/phobicity and oleophilicity/phobicity properties of MOFs. Recently, the effect of the morphology on wetting properties of MOFs have been investigated by Medina, et al. ${ }^{8} \mathrm{M}-\mathrm{CAT}-1 \mathrm{MOFs}$ have been prepared as pellets, oriented films and oriented/nanostructured films. Pellets have shown amphilic wetting properties (hydrophilic and oleophilic), while oriented MOF films with lower water contact angle of $30^{\circ}$ vs. a pellet $\left(46^{\circ}\right)$ and underwater oil contact angle of $130^{\circ}$ (indicating oleophobic characters). The polar 
component of the surface tension has severely increased with the transition from pellet to oriented films, finding that it doubled from $\sim 10$ to $20 \mathrm{mN} \mathrm{m}^{-1}$ for oriented films and further increased to $30 \mathrm{mN} \mathrm{m}^{-1}$ for nanostructured films. Oriented and nanostructured MOF films have shown extreme wetting properties with spreading water contact angle and under water oil contact angle of $174^{\circ}$. Superhydrophilic and superhydrophobic MOFs have been obtained with only changing the morphology from randomly oriented to nanostructured with the increase in the surface energy from $\sim 60$ to $80 \mathrm{mN} \mathrm{m}^{-1}$ due to the increase in the polar component. In another recent study, electrochemically grown superhierarchically rough $\mathrm{Cu}$-BTC MOF films have been investigated in terms of its omniphobicity. ${ }^{9}$ Their results show that both water and diiodomethane have relatively high contact angle values, 107.1 and 99.2 respectively. In addition, low-surface-tension fluids such as acetone also formed a droplet on the surface.

A few studies on MOFs and their adhesion properties, beyond hydrophobicity/hydrophilicity, have been found in the literature. In these studies, mostly diiodomethane (non-polar) and water (polar) contact angle values have been used to obtain dispersive and polar components of the surface energy via Fowkes theory. For example, interfacial properties of photoswitchable MOF film, $\mathrm{Zn}(\mathrm{AzDC})(4,4 \text { '-BPE })_{0.5}$ grown on carbon fiber have been investigated. ${ }^{10}$ Increased surface energy with the deposition of MOFs on the carbon fiber surface was attributed to the increase in the polar component of the surface energy which has an influence on the wettability properties of these fibers and its interaction to epoxy composites. Kim et al., have explored the UiO-66 and polyurethane compatibility for the composite films." The surface energy of UiO-66 pellets have been found as $53.3 \mathrm{mN}$ $\mathrm{m}^{-1}$ through water and diiodomethane contact angle measurements. The results show that dispersive components are more dominant than the polar component for UiO-66 MOFs (42.0 and $11.8 \mathrm{mN} \mathrm{m}^{-1}$, respectively). One of the benchmark MOFs, $\mathrm{Cu}-\mathrm{BTC}$, has been studied for its interaction with PLA. ${ }^{12}$ The surface energy components were calculated by using ethylene glycol and diiodomethane due to the large deviations in water contact angles. Surface energy of Cu-BTC with $53.3 \pm 2.5 \mathrm{mN} \mathrm{m}^{-1}$ and PLA with 
$57.1 \pm 3.3 \mathrm{mN} \mathrm{m}^{-1}$ have been calculated and their dispersive components have been found much higher than the polar interactions. Although polar and dispersive surface components shed light on the interfacial properties of MOFs, as known from zeolites, electron donor and acceptor components of the polar interactions are also valuable information to understand especially the hybrid systems. The interaction of MFI type zeolites and different polymer interfaces has been investigated with AFM and surface energy analysis. ${ }^{13}$ These experiments showed the importance of Lewis basicity for the polymer more than van der Waals component. Better adhesion can be obtained with acidic (electron acceptor) component of zeolites and the basic (electron donor) component of the polymer. Similarly, Ferraris, et al. have studied the ZIF- 8 interfacial properties to control the interface between two immiscible polymers, representing one of the few studies on this aspect (to the best of our knowledge). ${ }^{14,15}$ Measuring water contact angles and assuming only apolar liquid-liquid interactions for the MOF led to estimating the interfacial tension of ZIF-8/PBI and ZIF-8/6FDAA as 0.90 and $1.24 \mathrm{mN} \mathrm{m} \mathrm{m}^{-1}$, respectively. Their results show that ZIF-8 play an interface compatibilizer role for this system by lowering the interfacial energy of PBI/6FDD (4.3 $\mathrm{mN} \mathrm{m}^{-1}$ ).

MOFs themselves prove a challenging material to assess interfacial properties on, due to their porous nature, high roughness, lack of consistency between different measurement techniques and absorption of probe liquids as discussed in detail by Fischer et al. ${ }^{16}$ However, the information regarding interfacial properties, that is experimentally accessible, is highly valuable in order to understand MOF properties such as suspension stability (Hamaker constant/van der Waals interactions), as well as MOF-substrate interactions. In the literature, it is possible to find some studies on hydrophobic MOFs which focus primarily on the water contact angle (WCA) and oleophilic/oleophobic properties of MOFs. WCA can provide information about the hydrophilicity/phobicity properties of a material, in this case MOF, but is not sufficient for a full determination of the surface properties which consist of both polar and non-polar contributions. ${ }^{17}$ Comparing with other materials, quantification of the interfacial properties of MOFs has received relatively little experimental focus. ${ }^{8,16,18-23}$ 
ZIF-8 has been one of the most studied MOFs due its reported hydrophobic and oleophilic properties. 14,21,24-33 However, the reported WCA values vary between the studies depending on the morphology of the samples, substrates and measurement conditions. Hydrophobic and oleophilic nature of ZIF-8 has been tested on the powder samples, with WCA of $142 \pm 1.2^{\circ}$ and showing spreading behavior for $n$-hexadecane angle ${ }^{26}$ and on ZIF-8 films grown on carbon nitride, with WCA of $135^{\circ}$ and with absorbing oil up to $58 \mathrm{wt} \%$ from water/oil mixtures. ${ }^{27}$ In another study, WCA of thin ZIF films on glass substrate prepared via dip-coating have been measured. WCA of ZIF films as one-layer and two- layers on glass substrate and four-layers on QCM have been reported along with standard deviations, respectively: WCA of ZIF-8 (62.2 $\pm 2^{\circ}$, $\left.78 \pm 5^{\circ}, 122 \pm 0^{\circ}\right) .{ }^{30}$ Dip-coating technique has been also used for preparation of ZIF-8 on polyimide support and the reported WCA values were around $40^{\circ}$ and $54^{\circ}$ for ZIF8 and ZIF-67, respectively. ${ }^{31}$ Although the hydrophobicity of the polyimide supports increased after MOF coating, values are lower than other reported values. Roughness, air pockets, porous structure absorbing water were discussed as reasons of the low contact angles. WCA of spin-coated ZIF-8 films on silicon wafer were reported as 86.4 $\pm 3 \cdot 7^{\circ} \cdot{ }^{14}$ As it can be seen from these studies, there is not one ultimate contact angle value for ZIF-8, values are found in between $40-140^{\circ}$. Despite its hydrophobic reputation, many studies have reported WCA below $90^{\circ}$ or at the limits of at the limit of hydrophilic and hydrophobic material $\left(90^{\circ}\right)$.

The measurement of sessile droplet contact angle of a liquid on a probe surface is a method by which interfacial energies can be determined. ${ }^{34}$ The most commonly measured angle is the well-known water contact angle as discussed previously, however through the use of additional non-polar, monopolar and polar probe liquids a larger degree of insight towards the interfacial properties of a material can be achieved. This is exemplified in the so-called three-component interfacial tension component method of Van Oss/Good/Chouwdury (vOGC) (van der Waals/Lewis Acid/Lewis base) or two-component the Owens-Wendt (O-W) (dispersion/polar). Each of these relative scales allows for estimating interfacial properties, although both have their own limitations (vOGC is a relative scale against water and $\mathrm{O}-\mathrm{W}$ does not 
allow for negative interfacial tensions). From these measurements, estimates of interfacial adhesion energy strength can be computed or the Hamaker constant of a material determined. This means that the additional probe liquids provide a "simple" method for quantifying interfacial energy.

However, as is well known within the interface science community while the concept of a liquid contact angle on a surface is a simple concept in practice the measurement and interpretation can be rather complicated. The contact angle and the interfacial energies (tensions) are balanced only in equilibrium, meaning that the desired contact angle is the equilibrium or Young angle. In practice, measuring such an angle on a substrate is challenging as there are numerous metastable states which a droplet can be kinetically trapped in ("pinned"). On top of this, analysis is complicated by: the need for a macroscopically flat substrate, potential evaporation of the droplet in this pinned state and possibly inhomogeneities of the substrate or impurities in the probe liquids. Quite often the advancing and receding angles are considered to be more rigorous quantities, although these themselves are also subject to interpretation. ${ }^{16,35,36}$ The time scale for evaporation and for achieving the equilibrium (or more practically, most stable contact angle) are typically not compatible. This means that in order to make use of the wealth of information possible via contact angle measurements, some method must be employed to ensure that the most stable contact angle has been achieved.

A number of techniques have been proposed in order to ensure that the reported contact angle is in fact the most stable angle allowing use of the Young-Dupré equation. For example, the use of a microbalance for accurate determination of the contact angle has been demonstrated previously. ${ }^{37}$ As a conceptually simpler method, applying vibration has been considered to overcome local energy barriers, depin droplets and arrive at the most stable contact angle in a relatively short time frame (prior to substantial droplet evaporation). This concept has been used irregularly in the $\sim 150$ years since Thomas Young first reported contact angles and the law that bears 
his name but has attracted more attention in recent years as a relatively simple method that can be used with existing goniometer systems..$^{8}$

In this study, we explore and quantify the interfacial properties of a synthesized MOF (zeolitic imidazolate framework 8, ZIF-8) through contact angle measurements of multiple probe liquids on spin-coated ZIF-8 films through systematic investigation. We achieve the most stable contact angle using piezoactuation, comparing the values with and without vibration and demonstrate that the angles achieved without vibration are far closer to the advancing angle vs. the "most stable contact angle", as well as investigate the possible influence of film roughness on the resulting behavior. From our determined contact angles, we determine the surface energy components of ZIF-8 and relate this to adhesive energy with various substrates, as well as suspension stability. Our findings of the van der Waals interfacial component was tested against the theoretical prediction of the Hamaker constant of ZIF-8, computed using the refractive index and dielectric constant as measured by ellipsometry (and compared to literature). We highlight how the measured interfacial properties of ZIF-8 help to explain its suspension stability in various liquids, which is crucial for the ability to cast films on a substate. This work highlights the value in using multiple probe liquids with varying polarity to assess surface properties for MOFs, while also quantifying the challenges involved in measuring on such materials. 
Table 5.1 Probe liquids for contact angle measurements and surface tension properties $\left(\right.$ at $\left.20^{\circ} \mathrm{C}\right) .39$

\begin{tabular}{|c|c|c|c|c|c|}
\hline Probe Liquids & Formula & $\gamma$ & $\gamma^{\mathrm{LW}}$ & $\gamma^{\oplus}$ & $y^{\ominus}$ \\
\hline $\begin{array}{l}\text { Diiodomethane } \\
\text { (DIM) }\end{array}$ & $\mathrm{CH}_{2} \mathrm{I}_{2}$ & 50.8 & 50.8 & o & o \\
\hline Water (W) & $\mathrm{H}_{2} \mathrm{O}$ & 72.8 & 21.8 & $25 \cdot 5$ & $25 \cdot 5$ \\
\hline Formamide $(\mathrm{F})$ & $\mathrm{CH}_{3} \mathrm{NO}$ & 58.0 & 39.0 & 2.28 & 39.6 \\
\hline $\begin{array}{l}\text { Ethylene glycol } \\
\text { (EG) }\end{array}$ & $\mathrm{C}_{2} \mathrm{H}_{6} \mathrm{O}_{2}$ & 48.0 & 29.0 & 3.0 & 30.1 \\
\hline
\end{tabular}

$\gamma$ : surface tension, $\gamma^{\mathrm{LW}}$ : Lifshitz-van der Waals surface component, $\gamma^{\oplus}$ : electronacceptor surface, component, $\gamma \ominus$ : electron-donor surface component

\subsection{Theoretical Background}

At equilibrium, the forces at the three-phase contact line are balanced and give rise to the classic Young-Dupré equation (below):

$$
\gamma_{L} \cos \theta_{e q}=\gamma_{S}-\gamma_{S L}
$$

where $\gamma_{L}$ is the liquid free surface energy, $\theta_{e q}$ is the contact angle, $\gamma s$ is the solid free surface energy and $\gamma_{S L}$ is the interfacial tension between solid-liquid. (Fig. 5.1)

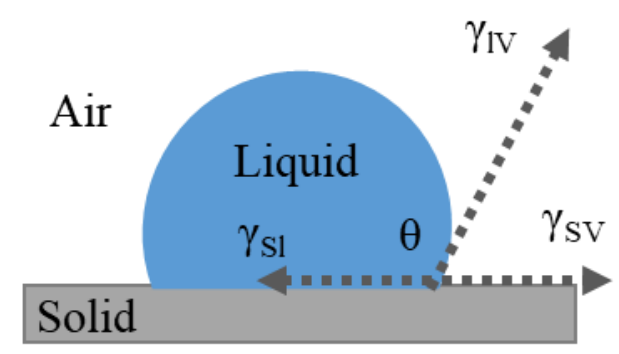

Figure 5.1 Schematic representation of a liquid droplet on a solid with interfacial tension components. 
Through the use of a suitable combining rule for surface and interfacial tensions, individual contributions can be determined as resulting from van der Waals (dispersion) type interactions and polar interactions such as in the Owens-Wendt formulation (equivalent formulation by Fowkes). These polar interactions can be further subdivided as in the Van Oss-Chaudhury-Good (vOCG) method as Lewis acid/base type interactions. The vOCG approach is based on a relative scale with the acid and base components given relative to water. In both cases, it is a crucial to note that the Young-Dupré equation applies only at equilibrium. That is, effectively at the most stable contact angle a droplet will form on a macroscopically flat substrate. In order to achieve this angle prior to liquid evaporation, it is possible to actuate (shake) the droplet to overcome local energy minimum and arrive at the apparent most favorable energetic state of a droplet (most stable contact angle) which can be equated with the equilibrium angle. (Fig. 5.2) Typically droplets placed on a surface without actuation or some other energy supplied to depin the droplet will initially assume angles far closer to that of the advancing contact angle..$^{40-43}$

Owens-Wendt Approach (Fowkes):

$$
\gamma_{L}\left(1+\cos \theta_{e q}\right)=2\left(\sqrt{\gamma_{L}^{D} \gamma_{S}^{D}}+\sqrt{\gamma_{L}^{P} \gamma_{S}^{P}}\right)
$$

where $\gamma_{L}$ is the liquid free surface energy, $\theta_{e q}$ is the contact angle, $\gamma_{L}{ }^{D}$ and $\gamma_{L}{ }^{P}$ are the liquid dispersive and polar surface components, respectively, and $\gamma s^{D}$ and $\gamma s^{P}$ are the solid dispersive and polar surface components, respectively.

Van Oss-Chaudhury-Good Method:

$$
\gamma_{L}\left(1+\cos \theta_{e q}\right)=2\left(\sqrt{\gamma_{L}^{L W} \gamma_{S}^{L W}}+\sqrt{\gamma_{L}^{\oplus} \gamma_{S}^{\ominus}}+\sqrt{\gamma_{L}^{\ominus} \gamma_{S}^{\oplus}}\right)
$$

where $\gamma_{L}{ }^{L W}$ and $\gamma_{S}{ }^{L W}$ are the liquid and solid Lifshitz-van der Waals surface component, respectively, $\gamma_{L}{ }^{-}$and $\gamma_{L^{+}}$are liquid electron-donor and electron-acceptor polar surface components, respectively, and $\gamma s^{-}$and $\gamma s^{+}$are solid electron-donor and electron-acceptor polar surface components, respectively. 
In either case, detailed information about interfacial properties and energy can be computed if the material surface tension components are known. The vOCG approach requires a minimum of three probe liquids, one non-polar, one polar and one monopolar liquid in order to attempt to estimate these parameters as independently as possible. The choice of probe liquids strongly influences the uncertainty of the resulting parameter set. The advantage of this approach is the ability to use liquid contact angle measurements in order to determine solid properties, and then make predictions regarding stability, solubility/miscibility or adhesion of these materials. ${ }^{44}$ Compared to the two-component models, the vOCG is capable of predicting negative interfacial tensions (miscible liquids/soluble materials) but comes with the added complications of finding three suitable probe liquids which have sufficiently different surface tension components and form finite contact angles on substrates. In this work, we compare both the two-component and three-component approaches and use the predictions to help explain experimental observations regarding ZIF-8 colloidal stability in various suspending liquids.

Advancing and receding contact angles (ACE and RCA) are important parameters for solid surface characterization, that represents the highest and lowest angle of contact angle hysteresis range, respectively. ACA is measured by adding liquid to the deposited droplet and at certain point, the contact line expands with constant angle which is ACA. The RCA is measured by removing liquid from the droplet. At first, the contact line will be stable with decrease in CA. When it is reached to RCA, CA remains stable and contract line is receding. ${ }^{34-36}$ ACA and RCA, besides giving range for the contact angle hysteresis, also gives a lot of information to understand solid-liquid systems.

In this work, we systematically investigate the influence of vibration on 'static' contact angles of various probe liquids on a ZIF-8 film, the advancing and receding water contact angles and the angle observed under piezoactuation. For this, the influence of substrate preparation conditions (drying temperature/time) are considered for its influence on the resulting interfacial properties. 


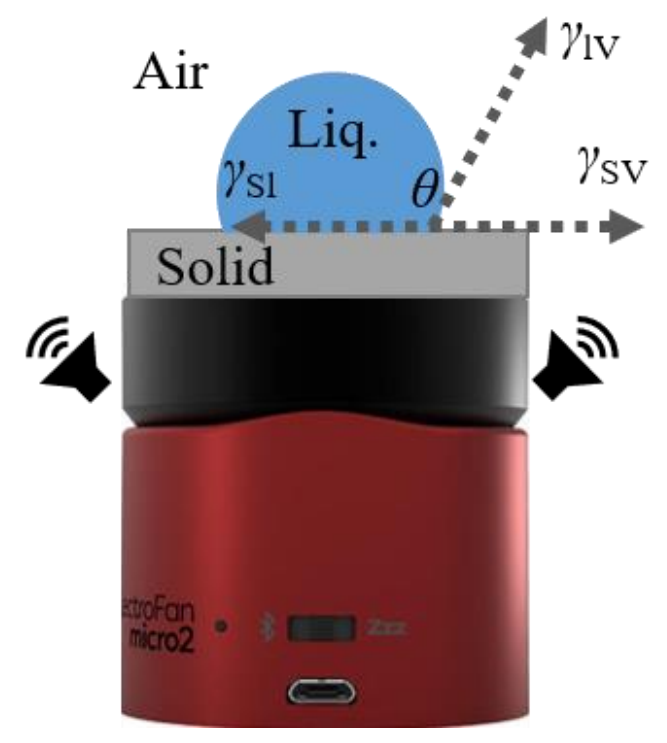

Figure 5.2 Schematic representation of a liquid droplet on a solid with interfacial tension components with piezoactuation as a mechanical stimulus ('LectroFan micro2 speaker).

\subsection{Experimental}

\subsubsection{ZIF-8 synthesis and film preparation}

ZIF-8 crystals were synthesized by the modified version of the recipe from Cravillion. ${ }^{45}$ Metal and organic ligand solutions were prepared separately with $2.9 \mathrm{~g}$ $\mathrm{Zn}\left(\mathrm{NO}_{3}\right)_{2} .6 \mathrm{H}_{2} \mathrm{O}$ (zinc nitrate hexahydrate, Sigma Aldrich, $\geq 99.0 \%$ ) and $6.5 \mathrm{~g} \mathrm{2-}$ methylimidazole (HMIM, Sigma Aldrich, 99\%) dissolved in $200 \mathrm{ml}$ methanol (MeOH, Sigma Aldrich, anhydrous 99.8\%). Zn solution poured slowly into the organic ligand solution and the mixture was mixed with magnetic stirrer for one hour. The synthesis mixture turned into a milky color as the synthesis started in couple of minutes. ZIF-8 crystals were obtained via centrifuge and washed with methanol and ethanol $(\mathrm{EtOH}$, EMSURE ${ }^{\circledR}$, absolute for analysis), respectively. ZIF-8 colloidal solution in EtOH was prepared directly at this point without drying the crystals. For material characterization, ZIF-8 crystals were dried at $40{ }^{\circ} \mathrm{C}$ under vacuum overnight. For comparison, commercial ZIF-8 (Basolite Z120o, Sigma Aldrich) was used. 
For thin ZIF-8 film, o.2 M ZIF-8 colloidal solution in EtOH was prepared after the synthesis. The solutions were spin coated onto silicon wafer with native oxide layer in Laurell WS-40oB-6NPP-Lite spin coater. For this, $\sim 0.4 \mathrm{~mL}$ ZIF-8 solution was injected on the silicon wafer followed by rotating at $3000 \mathrm{rpm}$ for $30 \mathrm{~s}$ with an acceleration rate of $1000 \mathrm{rpm} \mathrm{s}^{-1}$. After spin coating, the samples were dried in a nitrogen box, or at 30 $60{ }^{\circ} \mathrm{C}$ under vacuum for overnight prior to the contact angle measurements.

\subsubsection{Characterization}

ZIF-8 powder - The XRD patterns of the ZIF-8 powders were determined by powder Xray diffraction (XRD) on a Bruker D2 PHASER operated at $10 \mathrm{~mA}$ and $30 \mathrm{kV}$ using a $\mathrm{CuK} \alpha$ source with a wavelength $(\lambda)^{1 / 4} 1.54 \AA$ at room temperature. Scans were made at variable angle, ranging from 5 to $45^{\circ}$ with a $2 \theta$ step size of $0.02^{\circ}$ and a scan speed of 1 s per step. The ZIF-8 powders were also investigated using a field-emission electron microscope (FE-SEM, JEOL, Japan). The intensity-weighted particle size distribution of the ZIF-8 powders was determined by the dynamic light scattering (DLS) technique using a Malvern Zetasizer Nano ZS instrument. The ZIF-8 colloidal solution was diluted to $10 \mathrm{ppm}$ for the DLS measurement. Fourier transform infrared spectroscopy (FT-IR, Spectrum Two, Perkin Elmer) was used with Universal ATR Two attachment) for the surface analysis of ZIF-8 coated Si wafers.

ZIF-8/Si wafer - Spectroscopic ellipsometer M-20ooX (J.A. Woollam Co., Inc.) was used to determine the thickness and refractive index of the spin-coated ZIF-8 films. Measurements were performed with light reflected at $70^{\circ}$ angle of incidence. The Complete EASE v.4.64 software package (J.A. Woollam Co., Inc.) was used to model the data in the wavelength of 370-1000 nm. 6FDA-DAM films were modelled with Cauchy dispersion and B-spline (fit parameters: thickness, A, B) using the built-in optical properties of silicon wafer as a substrate. The results reported as the average of five measurement from different spots of the sample along with the standard errors. Atomic force microscopy (AFM) (Vecco Dimension 3100) was used for roughness/surface characterization about the ZIF-8/Si wafer films. The measurements are done with probe type PPP-NHCR-2o (NanoSensors) by using tapping mode in air. 
White light interferometry (Bruker WLI Contour GT-I (ILP) has been used to create $2 \mathrm{D} / 3 \mathrm{D}$ picture of the MOF film surface.

\subsubsection{Contact angle measurements}

A contact angle goniometer (DataPhysics OCA2o) was used for contact angle measurements at ambient temperature $\left(20-22{ }^{\circ} \mathrm{C}\right)$ and relative humidity $(45-55 \%)$. Milli Q Water (18.2 M $\Omega$ cm), diiodomethane (DIM, Sigma Aldrich, ReagentPlus ${ }^{\circledR}, 99 \%$, containing copper as stabilizer), formamide (F, Supelco, for analysis EMSURE $^{\circledR}, \geq 99.2$ \%) and ethylene glycol (EG, Sigma Aldrich, anhydrous, 99.8\%) were used as probe liquids. ${ }^{44}$ A separate syringe was dedicated for each probe liquids. $2 \mu \mathrm{L}$ droplet was carefully deposited onto the sample surface. In this study, each contact angle measurement has been tested on a different sample prepared under the same conditions. Re-measuring on the same sample was strictly avoided in order not to change the surfaces through irreversible chemical changes. The image of static contact angle was taken after three different waiting times: $30 \mathrm{~s}, 2 \mathrm{~min}$ and $5 \mathrm{~min}$, reported contact angles based on 3-5 repeats per sample. Advancing and receding contact angles (ACA and RCA) of water were measured in sessile drop needle-in mode by leaving the needle in the droplet. Continuously supplying and withdrawing water up to $10 \mu \mathrm{l}$ at $0.2 \mu \mathrm{min}^{-1}$ within three cycles to calculate ACA and RCA, respectively as per the procedure recommended by Korhonen et al. ${ }^{35}$ In order to overcome the energy barriers for the droplet without substantial evaporation of the probe liquids, a vibration method has been used after the droplet placed onto the sample. For this, a 'LectroFan Micro 2' speaker was used with the Physics Toolbox Suite free application (for Android) to generate a tone. ${ }^{46}$ The frequency and waveform were chosen based on previously reported experiments, as well as experimentation. ${ }^{40,42} \mathrm{ZIF}-8 / \mathrm{Si}$ wafer samples attached to top surface of the speaker. After the droplet has been put on the sample, the speaker turned on with a tone generated (sine wave- frequency of $25 \mathrm{oHz}$ ) for $30 \mathrm{~s}$. The contact angle values are reported along with the standard error and the size of the sample. 


\subsection{Results and discussion}

\subsubsection{ZIF-8 characterization}

Powder XRD patterns confirm the crystal structure of the ZIF-8 as a proof of the successful synthesis of ZIF-8 (Fig. 5.3 (a)). FE-SEM image in Fig. 5.3 (c) shows uniform ZIF-8 crystal formation with small particle size between 50-80 nm diameter. In (Fig. 5.3 (b)), DLS result show that the intensity size distribution is narrow and the average particle size is $122 \mathrm{~nm}$ with PDI of 0.102 The difference between the particle size obtained by SEM and DLS is due to the different measuring techniques and the environment. DLS measurement was performed in a diluted dispersed ZIF-8 powders in $\mathrm{EtOH}$ and particles can be agglomerated to a certain degree.

The thickness of the ZIF-8 films were estimated using ellipsometry as $206.5 \pm 10.3 \mathrm{~nm}$. Spin-coated ZIF-8 films were also investigated with FT-IR spectrum, as it can be seen in Fig. 5.4 (a). Bare Si wafer is also reported along with ZIF-8/Si wafer. The main bands at 3144, 2931, 1662, 1580, 1505, 1422, 1376,1308, 1143, 994, 755, $695 \mathrm{~cm}^{-1}$ are all visible for ZIF-8/Si wafer. The result is consistent with the previous studies. ${ }^{45,47}$ To be more precise, the peaks at 3144 and $2931 \mathrm{~cm}^{-1}$ represents aromatic and aliphatic $\mathrm{C}-\mathrm{H}$ vibrations, respectively. $C=C$ stretching and $C=N$ stretch vibration are visible at 1662 and $1580 \mathrm{~cm}^{-1}$. The bands at 1300 and $1422 \mathrm{~cm}^{-1}$ are showing the ring stretching, while the peak at $1143 \mathrm{~cm}^{-1}$ is corresponding to the aromatic $\mathrm{C}-\mathrm{N}$ stretching. The bands at 994 and $755 \mathrm{~cm}^{-1}$ are related to $\mathrm{C}-\mathrm{N}$ bending vibration and $\mathrm{C}-\mathrm{H}$ bending mode, respectively. Lastly, The peak at $694 \mathrm{~cm}^{-1}$ is corresponding to the ring-out-of plane bending vibration of HMIM. 
a)

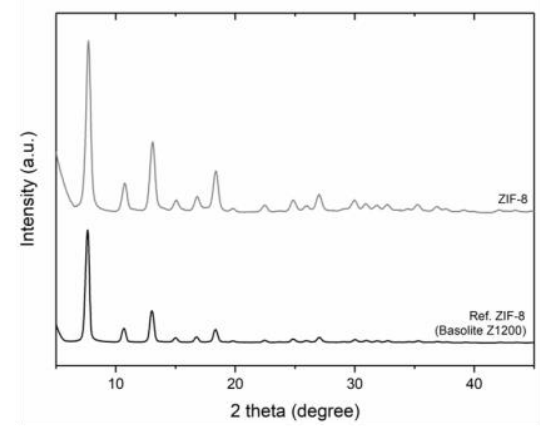

b)

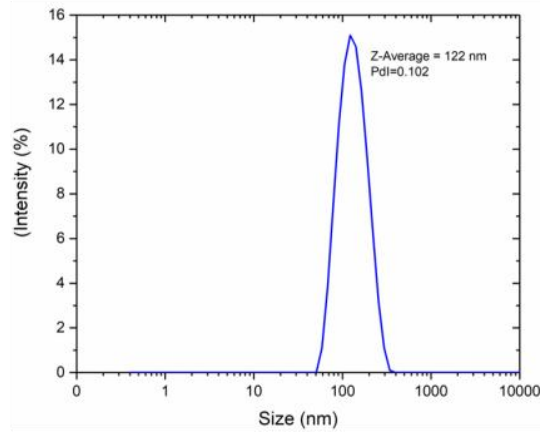

c)

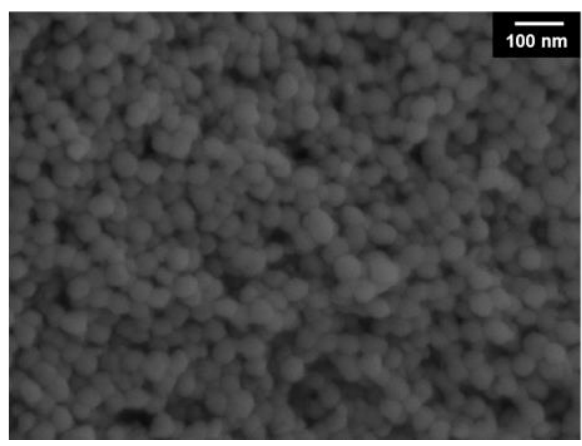

Figure $5 \cdot 3$ Characterization results of ZIF-8 powders a) XRD patterns of ZIF-8 powders and commercial ZIF-8 (Basolite Z1200), b) Intensity size distribution of ZIF8 crystals in ethanol obtained by DLS and c) FE-SEM image of ZIF-8 as-synthesized powders (x100.00o magnification).

From the SEM and other characterization methods, it is clear that while the substrate appears macroscopically flat (and no visible deviation is observed in the baseline when doing visual contact angle analysis) the actual substrate has a degree of surface roughness. ${ }^{48} \mathrm{AFM}$ and WLI were used t to obtain an estimate of the surface roughness. The ZIF-8 particles used in this work are in the range of $50-80 \mathrm{~nm}$ and coated on the silicon wafer as an ideally close-packed thin film with a thickness of $\sim 200 \mathrm{~nm}$, as estimated from ellipsometry. Based on either atomic force microscopy or white light interferometry, the observed 'roughness' macroscopically does not alter the contact area to a substantial degree indicating the substrate is effectively "flat" (see SI for computation: Fig. S5.1 and 2). ${ }^{48,49}$ While the estimated surface roughness did not indicate there would be a substantial impact on the estimated contact angle, this is only an estimate of the surface value and as the substrate is porous a larger impact could be possible when measuring upon a MOF film (i.e. the case where there is 
uncovered bare substrate in contact with the liquid or larger wetting networks throughout the porous structure). ${ }^{48,5^{\circ}}$ Given the particle size, the expected gap spacing between particles was quite small and AFM estimates of roughness showed no more than a $10 \%$ increase in the surface contact area. WLI indicated a roughness of 1.002, indicating it is relatively flat. (Fig $\mathrm{S}_{5.2}$ )
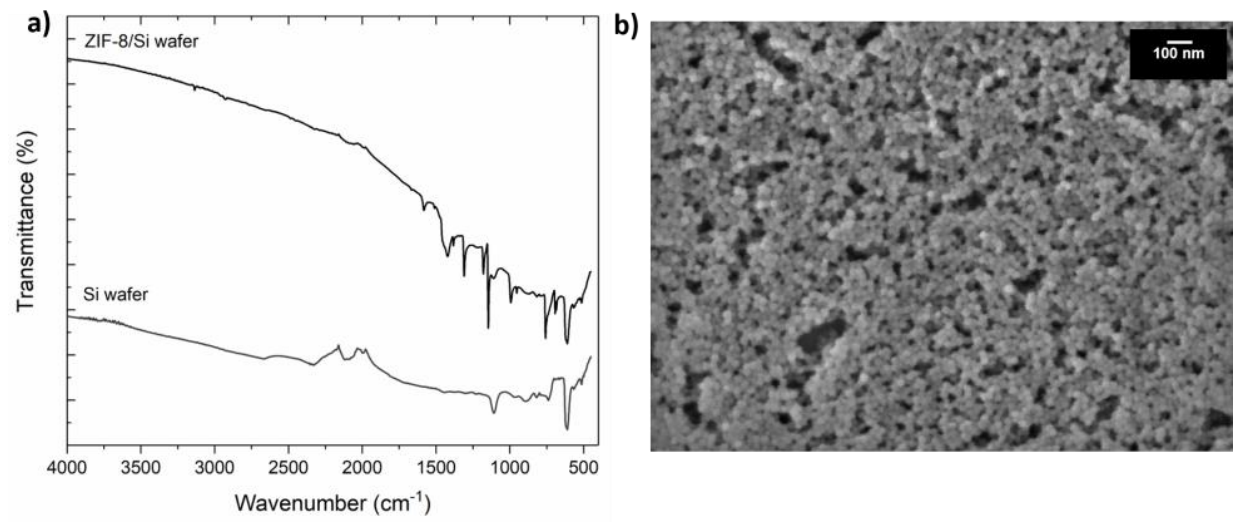

Figure 5.4 a) FT-IR spectra of ZIF-8/Si wafer and bare Si wafer samples and b) FESEM image of ZIF-8/Si wafer.

\subsubsection{Static contact angle}

Influence of the drying conditions - First, we have explored the 'typical' approach of contact angle measurements. As-prepared ZIF-8 films after drying at room temperature under nitrogen box have different contact angle values compared to the ones dried at higher temperature. The effect of the residual solvent in the thin films changes the surface characteristics drastically. As it can be seen Table 5.2 and Fig. 5.5, changing the drying conditions to $60^{\circ} \mathrm{C}$, where presumably all ethanol has evaporated, led to approximately doubled water contact angle, from $45.7^{\circ}$ to $98.9^{\circ}$. Initially spreading DIM droplets were found to a finite angle of $50.7 \pm 0.3^{\circ}$ while CA-F have increased from $8.5 \pm 1.1^{\circ}$ to $45 \cdot 3 \pm 0.8^{\circ}$. Drying at ambient temperature under nitrogen presumably was not sufficient to remove all the ethanol. Beside the effect of the residual solvent, change in the surface energy may be also due to long drying time under vacuum. Under vacuum there may be defect formation and/or increase in the roughness on the surface that liquid droplet sets on an air cushion instead of the solid 
which is a desired characteristic of hydrophobic surfaces. ${ }^{51,52}$ Capillary condensation is also another possible phenomenon can take place on the porous material like MOF films. ${ }^{53}$ However, the droplet and the surface were stable after these conditions. Although the WCA of $45 \cdot 7 \pm 0.24$ is consistent with previously reported values, ${ }^{31}$ the drastic change in WCA after drying is also in the range of previously reported values in the literature. .4,29,33 $^{2}$

Table 5.2 Contact angle results of probe liquids on ZIF-8 film dried in different conditions

\begin{tabular}{|c|c|c|c|c|c|c|c|}
\hline Sample & $\begin{array}{c}\text { Drying } \\
\text { conditions }\end{array}$ & $\begin{array}{l}\text { Waiting } \\
\text { time (s) }\end{array}$ & $\begin{array}{c}T \\
\left({ }^{\circ} \mathrm{C}\right)\end{array}$ & $\begin{array}{c}\text { Relative } \\
\text { humidity } \\
(\%)\end{array}$ & CA-W & $\begin{array}{c}\text { CA-DIM } \\
\left(^{\circ}\right)\end{array}$ & CA-F \\
\hline $\begin{array}{c}\text { Bara Si } \\
\text { wafer }\end{array}$ & N/A & 30 & 21.8 & 51 & $\begin{array}{c}42.4 \pm 0.5 \\
(n=6)\end{array}$ & $\begin{array}{c}45 \cdot 3 \pm 0.8 \\
(n=6)\end{array}$ & $\begin{array}{c}23.6 \pm 0.5 \\
(n=7)\end{array}$ \\
\hline $\begin{array}{c}\text { ZIF-8/Si } \\
\text { wafer }\end{array}$ & $T_{\text {room }}-\mathrm{N}_{2}$ & 30 & 22.1 & 53 & $\begin{array}{c}45 \cdot 7 \pm 0.24 \\
(n=4)\end{array}$ & Spreading & $\begin{array}{c}8.5 \pm 1.1 \\
(n=3)\end{array}$ \\
\hline $\begin{array}{c}\text { ZIF-8/Si } \\
\text { wafer }\end{array}$ & $\begin{array}{c}60^{\circ} \mathrm{C}- \\
\text { vacuum }\end{array}$ & 30 & 20.8 & 50 & $\begin{array}{c}98.9 \pm 0.7 \\
(n=4)\end{array}$ & $\begin{array}{c}50.7 \pm 0.3 \\
(n=4)\end{array}$ & $\begin{array}{c}45 \cdot 3 \pm 0.8 \\
(n=3)\end{array}$ \\
\hline
\end{tabular}

$n$ : size of the sample, reported along with the standard error (CA \pm standard error) 
$\operatorname{Tdry}\left({ }^{\circ} \mathrm{C}\right)$

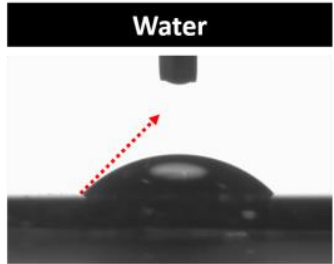

1

60

(vacuum)
Diiodomethane
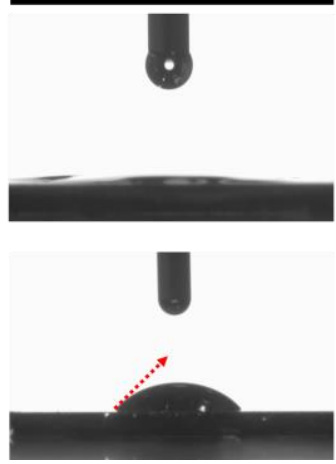

Formamide
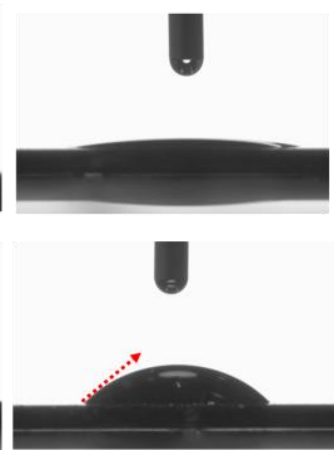

Figure 5.5 Contact angle results of probe liquids on ZIF-8 film dried in different conditions.

Time dependence - For the contact angles of the probe liquids, three different waiting times have been used, $30 \mathrm{~s}, 2$ min and $5 \mathrm{~min}$. Measurement time is the time between droplet is deposited on the surface and the contact angle is measured. Water contact angle has not been measured for 5 min due to significant evaporation of the droplet. As it is reported in Table 5.3, CA-DIM values are more stable compared to the other probe liquids because it has a low volatility and is thereby less affected by the long measurement time, as well it possesses no substantial polar interactions. CA-W values have been decreased with the longer waiting times. Due to the evaporation of water droplet, it is difficult to discuss these results based on the surface characteristic. On the other hand, CA-F has strongly affected by the measurement time, as it can be also seen in large deviations reported along with the contact angle results. In the case of $60^{\circ} \mathrm{C}$ drying did not show large deviations in contact angle vs. time (likely relating to the low relative volatility of this solvent). However, after examination of the substrate it became apparent that formamide actually dissolved the ZIF-8 thin films on the silicon wafer. (Fig. 5.6) This implies that the interfacial tension of formamide/ZIF-8 may be negative, which has implications as to the possible polar nature of ZIF- 8 and necessitated the use of an additional probe liquid. As an alternative monopolar liquid, ethylene glycol was considered. This liquid has been used previously by Li et al. as a probe liquid, although it is less ideal vs. formamide due to its potentially hygroscopic nature. ${ }^{12,54}$ Hygroscopicity of ethylene glycol can also have a strong influence on the 
contact angle as water can cluster at the interface and this may be the cause behind the much larger variance of these contact angles. In order to practically reach the equilibrium/most stable contact angle, which are required in order to fully characterize the interfacial properties of the ZIF-8 film, these obstacles need to be overcome. Due to the evaporation of the solvents within the measurement time and possible adsorption of the liquids by the porous crystal structure of the MOFs are the challenges.

\section{$30 \mathrm{~s}$}

\section{$2 \mathrm{~min}$}
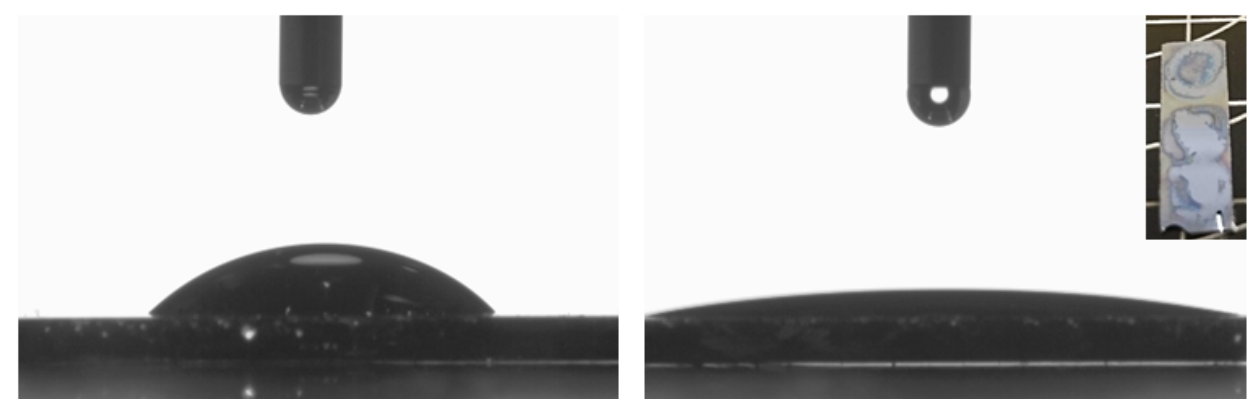

Figure 5.6 Contact angle results of formamide with 30 and 2 min waiting time, inset showing the ZIF-8 film removal after the formamide contact. 
Table 5.3 Contact angle measurements of three probe liquids with different measurement time.

\begin{tabular}{|c|c|c|c|c|c|}
\hline $\begin{array}{c}\text { Drying } \\
\text { conditions }\end{array}$ & $\begin{array}{l}\text { Measureme } \\
\text { nt time }\end{array}$ & $\begin{array}{c}\text { Measurement } \\
\text { conditions }\end{array}$ & CA-W & $\begin{array}{c}\text { CA-DIM } \\
\left({ }^{\circ}\right)\end{array}$ & CA-F \\
\hline \multirow{3}{*}{$60^{\circ} \mathrm{C} /$ vacuum } & $30 \mathrm{~s}$ & \multirow[b]{2}{*}{$\begin{array}{l}\mathrm{T}: \mathbf{2 1 . 0}{ }^{\circ} \mathrm{C} \\
\mathrm{RH}: 50.0 \%\end{array}$} & $\begin{array}{c}91 \cdot 3 \pm 3.0 \\
(n=8)\end{array}$ & $\begin{array}{c}49.2 \pm 0.6 \\
(n=8)\end{array}$ & $\begin{array}{c}44 \cdot 3 \pm 0.8 \\
(n=6)\end{array}$ \\
\hline & $2 \min$ & & $\begin{array}{c}79 \cdot 4 \pm 4 \cdot 0 \\
(n=8)\end{array}$ & $\begin{array}{c}48.8 \pm 0.6 \\
(n=8)\end{array}$ & $\begin{array}{c}35 \cdot 0 \pm 4 \cdot 0 \\
(n=6)\end{array}$ \\
\hline & $5 \mathrm{~min}$ & & (evaporation) & $\begin{array}{c}49.6 \pm 0.6 \\
(n=4)\end{array}$ & $\begin{array}{c}24 \cdot 7 \pm 6.6 \\
(n=3)\end{array}$ \\
\hline
\end{tabular}

$n=$ size of the sample, reported along with the standard error (CA \pm standard error $)$

Films in presence of humidified air - To understand the effect of the humidity on the contact angle measurements, ZIF-8/Si wafer samples have left in a box filled with water with no contact with water for two days, assuming complete water vapor saturation. The results are reported in Table 5.5 and Fig. 5.7 indicating only a slight increase in the contact angle after the humidity treatment. ZIF-8 is known as a hydrophobic MOF in the literature. In a previous study by Liu et al., it has been used as a hydrophobic coating for zeolites. 55 However, it also reported that it has hydrophilic crystal surface. ${ }^{16}$ As discussed in the introduction, there are values of water contact angles for ZIF-8 systems ranging from relatively hydrophilic to slightly hydrophobic. Our results agrees with the hydrophobic character of the ZIF-8, as it is almost stable after the humidity treatment. On the other hand, ZIF-8 water stability is also open to discussion. Lin et al., has shown the degradation of the morphology due to the hydrolysis of ZIF-8. ${ }^{56}$ Their XRD results implied stable crystals with some intensity lost until $48 \mathrm{~h}$ water immersion time however their study showed that longer water immersion times resulted in severe defects of the film, shorter contact times may even microscopically alter the surface characteristics. 


\section{Dry}

\section{Humidified}
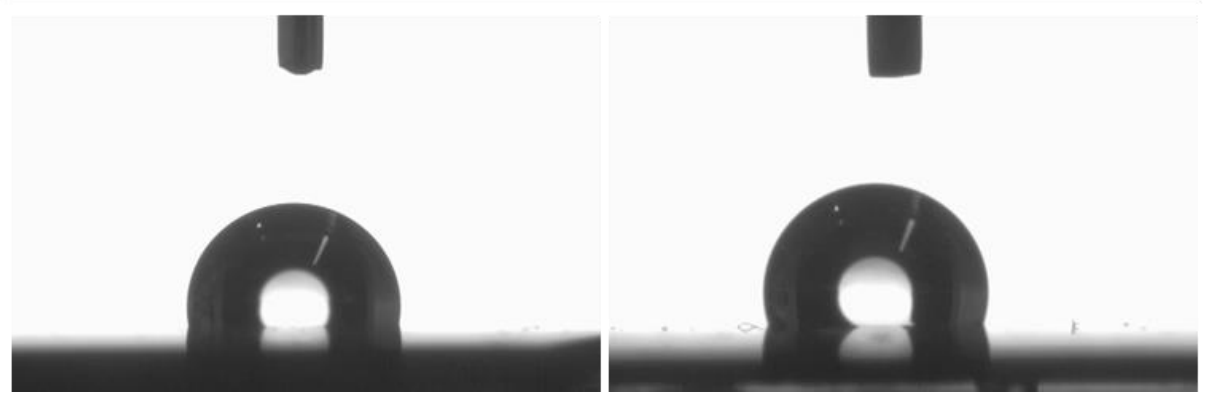

Figure 5.7 Contact angle of water on dried and humidified samples.

Table 5.4 Contact angle of water on dried and humidified samples.

\begin{tabular}{|c|c|c|c|c|}
\hline $\begin{array}{c}\text { Drying } \\
\text { conditions }\end{array}$ & $\begin{array}{l}\text { Measurement } \\
\text { Conditions }\end{array}$ & $\begin{array}{c}T \\
\left({ }^{\circ} \mathrm{C}\right)\end{array}$ & $\begin{array}{c}\text { Relative } \\
\text { humidity } \\
(\%)\end{array}$ & $\begin{array}{c}\text { CA-W } \\
\left({ }^{\circ}\right)\end{array}$ \\
\hline $60^{\circ} \mathrm{C} /$ vacuum & $30 \mathrm{~s}$ & 20.8 & 50 & $\begin{array}{c}105 \cdot 4 \pm 2.5 \\
(n=2)\end{array}$ \\
\hline $\begin{array}{l}\text { Humidity } \\
\text { (2 days) }\end{array}$ & $30 \mathrm{~s}$ & 21.5 & 46.3 & $\begin{array}{c}111.9 \pm 1.8 \\
(n=3)\end{array}$ \\
\hline
\end{tabular}

The results of three advancing-receding contact angle (ARCA) cycles (cycles are measured in row) at three different locations of the sample shows an overlap as an indication of homogenous coating of ZIF-8 film on Si wafer. (Fig. 5.8) However, the surface alters once it contacts with the droplet that we see this hysteresis between cycles. The contact with water may cause some contaminations on the sample surface. Recently, the microdroplet contamination has been investigated for superamphiphobic (superhydrophobic and superoleophobic) surfaces by Butt et. al., similar phenomenon may also happen on the ZIF-8 surface. ${ }^{57}$ Therefore, in this study, 
always fresh samples have been used to measure contact angle values, except for this three cycle advancing-receding contact angle measurement. Comparison with the static water contact angle results, ACA values are closer to the short waiting time measurements, while RCA values are in the range of longer waiting time results. ACA and RCA results represent the maximum and minimum contact angle values can be obtained from one system, respectively, also called as contact angle hysteresis. ${ }^{8}$ For ZIF-8 films, ACA values are closer to the short waiting time values and RCA results are closer to the longer waiting time measurements. As a result, they are all in the range of this contact angle hysteresis. However, in order to obtain most stable contact angle values which is also expected to be in this range, a mechanical stimulus is needed. ACA and RCA are playing a critical role to decide surface characteristic of a solid. However, they are also considered as sensitive measurements with their own challenges. 35

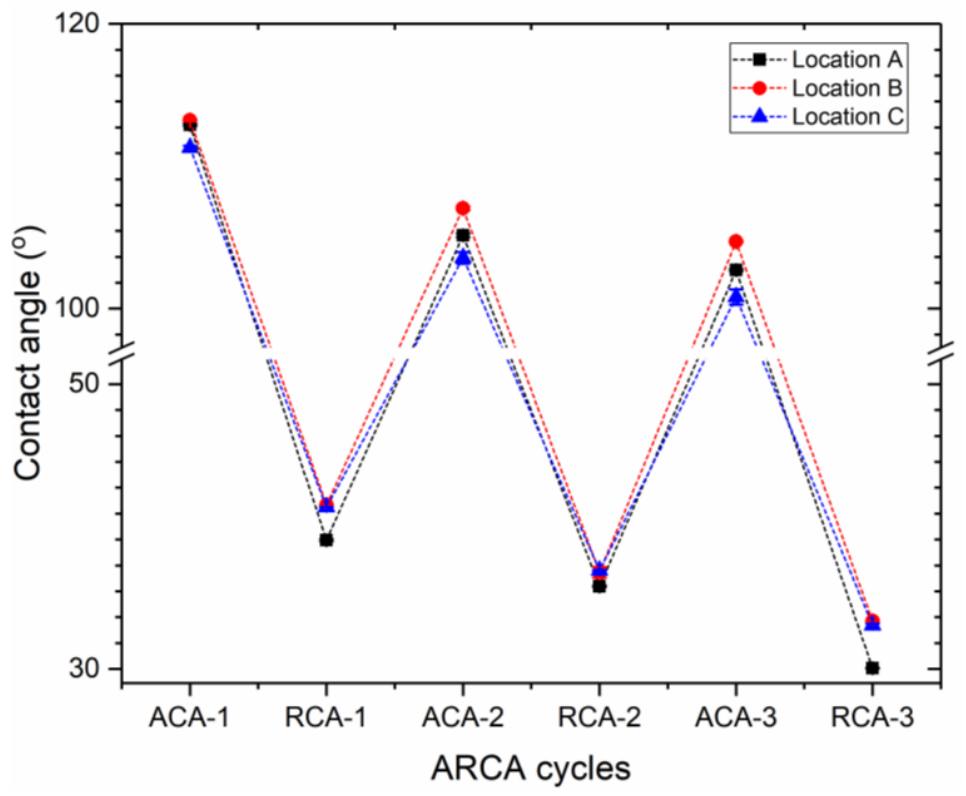

Figure 5.8 ARCA measurement results with three cycles at three different locations of a sample. 
Table 5.5 Advancing and receding contact angle of water on sample dried in $60{ }^{\circ} \mathrm{C}$. ACA and RCA have been performed with consecutive three cycles.

\begin{tabular}{|c|c|c|c|c|c|}
\hline \multirow[t]{2}{*}{$\begin{array}{c}\text { Drying } \\
\text { conditions }\end{array}$} & $\begin{array}{c}\text { Measurement } \\
\text { Conditions }\end{array}$ & \multicolumn{2}{|c|}{$\begin{array}{c}\text { ACA-W } \\
\left({ }^{\circ}\right)\end{array}$} & \multicolumn{2}{|c|}{$\begin{array}{c}\text { RCA-W } \\
\left(^{\circ}\right)\end{array}$} \\
\hline & Volume: $10 \mu \mathrm{L}$ & Cycle 1 & $\begin{array}{c}112.5 \pm 0.1 \\
(n=3)\end{array}$ & $\begin{array}{c}\text { Cycle } \\
1\end{array}$ & $\begin{array}{c}40.6 \pm 0.1 \\
(n=3)\end{array}$ \\
\hline $\begin{array}{c}60^{\circ} \mathrm{C} \\
\text { vacuum }\end{array}$ & $\begin{array}{l}\text { Speed: } 0.2 \mu \mathrm{L} \mathrm{s}^{-1} \\
\mathrm{~T}: 21.0^{\circ} \mathrm{C}\end{array}$ & Cyclez & $\begin{array}{c}105 \cdot 3 \pm 0.3 \\
(n=3)\end{array}$ & $\begin{array}{c}\text { Cycle } \\
2\end{array}$ & $\begin{array}{c}36.5 \pm 0.4 \\
(n=3)\end{array}$ \\
\hline & $\mathrm{RH}: 46.5 \%$ & Cycle 3 & $\begin{array}{c}102.7 \pm 0.5 \\
(n=3)\end{array}$ & $\begin{array}{c}\text { Cycle } \\
3\end{array}$ & $\begin{array}{c}32.2 \pm 0.0 \\
(n=3)\end{array}$ \\
\hline
\end{tabular}

$n=$ size of the sample, reported along with the standard error (CA \pm standard error $)$ * average of three measurements reported with std error.

\subsubsection{Most stable contact angle}

The contact angle hysteresis from ACA and RCA give an indication of the equilibrium contact angle which is needed for the characterization of solid surface. However, measuring ECA has some challenges, therefore, most stable contact angle which is described as the only measurable contact angle related to the average surface energy is becoming more common. ${ }^{37}$ For this, a mechanical stimuli vs. is required for the relaxation of the droplet while avoiding the evaporation of the liquid. Here, we have used piezoactuation ( $250 \mathrm{~Hz}$ sine wave-30 s). The contact angle results are reported in Table 5.6 an Fig. 5.9. Water contact angles achieved with vibration shows more deviation compared to the other probe liquids. The effect of the evaporation of the liquid and the polar-apolar characteristic of the liquid may have an impact on this as well as the roughness characteristic of the MOF films. Diiodomethane is a less volatile liquid with only van der Waals surface component. As the polarity increased the spread in measurements increased. Hygroscopic nature of ethylene is also another concern that it can be affected by the humidity. 
The contact angle results achieved with and without vibration, they are all in the range of the contact angle hysteresis as it is found with ACRA measurements. Static water contact angles reported in this study are $91.3 \pm 3.0^{\circ}$ and $105.4 \pm 2.5^{\circ}$ with $30 \mathrm{~s}$ waiting time from two separate samples. However, the most stable contact angle with vibration is reported as $91.0 \pm 2.5^{\circ}$. This result show that ZIF-8 films are not highly hydrophobic but nearly the transition of hydrophilic and hydrophobic, which is consistent with many of the reported studies in literature. Although, many studies have been focused on hydrophobic ZIF-8 properties, ZIF-8 possess hydrophilic crystal nature with hydrophobic pore surface due to the flexible methyl groups. ${ }^{16}$ The internal and the external surface characteristics are different as it is also observed for another MOF, ZIF-71. ${ }^{59}$ The ZIF-8 films in this work are randomly oriented and in general this will be the case until dedicated synthesis methods are used. ${ }^{60,61}$ The large deviations in the literature values and this study might be due to the different domains (hydrophilic and hydrophobic) present on the surface. These domains may also respond the contact with probe liquids differently than each other, i.e. varying degrees of hydrophobicity and hydrophilicity, the reported instability of ZIF-8 in water also challenge interpreting based on WCA.

For diiodomethane, the difference between the static and most stable contact angle is more severe as it decreases to $23.1 \pm 0.6^{\circ}$ from $50.7 \pm 0.3^{\circ}$. In both cases, the standard deviation of droplets on the surface was greatly reduced vs. water. This may be attributable to the same potential orientation effect that increased the spread in water contact angles having a negligible impact on the van der Waals interactions (apolar). Difference in the surface morphology may also effect such a difference, as it is previously reported on the surface holes/defects cause a transition from Wenzel to Cassie state. $^{62}$ 
Table 5.6 Contact angle of probe liquids with after vibration (250 Hz sine wave - 30 s)

\begin{tabular}{clccc}
\hline $\begin{array}{c}\text { Drying } \\
\text { conditions }\end{array}$ & $\begin{array}{c}\text { Measurement } \\
\text { Conditions }\end{array}$ & CA-W & CA-DIM & CA-EG \\
& & & $\left({ }^{\circ}\right)$ & \\
$60^{\circ} \mathrm{C}$ & sine wave & $91.0 \pm 2.5$ & $23.1 \pm 0.6$ & $40.1 \pm 1.1$ \\
& & & & \\
$(2$ weeks) $/$ vacuum & $\mathrm{T}: 21 .{ }^{\circ} \mathrm{C}$ & $(n=20)$ & $(n=12)$ & $(n=12)$ \\
& $\mathrm{RH}: 53.3 \%$ & & &
\end{tabular}

$n=$ size of the sample, reported along with the standard errors. (CA \pm standard error)

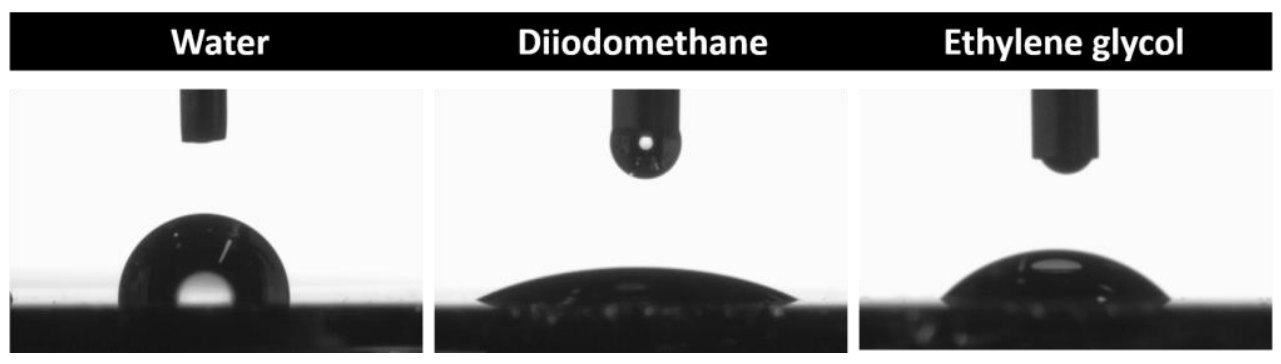

Figure 5.9 Contact angle of the probe liquids after $250 \mathrm{~Hz}$ sine wave vibration.

\subsubsection{Interfacial properties}

Non-polar contribution (DIM): The dispersive component of ZIF-8 can be estimated by using diiodomethane contact angle measurements with piezoactuation. In principle with piezoactuation, we have ensured to have achieved the most stable contact angle and we use this as our estimate in the Young-Dupré equation. For either the two or three-component surface tension, this estimate is not affected as diiodomethane possesses only dispersive interactions (van der Waals).

We can re-write the Young-Dupré equation for a non-polar liquid and re-arrange to achieve the dispersive $(\mathrm{VdW})$ component as: 


$$
\gamma_{S}^{D}=\gamma_{L} \frac{\left(1+\cos \theta_{e q}\right)^{2}}{4}
$$

For ZIF-8, we estimate a value of $46.8 \mathrm{mN} \mathrm{m}^{-1}$ based on the mean of our diiodomethane measurements. For comparison, it is in the same range with other MOFs reported such as $\mathrm{Cu}-\mathrm{BTC}$ and UiO-66. ${ }^{11,12}$ Ferraris et al. calculated the ZIF-8 surface tension from water contact angle measurements as $20.34 \mathrm{mN} \mathrm{m}^{-1}$ by neglecting the polar component of ZIF-8. ${ }^{14}$ Even a small polar component for ZIF-8, given the high polarity of water, would then have a large impact on the estimated dispersive component. Given that other authors have reported substantial polar contributions for MOF systems and zeolites, ${ }^{9,12,13}$ we will assess the validity of this assumption through testing with polar liquids.

As an additional consistency check, we also estimate the Hamaker constant based on the relationship derived by Israelachvili and use this to compute the dispersive component of surface tension of ZIF-8. ${ }^{63}$ The refractive index of ZIF-8 (based on dense films) has been reported as $1.584^{64}$ and the dielectric constant as $2.5 .{ }^{65}$ The UV absorption frequency of ZIF-8 has not been reported but these values are often in the range of 1.5 to $2.5 \times 10^{16}$ rad s$^{-1}$ and we use this to get a range of plausible values. ${ }^{63}$ Based on this relationship for the Hamaker constant, we estimate that the dispersive component of surface tension of ZIF-8 is between $\sim 42 \mathrm{mN} \mathrm{m}^{-1}$ to $5^{2} \mathrm{mN} \mathrm{m}^{-1}$ which is consistent with our value determined from contact angle measurements and also inline with dispersive values reported for other MOF materials. ${ }^{10-12}$

Since we have a porous film, it is possible that there is an influence of roughness (as well as chemical heterogeneity) on the interpretation of the contact angles. As discussed earlier both AFM and WLI measurements indicate that the surface roughness value is extremely low which is consistent with the reports of Li et al.33 In the case of porous substrates, one can imagine that there is successive wetting events throughout the different layers and that this effective roughness may be larger. However, given that the spread in contact angle measurements across multiple different prepared substrates was quite minimal for diiodomethane (standard error $=$ 
o.6, $n=12$ ), that the value computed based on Hamaker theory is also comparable and that the value is in-line with other reported MOF dispersive components it implies that any effect of roughness may be negligible. We will further test this consistency by comparing the results with multiple liquid probes.

Two-component probe liquids (DIM-EG): We extend the analysis now to include the use of a polar probe liquid. The typical probe liquid for polar properties is typically water, however for the case of ZIF-8 this is challenging. As discussed previously, ZIF8 is composed of both hydrophilic and hydrophobic domains which can complicate interpretation of this value (although evidently not the dispersive component) based on the stability of DIM and also the water stability of ZIF-8 itself is also debatable based on the results of Zhang et al. ${ }^{56}$ This is evident in the spread in the most stable contact angle, as well as the cycling of ACRA and in the larger spread in static angle measurements. For these reasons, interpretation of the polar aspects of ZIF-8 using water is problematic and therefore we turn to the use of ethylene glycol. This was also the case for Elangovan, who explored multiple probe liquids for $\mathrm{Cu}$-BTC pellets but analyzed via the two-component using diiodomethane and ethylene glycol. ${ }^{12}$

Using Eq. 5.2, we fit the dispersive and polar components of ZIF-8 based on the most stable contact angle measurements of DIM and EG in a least-squares sense. For this fit, we estimate the following values (along with 95\% confidence intervals): $\gamma_{S}^{D}=46.8$ $\pm 0.9 \mathrm{mN} \mathrm{m}^{-1}$ and $\gamma_{S}^{P}=0.4 \pm 0.1 \mathrm{mN} \mathrm{m}^{-1}$. The residuals from the fit were found to be normally distributed with a mean of zero, based on a normal probability plot.

The dispersive component is not impacted by the regression simultaneously using diiodomethane and ethylene glycol and a small (but non-negligible) polar component is estimated from these results. Based on estimate parameters, we estimate the water contact angle based on the known properties of water and estimate a contact angle of $\sim 83^{\circ}$ which can be considered closer with the mean of the most stable water angle $\left(\sim 91^{\circ}\right)$ as determined from piezoactuation but farther than that observed in static or ACRA measurements for water. This value is consistent with the measurement of Ferraris et al. for water, indicating that the difference in estimated dispersive 
component is more likely related to that work assuming no substantial polar component for ZIF-8. ${ }^{14}$

Three-component estimates (DIM-EG -Water): In principle, the Lewis acid/base subdivision of polar interactions can provide a much greater detail for understanding the nature of adhesion. Lee et al. previously identified the importance of these types of interactions for zeolites, helping to explain the interfacial interactions for potential application as gas separation hybrid membranes. ${ }^{13}$ Given the emphasis in the MOF research community on this topic, a similar analysis for MOFs can be beneficial. However, given the spread in the most stable water contact angle and the previously discussed issues relating to water and ZIF-8, it is difficult to further quantify the nature of interaction. Formamide dissolved ZIF-8 and other polar probe liquids such as ethanol or glycerol are either too volatile or too close in nature to that of ethylene glycol in order to likely obtain statistically significant regressions. The increase in the spread of measurement most stable contact angles appears to increase with increasing polarity, which is consistent with potential heterogeneity in the wetted perimeter of the substrate (hydrophilic/hydrophobic domains of the MOF). When including the water contact angle data and regressing via Eq. 5.3 (Van Oss-Chaudhury-Good) for the van der Waals components we estimate a $\gamma^{L W}$ of $46.9 \mathrm{mN} \mathrm{m}^{-1}$ with a much wider confidence interval ( 41 to $52 \mathrm{mN} \mathrm{m}^{-1}$ ) but both polar components (electron donor or acceptor) have $95 \%$ confidence intervals which pass through zero. The van der Waals estimate was evidently not effected, which is also consistent as the predicted water contact angle for the two-component model is consistent with the mean experimental value for most stable water angle. At least for the case of ZIF-8 use of water as a probe liquid to assess interfacial properties is prone to many challenges, but we note that this may not be the case for other MOFs and stress that a full three-liquid probe analysis can be extremely valuable.

\subsection{Conclusion}

ZIF-8 films have been prepared on silicon wafer via spin-coating technique. In order to explore the interfacial properties of the MOF films, contact angle measurements 
have been performed in three different manner: static, advancing-receding and moststable. Static contact angle analysis showed the effect of the drying conditions of the films. Drying at higher temperatures under vacuum results higher contact angle values for the three probe liquids. Longer waiting time of the droplet before measuring the contact angle showed the challenges of using porous materials. Evaporation of the liquid, possible absorption, air pockets on the surface and capillary condensation have been affected the results and hinders the relaxation of the droplet to reach the most stable contact angle. The contact angle hysteresis have been found with advancing receding contact angle measurements. After each cycles, ACA and RCA were shifting to low values. Roughness, deformation of the surface and possible microdroplet contaminations might have a role on this change. Most stable contact angle have been measured after applying 30 second of $250 \mathrm{~Hz}$ sine wave to the samples that placed on top of a pieozospeaker. Although ZIF-8 is known as a hydrophobic MOFs, the most stable water contact angle of $91.0 \pm 2.5^{\circ}$ is in the limit of hydrophilicity and hydrophobicity that may be related to the chemical heterogeneities in the MOF films. Interfacial properties of ZIF-8 films has been estimated by using the most stable contact angle values. Dispersive component of ZIF-8 films were calculated using DIM contact angle values and has been found consistent with the dispersive component calculated from Hamaker theory. In order to calculate the polar surface energy component of $0.4 \mathrm{mN} \mathrm{m}^{-1}$, DIM an EG contact angle measurements have been used that is much lower than the dispersive component of $46.8 \mathrm{mN} \mathrm{m}^{-1}$. Due to the large spreads in the measurements, water contact angle has not been used for the estimations. This can be attributed to the evaporation of water as well as the effect of the polar component of water and their interactions with ZIF-8 films.

Our results show that pretreatment has an enormous effect on the contact angles, as does the measurement approach (vibration vs. no vibration, repeated cycles of ACRA). There is a large deviations for the reported contact angle values of ZIF-8, as it is discussed in the introduction. These deviations may arise from the sample morphology as the contact angles are reported on powders, pellets, randomly oriented films and oriented films. CAs are a way to try to assess the surface characteristic of a 
material but it is also quite challenging, although commonly used (but the pitfalls are not commonly discussed). Interfacial properties of MOFs can help to choose a good solvent for the well-dispersion, for designing MOF hybrid films (MOF-polymersolvent systems), for the choice of the substrate for supported MOF films, etc. Therefore, exploring the interfacial properties of MOFs via surface tension components are quite important for the any MOF based systems. Challenges arise due to the porous nature, roughness, absorption, etc. have been also considered in this study. Our findings motivate future studies on more continuous films and on preparation techniques to really probe under controlled dynamic conditions how these films age.

\section{Acknowledgments}

We would like to thank Jan van Nieuwkasteele for the WLI measurements, his assistance in piezo experiments and his guidance in general; Iske Achterhuis for doing AFM measurements; and Ineke Punt for her guidance to the contact angle measurements.

\section{References}

$1 \quad$ M. Sindoro, N. Yanai, A. Y. Jee and S. Granick, Acc. Chem. Res., 2014, 47, 459469 .

2 R. Castro-Muñoz, V. Fíla, V. Martin-Gil and C. Muller, Sep. Purif. Technol., 2019, 210, 553-562.

3 R. Lin, B. Villacorta Hernandez, L. Ge and Z. Zhu, J. Mater. Chem. A, 2018, 6, 293-312.

4 T.-H. Bae, J. S. Lee, W. Qiu, W. J. Koros, C. W. Jones and S. Nair, Angew. Chemie Int. Ed., 2010, 49, 9863-9866.

5 G. Liu, Y. Labreche, V. Chernikova, O. Shekhah, C. Zhang, Y. Belmabkhout, M. Eddaoudi and W. J. Koros, J. Memb. Sci., 2018, 565, 186-193.

6 Z. Liu, J. Zhu, C. Peng, T. Wakihara and T. Okubo, React. Chem. Eng., 2019, 4, 1699-1720.

7 D. Bradshaw, A. Garai and J. Huo, Chem. Soc. Rev., 2012, 41, 2344-2381. 
A. Mähringer, J. M. Rotter and D. D. Medina, Beilstein J. Nanotechnol., 2019, 10, 1994-2003.

9 J. Sablowski, J. Linnemann, S. Hempel, V. Hoffmann, S. Unz, M. Beckmann and L. Giebeler, Sci. Rep., 2018, 8, 15400.

10 Y. Li, B. Jiang and Y. Huang, Appl. Surf. Sci., 2020, 145870.

K. Kim, J. Y. Seo, K. Y. Baek, J. Y. Bae and S. Shin, Polym. Int., 2019, 68, 15021508 .

D. Elangovan, Michigan State University, 2010.

J.-H. Lee, B. J. R. Thio, T.-H. Bae and J. C. Meredith, Langmuir, 2009, 25, 91019107 .

N. P. Panapitiya, S. N. Wijenayake, Y. Huang, D. Bushdiecker, D. Nguyen, C. Ratanawanate, G. J. Kalaw, C. J. Gilpin, I. H. Musselman, K. J. Balkus and J. P. Ferraris, Polymer (Guildf)., 2014, 55, 2028-2034.

15 P. Song, X. Mao, Y. Ren, H. Zeng and Q. Lu, Langmuir, 2020, acs.langmuir.9bo3459.

16 K. Jayaramulu, F. Geyer, A. Schneemann, Š. Kment, M. Otyepka, R. Zboril, D. Vollmer and R. A. Fischer, Adv. Mater., 2019, 1900820, 1900820.

17 C. . Van Oss, R. . Good and M. . Chaudhury, J. Colloid Interface Sci., 1986, 111, 378-390.

18 S. Rodr, M. Y. Tsang, C. Vignatti, K. C. Stylianou, V. Guillerm, P. Ø. Javier, F. Teixidor, C. Viças, D. Choquesillo-, C. Verdugo-escamilla, I. Peral, J. Juanhuix, A. Verdaguer, I. Imaz, D. Maspoch and J. Ø. G. Planas, 2016, 16049-16053.

D. Zacher, O. Shekhah, C. Wöll and R. A. Fischer, Chem. Soc. Rev., 2009, 38, 1418.

M. A. Andrés, C. Sicard, C. Serre, O. Roubeau and I. Gascón, Beilstein J. Nanotechnol., 2019, 10, 654-665.

21 S. Aguado, J. Canivet, Y. Schuurman and D. Farrusseng, J. Catal., 2011, 284, 207214.

H. Zhang and R. Q. Snurr, J. Phys. Chem. C, 2017, 121, 24000-24010.

23 T. T. Y. Tan, M. R. Reithofer, E. Y. Chen, A. G. Menon, T. S. A. Hor, J. Xu and J. M. Chin, J. Am. Chem. Soc., 2013, 135, 16272-16275.

24 J. Yuan, Q. Li, J. Shen, K. Huang, G. Liu, J. Zhao, J. Duan and W. Jin, Asia-Pacific 
J. Chem. Eng., 2017, 12, 110-120.

25 J. B. James, L. Lang, L. Meng and J. Y. S. Lin, ACS Appl. Mater. Interfaces, 2020, 12, 3893-3902.

26 E. E. Sann, Y. Pan, Z. Gao, S. Zhan and F. Xia, Sep. Purif. Technol., 2018, 2o6, 186-191.

27 D. Kim, D. W. Kim, O. Buyukcakir, M. K. Kim, K. Polychronopoulou and A. Coskun, Adv. Funct. Mater., 2017, 27, 1-8.

28 Z. Lei, Y. Deng and C. Wang, J. Mater. Chem. A, 2018, 6, 3258-3263.

29 Q. Ma, G. Li, X. Liu, Z. Wang, Z. Song and H. Wang, Chem. Commun., 2018, 54, 5530-5533.

30 L. Sarango, J. Benito, I. Gascón, B. Zornoza and J. Coronas, Microporous Mesoporous Mater., 2018, 272, 44-52.

31 L. Sarango, L. Paseta, M. Navarro, B. Zornoza and J. Coronas, J. Ind. Eng. Chem., 2018, 59, 8-16.

32 H. Ye, D. Chen, N. Li, Q. Xu, H. Li, J. He and J. Lu, ACS Appl. Mater. Interfaces, 2019, 11, 38313-38320.

33 Y. Li, L. H. Wee, A. Volodin, J. A. Martens and I. F. J. Vankelecom, Chem. Commun., 2015, 51, 918-920.

34 T. Huhtamäki, X. Tian, J. T. Korhonen and R. H. A. Ras, Nat. Protoc., 2018, 13, $1521-1538$

35 J. T. Korhonen, T. Huhtamäki, O. Ikkala and R. H. A. Ras, Langmuir, 2013, 29, 3858-3863.

36 F. J. M. Ruiz-Cabello, M. A. Rodríguez-Valverde and M. A. Cabrerizo-Vílchez, Adv. Colloid Interface Sci., 2014, 206, 320-327.

37 J. W. Drelich, Adv. Colloid Interface Sci., 2019, 267, 1-14.

38 T. Young, Philos. Trans. R. Soc. London, 1805, 95, 65-87.

39 C. J. van Oss, Interfacial Forces in Aqueous Media, CRC Press, 2006.

40 T. S. Meiron, A. Marmur and I. S. Saguy, J. Colloid Interface Sci., 2004, 274, 637644 .

41 C. Della Volpe, D. Maniglio, M. Morra and S. Siboni, Colloids Surfaces A Physicochem. Eng. Asp., 2002, 206, 47-67. 
42 C. A. Fuentes, K. Beckers, H. Pfeiffer, L. Q. N. Tran, C. Dupont-Gillain, I. Verpoest and A. W. Van Vuure, Colloids Surfaces A Physicochem. Eng. Asp., 2014, 455, 164-173.

43 T. Urai, M. Kamai and H. Fujii, J. Mater. Eng. Perform., 2016, 25, 3384-3389.

44 A. Rudawska and E. Jacniacka, Int. J. Adhes. Adhes., 2018, 82, 139-145.

45 J. Cravillon, S. Münzer, S.-J. Lohmeier, A. Feldhoff, K. Huber and M. Wiebcke, Chem. Mater., 2009, 21, 1410-1412.

46 Physics Toolbox Suite, https://play.google.com/store/apps.

47 Y. Zhang, Y. Jia, M. Li and L. Hou, Sci. Rep., 2018, 8, 9597.

48 C. K. Söz, E. Yilgör and I. Yilgör, Polymer (Guildf)., 2016, 99, 580-593.

49 A. Hongru, L. Xiangqin, S. Shuyan, Z. Ying and L. Tianqing, RSC Adv., 2017, 7, 7052-7059.

$50 \quad$ R. Di Mundo, F. Bottiglione and G. Carbone, Appl. Surf. Sci., 2014, 316, 324-332.

51 Y. Wang, J. Zhao, D. Zhang, M. Jian, H. Liu and X. Zhang, Langmuir, 2019, 35, 9970-9978.

52 Hideo Nakae, Ryuichi Inui, Yosuke Hirata and Hiroyuki Saito, Acta Mater., 1998, 46, 2313-2318.

53 J. Canivet, J. Bonnefoy, C. Daniel, A. Legrand, B. Coasne and D. Farrusseng, New J. Chem., 2014, 38, 3102-3111.

54 A. Kozbial, Z. Li, C. Conaway, R. McGinley, S. Dhingra, V. Vahdat, F. Zhou, B. Durso, H. Liu and L. Li, Langmuir, 2014, 30, 8598-8606.

55 F. Gao, Y. Li, Z. Bian, J. Hu and H. Liu, J. Mater. Chem. A, 2015, 3, 8091-8097.

56 H. Zhang, D. Liu, Y. Yao, B. Zhang and Y. S. Lin, J. Memb. Sci., 2015, 485, 103111.

57 W. S. Y. Wong, T. P. Corrales, A. Naga, P. Baumli, A. Kaltbeitzel, M. Kappl, P. Papadopoulos, D. Vollmer and H.-J. Butt, ACS Nano, 2020, acsnano.9bo8211.

$58 \quad$ R. Tadmor, Langmuir, 2004, 2o, 7659-7664.

59 X. Dong and Y. S. Lin, Chem. Commun., 2013, 49, 1196-1198.

6 J. Su, W. Wu, Z. Li and W. Li, Dalt. Trans., 2019, 48, 11196-11199.

61 V. Chernikova, O. Shekhah and M. Eddaoudi, ACS Appl. Mater. Interfaces, 
2016, 8, 20459-20464.

62 R. Chunbo, D. Guqiao, L. Weichang, D. Yan and H. Wentao, Langmuir, 20o8, 24, 9952-9955.

63 J. N. Israelachvili, in Intermolecular and Surface Forces, Elsevier, 2011, pp. 253289.

64 J. Cookney, W. Ogieglo, P. Hrabanek, I. Vankelecom, V. Fila and N. E. Benes, Chem. Commun., 2014, 50, 11698-11700.

65 S. Eslava, L. Zhang, S. Esconjauregui, J. Yang, K. Vanstreels, M. R. Baklanov and E. Saiz, , DOI:10.1021/cm302610z. 


\section{Supporting Information}

All roughness metrics indicate a smooth surface (Fig $\mathrm{S}_{5.1}$ and $\mathrm{S}_{5.2}$ ). Wenzel roughness factor has been calculated (Eq. S5.1) as $\mathrm{r} \approx 1$, indicating the surface is flat from macroscopic perspective. Depth measured via Dektak (scratch test) was also found consistent with ellipsometry results.

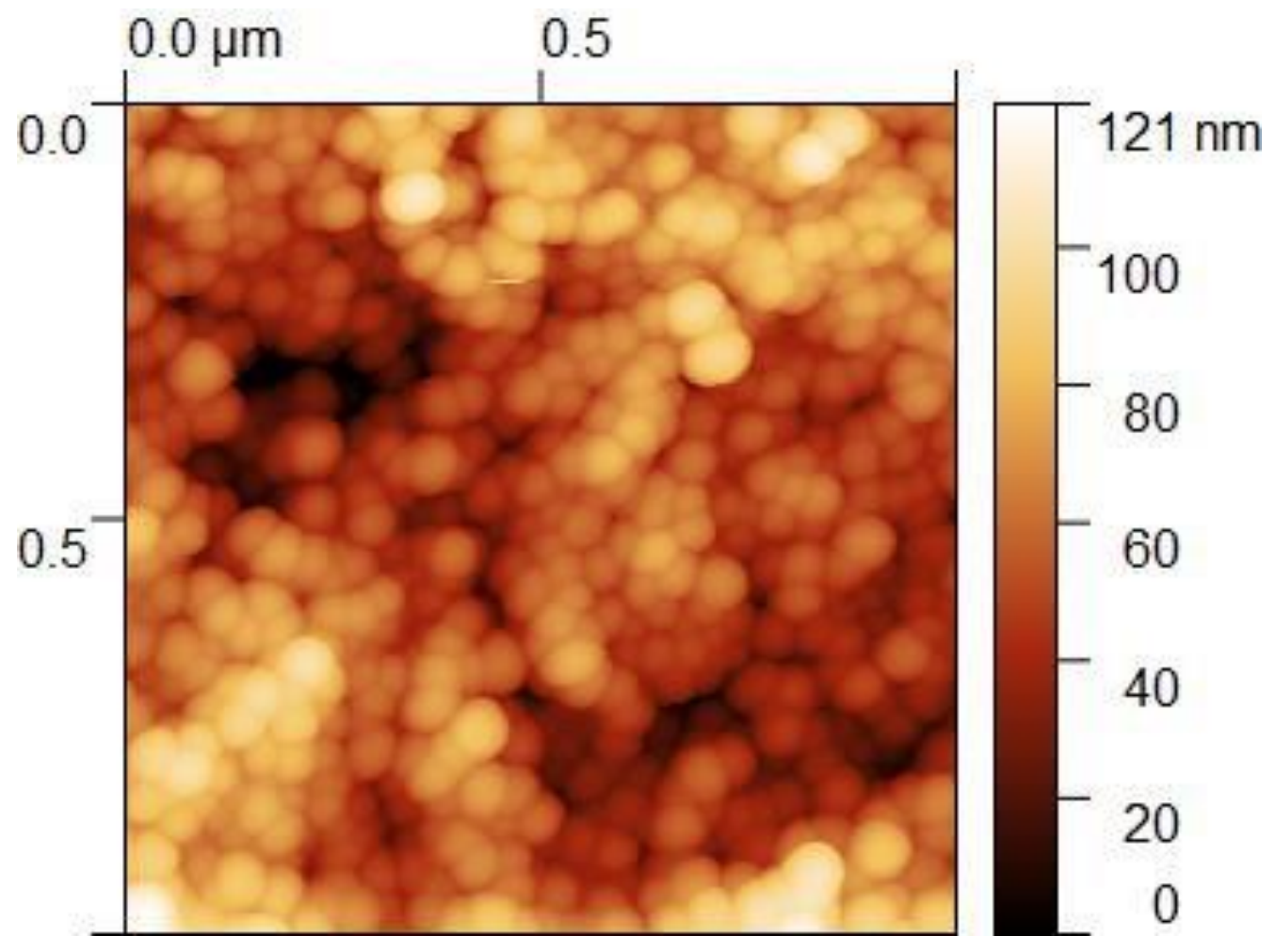

Figure S5.1 AFM images of ZIF-8/Si wafer samples (1 $\mu \mathrm{m} \times 1 \mu \mathrm{m})$. The surface roughness values were calculated as $18.9 \mathrm{~nm}$ (Rms). 

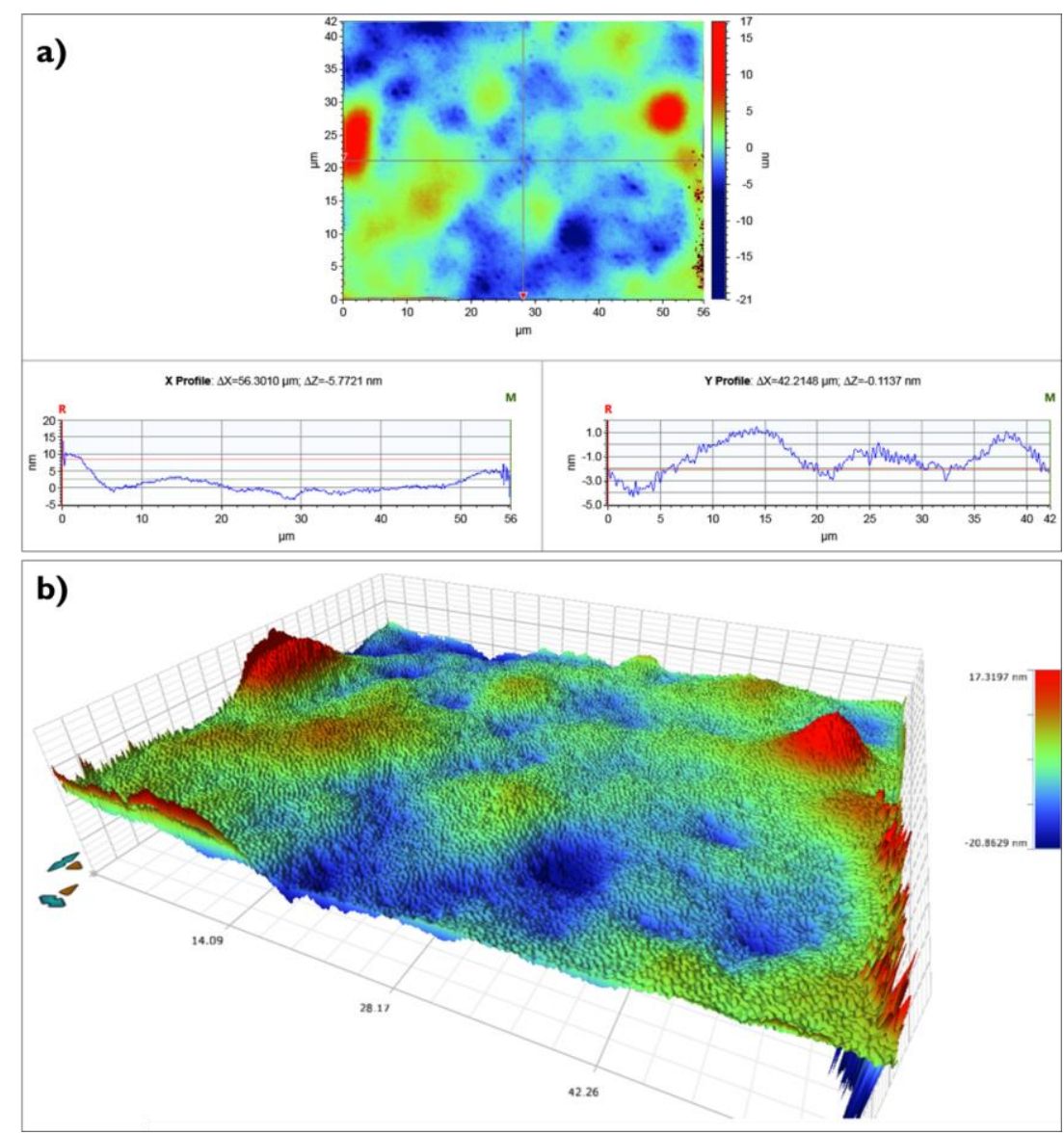

Figure $S_{5.2}$ (a) $2 \mathrm{D}$ corresponding roughness profiles along $\mathrm{x}$-axis and y-axis $(42 \mu \mathrm{m} x$ $56 \mu \mathrm{m}$ ) and (b) 3D WLI images. The average surface roughness values were calculated as $2 \mathrm{~nm}(\mathrm{Ra})$.

The Wenzel roughness is taken as the average of the roughness based on lines over $\mathbf{x}$ (at fixed y-values)

$r_{W}=\frac{1}{M} \frac{\sum_{j=1}^{M} \sum_{i=1}^{n-1}\left[\sqrt{\left\{\left(x_{i, j}-x_{i-1, j}\right)^{2}+\left(z_{i, j}-z_{i-1, j}\right)^{2}\right\}}\right.}{x_{n}-x_{1}}$

$\mathrm{X} \rightarrow\left[\mathrm{X}_{1}, \mathrm{X}_{\mathrm{N}}\right], \mathrm{Y} \rightarrow\left[\mathrm{Y}_{1}, \mathrm{Y}_{\mathrm{M}}\right](\mathrm{X}$ is in $\mathrm{N}$-lines and $\mathrm{Y}$ is divided into $\mathrm{M}$-lines based on the spatial resolution of the WLI) 
CHAPTER 6

Reflection and Perspectives 


\subsection{Reflections}

The overall objective of this thesis was to develop new insights to understand the role of the interface for MOF film preparation and properties. Firstly, thin films of benchmark MOFs, Cu-BTC and ZIF-8 have been prepared on two novel functional supports (metal: porous copper hollow fiber and polymer: ion exchange membranes) by controlling the transport of the reactants at the interface. Secondly, the effect of the interfacial properties on gas separation performance have been investigated for MOF embedded polymer films. At last, we have looked at the interfacial properties of MOFs from the surface characteristic and adhesion properties point of view.

Porous copper hollow fibers were utilized as both support and a metal source for electroforming MOF films on the outer surface of the hollow fiber. Here, we critically assess the current knowledge on electrochemical synthesis for MOF film formation. Unlike the conventional electrochemical synthesis approach, here we propose the limited use of the supporting electrolyte in the synthesis solution and lower applied potential to obtain thin and reproducible MOF films. By using an electrolyte-free synthesis, a large potential drop occurs in the bulk in electrolyte-free solution and a smaller contribution is given towards electrode reactions. This lower potential drop at the electrode surface lowers the rate of copper ion generation, while the larger potential drop in the bulk enhances the transport of the charged organic ligand, leading to an improved overall film quality. The findings of this work stress the importance of understanding the transport rate of the reactants at the interface for controlled electrosynthesis of MOF films on copper hollow fiber support.

Electrochemically formed MOFs on HF may be interesting candidates for electrochemical reduction of $\mathrm{CO}_{2}$. As one of the important factors in electroreduction of $\mathrm{CO}_{2}$ is the solubility in aqueous solution, MOF can capture $\mathrm{CO}_{2}$ with the unsaturated $\mathrm{Cu}$ sites, therefore it can increase the $\mathrm{CO}_{2}$ concentration near the catalyst. ${ }^{1}$ However, our preliminary experiments on $\mathrm{CO}_{2}$ electro-conversion did not show any improvement with the existence of MOF films on copper hollow fibers. This was attributed to the poor mechanical stability of the obtained films and poor 
adhesion between MOF films and support. Here, future research should be towards improving the adhesion of these films to the copper hollow fibers. The fibers can be directly transfer to the electrochemical reduction set-up after the synthesis to avoid any delamination due to drying. The mechanical strength can also be improved potentially by using electrical conductive ionomer (e.g. Nafion) to protect the films against the $\mathrm{CO}_{2}$ flow from inside out to the hollow fiber. ${ }^{2}$ Moreover, these fibers can be utilized in various applications such as gas separation and storage, sensing and water adsorption, but only once the issue of adhesion is solved. ${ }^{3}$

In Chapter 3, ion exchange membranes (IEMs) have been introduced as a functional support for MOF ZIF-8 films providing a selective medium to control the reactants based on their charge. IEMs were used to separate the two reactant solutions in a diffusion-cell set-up, controlling both transport of reactants and local concentration via Donnan (charge) exclusion. In the course of this thesis the effect solvent type (varying dielectric constant), synthesis time and type of IEM were investigated. The results showed a high potential of this approach for controlling the local concentration of reactants to favor the crystallization of MOF films. For ZIF-8 synthesis, excessive organic ligand (HMIM) ratio is required compared to the metal source $\left(\mathrm{Zn}^{2+}\right)$. Donnan exclusion at the interface of anion-exchange membranes (AEMs) led to lower zinc concentration vs. bulk and compared to HMIM molecules which is favorable for the synthesis. Exclusion of the transport of protonated HMIM, $\mathrm{H}_{2} \mathrm{MIM}^{+}$by the AEM is also another beneficial condition for the ZIF-8 synthesis. Furthermore, methanol-based synthesis showed pure ZIF-8 film formation on IEM, by preventing hydrolysis side reaction of zinc ions even with a reduced Donnan exclusion effect vs. water. Aqueous synthesis with and without deprotonating agent was not successful although the charge-selective properties of IEMs are typically higher in water. Uncontrolled hydrolysis reactions, formation of $\mathrm{Zn}(\mathrm{OH})_{2}$ and $\mathrm{pH}$ stability of IEMs in the presence of deprotonation of HMIM were the main challenges for the specific case of ZIF-8 synthesis. 
This is the first demonstration for the use of ion exchange membranes as a functional support (Chapter 3). As future work, different IEMs with higher $\mathrm{pH}$ stability can be investigated for the aqueous synthesis of ZIF-8, although the issue of hydrolysis reactions at longer reaction times would remain. Using different organic ligands, especially with negative charge such as dicarboxylic acids, tricarboxylic acids and tetracarboxylic acids, may provide much better control for the synthesis of the different MOF. This approach can open new directions for controlled localized synthesis of MOF films in general, as well as for the controlled synthesis of patterned MOF films on IEMs. The ion-transport properties of MOFs are themselves extremely attractive, offering tunable monovalent ion-selectivity that is typically not observed in commercial polymeric IEMs and voltage-dependent divalent vs. monovalent transport. ${ }^{4}$ The enhancement of fluid-phase ion transport when using heterogeneous ion-exchange interfaces is well established, combined with the other ion-selective properties of MOFs this is a very attractive option for future research in ion-selective processes. ${ }^{5}$

Beside supported thin MOF films, MOF based mixed matrix membranes (MMMs) are also extensively studied in literature for gas separation applications. ${ }^{6-10}$ In this thesis, we have investigated thermal evolution of three different MMM (ZIF-8, sod-ZMOF and $\mathrm{K}^{+}$-sod-ZMOF/6FDA-DAM) systems for $\mathrm{CO}_{2} / \mathrm{CH}_{4}$ separation as well as that of the polymer, since the performance mainly depends on the properties of the polymer. The effect of the post-thermal treatment on polymer has already shown that it is possible to alter its performance from high permeable to high selective, as expected from the trade-off behavior. However, using an oxidative environment for the thermal treatment has been shown to have larger impact on obtaining highly selective membranes, due to the irreversible chemical modifications of the polymer matrix. These irreversible changes are confirmed with in-situ ellipsometry measurements. When MOFs are introduced to the polymer matrix, the thermal stability of MOFs had a strong impact on the final performances. We have observed stability/instability, oxidation and possible amorphization of MOFs. Unstable MOFs have made the membrane too brittle and further measurements were not possible. This was observed 
for the oxidative high temperature thermal treatments. Amorphization of MOFs may heal the leaky interfaces with possible crosslinking between MOF and polymer under oxidative environments, as it is also reported previously by Kertik et al."

Polymeric membranes suffer from the well-known trade-off between permeability and selectivity. In addition, the plasticization of the polymer at certain pressure decreases the performance of the polymeric membranes drastically. The idea of dispersing highly selective filler in polymer matrix is based on overcoming these problems and obtaining synergetic performance of two materials: processability and high separation performance. However, theoretical predictions are based on an ideal filler/polymer interface..$^{12}$ Therefore, in practice, MMMs have always suffered from not satisfying the theoretical performance due to leaky or rigidified interfaces. We have shown that post thermal treatment approach, among other efforts to overcome the problems of MMMs, may be used to tune the gas separation performances of both polymeric and hybrid membranes. Oxidation and amorphization of MOFs in MMMs needs to be investigated in more details to understand their potential in gas separation. The interfacial properties of both MOFs and polymer are the most critical parameters to obtain defect-free membranes. Therefore, more efforts needs to be directed to design compatible filler-polymer pairs by exploring their interfacial properties. ${ }^{13}$ If we look at a bigger picture for MMMs, even though many studies report high performance membranes, reproducibility in a large scale remains challenging for such a complex systems. The trade-off can be overcome by playing with process parameters.

The previous chapters have shown the importance of the interfacial properties of supported MOF films and MOF-polymer interface in mixed matrix membranes. However, in the literature there are relatively few studies quantifying the interfacial properties of MOFs. ${ }^{14-16}$ Therefore, in Chapter 6, the interfacial properties of ZIF-8 films have been investigated via contact angle measurements of multiple probe liquids. Firstly, our findings highlight the importance of the sample preparation and measurement techniques. The effect of the drying conditions of the samples changed the contact angle values drastically. Secondly, most stable contact angle has been 
achieved by applying mechanical stimulus (piezoactuation) and these values have been used to calculate the surface energy component of the MOF films. The most stable water contact angle of $91.0 \pm 2.5^{\circ}$ is in the limit of hydrophilicity and hydrophobicity. This may be explained with the chemical heterogeneity of the surface as it is randomly oriented films. In the literature, water contact angle values of ZIF-8 has been also reported between $\sim 60-150^{\circ}$ indicating sample preparation and configuration (powders, pellets, films, etc.) have huge impact on the contact angle values. Diiodomethane contact angle measurements (most stable) have been used to estimate dispersive component that is found also extremely close to theoretical predictions based on Hamaker constant. Polar component has been estimated as 0.4 $\mathrm{mN} \mathrm{m}^{-1}$ by using diiodomethane and ethylene glycol contact angle measurements by Fowkes model. Polar contributions are much lower than the dispersive contributions $\left(46.8 \mathrm{mN} \mathrm{m}^{-1}\right)$ but have a substantial impact on interaction with water. Unfortunately, due to large spreads in the water contact angle measurements three-component Van Oss-Chaudhury-Good Method could not be used to calculate the subdivision of the polar component (electron donor and acceptor) which provided valuable information to understand the interaction with other materials such as MOF/polymer interface in mixed matrix membrane applications.

Contact angle measurement is an "easy" approach to assess the interfacial properties. However, the challenges in the measurements and interpretation can make it more complicated, especially for porous crystalline materials as MOFs. In a relatively current review on hydrophobic MOFs by Jayaramulu et al., discuss the challenges to measure the surface energy of porous crystalline materials. ${ }^{17}$ Roughness, porosity, surface coverage, adsorption of the probe liquids are some of the challenges. The information is obtained by assessing the interfacial properties would be used in designing compatible MOF based hybrid materials, choosing a solvent for stable colloidal systems, choosing a substrate for supported MOF films, etc. Therefore, despite challenges, understanding the surface characteristic of MOFs are quite valuable. Using the same configuration as the interaction such as powder, pellet or 
films, would be useful and more attention needs to be given for sample preparation and measurement techniques.

\subsection{Challenges across the thesis}

In this part, so-called "negative results" on amorphous MOFs and efforts on understanding the ion transport properties of MOFs that were obtained during this thesis are presented. These topics are relatively new areas in MOF field and there were many questions to be answered to understand their potential in various applications.

\subsubsection{Amorphous MOFs - ZIF-4 vs. ZIF-zni}

Amorphous MOFs (aMOFs) are a new class of porous material that are built of metal ions/cluster bonded organic linkers. The main characteristic is the lack of the longrange periodic order array. aMOF are obtained by post treatments to crystalline MOFs, such as pressurization, heating, ball milling, dielectric-barrier discharge, and dehalogenation with $\mathrm{NH}_{3}$. There is limited literature on aMOFs and in particular on aMOF films. Thus, we aimed to prepare one of the most studied aMOFs, ZIF-4. ZIF-4 can be amorphized thermally and it shows unique behavior when it is heated. At $300^{\circ} \mathrm{C}$ it is completely amorphized and at $400^{\circ} \mathrm{C}$, another MOF structure, dense ZIF-zni is formed. ZIF-4 and ZIF-zni have the same chemical formula with different morphology. We have followed the synthesis procedure from Bennett, et al. ${ }^{18}$ Our first trial yielded a negligible amount of ZIF-4 particles, which was not possible to analyze. After some modifications in the synthesis procedure, we have consistently synthesized ZIF-zni instead of ZIF-4 as it can be seen in XRD and SEM results. (Fig. 6.1 and 6.2)

This reproducibility problem why we could not obtain ZIF-4 in our laboratory may be due the lack of details in the experimental sections, different synthesis conditions, different purities of the raw materials and human factor. The number of MOF entries in Cambridge Structural Database has reached to more than 80,0oo. A one-time synthesis is enough to be registered as a new MOF. Reproducibility should be a highlighted problem in general within the scientific community, as well as in 
particular for MOF synthesis. Researchers should be motivated to provide as much of details as possible in their publications. As the reproducibility of adsorption data of MOFs have been critically discussed by Sholl et al. and the importance of the reporting the details of the synthesis and measurement conditions to assess the different crystal phases were underlined. ${ }^{19}$

a)

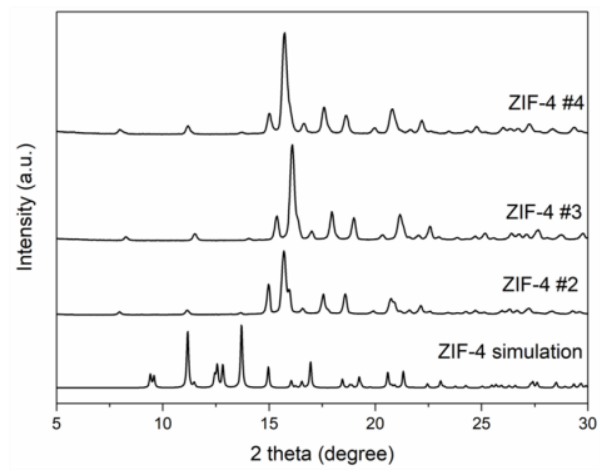

b)

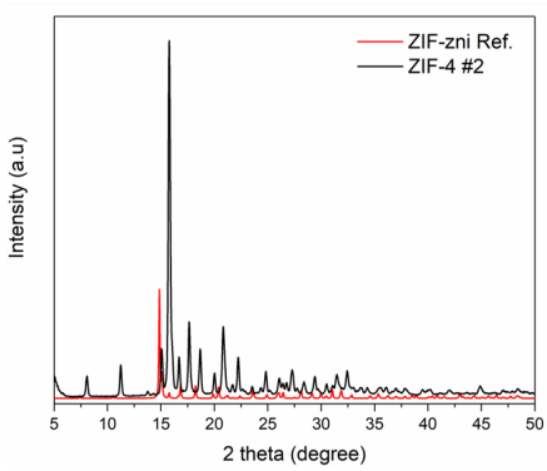

Figure 6.1 XRD spectrum a) different synthesis methods to obtain ZIF-4 b) ZIF-4 synthesis results as ZIF-zni.
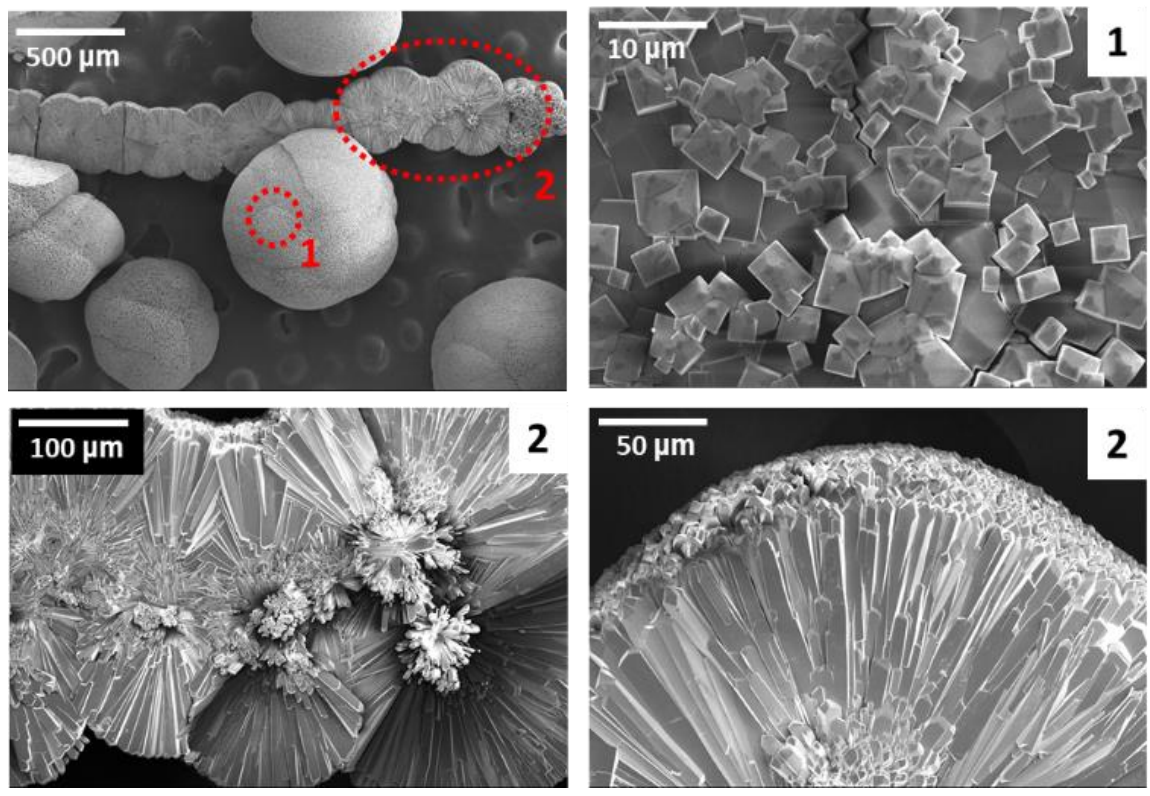

Figure 6. 2 SEM images of ZIF-zni crystals. 
The ultimate goal of this study was to investigate aMOF films. Therefore, we decided to continue with obtaining ZIF-4 films. We have used the same synthesis solution as ZIF-4 powder synthesis and tried different approaches to form a ZIF-4 film on porous anodic alumina oxide (AAO) supports: counter-diffusion, dip coating and secondary growth. Counter diffusion at room temperature and dip coating followed with thermal treatment did not any film formation on the AAO support. However, the secondary growth method resulted as a formation of yellow, sticky, gel-like formation (Fig. 6.3 (b)). XRD results shows that there is no crystal formation but an amorphous structure formed. (Fig. 6.3 (a)) We have also confirmed this with the SEM images in Fig. 6.3(ce). Unfortunately, removing this polymer-like amorphous structure from a glass petri dish without deforming the AAO proved to be extremely challenging.

a)

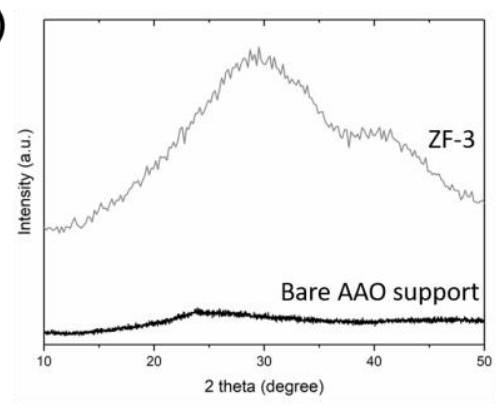

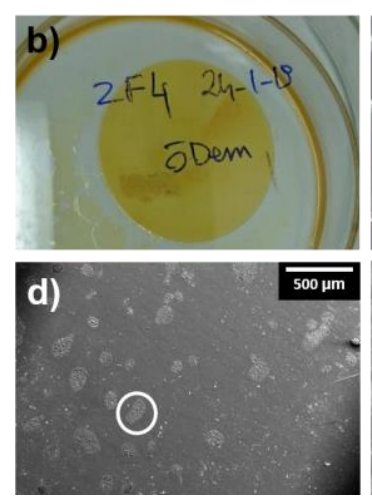

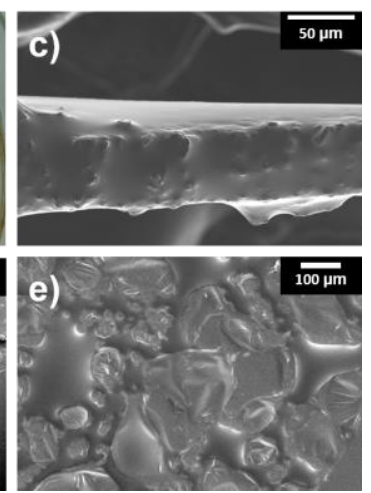

Figure 6.3 The XRD and SEM results of ZIF-4 films a) XRD spectra of ZF-3 sample and bare AAO support b) the picture of the ZF-4 sample after the synthesis c) cross sectional SEM image d) the top surface of the films with circle indicating where the SEM image in e) was taken.

\subsubsection{Ion transport through nanopores of MOFs}

Ion transport through the nanopores of MOFs is a relatively new application of MOFs. This research area has been dominated with theoretical studies, with only a relatively few experimental studies emerging in the past few years. ${ }^{4,20,21}$ Ion transport in nanoporous materials can be explained with different mechanisms such as electrical double overlap, Donnan exclusion - charge selectivity, dielectric exclusion, ionic Coulomb blockade or the combinations of all of these mechanisms. Recent studies 
have postulated that the transport of alkali metal ions in MOFs is based on partial dehydration as in biological-channels. ${ }^{4}$ In this thesis, some efforts were been made to study the ion transport in MOFs and investigate different selectivity mechanisms. In order to do this, obtaining defect free and continuous MOF films was the starting point to understand the mechanism.

Our first trial was to obtain a MOF plug at the top of the nano-pipette as in Fig. 6.4. We could study the ion transport by forcing ions from one to pass through the pores of the MOFs. The synthesis method was adopted from Jiang et al. ${ }^{22}$ However, we came across problems due to poor adhesion between MOF and glass. Preliminary results also showed that the MOF plug was leaking based on the experiments with methyl orange dye. Upon closer inspection of the MOF plug inside the pipette, it was found that the MOF plug was not well attached to the glass wall. Additionally, it was hard to control the location where the ZIF-8 plug would start synthesizing, since the reaction occurred at the interface of the zinc solution and the HMIM solution. Furthermore, permselectivity values (0.1 M KCl/o.5 M KCl) were not higher than $3 \%$ for all the samples. Therefore, it was not possible to study the ion transport with MOF-plug. The main challenge was to obtain a defect-free MOF plug with a good adhesion to the glass, highlighting against the importance of the interfacial properties of MOF materials and the need for more detailed investigations in this aspect of MOF behaviour. 


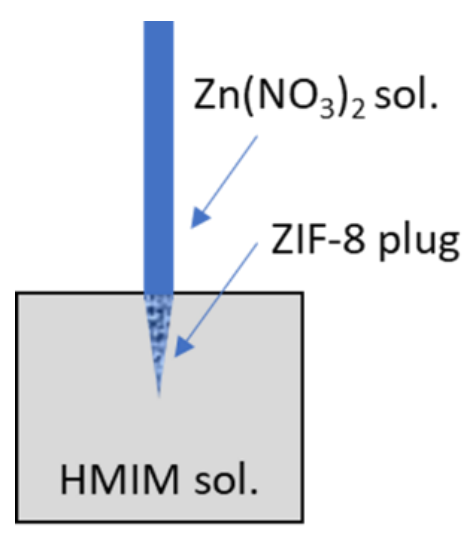

Figure 6.4 Schematic representation of the ZIF-8 plug formation on the tip of the nano-pipette.

The second approach to study ion transport was to obtain MOF/graphene oxide (GO) film on anodic alumina oxide (AAO) support. We aim to extend the study to selective multivalent ion transport, starting with a fabrication method based on the study of Zhang et al. where selective ion transport of alkali metal ions in MOFs was investigated. ${ }^{4}$ The fabrication method includes several steps, elaborate handling of the AAO since it is very brittle and long duration (4-5 days). During the preparation, some inhomogeneity has been observed in spin coating process due to porous nature of the support. This caused different zones on the porous support as it can be seen in the Fig. 6.5 (d). The coverage of the AAO surface with ZIF-8 films was successful as it can be seen in Fig. 6.5 (a) and (b) with bare support and ZIF-8/GO film on AAO support, respectively. There was also some uncovered parts in SEM analysis for some samples. MOFs on IEM in Chapter 3, can be better candidates compared to AAO supported MOF/GO membranes due to simplicity of the procedure and as well as improved mechanical stability of IEMs than AAO (elastic polymer vs. brittle nanoporous aluminum oxide). 

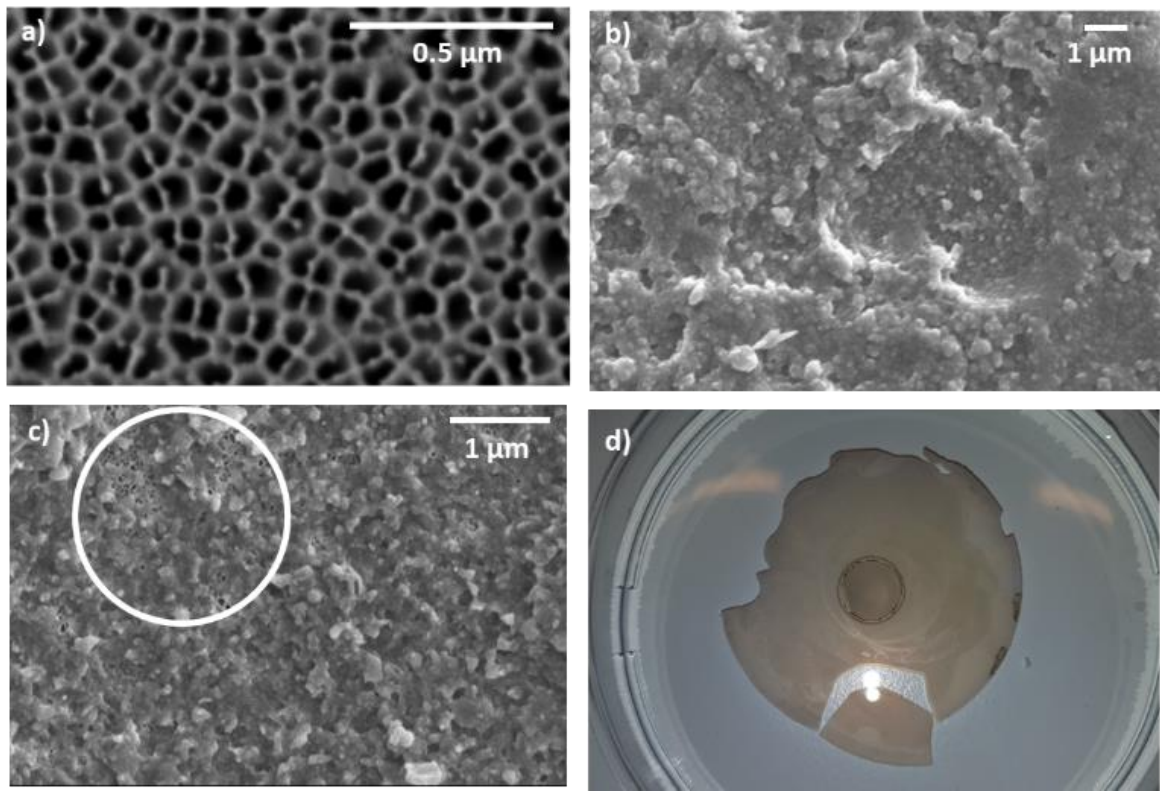

Figure 6.5 a) SEM image of the bare AAO support, b) ZIF-8 film on AAO support, c) uncovered regions $d$ ) the sample after spin coating to show the different zones and the brittleness of the support.

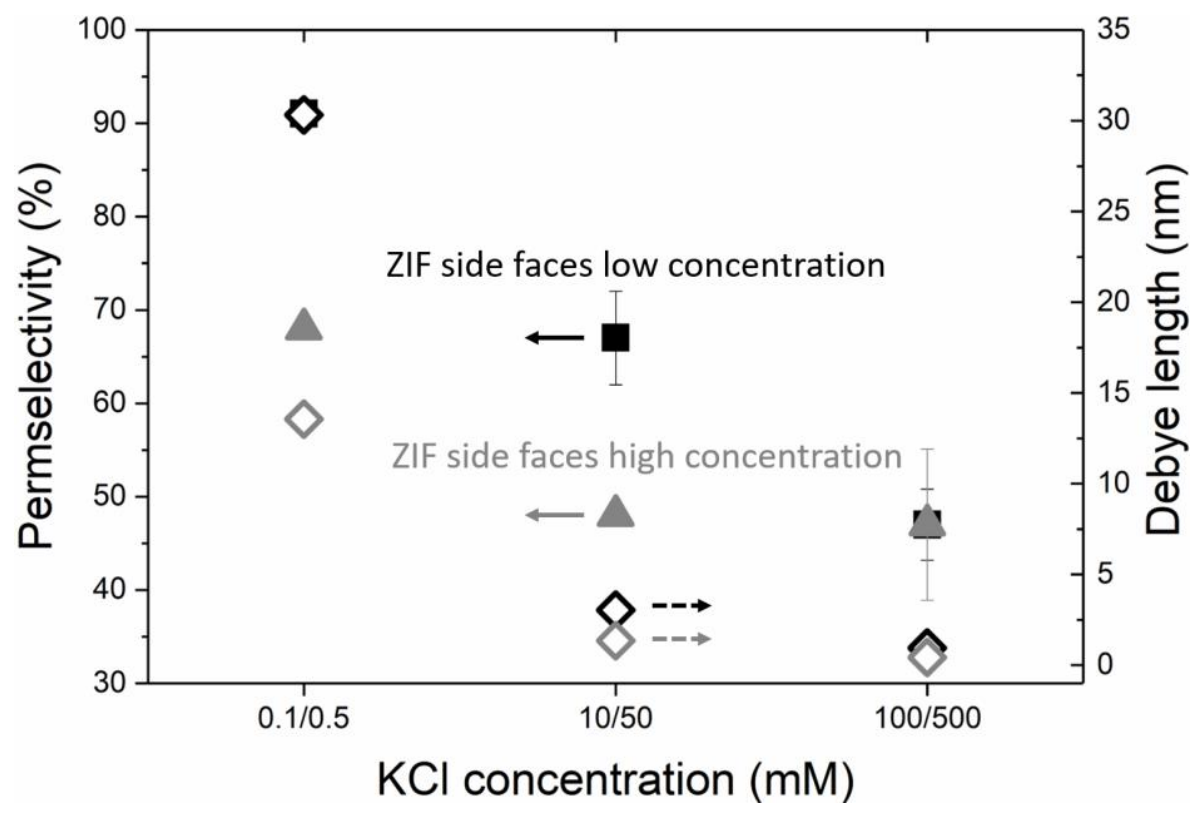

Figure 6.6 Permselectivity and Debye length results based on different salt concentrations. 
As a first step to study ion transport properties, we have performed permselectivity measurements in different salt concentrations. The results in (Fig. 6.6) show that by changing the salt concentration permselectivity approaches to its theoretical value. We hypothesize that in our case effective ion-selectivity was dominated by cracks and the effect of these cracks was mitigated by achieving ion-selectivity due to Debye layer overlap between the charged walls of the cracks at low salt concentrations. This Debye layer overlap mechanism is consistent with other nano-scale ion-selective systems, such as nanopores or nanochannels. ${ }^{23,24}$ The defects in synthesized materials were also confirmed with further dye-tests and obtaining defect-free MOF films remained as a challenge. In this process, the control over the film fabrication was very challenging due to the multiple steps. In order to open up new research directions, reproducible results and knowledge-transfer, facile synthesis and clear communication are needed among scientists. The future direction for this study would be obtaining defect-free MOF films, in order to continue investigating the ion transport properties of these films with different salts/valances and studying their performance as electrodialysis (ED) membranes or modifying ED membranes. This work also helped to motivate our study of MOF synthesis on IEMs, where initially the goal was purely to study iontransport but the clear advantages of using the IEM as a synthesis platform became apparent as experiments were carried out.

\subsubsection{MOFs-on-Lewatit ${ }^{\circledR}$}

Water sorption on $\mathrm{CO}_{2}$ adsorbents is a critical problem as it causes very high energy cost in the regeneration step and lowers the $\mathrm{CO}_{2}$ adsorption. In order to mitigate the water sorption, hydrophobic ZIF-8 shell was grown on the outer surface of Lewatit . For this, the experimental procedure of Gao et al. was adapted, where ZIF-8 crystals were grown on zeolite $5 \mathrm{~A}$ to enhance the hydrophobicity. ${ }^{25}$ This procedure includes seeding and secondary growth steps. During secondary growth, the temperature was kept at $-15^{\circ} \mathrm{C}$ in order to control the continuous MOF growth on the outer surface of Lewatit ${ }^{\circ}$ without defects. As it can be seen in SEM images (Fig. 6.7) and XRD analysis in Fig. 6.8, MOF particles have grown successfully on the outer surface of $\sim 0.7 \mathrm{~mm}$ 
diameter, Lewatit ${ }^{\circ}$ The synthesis procedure was repeated several times to ensure defect-free formation. However, the $\mathrm{CO}_{2}$ sorption of the MOF/Lewatit did not show any improvement and in fact it actually substantially reduced with no substantial different in the water uptake. This can be because the ZIF-8 crystals are not spread equally on the Lewatit but form clusters. As it is also discussed in Chapter 5 , the hydrophobic properties of ZIF-8 is open to discussion and it depends on many parameters. ZIF-8 shows hydrophobic characteristics only after post-synthetic approaches such as coating with carbon nitride foam, ${ }^{26}$ modification with alkyl chains $^{27}$ as it is discussed in the review of Jayaramulu et al. on hydrophobic MOFs. ${ }^{17}$
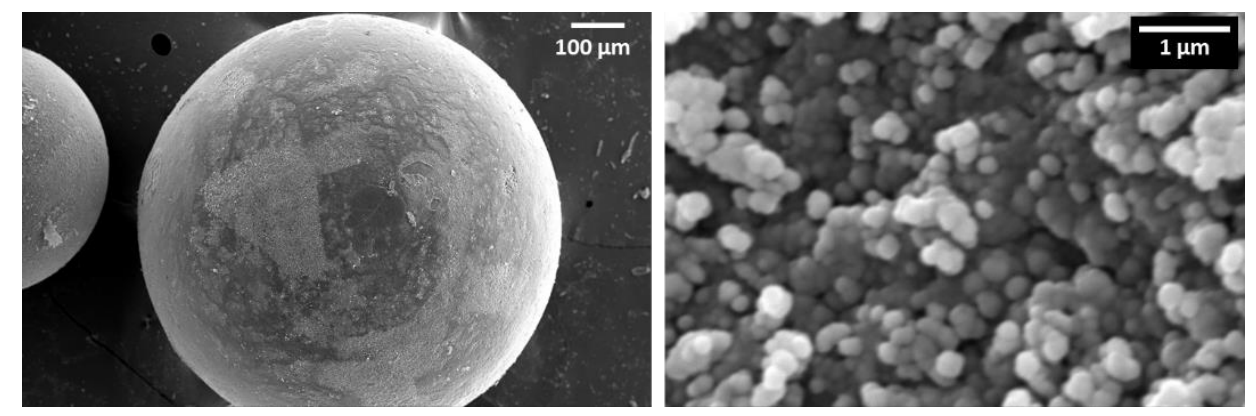

Figure 6.7 SEM images of Lewatit ${ }^{\curvearrowleft}$ with MOF formation on the outer surface. 


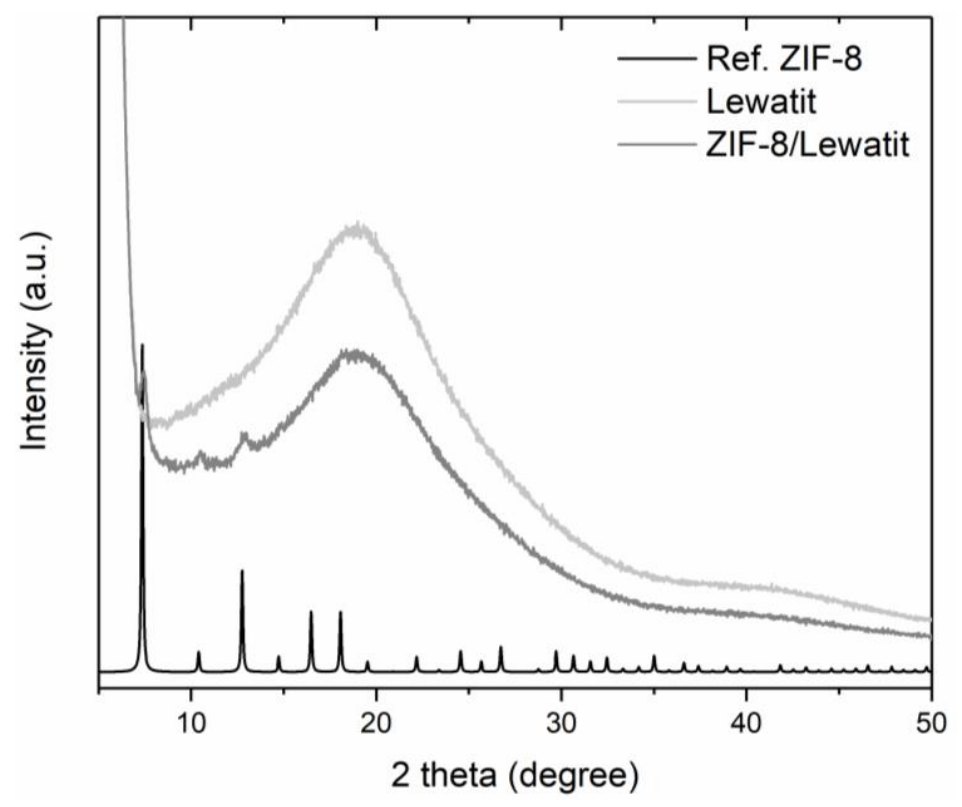

Figure 6.8 XRD spectra of ZIF-8 reference, Lewatit ${ }^{\circledR}$ and ZIF-8/Lewatit ${ }^{\circledR}$.

\subsection{Perspectives}

The field of metal-organic frameworks (MOFs) is a relatively new and growing field, consisting of many different disciplines. Since their discovery in $1995,{ }^{28}$ many new chemistries have been used to synthesize new MOFs. In 2017, the number of MOFs has reached to 80,0oo in The Cambridge Crystallographic Data Centre. ${ }^{29}$ This number already shows how fast the field growing in the last 22 years. MOF researchers have come together for the first time at the $1^{\text {st }}$ International Conference on Metal-Organic Frameworks and Open Framework Compounds, organized in 2008 in Germany. The conference covered porous solids and particularly MOFs, from new synthesis to applications. Following this, $1^{\text {st }}$ European Conference on Metal Organic Frameworks (EUROMOF) and Porous Polymers, Germany has been organized in 2015. It was stated in the invitation letter that innovative porous materials would find applications in various fields, like adsorption, separation or energy transformation and storage. As new materials were synthesized with great potential on many different applications, the lack of applications was the missing link. Some part of this thesis has been also 
presented in the last two EUROMOF conferences. In EUROMOF 2017, in the Netherlands, the focus was still mainly academic research including different MOF structures and morphologies along with different synthesis strategies and their applications. The take-home message of the conference was that there were multiple ways to obtain many different MOF structures that can be used in numerous applications in theory or in small scale. In 2019, the $3^{\text {rd }}$ EUROMOF conference took place in Paris with over 450 delegates from 37 countries. Within a 2 year time, the MOF community doubled along with the involvement of many companies, both spinoff companies and dedicated MOF departments in big companies. Within the conference oral presentation program, there were many presentations from companies. This conference showed that the gap between academia and industry has started to disappear for MOFs. The differences between two conferences in last two years were regarding growing from lab scale to large scales, from complex synthesis methods to easy and reproducible methods. Developments of flow synthesis, ${ }^{30-33}$ mechanochemical synthesis ${ }^{34-39}$ and spray-drying ${ }^{40-42}$ have opened the door to (economic) scale-up the MOF production. Beside larger companies supplying MOFs such as BASF43, spin-off companies such as MOF technologies, NuMat, Framergy, Promethean Particles, Profmof with close contact to the academia started to create the MOF market. Trupick and ION-X are first commercial examples of MOF applications designed by MOF Technologies and NuMat, respectively. ${ }^{44}$

While MOF powders have started to find some applications in the industry, MOF films are still in the early stage of the development. Obtaining homogenous, defect-free, oriented or intergrown MOF films are some of the requirements for certain applications such as gas separation and storage, catalysis as well as the electrical applications for advanced nanotechnology applications. ${ }^{45}$ Chemical solution growth, ${ }^{46}$, layer-by-layer, ${ }^{47}$ electrochemical film growth, ${ }^{48}$ films of preformed MOF particles (via spin coating, dip coating, etc.), ${ }^{49,50}$ interfacial synthesis ${ }^{51}$ and counterdiffusion ${ }^{52}$ are main MOF thin film preparation techniques. ${ }^{45}$ For gas separation applications, obtaining defect free and continuous MOF films is the main requirement to avoid leakage together with stability of the films. For the electronic devices 
including memory devices and field-effect transistors (FETs), formation of oriented films with green chemistries and the control over the roughness are main requirements. ${ }^{53}$ In the review of Ameloot et al., MOFs potential in electronic devices is extensively discussed. ${ }^{44}$ MOFs can be used as an integral part of solid-state electronics and the preparation of MOF films is also important part of the valorization process. MOF film preparation/deposition technique should be also compatible with the current technology in cleanroom environment. Other potential applications of MOF films are photovoltaics for solar energy conversion, electrochemical/photocatalytic $\mathrm{CO}_{2}$ reduction, water splitting, the fabrication of components for information technology, energy storage, including supercapacitors and batteries, and thermoelectric devices. ${ }^{45}$

This thesis deals with MOF film growth onto sacrificial metal and charge selective polymer supports, preparation of MOF-based MMMs along with their gas separation performances and assessing interfacial properties of MOF films. It is hoped that the research presented in this thesis helps towards transferring the MOF powder synthesis knowledge into MOF film preparation methods. For this, the control over the concentrations of the reactants at the interface of the substrate are found very crucial. Moreover, the MOF-polymer interfaces to prepare defect-free films are the vital parameter towards gas separation applications. As a result of the post-thermal treatment approach to improve the separation performance, amorphization and oxidation of MOFs should be further investigated to understand the MOF/polymer interface as well as the gas separation performance. At last, the importance is stressed of the interfacial properties of MOFs based on their interactions with various solvents, substrates, etc. Their potential in various applications can be further explored by using the work of this thesis. MOF film preparation and understanding their interfacial properties can inspire future research on use of functional substrates, designing better MOF/polymer or MOF/substrate interfaces to improve the adhesion and compatibility. It is hoped the work of this thesis along with all these positive and negative results can be expected to aid further development and application of thin MOF films. 


\section{References}

1 Y.-L. Qiu, H.-X. Zhong, T.-T. Zhang, W.-B. Xu, P.-P. Su, X.-F. Li and H.-M. Zhang, ACS Appl. Mater. Interfaces, 2018, 10, 2480-2489.

2 Y.-L. Qiu, H.-X. Zhong, T.-T. Zhang, W.-B. Xu, P.-P. Su, X.-F. Li and H.-M. Zhang, ACS Appl. Mater. Interfaces, 2018, 10, 2480-2489.

A. Perea-Cachero, J. Dechnik, R. Lahoz, C. Janiak, C. Téllez and J. Coronas, CrystEngComm, 2017, 19, 1470-1478.

4 H. Zhang, J. Hou, Y. Hu, P. Wang, R. Ou, L. Jiang, J. Z. Liu, B. D. Freeman, A. J. Hill and H. Wang, Sci. Adv., 2018, 4, eaaqoo66.

F. Radmanesh, T. Rijnaarts, A. Moheb, M. Sadeghi and W. M. de Vos, J. Colloid Interface Sci., 2019, 533, 658-670.

6 S. R. Venna, M. Lartey, T. Li, A. Spore, S. Kumar, H. B. Nulwala, D. R. Luebke, N. L. Rosi and E. Albenze, J. Mater. Chem. A, 2015, 3, 5014-5022.

A. Kertik, A. L. Khan and I. F. J. Vankelecom, RSC Adv., 2016, 6, 114505-114512.

B. Seoane, J. Coronas, I. Gascon, M. E. Benavides, O. Karvan, J. Caro, F. Kapteijn and J. Gascon, Chem. Soc. Rev., 2015, 44, 2421-2454.

9 A. Kılıç, Ç. Atalay-Oral, A. Sirkecioğlu, Ş. B. Tantekin-Ersolmaz and M. G. Ahunbay, J. Memb. Sci., 2015, 489, 81-89.

R. Mahajan and W. J. Koros, Ind. Eng. Chem. Res., 200o, 39, 2692-2696.

A. Kertik, L. H. Wee, M. Pfannmöller, S. Bals, J. A. Martens and I. F. J. Vankelecom, Energy Environ. Sci., 2017, 10, 2342-2351.

R. Mahajan, R. Burns, M. Schaeffer and W. J. Koros, J. Appl. Polym. Sci., 2002, 86, 881-890.

J.-H. Lee, B. J. R. Thio, T.-H. Bae and J. C. Meredith, Langmuir, 2009, 25, 91019107.

14 N. P. Panapitiya, S. N. Wijenayake, Y. Huang, D. Bushdiecker, D. Nguyen, C. Ratanawanate, G. J. Kalaw, C. J. Gilpin, I. H. Musselman, K. J. Balkus and J. P. Ferraris, Polymer (Guildf)., 2014, 55, 2028-2034.

D. Elangovan, Michigan State University, 2010.

16 D. Kim, D. W. Kim, O. Buyukcakir, M. K. Kim, K. Polychronopoulou and A. Coskun, Adv. Funct. Mater., 2017, 27, 1-8. 
17 K. Jayaramulu, F. Geyer, A. Schneemann, Š. Kment, M. Otyepka, R. Zboril, D. Vollmer and R. A. Fischer, Adv. Mater., 2019, 1900820, 1900820.

18 T. D. Bennett, D. A. Keen, J. C. Tan, E. R. Barney, A. L. Goodwin and A. K. Cheetham, Angew. Chemie - Int. Ed., 2011, 50, 3067-3071.

19 J. Park, J. D. Howe and D. S. Sholl, Chem. Mater., 2017, 29, 10487-10495.

20 X. Li, H. Zhang, P. Wang, J. Hou, J. Lu, C. D. Easton, X. Zhang, M. R. Hill, A. W. Thornton, J. Z. Liu, B. D. Freeman, A. J. Hill, L. Jiang and H. Wang, Nat. Commun., 2019, 10, 2490.

21 E. Madrid, M. A. Buckingham, J. M. Stone, A. T. Rogers, W. J. Gee, A. D. Burrows, P. R. Raithby, V. Celorrio, D. J. Fermin and F. Marken, Chem. Commun., 2016, 52, 2792-2794.

22 Z. Y. Jiang, H. L. Liu, S. A. Ahmed, S. Hanif, S. Bin Ren, J. J. Xu, H. Y. Chen, X. H. Xia and K. Wang, Angew. Chemie - Int. Ed., 2017, 56, 4767-4771.

23 A. M. Benneker, H. D. Wendt, R. G. H. Lammertink and J. A. Wood, Phys. Chem. Chem. Phys., 2017, 19, 28232-28238.

24 A. M. Benneker, J. A. Wood, P. A. Tsai and R. G. H. Lammertink, Nat. Publ. Gr., 2016, 1-11.

25 F. Gao, Y. Li, Z. Bian, J. Hu and H. Liu, J. Mater. Chem. A, 2015, 3, 8091-8097.

26 H. Zhou, H. Wang, H. Niu, A. Gestos, X. Wang and T. Lin, Adv. Mater., 2012, 24, 2409-2412.

27 J. Canivet, S. Aguado, C. Daniel and D. Farrusseng, ChemCatChem, 2011, 3, 675678.

28 O. M. Yaghi and H. Li, J. Am. Chem. Soc., 1995, 117, 10401-10402.

29 The Cambridge Crystallographic Data Centre (CCDC), The Cambridge Structural Database Data Update, https://www.ccdc.cam.ac.uk/support-andresources/ccdcresources/csd-2017-updates/, (accessed 16 February 2020).

30 R. M. Myers, D. E. Fitzpatrick, R. M. Turner and S. V. Ley, Chem. - A Eur. J., 2014, 20, 12348-12366.

31 Z. Liu, J. Zhu, C. Peng, T. Wakihara and T. Okubo, React. Chem. Eng., 2019, 4, 1699-1720.

32 M. P. Batten, M. Rubio-Martinez, T. Hadley, K. C. Carey, K. S. L. A. Polyzos and M. R. Hill, Curr. Opin. Chem. Eng., 2015, 8, 55-59. 
33 P. W. Dunne, E. Lester and R. I. Walton, React. Chem. Eng., 2016, 1, 352-36o.

34 G. Zhan and H. C. Zeng, Chem. Commun., 2017, 53, 72-81.

35 D. E. Crawford, C. K. G. Miskimmin, A. B. Albadarin, G. Walker and S. L. James, Green Chem., 2017, 19, 1507-1518.

36 P. Li, F. F. Cheng, W. W. Xiong and Q. Zhang, Inorg. Chem. Front., 2018, 5, 2693-2708.

37 T. Stassin, I. Stassen, J. Marreiros, A. J. Cruz, R. Verbeke, M. Tu, H. Reinsch, M. Dickmann, W. Egger, I. F. J. Vankelecom, D. E. De Vos and R. Ameloot, Chem. Mater., 2020, acs.chemmater.9bo3807.

38 D. Crawford, J. Casaban, R. Haydon, N. Giri, T. McNally and S. L. James, Chem. Sci., 2015, 6, 1645-1649.

39 Q. Cao, J. L. Howard, D. E. Crawford, S. L. James and D. L. Browne, Green Chem., 2018, 20, 4443-4447.

40 L. Garzón-Tovar, S. Rodríguez-Hermida, I. Imaz and D. Maspoch, J. Am. Chem. Soc., 2017, jacs.6b11240.

41 C. Echaide-Górriz, C. Clément, F. Cacho-Bailo, C. Téllez and J. Coronas, J. Mater. Chem. A, 2018, 6, 5485-5506.

42 M. Rubio-Martinez, C. Avci-Camur, A. W. Thornton, I. Imaz, D. Maspoch and M. R. Hill, Chem. Soc. Rev., 2017, 46, 3453-3480.

43 United States Patent, US 7,968,739 B2, 2011.

$44 \quad$ Nat. Chem., 2016, 8, 987-987.

45 J. Liu and C. Wöll, Chem. Soc. Rev., 2017, 46, 5730-5770.

46 H. Bux, F. Liang, Y. Li, J. Cravillon, M. Wiebcke and J. Caro, J. Am. Chem. Soc., 2009, 131, 16000-16001.

47 Z. Wang and C. Wöll, Adv. Mater. Technol., 2019, 4, 1-22.

48 Ö. H. Demirel, T. Rijnaarts, P. de Wit, J. A. Wood and N. E. Benes, J. Mater. Chem. A, 2019, 7, 12616-12626.

49 J. Gascon, S. Aguado and F. Kapteijn, Microporous Mesoporous Mater., 2008, $113,132-138$.

50 A. Demessence, C. Boissière, D. Grosso, P. Horcajada, C. Serre, G. Férey, G. J. A. A. Soler-Illia and C. Sanchez, J. Mater. Chem., 2010, 2o, 7676-7681. 
51 R. Ameloot, F. Vermoortele, W. Vanhove, M. B. J. Roeffaers, B. F. Sels and D. E. De Vos, Nat. Chem., 2011, 3, 382-387.

52 J. Yao, D. Dong, D. Li, L. He, G. Xu and H. Wang, Chem. Commun., 2011, 47, 2559.

53 M. D. Allendorf, A. Schwartzberg, V. Stavila and A. A. Talin, Chem. - A Eur. J., 2011, 17, 11372-11388.

54 I. Stassen, N. Burtch, A. Talin, P. Falcaro, M. Allendorf and R. Ameloot, Chem. Soc. Rev., 2017, 46, 3185-3241. 
Acknowledgments 
I am writing this acknowledgments from a stay-at-home period in Eindhoven due to the Covid-19 pandemic. For this reason, I could not say a proper goodbye to my MST family. This "most-read" part is now a great opportunity for me to thank all of you. Without the help and support I received from you, it would not be possible to finalize this thesis.

To start with, I would like to thank Nieck Benes for accepting me to his group, FIF and became my supervisor and promotor, when I was an orphan $\mathrm{PhD}$ without a supervisor and a project. Dear Nieck, I have always felt very lucky to be your student and be part of the FIF group. Thanks to you, I could initiate my own projects with nice collaborations and learn how to become an independent researcher. I am very grateful for your guidance and unique vision to help me to see the bigger picture. Your interventions when I lost myself in the darkness of the experiments helped me to stay on track. I also very much appreciate the concept of "Nieckified" presentations and graphs that will remain in my system forever. Thanks also for the many social events, including cooking workshops, the company visit and nice routes you brought us in Winterschool.

Dear Jeff Wood, our long history started as being close friends and continued with the addition of the co-supervisor/student relationship. I have kept telling this to you many times but I would like to repeat it one more time: "I could not finish this thesis without your help". Your input to our first paper was like a catalyst to the process. After that, we started to work together on ÖzMOF projects. You were not only a great supervisor but also a great listener. Thank you for all the scientific discussions, the fast revisions, all the fun times and support. As friends, I hope we will continue collecting more memories as we did during the TTD days, the Pinkpop adventure and the times you cooked delicious scones and pancakes.

To my paranymphs, Elif Nur and Timon, I am very thankful to both of you for accepting to be my paranymphs. Although I might not see you on my side during a possible online defense due to the pandemic, I have always felt your constant support and great friendship by my side all the time during my $\mathrm{PhD}$.

My FAE (Friday Afternoon Experiment) team, Timon and Patrick, I would like to thank you both for initiating the MOF-hollow fiber project. This project gave me the first push to start my own research and explore my potential in electrochemistry. I learnt a lot from both of you and it was great working with you. I also would like to thank Anne S. for supplying me with her precious hollow fibers.

The MMMs project was only possible thanks to Ayșe's six-month visit at UT which has been a great motivation for me. It was very nice to work together again like the 
old days at ITU. Dear Ayșe, I wish you all the best for finalizing your thesis and for the rest. I also would like to extend my gratitude to both Göktuğ Ahunbay and Birgül Tantekin Ersolmaz for this collaboration opportunity.

Next, I would like to thank my students: Karen, Fleur and Tom. I have learnt a lot from you. Thank you all for your contributions to this thesis.

Now, I would like to highlight that MST has been a real family to me in the last 4.5 years. If I am able to finalize my thesis today, it is thanks to the technical, scientific and emotional support of this big family. Firstly, I would like to take the opportunity to thank Annet and Susanne for always being positive and helpful. Despite being the only one working on MOFs in the cluster, I have always received many great help from my colleagues. I would like to specifically thank Alberto, Bob, Cindy, Denys, Dona, Farzaneh, Frank, Harmen, Herman, Ineke, Iske, Jan, Mariël and Oğuz for their input. I have been always very lucky with my officemates, namely, Anne B., Bob, Josh, Khalid, Kristianne, Lily, Pim, Xiuqin, Sinem and Timon. During my writing process, I received constant positive energy from Lily and a great support from my dear long-hour-company Xiuqin. Xiexie and good luck with your PhDs! I also enjoyed very much being part of the FIF group. Thank you for all the fun times during the cooking workshops and the many nice discussions during lunch meetings. My FIF angels, Anne S., Farzaneh and Mariël, I have always felt your support and positive energy during my $\mathrm{PhD}$ journey. I wish you all a lot of success for the rest of your PhDs! Dear Kristianne, I am very glad to get to know you better when we became officemates. Your kindness, positivity and hard-working have always inspired me. I would like to thank Timon and Rian for hosting great potluck dinner parties and for the great company in our little "turismus" in Spain. I am looking forward our reunion in the South after Corona. Dear Dona, I cannot thank you enough for all the nice alternative coffee breaks and for your endless support. You have always cheered me up with your positive energy. I wish you all the best for the future. I am also thankful to Ameya, Irshad, Lily and Tao for inviting me to the special dinners with extremely delicious foods and games. Dear Harmen, from day one, I have always enjoyed listening your cool stories and appreciated all your cool questions during the Monday Morning Meetings. Thanks also for your contribution to the MOF-IEM project! Dear Antoine, I will always remember your mood swings depending on the day or time as well as your enthusiasm to keep our labs safe and your contribution to the Friday borrels. Dear Saskia, it was a pleasure for me to work together with you on Chemische Evenwicht course. I also would like to extend my gratitude to other MST members, Almohanad, Andrew, Angela, Arputha, Audrey, Aura, Dennis, Esra, Hanieh, Heleen, Jason, Joris, Jurjen, Liniker, Mehrdad, Nicole, Nikos, Piotr, Renaud, 
Rob, Tymen, Wiebe and Wouter. I also would like to thank Kitty Nijmeijer for giving me an opportunity to start my PhD in MST.

Talking about the MST family, I have also found my sister there, Valentina, not only a sister, but a great roommate, colleague and friend. I will always miss our times together in the kitchen-bedroom apartment and in Park de Kotten. You have been a great support in the difficult times and an awesome company in the good times. Visiting you in your mini house, joining your wedding in Sardinia and meeting your family were also unforgettable and lovely memories. As a co-founder of TTD (Traditional Thursday Dinners), together with you, I also would like to extend my gratitude to all TTD members. :- Fortunately, I had the chance to spend time with the previous generation of MST, including Beata, Damon, Erik, Izabella, Jeroen, Krzysztof, Olga, Sinem and Yali. It was a great honor to be invited to Salman Summer School. I cannot thank you enough for all the fun times and your mentorship at the beginning of my $\mathrm{PhD}$ journey. During the $\mathrm{PhD}$, I had to say goodbye to many people who have a big place in my hearth, namely, Alfredo, Daria, Lady Shazia, Namik, and Nora. Thank you all for the lovely times we spent together. As an advantage of living close to the German border, I reunited with my Menuhin Haus friends in Germany after many years. To Anne, Christopher, Matthias, Sarah, Tim and the little surprise baby members Frieda and Joris, thanks for this special friendship. Also, many thanks to Afroditi, Ana M., Ana R., Arya, Ayşegül, Bart, Carlos, David, Dinis, Fenna, Francisca, Guillaume, Ines, Jaap, Jessica, Joana, Joanna, Jonnie, Karabelas, Lucie, Maike, Marco, Marina, Melis, Melisa, Michel, Moh, Olivier and Pablo for all the great times we spent together in the last years.

A big thanks goes to P-NUT, it was a pleasure to be part of this great team. I have learned a lot and had so much fun to organize events together.

Sevgili Kafiye abla, güleryüzün ve desteğin için ne kadar teşekkur etsem az, sabahları masama bıraktığın lezzetli sürprizler için ise ayrıca teşekkürler. Şermin abla, sana da hem lezzetli yemeklerin için hem de desteğin için çok teşekkür ederim. Sevgili Türk mafyası, son zamanlarda aranıza pek katılamasam da varlığınızın bana her zaman güç verdiğini söylemem gerekir. Yollumun kesiștiği tüm mafya üyelerine özellikle de Akın, Atlas, Arya, Aysun, Burcu, Cihan, Damla, Derya A., Derya D., Devrim, Erkan, Güner, Mehmet, Muharrem Başkan, Mehmet, Nil Bilge, Nurcan, Oğuzhan, Ozan, Pelin, Senem, Sıla, Sinem, Yiğitcan ve Yusuf'a gönülden teşekkürler. Sevgili adaşım, Özlem, ev arkadaşlığı ile başlayan dostluğumuz için, geçirdiğimiz her guzel eğlenceli an için ve verdiğin sonsuz destek için ne kadar teșekkür etsem az. Ve sevgili Burak, doktoramın son aylarında verdiğin destek benim için çok büyük bir motivasyon oldu, çok teşekkürler! Bol şans diliyorum yeni 
başladığın bu doktora serüveninde, JUST DO IT! Ömer seni de en yakin zamanda güneșli, masmavi bir deniz kenarında ziyaret etmek için sabırsızlanıyorum. Keyifli sohbetin ve desteğin için sana da çok teșekkürler!

Vee benim sevgili dostlarim, uzaklarda da olsa yakında olanlarım. Sizlerin inanci ve desteğini her zaman yanımda hissettim. Hatta bazen yanıbaşımda hissettim, Enschede'ye yolunuzu düşürmeniz benim için ne kadar değerliydi bilemezsiniz. Didem, K. Anıl, Nergis ve Şule, uzak mesafeli arkadașlı̆̆ımızı sürdürebilmemiz için verdiğiniz her emek için binlerce kez teșekkür ederim. Sevgili A. Gençay, B. Ece, Büşra, Didar, Ipek, Mustafa, Sevgül, Tuğçe B. ve Tuğçe I. sizlere de mesafelere rağmen her görüştüğümüzde dostluğumuza kaldığımız yerden devam edebildiğimiz için çok teșekkür ederim.

Sevgili Elif Nur, ömürlük bir dost kazandım MST sayesinde. Verdiğin her türlü sanatsal, bilimsel, duygusal, gündemsel, dedikodusal, yemeksel, eğlencesel ve daha nicesel destek için çok ama çok teşekkürler. Uzatmalı kahve molalarımız, şarap gecelerimiz, sanat odaklı alișveriş/konser turismuslarımız ve biricik Berlin çıkartmamız, tatlı anılarımızın sadece mini bir özeti. Daha nice güzel anılar biriktirmek dileğiyle, doktoranın son düzlüğünde bol șans!

Querida Teresa, gostaria te agradecer por sempre me fazer sentir parte da família e por a tua infinita hospitalidade em Provins e Madeira. Espero que um dia possamos conversar sem usar o Google Translate, quando eu aprender a falar Português (ou Francês) e conseguir pronunciar corretamente "pão". Também gostaria de agradecer a todos os amigos e familiares na França e na Madeira por fazerem o possível para me fazer sentir em casa.

Canım Annecim, bu özlemli serüvenimizde verdiğin tüm destek ve emekler için, sonsuz pozitif enerjin ve sevgin için çok ama çok teșekkür ederim. Senin kızın olduğum için kendimi hep şanslı hissettim, senin emeklerin olmasa burada olamazdım bugün. Seni çok seviyorum! Canım Abicim, en çok kimi seviyorsun sorusuna her seferinde bıkmadan verdiğin "bebekcim" cevabı ve dünyadaki en içten sevgiyi bana gönülden hissettirdiğin için çok teșekkürler. Iyi ki varsın!

Liuuuu, you are the most unexpected gift that Enschede gave to me during Grolsch Brewery tour! Thanks for not moving to France. Thanks for your endless support, love and patience during the times we spent between Eindhoven and Enschede. Thanks for handling all my frustrations wisely, for your realistic and critical view to the world, for being a better cook than me, for being a great travel-company, and above all for always finding a unique way to express your love. 


\section{About the Author}

Özlem Haval Demirel was born on the $12^{\text {th }}$ of June 1989 in Istanbul, Turkey. In 2011, she obtained her bachelor degree in Chemical Engineering from Yildiz Technical University. During her bachelor study, she performed a three-month internship in Evonik Industries, Germany via IAESTE (International Association for the Exchange of Students for Technical Experience). This internship was the starting point for her

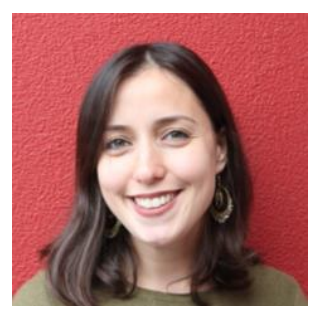
career in membrane technology. Following that, she continued with her master's studies in Chemical Engineering at Istanbul Technical University (ITU) where she focused on gas separation membranes. During her master study, she visited the Institute of Chemical Technology Prague for six months and performed a project work on the synthesis of zeolites as fillers for mixed matrix membranes. At ITU, she also worked as a teaching and research assistant in the Chemical Engineering Department. In February 2015, she completed her master thesis entitled "Utilization of TitaniumSilicalite-1 (TS-1) as Inorganic Filler in Mixed Matrix Membrane Formation for $\mathrm{CO}_{2}$ Separation" at the Membrane Materials $\mathcal{E}$ Separation Technologies Research Laboratory at ITU.

Starting from September 2015, she started her PhD in the Membrane Science and Technology cluster at the University of Twente. Her doctoral thesis has been supervised by prof. dr. ir. Nieck E. Benes and dr. Jeffery A. Wood in the Films in Fluids group. She presented her research at multiple international conferences, including EuroMOF 2017 in Delft, The Netherlands, Gordon Research Conference on Nanoporous Materials and their Applications in Andover, U.S.A., and EuroMOF 2019 in Paris, France. She was also an active board member of P-NUT (PhD Network of University of Twente) between 2017 and 2019.

On May $18^{\text {th }}$, Özlem started her new role as Customer Support Applications Engineer in ASML, The Netherlands. 


\section{List of Publications}

Per April 2020

\section{Peer-reviewed international journals}

- Ö. H. Demirel, T. Rijnaarts, P. De Wit, J. A. Wood, N. E. Benes "Electroforming of a metal-organic framework on porous copper hollow fibers" Journal of Materials Chemistry A, 7(20), 12616-12626 (2019)

\section{Manuscripts in preperation}

- A. Kiliç ${ }^{+}$Ö. H. Demirel ${ }^{+}$, S.B. Tantekin-Ersolmaz, M. G. Ahunbay, N. E. Benes "Tuning gas separation performances of 6FDA-DAM based mixed matrix membranes with thermal treatment" (2020) (Manuscript in preparation)

- Ö. H. Demirel, T. van der Meer, H. Zwijnenberg, N.E. Benes, J. A. Wood "MOFson-Ion Exchange Membranes: Using a charge-selective interface for localized film formation" (2020) (Manuscript in preparation)

- Ö. H. Demirel, N.E. Benes, J. A. Wood “Assessing interfacial properties of MOFs using contact angle measurements: Promise and Pitfalls” (2020) (Manuscript in preparation)

\section{Selected conference presentations}

- Ö.H. Demirel, T. van der Meer, N. E. Benes, J. A. Wood "Selective Ion-Transport using Metal Organic Frameworks” EuroMOF conference, Paris, France (2019) (Poster)

- Ö. H. Demirel, T. Rijnaarts, P. De Wit, N. E. Benes “Electroforming MOFs on pure metal hollow fibers" Gordon Research Conference: Nanoporous Materials and Their Applications, Andover, The United States of America (2017) (Poster)

- Ö. H. Demirel, T. Rijnaarts, P. De Wit, N. E. Benes "Electroforming Cu-BTC MOF on porous copper hollow fibers" EuroMOF conference, Delft, The Netherlands (2017) (Poster)

- Ö. H. Demirel, V. Fila, V. Martin, S. B. Tantekin-Ersolmaz "Utilization of TitaniumSilicalite-1 (TS-1) as Inorganic Filler in Mixed Matrix Membrane Formation for $\mathrm{CO}_{2}$ Separation” ICOM, Suzhou, China (2014) (Oral Presentation) 
